Aus der Abteilung Zelluläre und Molekulare Immunologie

(Prof. Dr. rer. nat. J. Wienands)

im Zentrum Hygiene und Humangenetik

der Medizinischen Fakultät der Universität Göttingen

\title{
Untersuchung des Effekts einer Überexpression von Cathepsin B in Zielzellen zytotoxischer T-Zellen
}

\section{INAUGURAL-DISSERTATION}

zur Erlangung des Doktorgrades

der Medizinischen Fakultät

der Georg-August-Universität zu Göttingen

vorgelegt von

Andreas Kahlmeyer

aus

Kassel

Göttingen 2012 
Dekan:

1. Berichterstatter:

2. Berichterstatter/in:

3. Berichterstatter/in:
Prof. Dr. med. C. Frömmel

Prof. Dr. med. R. Dressel

Tag der mündlichen Prüfung: 


\section{Abkürzungsverzeichnis}

Abb.

ADPKD

APC

APS

APT

AS

bp

${ }^{\circ} \mathrm{C}$

ca.

CD

CDK-4

cDNA

CIP

CMV

cpm

DAB

DFF40/CAD

DFF45/ICAD

$\mathrm{dH}_{2} \mathrm{O}$

DMEM

DMSO

DNA

dNTP

E. coli

EBV

EDTA

eGFP

EGTA

et al.
Abbildung

autosomal-dominante

polyzystische Nierenerkrankung

adenomatöse Polyposis Coli

Ammoniumpersulfat

Aminoglykosid-Phosphotransferase

Aminosäuren

Basenpaar

Grad Celsius

zirka

cluster of differentiation

cyclin dependent kinase 4

complementary DNA

calf intestinal alkaline phosphatase

Zytomegalievirus

counts per minute

Diaminobenzidin

DNA-Fragmentations-Faktor /

caspase-activated deoxyribonuclease

DNA-Fragmentations-Faktor-Inhibitor /

inhibitor of caspase-activated deoxyribonuclease

destilliertes Wasser

Dulbeccos modifiziertes Eagle Medium

Dimethylsulfoxid

Desoxyribonukleinsäure

Desoxynukleosidtriphosphat

Escherichia coli

Epstein-Barr-Virus

Ethylendiamintetraacetat

enhanced green fluorescent protein

Ethylenglycol-bis(2-aminoethylether)-

$\mathrm{N}, \mathrm{N}, \mathrm{N}^{\prime}, \mathrm{N}^{\prime}-$ Tetraacetat

et alii 


\begin{tabular}{|c|c|}
\hline FACS & Durchflusszytometrie \\
\hline FBS & fetales bovines Serum \\
\hline $\mathrm{g}$ & Erdbeschleunigung \\
\hline G 418 & Geneticin \\
\hline $\mathrm{h}$ & Stunde \\
\hline HA & Hämagglutinin \\
\hline HRPO & horseradish-peroxydase \\
\hline HSC70 & heat shock cognate 70 \\
\hline IDO & Indolamin-2,3-Dioxygenase \\
\hline $\operatorname{IgG}$ & Immunglobulin $\mathrm{G}$ \\
\hline IL-2 & Interleukin 2 \\
\hline IL-6 & Interleukin 6 \\
\hline IL-10 & Interleukin 10 \\
\hline IL-13 & Interleukin 13 \\
\hline $\mathrm{kb}$ & Kilobasen \\
\hline $\mathrm{kDa}$ & Kilodalton \\
\hline LB-Medium & Luria-Bertani-Medium \\
\hline LMP2 & low molecular mass polypeptide 2 \\
\hline LMP7 & low molecular mass polypeptide 7 \\
\hline LPS & Lipopolysaccharid \\
\hline $\mathrm{mA}$ & Milliampere \\
\hline$\mu \mathrm{Ci}$ & Mikrocurie \\
\hline$\mu \mathrm{F}$ & Mikrofarad \\
\hline MFI & mittlere Fluoreszenzintensität \\
\hline$\mu g$ & Mikrogramm \\
\hline $\mathrm{mg}$ & Milligramm \\
\hline MHC & Haupthistokompatibilitätskomplex \\
\hline $\min$ & Minute \\
\hline$\mu 1$ & Mikroliter \\
\hline $\mathrm{ml}$ & Milliliter \\
\hline$\mu \mathrm{M}$ & Mikromolar \\
\hline $\mathrm{mM}$ & Millimolar \\
\hline MPR & Mannose-6-Phosphat-Rezeptor \\
\hline mRNA & messenger RNA \\
\hline $\mathrm{ms}$ & Millisekunden \\
\hline $\mathrm{Neo}^{\mathrm{r}}$ & Neomycin-Geneticin-Resistenzgen \\
\hline
\end{tabular}


ng

nm

$\mathrm{nM}$

NP 40

OD

p53

PBS

PCR

PE

$\mathrm{pH}$

PI-9

PJ

RAG

rm IL-2

RNA

SDS

SDS-Page

$\sec$

SIINFEKL

SMFI

TAE-Puffer

TAP1

Taq

TC

TEMED

TGF- $\beta$

Tris

Tween-20

$\mathrm{u}$

uPA

UTR

V

$\mathrm{v} / \mathrm{v}$

$\mathrm{w} / \mathrm{v}$
Nanogramm

Nanometer

Nanomolar

Nonidet P40

optische Dichte

Protein 53

phosphatgepufferte Salzlösung

Polymerase-Kettenreaktion

Phycoerythrin

potentium hydrogenii

Proteaseinhibitor 9

Propidiumiodid

Recombinase-aktivierendes Gen

rekombinantes murines Interleukin 2

Ribonukleinsäure

Natriumdodecylsulfat

SDS-Polyacrylamid-Gelelektrophorese

Sekunde

Ovalbumin Aminosäuren 257 bis 264

spezifische mittlere Fluoreszenzintensität

Tris-Acetat-EDTA-Puffer

transporter associated with antigen processing 1

Thermus aquaticus

Tri-Color ${ }^{\circledR}$

$\mathrm{N}, \mathrm{N}, \mathrm{N}, \mathrm{N}^{\prime}-$ Tetramethylethylendiamin

transforming growth factor $\beta$

Tris-(hydroxymethyl)-aminomethan

Polyoxyethylen(20)-sorbitanmonolaureat

unit

Urokinase

untranslatierte Region

Volt

volume per volume

weight per volume 


\section{Inhaltsverzeichnis}

$1 \quad$ Einleitung 1

$1.1 \quad$ Cathepsin B 1

1.1.1 Das Cathepsin-B-Gen 1

1.1.2 Die Cathepsin-B-Expression 2

1.1.3 Aktivierungsmechanismen und Haltbarkeit von Cathepsin B im Lysosom 2

1.1.4 Struktur und molekulare Funktion von Cathepsin B 3

1.1.5 Physiologische Funktionen von Cathepsin B 3

1.1.6 Pathophysiologische Funktionen von Cathepsin B 4

1.1.7 Cathepsin B in Tumorerkrankungen 4

1.1.8 Pathophysiologische Besonderheiten der Cathepsin-B-Expression 5

1.2 Zelluläre Zytotoxizität 9

1.2.1 Bildung und Bestandteile der zytotoxischen Granula 10

1.2.2 Die Granula-Exozytose 11

1.2.3 Die Zelltodinduktion 11

1.2.4 Selbstschutz zytotoxischer T-Lymphozyten 12

1.3 Tumore und das Immunsystem 14

1.3.1 Tumorantigene 15

1.3.2 Immune-Escape-Mechanismen 16

$\begin{array}{lll}1.4 & \text { Fragestellung } & 18\end{array}$

$2 \quad$ Material und Methoden $\quad 19$

$2.1 \quad$ Material 19

2.1.1 Biologisches Material 19

2.1.2 Gene 19

2.1.3 Der CAG-PEGFP-1- Expressionsvektor 20

2.1.4 Oligonukleotide 21

2.1.5 Enzyme 22

$\begin{array}{lll}2.1 .6 & \text { Antikörper } & 22\end{array}$

2.1.7 Puffer und Stammlösungen 23

2.1.8 Kulturmedien 25

2.1.9 Chemikalien 26

2.1.10 Gebrauchsfertige Reaktionssysteme 27

2.1.11 Gebrauchswaren 28

2.1.12 Geräte 28

2.1.13 Datenbanken und Software 30

2.1.14 Hersteller 30 
$2.2 \quad$ Methoden $\quad 32$

2.2.1 Mikrobiologische Methoden 33

2.2.2 Molekularbiologische Methoden 34

2.2.3 Proteinbiochemische Methoden 40

2.2.4 Zellbiologische Methoden $\quad 42$

$3 \quad$ Ergebnisse $\quad 50$

$3.1 \quad$ Herstellung der CBG-Klone $\quad 50$

$3.2 \quad$ Herstellung der MCBG-Klone 53

3.3 Durchflusszytometrische Untersuchungen 57

3.3.1 Nachweis der durch das LV-Konstrukt induzierten eGFP-Expression $\quad 57$

3.3.2 Nachweis der Expression des CBG-Fusionsproteins 58

3.3.3 Nachweis der Expression des MCBG-Fusionsproteins 58

3.3.4 Gesteigerte zelluläre Cathepsin-B-Expression in Zellen der CBG- und MCBG-Klone $\quad 59$

3.3.5 Geringgradig gesteigerte oberflächengebundene Cathepsin-B-Expression von Zellen der CBG- und MCBG-Klone 61

3.3.6 Kein Nachweis einer oberflächengebundenen Expression des MCBGFusionsproteins mit Hilfe des HA-Tags 63

$3.4 \quad$ Immunoblots $\quad 65$

3.4.1 Nachweis des CBG-Fusionsproteins im Westernblot $\quad 65$

3.4.2 Nachweis des MCBG-Fusionsproteins im Westernblot 66

$3.5 \quad$ Konfokale Laser-Scanning-Mikroskopie 66

3.5.1 Perinukleäre, vesikuläre und membrangebundene Cathepsin-B-Aktivität bei diffuser zytoplasmatischer Verteilung von eGFP in den Zellen der LV-Klone

3.5.2 Intrazelluläre Kolokalisation des CBG-Fusionsproteins und der Cathepsin-B-Aktivität in den Zellen der CBG-Klone 68

3.5.3 Intrazelluläre Kolokalisation des MCBG-Fusionsproteins und der Cathepsin-B-Aktivität in den Zellen der MCBG-Klone 69

$\begin{array}{lll}3.6 & \text { Zytotoxizitätstests } & 69\end{array}$

3.6.1 Vergleichbare oberflächenassoziierte $\mathrm{H} 2 \mathrm{~K}^{\mathrm{b}}$-Expressionen auf den Zellen $\begin{array}{ll}\text { aller Klone } & 70\end{array}$

3.6.2 Unveränderte Lyse der Zellen der CBG-Klone 70

3.6.3 Unveränderte Lyse der Zellen der MCBG-Klone $\quad 73$

4 Diskussion $\quad 75$

$\begin{array}{lll}5 & \text { Zusammenfassung } & 88\end{array}$

$\begin{array}{lll}6 & \text { Literaturverzeichnis } & 90\end{array}$ 


\section{Einleitung}

\subsection{Cathepsin B}

Cathepsin B ist ein lysosomales Enzym der Papain-Gruppe, einer Untergruppe der PapainSuperfamilie der Cystein-Proteasen. Neben Cathepsin B enthält diese Gruppe weitere lysosomale Cystein-Proteasen der Säugetiere (Berti und Storer 1995). Cathepsin B ist, wie alle Cathepsine, mit Lysosomen assoziiert (Rozhin et al. 1987), wobei Lysosomen höherer Organismen verschiedene Cathepsine gleichzeitig enthalten (McGrath 1999). Obwohl Cathepsine unter unterschiedlichen Reaktionsbedingungen arbeiten und obwohl ihre Verteilung in den Geweben heterogen ist, sind ihre Funktionen im intrazellulären Proteinabbau zum großen Teil redundant (Turk V et al. 2001).

Cathepsin B ist in den Körperzellen verschiedener Säugetiere enthalten (Reinheckel et al. 2001; Turk V et al. 2001). Als seine Hauptfunktion gilt der Abbau von Proteinen, welche die Lysosomen von außen, über Endozytose und Phagozytose (Shaw und Dean 1980), oder aus intrazellulären Kompartimenten, über Autophagozytose (Bohley und Seglen 1992), erreicht haben.

Der Begriff Cathepsin bezeichnete ursprünglich alle Nicht-Pepsin-Proteasen, die in saurem pH-Bereich aktiv sind (Willstätter und Bamann 1929). Heute wird die Bezeichnung Cathepsin zur Beschreibung lysosomaler Cystein-Proteasen verwendet, aber auch Enzyme anderer Protease-Klassen werden nach wie vor als Cathepsine bezeichnet. Cathepsin D und E sind Aspartyl-Proteasen, Cathepsin A und G sind Serin-Proteasen und Cathepsin III ist eine Metallo-Protease (McGrath 1999).

\subsubsection{Das Cathepsin-B-Gen}

In der Maus und im Menschen existiert jeweils nur ein Gen für Cathepsin B. Das humane Cathepsin-B-Gen liegt auf dem kurzen Arm von Chromosom 8 (Fong et al. 1992), umfasst $27 \mathrm{~kb}$ und besteht aus 14 Exons. Zunächst wurden nur die Exons 1 - 12 beschrieben (Gong et al. 1993), die Exons 2a und 2b zwischen Exon 2 und 3 wurden später ergänzt (Berquin et al. 1995). Die Exons 1 bis $2 \mathrm{~b}$ und ein Teil von Exon 3 entsprechen der 5'-untranslatierten Region (UTR) der Cathepsin-B-mRNA. Darauf folgt bis zum Anfang von Exon 11 der translatierte Bereich. Der Rest von Exon 11 und das gesamte Exon 12 bilden die 3'-UTR. Der offene Leserahmen codiert für Pre-Pro-Cathepsin B, bestehend aus einem 17 AS großen Pre-Peptid $^{1}$, dem darauf folgenden 62 AS großen Pro-Peptid ${ }^{1}$ und dem 254 AS großen Cathepsin B in seiner reifen, einkettigen Form. C-terminal folgen sechs weitere Aminosäuren, die nicht Teil der reifen Cathepsin-B-Formen sind (Berquin et al. 1995; Gong et al. 1993). Durch Initiation der Translation an verschiedenen Promotorregionen und durch alternatives Splicing entstehen je nach Gewebe unterschiedliche mRNA-Varianten, die allerdings hauptsächlich in den untranslatierten Bereichen voneinander abweichen (Berquin et al. 1995).

\footnotetext{
${ }^{1}$ Die Begriffe Pre-Peptid und Pro-Peptid werden zur Beschreibung der bei der Prozessierung von Pre-ProCathepsin B zu Pro-Cathepsin B beziehungsweise der bei der Prozessierung von Pro-Cathepsin B zu reifem Cathepsin B abgespaltenen Peptide verwendet.
} 
Das Cathepsin-B-Gen gehört zu den ubiquitär exprimierten Haushaltsgenen (Qian et al. 1991), dennoch wird seine Expression durch Interaktion mit der umgebenden Matrix beeinflusst. So wird die Expression und Sekretion von Pro-Cathepsin B aus Fibroblasten aus physiologischem Brustgewebe und malignen Brusttumoren durch Interaktion mit Kollagen Typ I deutlich gesteigert. Die Expression der mRNA und die Menge des intrazellulären reifen Cathepsin B werden dabei allerdings nicht beeinflusst (Koblinski et al. 2002).

\subsubsection{Die Cathepsin-B-Expression}

Die Cathepsin-B-mRNA wird an membrangebundenen Ribosomen des endoplasmatischen Retikulums translatiert. Das entstehende Pre-Pro-Cathepsin B wird kotranslational an zwei Asparaginen N-glykosyliert und das Pre-Peptid abgespalten (Mort und Buttle 1997). Das entstehende Pro-Cathepsin B gelangt aus dem rauen endoplasmatischen Retikulum in den Golgi-Apparat, wo es durch weitere Glykosylierung und Phosphorylierung zwei Mannose-6Phosphat-Motive erhält. Im trans-Golgi-Netzwerk bindet es an Mannose-6-PhosphatRezeptoren und wird in speziellen Vesikeln zu den Lysosomen transportiert (Kuliawat und Arvan 1994). Für einen effizienten Transport sind dabei sowohl der 300-kDa-MPR als auch der 46-kDa-MPR notwendig (Kuliawat et al. 1997; Lorenzo et al. 2000; Ludwig et al. 1994). Durch Ansäuerung der Vesikel beim Erreichen der Lysosomen kann sich das Pro-Enzym vom Rezeptor lösen (Mort und Buttle 1997). Die gleichzeitige Entfernung des Phosphats vom Mannose-6-Phosphat-Motiv verhindert den Rücktransport zum Golgi-Apparat (Roshy et al. 2003). In humanen HT-29-Kolonkarzinomzellen konnte auch ein MPR-unabhängiger Transport von Pro-Cathepsin B in die Lysosomen nachgewiesen werden (De Stefanis et al. 1997). Neben dem Transport in die Lysosomen wird Pro-Cathepsin B auch sezerniert (Hanewinkel et al. 1987; Mach et al. 1992). Der Anteil der Sekretion beträgt in normalen Zellen allerdings weniger als $5 \%$ des gebildeten Pro-Cathepsin B (Roshy et al. 2003).

\subsubsection{Aktivierungsmechanismen und Haltbarkeit von Cathepsin B im Lysosom}

Bis zum Erreichen der Lysosomen ist Pro-Cathepsin B durch das angehängte Pro-Peptid inaktiviert. Das Pro-Peptid liegt der Oberfläche des eigentlichen Cathepsin B an und blockiert dessen proteolytische Aktivität durch Anlagerung an das aktive Zentrum, ähnlich einem Substrat, allerdings in umgekehrter Orientierung (Chen et al. 1996). Die Zelle ist so während der Synthese und Prozessierung vor der proteolytischen Funktion von Cathepsin B geschützt. Neben dem Zellschutz dient das Pro-Peptid auch der Stabilisierung des Enzyms in der Synthesephase. Ohne Pro-Peptid ist Cathepsin B in neutralem und alkalischem $\mathrm{pH}-$ Bereich instabil und denaturiert irreversibel (McGrath 1999). Möglicherweise ist das Pro-Peptid, wie bei einigen Serin-Proteasen beschrieben, auch an der Faltung des Enzyms beteiligt (McGrath 1999).

Die Reifung zur aktiven, $31 \mathrm{kDa}$ großen einkettigen Form beginnt erst nach Dislokation vom MPR (Mach et al. 1992) und wird auch durch das saure Milieu der Lysosomen induziert (Mort und Buttle 1997). Die Abspaltung des Pro-Peptids beruht hauptsächlich auf unimolekularer Autoprozessierung, kann aber auch durch andere Proteasen wie Cathepsin D und Cathepsin L oder durch bereits aktiviertes Cathepsin B intermolekular katalysiert werden (Rowan et al. 1992). Die Abspaltung des Pro-Peptids dauert nur etwa 30 Minuten (Mach et al. 1992) und das entstehende einkettige Cathepsin B ist ohne weitere Umlagerungen enzymatisch aktiv (Cygler et al. 1996; Takio et al. 1983). 
Einkettiges Cathepsin B kann im Lysosom unter Verlust eines Dipeptids proteolytisch zu einer zweikettigen Form gespalten werden. Die entstehenden Ketten besitzen ein Molekulargewicht von $26 \mathrm{kDa}$ und $5 \mathrm{kDa}$ (Mach et al. 1992) und sind durch eine Disulfidbrücke verbunden (McGrath 1999). Sowohl die Spaltung in die zweikettige Form als auch die ebenfalls stattfindenden Kürzungen der anhängenden Oligosaccharide beeinflussen die Aktivität von Cathepsin B nicht (Mort und Buttle 1997). Beide Formen werden in perinukleären Lysosomen gespeichert und dienen dort als Haushaltsenzyme (Cavallo-Medved und Sloane 2003).

Im Lysosom beträgt die Halbwertszeit von Cathepsin B, wie die der meisten anderen löslichen Enzyme, etwa 24 Stunden (Mort und Buttle 1997). Ein Prolin in der Nähe des N-Terminus verhindert den Abbau durch lysosomale Amino-Peptidasen (Mort und Buttle 1997).

\subsubsection{Struktur und molekulare Funktion von Cathepsin B}

Reifes Cathepsin B ähnelt zu großen Teilen, besonders aber im Aufbau seines aktiven Zentrums, dem Papain (Musil et al. 1991). Eine bewegliche Schleife (occluding loop) kann den Substratbindungscharakter von Cathepsin B so verändern, dass es sowohl als Endo-Peptidase als auch als Exo-Peptidase wirkt (Roshy et al. 2003).

Als Endo-Peptidase spaltet Cathepsin B abzubauende Proteine so, dass neue Angriffspunkte für Exo-Peptidasen entstehen, wodurch der lysosomale Proteinabbau stark beschleunigt wird (Mort und Buttle 1997). Die bewegliche Schleife gibt hierzu bei neutralen und alkalischen pH-Werten das aktive Zentrum vollständig frei. Da die Umlagerung der Schleife Energie erfordert, arbeitet Cathepsin B weniger effektiv als andere Endo-Peptidasen der PapainSuperfamilie (Cygler et al. 1996; Nagler et al. 1997). Außerdem verliert lysosomales Cathepsin B bei pH-Werten über 7,0 die metastabile Struktur seines aktiven Zentrums und damit auch seine enzymatische Funktion (Turk B et al. 1994). Im Rahmen von Erkrankungen entstehen jedoch nicht-lysosomale Cathepsin-B-Formen, die auch im neutralen und alkalischen Milieu stabil sind und als Endo-Peptidasen wirken können (Linebaugh et al. 1999). Im sauren $\mathrm{pH}$-Bereich der Lysosomen lagert sich die bewegliche Schleife so an das aktive Zentrum an, dass sie die Substratbindungstasche partiell blockiert. In dieser Konfiguration spaltet Cathepsin B als Exo-Peptidase Dipeptide vom C-Terminus von Proteinen ab (Mort und Buttle 1997).

Seine kombinierte Funktion als Endo- und Carboxy-Peptidase gilt als Hinweis für eine Beteiligung von Cathepsin B sowohl an frühen als auch an späten Stadien des lysosomalen Proteinabbaus (Mort und Buttle 1997). Im sauren Milieu der Lysosomen arbeitet Cathepsin B allerdings fast ausschließlich als Exo-Peptidase (Roshy et al. 2003). Diese Funktion kann durch redundante lysosomale Enzyme wie beispielsweise Cathepsin L ersetzt werden. Cathepsin-B-defiziente Mäuse zeigen keine Defekte im lysosomalen Proteinumsatz (Halangk et al. 2000), nur Mäuse, die defizient für beide Enzyme sind, sterben bereits kurz nach der Geburt an Hirnatrophie (Felbor et al. 2002).

\subsubsection{Physiologische Funktionen von Cathepsin B}

Neben seiner oben beschriebenen Funktion im lysosomalen Proteinabbau besitzt Cathepsin B weitere gewebsspezifische Funktionen. Cathepsin B ist an der Herstellung von Schilddrüsenhormonen aus deren Vorläufermolekül Thyreoglobulin beteiligt (Brix et al. 1996) und trägt in Osteoklasten, als intrazellulärer Aktivator von Enzymen, zur Resorption 
des organischen Anteils des Knochens bei (Page AE et al. 1992). Außerdem exprimieren zytotoxische Zellen auf ihrer Oberfläche Cathepsin B, um sich vor den zytotoxischen Inhaltsstoffen ihrer eigenen Granula zu schützen (Balaji et al. 2002). Da diese Funktion für die Frage nach dem Effekt einer Überexpression von Cathepsin B in Zielzellen zytotoxischer T-Zellen besonders wichtig ist, wird sie in Kapitel 1.2.4 (S. 12) näher beschrieben.

\subsubsection{Pathophysiologische Funktionen von Cathepsin B}

Neben diesen physiologischen Funktionen ist auch eine Reihe von pathologischen Situationen mit Veränderungen der Cathepsin-B-Expression assoziiert. Die Unterfunktion von Cathepsin B scheint pathophysiologisch unbedeutend zu sein. Selbst eine vollständige Cathepsin-B-Defizienz verursacht bei Mäusen lediglich Störungen in der Prozessierung pankreatischen Trypsinogens (Halangk et al. 2000). Von größerer medizinischer Relevanz sind Überfunktionen von Cathepsin B, die mit einer Reihe entzündlicher Erkrankungen assoziiert sind.

Bei entzündlichen Erkrankungen der Atemwege korreliert eine besondere, im alkalischen Milieu aktive Form von Cathepsin B mit der Schwere der Entzündung und dem Auftreten von Bronchiektasen (Buttle et al. 1988; Buttle et al. 1990). Diese höhermolekulare Form entsteht aus Pro-Cathepsin B, welches von Epithelzellen sezerniert und von Neutrophilenelastase aktiviert wird (Burnett et al. 1995). In ähnlicher Weise korreliert auch der Abbau extrazellulärer Knorpelsubstanz bei Osteoarthritis und rheumatoider Arthritis mit intra- und extrazellulärer Anreicherung von aktivem Cathepsin B (Baici et al. 1995; Lang et al. 2000). Hierbei gilt die intrazelluläre Aktivierung von Matrix-Metallo-Proteasen durch Cathepsin B als wichtiger Pathomechanismus (Hill et al. 1994). Die akute Pankreatitis beruht auf der Aktivierung proteolytischer Pro-Enzyme. Ein entscheidender Schritt ist hierbei die Fusion von Lysosomen und Exozytosegranula, die zur Aktivierung von Trypsinogen durch Cathepsin B führt (Lerch et al. 2000). Cathepsin-B-defiziente Mäuse zeigen nach experimenteller Induktion einer Autoimmunpankreatitis deutlich weniger Trypsin-Aktivität und auch deutlich weniger Gewebeschäden (Halangk et al. 2000).

Neben den beschriebenen Pathologien, bei denen eine entscheidende Beteiligung von Cathepsin B nachgewiesen wurde, gibt es noch eine Reihe weiterer entzündlicher Erkrankungen, bei denen ebenfalls erhöhte extra- und intrazelluläre Cathepsin-B-Aktivitäten beschrieben wurden. So korreliert beispielsweise bei der chronischen Zahnfleischentzündung die extrazelluläre Cathepsin-B-Menge mit der Schwere der entzündlichen Reaktion (Eley und Cox 1991; Kennett et al. 1997) und bei Patienten mit neurologischen Entzündungen ist die Cathepsin-B-Aktivität im Liquor erhöht (Nagai et al. 2000). Ebenso zeigt sich in fortgeschrittenen Stadien der autosomal-dominanten polyzystischen Nierenerkrankung (ADPKD) eine basale Cathepsin-B-Sekretion, die mit erheblichen Basalmembranschäden einhergeht (Hartz und Wilson 1997).

\subsubsection{Cathepsin B in Tumorerkrankungen}

Auch Tumorerkrankungen gehen mit Veränderungen der Cathepsin-B-Expression einher. In einer ganzen Reihe von Tumoren konnte eine deutliche Erhöhung der Cathepsin-BExpression gezeigt werden. Erhöhte Mengen an Cathepsin-B-mRNA finden sich in Kolorektalkarzinomen (Murnane et al. 1991), Prostatakarzinomen (Sinha et al. 1993), Gliomen (Rempel et al. 1994; Sivaparvathi et al. 1995) und malignen Melanomen (Froehlich et al. 2001). Erhöhte Protein- und Aktivitätslevel sind bei Kolorektalkarzinomen (Campo et al. 1994; Emmert-Buck et al. 1994; Hazen et al. 2000; Sheahan et al. 1989; Shuja et al. 
1991), Mammakarzinomen (Krepela et al. 1989; Lah et al. 1995), Bronchialkarzinomen (Ebert et al. 1994), Gliomen (Rempel et al. 1994; Sivaparvathi et al. 1995), Schilddrüsenkarzinomen (Kusunoki et al. 1995), Ösophaguskarzinomen (Hughes et al. 1998; Liu Y et al. 1998), malignen Melanomen (Froehlich et al. 2001) und Ovarialkarzinomen (Scorilas et al. 2002) beschrieben worden. Die Cathepsin-B-Aktivität ist dabei nicht gleichmäßig in allen Zellen eines Tumors erhöht, sie findet sich vor allem in den invasiv wachsenden Tumoranteilen und in Tumorzellen, die Kontakt zu extrazellulärer Matrix haben (Demchik et al. 1999; Froehlich et al. 2001; Sameni et al. 1995; Sinha et al. 1993).

Die funktionelle Bedeutung der Cathepsin-B-Expression in der Tumorentwicklung liegt in der Förderung der Invasivität durch Cathepsin B (Roshy et al. 2003). Allgemein gilt die zellmembranassoziierte proteolytische Aktivität als entscheidende Bedingung für die Bewegung von Krebszellen durch extrazelluläre Matrix im Rahmen der Metastasierung (Mort und Buttle 1997). Trotz zahlreicher weiterer zellmembranassoziierter proteolytischer Enzyme, die nachweislich an der Metastasierung beteiligt sind, spielen gerade lysosomale Enzyme wie Cathepsin B im sauren Milieu, das Tumorzellen umgibt, eine besondere Rolle (Mort und Buttle 1997). Zum einen kann Cathepsin B aufgrund seiner nur geringen Substratspezifität Fibrinogen (Gabrijelcic et al. 1988), die Knorpelkollagene Typ IX und Typ XI (Maciewicz et al. 1990) und die Basalmembrankomponenten Laminin, Fibronektin und Kollagen Typ IV (Buck et al. 1992) verdauen, zum anderen kann es durch Aktivierung von Proteasen wie Pro-Urokinase (Kobayashi et al. 1991) den extrazellulären Proteinabbau anregen. Bei Mammakarzinomen und Gliomen wurde die Beteiligung von Cathepsin B am intrazellulären und extrazellulären Verdau von Matrixproteinen gezeigt (Sameni et al. 2000; Sameni et al. 2001). Bei Magenkarzinomen (Khan et al. 1998) und Lungenkarzinomen (Higashiyama et al. 1993; Sukoh et al. 1994) korreliert die Degradation der Basalmembran mit erhöhter Cathepsin-B-Expression der Tumorzellen, und auch die Invasivität von Blasenkarzinomen (Visscher et al. 1994) und Gliomen (Demchik et al. 1999) geht mit gesteigerter Cathepsin-B-Aktivität im Tumor einher. Die tumorassoziierte Cathepsin-BAktivität hat auch Einfluss auf den klinischen Verlauf. Bei Kolorektalkarzinompatienten (Campo et al. 1994), Lungentumorpatienten (Ebert et al. 1994) und bei Patientinnen mit Ovarialkarzinom (Scorilas et al. 2002) oder Endometriumkarzinom (Devetzi et al. 2009) bedeuten hohe Cathepsin-B-Level im Tumorgewebe eine deutlich schlechtere Prognose.

Die Sekretion von Cathepsin B und Pro-Cathepsin B könnte möglicherweise auch diagnostisch zur Neoplasieerkennung genutzt werden (Mort und Buttle 1997). Beispielsweise kann die Cathepsin-B-Aktivität im Serum von Patientinnen in Studien Hinweise zur Unterscheidung von Uteruskarzinomen und benignen uterinen Tumoren liefern (Warwas et al. 1997).

\subsubsection{Pathophysiologische Besonderheiten der Cathepsin-B-Expression}

Neben der Steigerung von Cathepsin-B-Expression und Cathepsin-B-Aktivität weisen Tumore auch Veränderungen in der zellulären Verteilung von Cathepsin B auf. In nicht pathophysiologisch veränderten Zellen befindet sich Cathepsin B in perinukleären Vakuolen, die sich mit lysosomalen Markern anfärben lassen (Rozhin et al. 1987; Sameni et al. 1995). In malignen Zellen jedoch finden sich Vakuolen mit Cathepsin-B-Aktivität im gesamten Zytoplasma und auch in der Zellperipherie (Roshy et al. 2003). Besonders deutlich wird diese Umverteilung in polarisierten Geweben wie Kolonmukosa, Schilddrüsenepithel und Brustdrüsenepithel. Physiologischerweise liegen Cathepsin-B-haltige Vesikel in diesen 
Geweben am apikalen Pol der Zellen (Campo et al. 1994). Im Zuge der Umwandlung in prämaligne Läsionen und Malignome sind die Cathepsin-B-haltigen Vakuolen zunächst diffus im Zytoplasma verteilt und orientieren sich dann zum basalen Pol hin um (Campo et al. 1994). Bei der Entwicklung von Kolontumoren findet die Umverteilung der Cathepsin-BAktivität schon in späten Adenomen nach der K-ras-Mutation statt (Murnane et al. 1991), und Mäuse mit mutiertem adenomatöse-Polyposis-Coli-(APC)-Gen weisen bereits in Polypen eine Umverteilung und Überexpression von Cathepsin B auf (Marten et al. 2002).

\subsubsection{Membrangebundenes Cathepsin B}

Bei entzündlichen Erkrankungen und malignen Tumoren ist nicht nur die intrazelluläre Lokalisation von Cathepsin B verändert, auch Zellmembranassoziation und Sekretion von Pro-Cathepsin B und aktivem Cathepsin B sind beschrieben worden.

Physiologischerweise extrazelluläres Cathepsin B findet sich in den Follikeln der Schilddrüse. An die Zellmembran von Thyreozyten gebundenes sowie sezerniertes Cathepsin B kann in neutralem $\mathrm{pH}$-Bereich Thyreoglobulin prozessieren und ist so an der Bereitstellung der Schilddrüsenhormone beteiligt (Brix et al. 1996). Pro-Cathepsin B gelangt in diesen Zellen über das raue endoplasmatische Retikulum zum Golgi-Apparat und in die Lysosomen. Dort reift es zur einkettigen Form und gelangt dann über Transportvesikel zur Zellmembran und zur Sekretion (Linke et al. 2002).

Auch Tumore wie Mammakarzinome (Rozhin et al. 1987; Sameni et al. 1995; Sloane et al. 1994), Prostatakarzinome (Sinha et al. 2001), Gliome (Demchik et al. 1999) und Uteruskarzinome (Arkona und Wiederanders 1996) exprimieren oberflächenassoziiertes Cathepsin B. Wie Cathepsin B an Zellmembranen bindet, ist nicht abschließend geklärt. Es ist mit lysosomalem Cathepsin B fast identisch, eine spezielle Zelloberflächen-Isoform unterscheidet sich lediglich in ihrem Glykosylierungsstatus von den bekannten lysosomalen Formen (Moin et al. 1998). Alle Formen enthalten keine hydrophobe Region und benötigen somit zur Interaktion mit der Zellmembran einen Bindungspartner (Moin et al. 1992).

Am besten charakterisiert ist die Bindung von humanem Pro-Cathepsin B an Tumorzellen, wo es mit einem Teil des Annexin-II-Heterotetramers interagiert. Das Annexin-IIHeterotetramer ist ein Proteinkomplex, der durch Interaktion mit sauren Phospholipiden Membranen fusionieren kann (Waisman 1995). Das Pro-Peptid bindet direkt an p11, die leichte Kette des Annexin-II-Heterotetramers, welches wiederum an die schwere Kette p36 bindet und so die Interaktion mit der Plasmamembran vermittelt (Mai et al. 2000; Thiel et al. 1992). Die Lokalisation des Annexin-II-Pro-Cathepsin-B-Komplexes in Caveolae von Tumorzellen (Harder und Gerke 1994; Sargiacomo et al. 1993) deutet auf eine Beteiligung von Pro-Cathepsin B an der extrazellulären Matrixdegeneration hin. Caveolae gelten als Zentren der extrazellulären proteolytischen Aktivität (Roshy et al. 2003) und beinhalten sowohl zahlreiche weitere Proteasen wie Urokinase uPA (Stahl und Mueller 1995), MatrixMetallo-Proteinase-1 (Annabi et al. 2001) und Matrix-Metallo-Proteinase-2 (Puyraimond et al. 2001) als auch verschiedene potentielle Cathepsin-B-Substrate wie Heparin (Kassam et al. 1997), Kollagen Typ I (Wirl und Schwartz-Albiez 1990), Tenascin C (Chung und Erickson 1994) und Plasminogen (Kassam et al. 1998). Es konnte allerdings gezeigt werden, dass über Annexin II an die Oberfläche von Tumorzellen gebundenes Pro-Cathepsin B keine proteolytische Aktivität besitzt (Balaji et al. 2002).

An die Zelloberfläche degranulierter zytotoxischer Zellen gebundenes reifes Cathepsin B ist hingegen enzymatisch aktiv (Balaji et al. 2002). Da es mit EDTA von der Zelle abgelöst 
werden kann, ist seine Bindung an die Zellmembran calciumabhängig. Der Bindungspartner ist jedoch bisher nicht charakterisiert (Balaji et al. 2002). Mögliche Partner einer nicht calciumabhängigen Bindung stellen Heparine und Heparansulfate der Zellmembran dar, an die reifes Cathepsin B über das His111 der beweglichen Schleife binden kann. In vitro führt eine solche Bindung darüber hinaus auch zu einer Stabilisierung der Protease im alkalischen, extrazellulären Milieu und unterstützt die Endo-Peptidasefunktion (Almeida et al. 2001). Ein weiterer Bindungspartner wurde in Knochenmetastasen von Uteruskarzinomen gefunden. Cathepsin B bindet hier zumindest zum Teil über $\alpha$-2-Makroglobulin und den a-2-Makroglobulin-Rezeptor an die Zelloberfläche (Arkona und Wiederanders 1996).

\subsubsection{Sezerniertes Cathepsin B}

Neben dem oben beschriebenen Schilddrüsenepithel weisen auch viele Tumore wie Mammakarzinome (Krepela et al. 1989; Lah et al. 1995; Sloane et al. 1994), Kolorektalkarzinome (Campo et al. 1994; Emmert-Buck et al. 1994; Hazen et al. 2000; Murnane et al. 1991; Sheahan et al. 1989; Shuja et al. 1999), Ösophaguskarzinome (Berquin et al. 1995), Magenkarzinome (Liu Y et al. 1998), Bronchialkarzinome (Ebert et al. 1994) und Schilddrüsenkarzinome (Kusunoki et al. 1995) eine Sekretion von Cathepsin B auf. In der Umgebung der Tumorzellen befinden sich sowohl Pro-Formen als auch einkettige und zweikettige aktive Formen von Cathepsin B, sodass in Tumorzellen möglicherweise mehrere Mechanismen zur Sekretion von Cathepsin B beitragen (Roshy et al. 2003). Das von murinen Melanomzelllinien sezernierte Pro-Cathepsin B kann in vitro proteolytisch aktiviert werden und korreliert außerdem mit dem metastatischen Potential der jeweiligen Zelllinie (Qian et al. 1989). In der Zellkultur jedoch führt selbst die Freisetzung großer Pro-Cathepsin-B-Mengen nicht zu einer Aktivierung des Pro-Enzyms (Linebaugh et al. 1999) und auch in vivo reichert sich in verschiedenen Sekreten und Körperflüssigkeiten von Tumorpatienten unprozessiertes Pro-Cathepsin B an (Mort et al. 1983).

Obwohl Cathepsin B in vitro sehr sensitiv gegenüber Schwankungen der Ionenkonzentrationen der Umgebung ist (Dehrmann et al. 1996) und sich bei einem pH-Wert größer 7,0 schnell entfaltet (Turk B et al. 1994), wurde für verschiedene Tumorzelllinien gezeigt, dass auf der Zelloberfläche exprimiertes oder sezerniertes Cathepsin B katalytische Aktivität im extrazellulären Milieu aufweist (Hulkower et al. 2000). Dieses veränderte Verhalten in vivo beruht auf Bindungen von Cathepsin B an Zellmembranen (Sloane et al. 1994) und extrazellulären Matrixkomponenten (Guinec et al. 1992) sowie auf alternativen Aktivierungsmechanismen des freigesetzten Pro-Cathepsin B (Burnett et al. 1995).

\subsubsection{Mechanismen veränderter Cathepsin-B-Expression}

Die veränderte Cathepsin-B-Expression im Rahmen von Entzündungen und in Tumoren beruht auf unterschiedlichen Veränderungen, die das Cathepsin-B-Gen selbst, die Regulation seiner Expression oder die Prozessierung und den Transport von Cathepsin B betreffen (Frosch et al. 1999).

Eine Ursache erhöhter Cathepsin-B-Expression durch Tumorzellen liegt in der Amplifikation des Cathepsin-B-Gens, wie an Ovarialkarzinomzellen (Abdollahi et al. 1999) und Ösophaguskarzinomzellen (Hughes et al. 1998) gezeigt werden konnte. Über die Genvermehrung hinaus ist auch die Regulation der Transkription des Cathepsin-B-Gens in Tumoren verändert (Yan S und Sloane 2003). In Gliomen verursachen alternative Promotoren nach Bindung alternativer Transkriptionsfaktoren wie SP1, SP3 und ETS-1 die 
Überexpression von Cathepsin B (Yan S et al. 2000). ETS-1 wird durch Interaktion von epithelialen Zellen mit Kollagen Typ I induziert (Naito $S$ et al. 2002) und führt im Rahmen der Tumorentstehung zur Expression vieler weiterer malignomassoziierter Proteasen (Fafeur et al. 1997). Weitere Promotoren befinden sich auch vor Exon 3 und Exon 4 und verursachen in Gliomen mRNA-Transkriptvarianten, die mit Exon 3 und Exon 4 beginnen (Berquin et al. 1995).

Weiterhin haben auch Veränderungen auf mRNA-Ebene Einfluss auf die Cathepsin-BExpression. Sowohl in Tumoren (Berquin et al. 1995; Frosch et al. 1999; Mehtani et al. 1998; Qian et al. 1989) als auch im Rahmen der entzündlich-degenerativen Arthritis (Berardi et al. 2001) verursacht alternatives Splicing eine Steigerung der Translationseffizienz und der Stabilität der Cathepsin-B-mRNA, wodurch die Cathepsin-BExpression erhöht wird. Eine verlängerte Halbwertszeit der Cathepsin-B-mRNA findet sich auch in Magen-Adenokarzinomzellen. Sie ist hier allerdings auf eine Mutation in der 3'-UTR zurückzuführen (Cao et al. 1994). mRNA-Varianten, denen aufgrund von alternativem Splicing (Gong et al. 1993) oder aufgrund alternativer Transkriptionsinitiationspunkte (Berquin et al. 1995) Exon 3 fehlt, können zur Expression von Cathepsin-B-Formen führen, denen das Pre-Peptid und Teile des Pro-Peptids fehlen. Diese Cathepsin-B-Varianten sollten theoretisch nicht in das vesikuläre Zellkompartiment gelangen und könnten so eine veränderte Lokalisation der Cathepsin-B-Aktivität in Zellen verschiedener Tumore bedingen (Frosch et al. 1999).

Auch die Aktivierung von Onkogenen beeinflusst die Cathepsin-B-Expression in Tumorzellen (Roshy et al. 2003). c-Ha-ras-transfizierte Brustdrüsenepithelzellen exprimieren trotz unveränderter mRNA-Expression deutlich mehr Cathepsin B als untransfizierte Kontrollzellen (Sameni et al. 1995; Sloane et al. 1994). Darüber hinaus verursacht die Transfektion eine Umverteilung perinukleärer Cathepsin-B-haltiger Vesikel zur Zellperipherie sowie das Erscheinen von Cathepsin B auf der Zelloberfläche (Sloane et al. 1994). Obwohl das onkogene ras-Protein am vesikulären Transport lysosomaler Enzyme beteiligt ist, beruht die Umverteilung nicht nur auf einem unspezifischen Defekt im lysosomalen Transport. Die peripheren Vesikeln enthalten entweder Cathepsin B oder Cathepsin D und unterscheiden sich daher von gewöhnlichen Lysosomen (Sameni et al. 1995). Ähnliche Veränderungen der Cathepsin-B-Expression finden sich auch bei Ki-ras3BVal-12-transfizierten (Yan $\mathrm{Z}$ et al. 1997) und spontan K-ras-mutierten Kolonepithelzellen (Kim et al. 1998). Diese Zellen zeigen allerdings einen unspezifischen Verlust der Zellpolarität mit konsekutiver Fehlverteilung aller lysosomalen Enzyme (Yan Z et al. 1997).

Die Sekretion von Pro-Cathepsin B durch Tumorzellen ist zumindest teilweise auf Defekte im lysosomalen Transportweg in Verbindung mit erhöhter Pro-Cathepsin-B-Produktion, zurückzuführen (Lorenzo et al. 2000; Roshy et al. 2003). Ebenso kann die Exozytose von Lysosomen auch einen unselektiven Mechanismus der Sekretion reifer lysosomaler Formen von Cathepsin B darstellen (Rozhin et al. 1994). In Tumorzellen, die besonders viel Cathepsin B exprimieren, kann es dabei das vorrangig sezernierte Enzym sein (Roshy et al. 2003). Auch Membranreparaturmechanismen können so zur Sekretion von Cathepsin B führen, da die Exozytose von Lysosomen der Reparatur von Membranschäden dienen kann (Gerasimenko et al. 2001). Darüber hinaus werden weitere Mechanismen zur spezifischen Sekretion von aktivem Cathepsin B vermutet, da beispielsweise Mammakarzinomzellen, Kolorektalkarzinomzellen und Glioblastomzellen die einkettige Form von Cathepsin B 
sezernieren, obwohl in ihren Lysosomen die zweikettige Form vorherrscht (Linebaugh et al. 1999).

\subsection{Zelluläre Zytotoxizität}

Die zelluläre Zytotoxizität dient der Abwehr intrazellulärer Erreger und maligne transformierter Zellen (Russell und Ley 2002). Wichtige Effektoren der adaptiven zellulären Immunantwort sind zytotoxische T-Zellen. Sie entstehen aus hämatopoetischen Stammzellen des Knochenmarks (Shortman und Wu 1996) und bilden im Thymus durch genetische Rekombination ihren spezifischen T-Zell-Rezeptor (Davis MM und Bjorkman 1988), mit dem sie durch MHC-Klasse-I-Moleküle präsentierte Antigene erkennen können (Zinkernagel und Doherty 1974). CD8 ${ }^{+}$-T-Zellen mit potentiell autoreaktivem oder ineffektivem T-Zell-Rezeptor werden bereits im Thymus eliminiert (Jameson et al. 1995; Kisielow und von Boehmer 1995), die übrigen erreichen die sekundären lymphatischen Organe. Hier verbleiben sie inaktiv, bis sie durch professionell antigenpräsentierende Zellen aktiviert werden (Cox et al. 2011). Diese präsentieren naiven T-Lymphozyten Teile phagozytierter Proteine (Albert et al. 1998). Durch Kreuzpräsentation können sie dabei Fragmente von Proteinen extrazellulären Ursprungs auch über MHC-Klasse-I-Moleküle präsentieren, sodass diese von T-Zellen mit MHC-Klasse-I-spezifischem CD8-Korezeptor erkannt werden können (Ackerman und Cresswell 2004). Naive CD8 ${ }^{+}$-T-Zellen, die mit ihrem T-Zell-Rezeptor ein solches Antigen binden, werden durch kostimulatorische Faktoren und Zytokine aktiviert (Boothby et al. 2001). Nach klonaler Expansion (Butz und Bevan 1998; Murali-Krishna et al. 1998) verlassen die aktivierten zytotoxischen T-Zellen die sekundären lymphatischen Organe und sind nun bereit, pathologisch veränderte Zellen, die das von ihnen erkannte Epitop durch MHC-Klasse-I-Moleküle präsentieren, zu lysieren.

Aktivierte zytotoxische Zellen besitzen verschiedene Möglichkeiten, den Tod von Zielzellen zu induzieren (Kagi et al. 1994 a; Kagi et al. 1996). Ein Mittel ist die Aktivierung von Todesrezeptoren der Zielzellen durch Expression des FAS-Liganden. Die rezeptorvermittelte Aktivierung von Caspasen führt zur Apoptose der Zielzelle (Peter und Krammer 2003). Ein weiterer Mechanismus ist der Granula-Exozytose-Weg. Er beschreibt die Apoptoseinduktion in Zielzellen durch Exozytose vorgebildeter und in speziellen sekretorischen Granula gespeicherter Toxine (Barry und Bleackley 2002; Lieberman 2003; Trapani und Smyth 2002). Die Zerstörung der Zielzellen erfolgt binnen weniger Minuten (Russell und Dobos 1980; Russell et al. 1980). Die zytotoxischen Substanzen der Granula wirken, indem sie in die Zielzelle eindringen und dort Apoptose induzieren (Russell und Ley 2002). Der Verlauf des Zelltodes hängt von der Art der Zielzelle und nicht von der Killerzelle ab, was eine aktive Selbstzerstörung der Zielzelle belegt (Sellins und Cohen 1991).

Die Apoptoseinduktion durch Freisetzung zytotoxischer Granula ist der vorrangige Weg der Zielzellzerstörung durch zytotoxische T-Zellen und NK-Zellen (Kagi et al. 1996). Er ist entscheidend für die Abwehr einiger viraler und bakterieller Infektionen (Harty et al. 2000) und auch verantwortlich für die Elemination maligne transformierter Zellen (Kagi et al. 1996; Smyth et al. 2000). Ebenfalls beteiligt ist er an der Regulation der T-Zell-Homöostase (Stepp et al. 1999) sowie an der Entwicklung von Autoimmunerkrankungen (Straus et al. 1999). 


\subsubsection{Bildung und Bestandteile der zytotoxischen Granula}

NK-Zellen enthalten schon vor ihrer zytokinvermittelten Aktivierung zytotoxische Granula (Trinchieri et al. 1987). CD8 ${ }^{+}$-T-Zellen hingegen bilden zytotoxische Granula erst nach antigenspezifischer Aktivierung in den sekundären lymphatischen Organen (Russell und Ley 2002). Die T-Zelle exprimiert nach ihrer Aktivierung über den T-Zell-Rezeptor verschiedene Zytokinrezeptoren, sodass die Interleukine IL-2 und IL-6 die Expression Granula-spezifischer Gene anstoßen können (Shresta et al. 1998). Das maximale zytotoxische Potential erreichen die zytotoxischen T-Zellen 1 - 3 Tage nach ihrer antigenspezifischen Aktivierung (Russell und Ley 2002).

Zytotoxische Granula sind spezialisierte Lysosomen (Page LJ et al. 1998), die ihre Inhaltsstoffe nach deren Synthese am rauen endoplasmatischen Retikulum über den GolgiApparat erhalten. Als zytotoxische Bestandteile enthalten die Granula Perforin und Granzyme. Das porenbildende, auch für die Killerzelle toxische Perforin wird als Pro-Form $(70 \mathrm{kDa})$ synthetisiert und erst bei Einlagerung in die zytotoxischen Granula am C-Terminus zur aktiven $60 \mathrm{kDa}$-Form prozessiert (Uellner et al. 1997). Die Granula selbst sind vor der porenbildenden Wirkung von Perforin durch Calreticulin geschützt. Calreticulin ist ein Chaperon des endoplasmatischen Retikulums, das ebenfalls Bestandteil der zytotoxischen Granula ist. Es kann im Experiment perforinvermittelte Membranschäden von Zielzellen verhindern, obwohl es weder selbst mit Perforin interagiert noch die Porenformation von Perforin durch Entzug freien Calciums verhindert (Fraser et al. 2000).

Perforin ist ein essentieller Bestandteil der zytotoxischen Granula. Zytotoxische T-Zellen und NK-Zellen Perforin-defizienter Mäuse sind in der Lyse von Zielzellen deutlich eingeschränkt (Kagi et al. 1994 b; Lowin et al. 1994 a). Die Tiere sind gegenüber vielfältigen viralen Infektionen empfindlicher (Kagi et al. 1994 b; Walsh et al. 1994) und auch ihre Fähigkeit zur Abstoßung von Tumorzellen ist vermindert (Kagi et al. 1994 b). Diese Einschränkungen sind auf einen vollständigen Funktionsverlust des GranulaExozytose-Wegs zurückzuführen. Die Restzytotoxizität der Perforin-defizienten zytotoxischen T-Zellen beruht auf rezeptorvermittelter Zelltodinduktion beispielsweise über den FAS-Weg (Kojima et al. 1994; Shresta et al. 1997 a; Walsh et al. 1994).

Als weiterer Bestandteil der Granula werden auch die Granzyme als Pro-Enzyme synthetisiert, glykosyliert und im Golgi-Apparat mit Hilfe der Mannose-6-PhosphatRezeptoren in die zytotoxischen Granula sortiert (Griffiths und Isaaz 1993). Erst unmittelbar vor der Speicherung in den Granula erfolgt die Abspaltung eines Signalpeptids sowie eines kurzen N-terminalen Pro-Peptids (Pham CT und Ley 1999). In den Granula liegt Granzym B dann im Komplex mit dem Glykosaminoglykan Serglycin vor. Granzym B bleibt in diesem Komplex proteolytisch aktiv und kann die Apoptose der Zielzelle einleiten (Galvin et al. 1999), aber auch reines Granzym B ohne Serglycin kann den Zelltod induzieren (Pinkoski et al. 1998).

Die Induktion apoptotischer Kernveränderungen durch Granzym-B-defiziente zytotoxische T-Zellen ist verzögert, bei verlängerter Inkubationszeit lysieren sie Zielzellen allerdings in gleicher Stärke wie Wildtypkontrollzellen (Shresta et al. 1997 a; Shresta et al. 1998). Diese zytotoxische Restfunktion wird auf alternative Mechanismen der Zelltodinduktion wie den FAS-Weg (Lowin et al. 1994 b; Shresta et al. 1997 a) oder auf das Vorliegen alternativer Granzyme wie zum Beispiel Granzym A zurückgeführt. Der Mangel an Granzym A allein führt lediglich zu Einschränkungen in der Abwehr einiger Viruserkrankungen (Ebnet et al. 1995; Mullbacher et al. 1996; Pereira et al. 2000; Shresta et al. 1997 b), die kombinierte 
Defizienz für Granzym A und B führt hingegen zu einem vollständigen Defekt der Fähigkeit, über den Granula-Exozytose-Weg apoptotische Kernveränderung in Zielzellen zu induzieren (Simon et al. 1997).

Granzym-Defizienz und Perforin-Defizienz führen zu vergleichbaren Defekten der durch Granula-Exozytose vermittelten Zytotoxizität. Dennoch zeigen in-vivo-Experimente Unterschiede beider Phänotypen. Granzym-A- und -B-doppeldefiziente Mäuse sind resistent gegenüber RMA-S-Tumoren, die durch verminderte MHC-Klasse-I-Expression charakterisiert sind. Perforin-defiziente Mäuse hingegen sind gegenüber diesen Tumoren sehr empfindlich. Auch sind sie deutlich empfindlicher gegenüber der Tumorinduktion durch Methylcholanthren. Perforin scheint daher essentieller Bestandteil zytotoxischer Granula in der Tumorkontrolle zu sein (Davis JE et al. 2001). Anders als bei den Granzymen A und B, die für die Immunabwehr von Tumorerkrankungen nicht zwangsläufig notwendig sind (Davis JE et al. 2001), stellt die Inaktivierung von Perforin somit potentiell einen sehr potenten Immune-Escape-Mechanismus von Tumorzellen dar.

Neben Perforin und Granzymen enthalten die Granula auch FAS-Liganden, die nach der Exozytose auch tatsächlich FAS-Rezeptoren der Zielzelle erreichen (Bossi und Griffiths 1999). Humane zytotoxische T-Zellen exprimieren außerdem das Protein Granulysin, dass wie Perforin Membranschäden verursachen, durch Depolarisation von Mitochondrien Cytochrom C freisetzen und Caspase 3 aktivieren kann (Gamen et al. 1998; Kaspar et al. 2001).

\subsubsection{Die Granula-Exozytose}

Die Exozytose der zytotoxischen Granula erfolgt, wenn eine aktivierte zytotoxische T-Zelle mit ihrem T-Zell-Rezeptor ein durch MHC-Klasse-I-Moleküle präsentiertes Antigen auf einer Zielzelle erkennt. Durch den T-Zell-Rezeptor selbst sowie weitere Adhäsionsmoleküle bilden beide Zellen eine immunologische Synapse (Russell und Ley 2002). Die zytotoxischen Granula wandern entlang der Mikrotubuli zum stimulierten T-Zell-Rezeptor (Kupfer und Dennert 1984; Yannelli et al. 1986) und setzen ihre zytotoxischen Inhaltsstoffe in einen abgeschlossenen interzellulären Spalt der immunologischen Synapse zwischen den Zellen frei (Stinchcombe et al. 2001).

\subsubsection{Die Zelltodinduktion}

Obwohl die Inhaltsstoffe der zytotoxischen Granula bekannt und ihre Wirkungen auf Zielzellen Gegenstand intensiver Forschung sind, so ist ihr komplexes Zusammenspiel in vivo bisher doch nur unzureichend verstanden (Pipkin und Lieberman 2007). Die ursprüngliche Hypothese, die Membranzerstörung durch Perforin sei der für die Zielzellzerstörung verantwortliche Mechanismus, beruht auf der Beobachtung, dass isoliertes monomeres Perforin in Anwesenheit von Calcium große Poren in Lipidmembranen bildet. Diese wirken als unselektive Ionenkanäle für monovalente und divalente Ionen und führen so zum Verlust der Membranspannung (Podack et al. 1985; Young et al. 1986). Die Bindung von Perforin an die Zielzellmembran erfolgt dabei zumindest zum Teil rezeptorabhängig. Als ein calciumabhängiger Perforin-Rezeptor auf Zielzellen wurde Phosphocholin identifiziert (Muller und Tschopp 1994; Tschopp et al. 1989).

Perforin-induzierte Membranschäden lysieren die Zielzelle, führen allerdings nicht zur DNA-Fragmentation (Duke et al. 1989). Da diese aber eines der Merkmale der Zielzelllyse 
durch zytotoxische T-Zellen ist, entstand schon bald die Hypothese, dass Perforin-Poren in der Zellmembran den Granzymen als Eintrittspforte dienen. Der Durchmesser der Poren ist allerdings selbst bei Perforin-Konzentrationen, die zu maximaler Lyse der Zielzellen im Chrom-Freisetzungs-Test führen, für den Durchtritt von Granzymen mit einer Größe von 30 - 65 kDa oder sogar noch deutlich größerer Komplexe mit Serglycin zu klein. Die Hypothese kann die sehr effektive Zytotoxizität schon bei niedrigen PerforinKonzentrationen nicht erklären (Browne et al. 1999). Das führte zur Entwicklung der Theorie der reparativen Endozytose: Perforin induziert durch seine Porenbildung in der Membran der Zielzellen einen Reparaturmechanismus, bei dem ganze Membranabschnitte mit den daran gebundenen Granzymen und Perforin in die Zelle aufgenommen werden (Keefe et al. 2005; Podack 1999).

Granzyme können allerdings auch in Abwesenheit von Perforin in Zielzellen eindringen (Froelich et al. 1996; Metkar et al. 2002; Shi L et al. 1997). Sie binden in einer sättigbaren Kinetik über einen hochaffinen Bindungspartner an der Oberfläche der Zielzellen und gelangen dann in endozytotischen Vesikeln in das Zellinnere (Froelich et al. 1996). Der zunächst als möglicher Rezeptor von Granzymen beschriebene kationenunabhängige Mannose-6-Phosphat-Rezeptor (Motyka et al. 2000) scheint nicht allein verantwortlich zu sein. Die Empfindlichkeit Mannose-6-Phosphat-Rezeptor-defizienter Zielzellen gegenüber Granula-assoziierter Zytotoxizität ist nicht reduziert (Dressel et al. 2004 a; Dressel et al. 2004 b).

Granzyme, die in Abwesenheit von Perforin in Zielzellen eindringen, können das endosomale Kompartiment nicht verlassen. Sie können den Nukleus nicht erreichen und lösen keine Apoptose aus (Shi L et al. 1997). Entscheidend für ihre zytotoxische Wirkung ist die Freisetzung aus den endosomalen Speichern in das Zytoplasma (Pinkoski et al. 1998). Diese kann entweder durch Behandlung mit sublytischen Konzentrationen von Perforin, durch Zugabe bakterieller Toxine oder durch Ko-Infektion mit Adenoviren erreicht werden (Browne et al. 1999; Froelich et al. 1996). Im Rahmen der killerzellvermittelten Zytotoxizität fusionieren die endosomalen Vesikel zu sogenannten Gigantosomen, in deren Membran Perforin erneut polymerisiert und durch seine Poren zunächst kleine Mengen der Granzyme in das Zytosol freigesetzt (Thiery et al. 2011). Nach etwa 15 Minuten zerfallen die Gigantosomen komplett und ihr gesamter Inhalt gelangt in das Zytoplasma (Thiery et al. 2011). Granzyme, die aus dem endosomalen Kompartiment freigesetzt sind, erreichen den Nukleus dann ohne die Hilfe von Perforin und ohne Veränderung der Kernporen (Jans et al. 1996; Trapani et al. 1996; Trapani et al. 1998 a). Auch per Mikroinjektion direkt in das Zytosol eingebrachte Granzyme lösen ohne weitere Faktoren die Apoptose der Zielzelle aus (Jans et al. 1998; Pinkoski et al. 1998). Die Apoptose-Einleitung durch Granzyme beruht auf der enzymatischen Aktivierung verschiedener Caspasen (Darmon et al. 1995; Duan et al. 1996; Martin et al. 1996; Metkar et al. 2003; Shi L et al. 1996; Talanian et al. 1997; Yang et al. 1998), Granzyme können aber auch unabhängig von Caspasen den Zelltod auslösen (Sarin et al. 1997; Trapani et al. 1998 b). Granzym B kann beispielsweise direkt den DNAFragmentations-Faktor-Inhibitor DFF45/ICAD spalten und den DNA-FragmentationsFaktor DFF40/CAD freisetzen (Thomas et al. 2000), wodurch apoptotische DNAFragmentation und Chromatin-Kondensation angestoßen werden (Widlak 2000).

\subsubsection{Selbstschutz zytotoxischer T-Lymphozyten}

Nicht nur die Zielzelle sondern auch die zytotoxische Zelle selbst ist nach der Degranulation den Inhaltsstoffen ihrer zytotoxischen Granula ausgesetzt. Es konnte gezeigt werden, dass 
zytotoxische T-Lymphozyten während der Zielzelllyse selbst nicht sterben, sondern sogar in der Lage sind, mehrere Zielzellen nacheinander zu lysieren (Rothstein et al. 1978). Sie müssen daher gegenüber den Inhaltsstoffen ihrer eigenen zytotoxischen Granula resistent sein (Nagler-Anderson et al. 1988; Verret et al. 1987).

Zunächst entstand die Hypothese, zytotoxische Zellen seien an sich resistent gegenüber den Inhaltsstoffen ihrer zytotoxischen Granula. Erste in-vitro-Experimente bestätigten die im Vergleich zu Tumorzellen verminderte Empfindlichkeit der Killerzellen gegenüber Angriffen zytotoxischer Zellen (Blakely et al. 1987; Kranz und Eisen 1987; Luciani et al. 1986), gegenüber Extrakten ihrer zytotoxischen Granula (Verret et al. 1987) und auch gegenüber aufgereinigtem Perforin (Liu CC et al. 1989; Muller und Tschopp 1994). Spezifische Zellwandbestandteile zytotoxischer Zellen verhindern die Einlagerung von Perforin in die Membran (Antia et al. 1992; Jiang et al. 1990; Ojcius et al. 1991) und auch das gebundene Perforin bildet erst bei im Vergleich zu Tumorzellen 10-fach höheren Konzentrationen Poren in der Zellmembran (Persechini et al. 1990). Andere Experimente zeigten allerdings, dass zytotoxische Zellen nicht weniger empfindlich gegenüber der durch Granula-Exozytose vermittelten Zytotoxizität sind als andere Lymphozyten (Schick und Berke 1990). Auch können sich peptidspezifisch aktivierte zytotoxische T-Zellen in Anwesenheit des Peptids gegenseitig lysieren (Dutz et al. 1992; Su et al. 1993; Walden und Eisen 1990).

Schließlich wurde gezeigt, dass Perforin zwar in gleicher Menge auf der Membran von zytotoxischen T-Zellen und Tumorzellen bindet, jedoch auf der Oberfläche der zytotoxischen T-Zellen eine veränderte Konformation aufweist (Muller und Tschopp 1994). Vor der Polymerisation zu relativ resistenten Porenkomplexen liegt Perforin direkt nach der Exozytose (Young et al. 1987) sowie nach der Membranassoziation (Kuta et al. 1991) in sehr proteolyseanfälligen Stadien vor und kann leicht durch Proteasen wie Trypsin (Muller und Tschopp 1994), Chymotrypsin und Pronase gespalten werden (Kuta et al. 1991; Young et al. 1987). Heute wird daher vermutet, dass durch Exozytose der Granula eine Protease auf der Oberfläche der zytotoxischen Zelle erscheint, welche Perforin, das an der Membran der Killerzelle bindet, inaktiviert (Balaji et al. 2002). Als mögliche Enzyme wurden lysosomale Proteasen identifiziert, die in großen Mengen in zytotoxischen Granula enthalten sind (Page LJ et al. 1998). Besonders Cathepsin B gilt als potentiell zytoprotektives Enzym, da es im extrazellulären Milieu Perforin schnell und effizient verdauen kann und außerdem die an der Oberfläche zytotoxischer T-Zellen detektierbare Cathepsin-B-Menge nach der GranulaExozytose deutlich ansteigt (Balaji et al. 2002). Die Quervernetzung von T-Zell-Rezeptoren führt zum lokalen und transienten Erscheinen von Cathepsin B am Ort der GranulaExozytose (Balaji et al. 2002).

Bestätigt wurde diese Theorie durch den Nachweis, dass extrazelluläre Cathepsin-BInhibitoren einen schnellen, Perforin-abhängigen Zelltod zytotoxischer Lymphozyten verursachen, wenn diese zur Degranulation angeregt werden. Dies gilt für zytotoxische T-Zellen ebenso wie für NK-Zellen, nicht aber für Zellen, die defizient für den GranulaExozytose-Weg sind (Balaji et al. 2002). Auch verhindern Inhibitoren der GranulaExozytose wie Concanamycin A und Calciumchelatoren die Autolyse der stimulierten Zellen in Gegenwart von Cathepsin-B-Inhibitoren (Balaji et al. 2002).

Zytotoxische T-Zellen, die kein Cathepsin B exprimieren, werden allerdings von allogenen zytotoxischen T-Zellen in gleicher Stärke lysiert wie Wildtyp-Kontrollzellen (Baran et al. 2006). Sie sind auch nach der Degranulation sowohl gegenüber reinem Perforin als auch 
gegenüber Extrakten ihrer zytotoxischen Granula nicht empfindlicher und lysieren Zielzellen in Chrom-Freisetzungs-Test auch bei verlängerter Inkubation nicht schlechter als Cathepsin-B-exprimierende Zellen (Baran et al. 2006). Auch werden die Cathepsin-Bdefizienten zytotoxischen T-Zellen selbst während des Chrom-Freisetzungs-Test nicht stärker lysiert als die Kontrollzellen (Baran et al. 2006). Die erhaltene zytotoxische Kapazität Cathepsin-B-defizienter zytotoxischer T-Zellen wurde auch in vivo durch Beobachtung der Lyse injizierter markierter syngener Zielzellen bestätigt (Baran et al. 2006). Die widersprüchlichen Ergebnisse der Chrom-Freisetzungs-Tests mit Cathepsin-BInhibitoren und Cathepsin-B-defizienten Zellen deuten auf die Existenz eines weiteren Enzyms hin, welches zwar ebenfalls durch den Cathepsin-B-Inhibitor inaktiviert wird, in den Cathepsin-B-defizienten Zellen aber die Inaktivierung von Perforin übernimmt. Ein mögliches Enzym könnte Cathepsin W darstellen, welches ausschließlich von NK-Zellen und $\mathrm{CD}^{+}$-T-Zellen exprimiert und von diesen Zellen während der Zielzelllyse sezerniert wird (Stoeckle et al. 2009).

Einen weiteren Selbstschutzmechanismus der Lymphozyten stellt die Expression des Protease-Inhibitors PI-9 dar. PI-9 ist ein spezifischer Inhibitor von Granzym B und schützt zytotoxische Zellen vor der Zerstörung durch zytotoxische Lymphozyten ebenso wie vor der Lyse durch isoliertes Granzym B und isoliertes Perforin (Bird et al. 1998).

\subsection{Tumore und das Immunsystem}

Alle Zellen sind Faktoren ausgesetzt, die eine maligne Umwandlung der Zellen anstoßen können. Aus diesem Grund besitzen höhere Organismen komplexe Mechanismen, die entweder zur Reparatur der verursachten Schäden oder zur Apoptose irreparabel beschädigter Zellen führen. Zellen, die Schäden nicht reparieren, trotzdem aber nicht absterben, sind potentiell tumorbildend, können aber vom Immunsystem unter Umständen erkannt und eliminiert werden (Smyth et al. 2001).

Die 1909 von Paul Ehrlich entwickelte Theorie, nur das Immunsystem könne eine sonst „ungeheuerliche Frequenz“ (Ehrlich 1909, S. 163) an Karzinomen unterdrücken, führte über den Nachweis, dass Tumorzellen anhand von Tumorantigenen vom Immunsystem erkannt werden (Klein 1966; Old und Boyse 1964), zum Tumorkontrollmodell von Burnet und Thomas: Alle großen, lang lebenden Tiere entwickeln immer wieder maligne Zellpopulationen, die allerdings vom Immunsystem erkannt und getötet werden, noch bevor klinische Zeichen ihrer Existenz sichtbar werden (Burnet 1970).

Eine große Anzahl von Studien mit immundefizienten Mäusen untermauert die Theorie der Tumorverhinderung durch die zelluläre Immunabwehr. Versuche mit Perforin-defizienten Mäusen zeigen eine zwei- bis dreifach erhöhte Tumorrate nach MethylcholanthrenTumorinduktion ebenso wie eine Steigerung der Inzidenz spontaner disseminierter Lymphome (Smyth et al. 2000; Street et al. 2001; van den Broek et al. 1996). Auch eine Interferon- $\gamma$-Defizienz (Dighe et al. 1994; Kaplan et al. 1998; Shankaran et al. 2001; Street et al. 2001; Street et al. 2002) verursacht eine erhöhte Empfindlichkeit gegenüber chemisch induzierten und spontanen Tumoren.

Beim Menschen führen besonders die Immunsuppression nach Transplantation (Elder et al. 1997; Penn 1981; Penn 1996 a; Suranyi et al. 1998) und primäre Immundefekte (Gatti und Good 1971; McClain 1997) zu erhöhter Inzidenz von Malignomen. Viele dieser Malignome sind vermutlich virusinduziert (Smyth et al. 2001), aber auch Karzinome, bei denen bisher keine virale Ätiologie bekannt ist, kommen bei Patienten mit schweren Immundefekten 
häufiger vor (Birkeland et al. 1995; Penn 1996 b; Pham SM et al. 1995). Die Immunabwehr verhindert aber nicht nur die Entstehung klinisch manifester Tumoren, auch bei bereits klinisch relevanten Tumoren hat die Interaktion zwischen Tumor und Immunsystem Einfluss auf den Verlauf der Tumorerkrankung. Die Infiltration von Lymphozyten im Tumor korreliert positiv mit der Prognose (Clark et al. 1989; Naito Y et al. 1998), wobei vor allem die Einwanderung von $\mathrm{CD}^{+}-\mathrm{T}-Z$ Zellen von prognostischer Bedeutung ist (Naito $\mathrm{Y}$ et al. 1998).

Die Mechanismen der Tumorerkennung und -bekämpfung durch das Immunsystem umfassen sowohl die angeborene Immunkontrolle durch NK-Zellen als auch die peptidspezifische adaptive T-Zell-Immunantwort (Smyth et al. 2001). Bei der adaptiven Immunantwort durch T-Zellen aktivieren maligne Tumoren antigenpräsentierende Zellen durch Proteine nukleären und zytosolischen Ursprungs, die von beschädigten und nekrotischen Zellen freigesetzt werden (Gallucci und Matzinger 2001; Gallucci et al. 1999; Shi Y et al. 2003). Aktivierte dendritische Zellen induzieren und kontrollieren nach ihrer Wanderung in die sekundären lymphatischen Organe die Immunabwehr des adaptiven Immunsystems, welche sich direkt gegen Tumorantigene richtet. Die dendritischen Zellen nehmen bei der Lyse von Tumorzellen freigesetzte Antigene auf und präsentieren sie nach Prozessierung durch MHC-Klasse-I und MHC-Klasse-II-Moleküle (Albert et al. 1998). Antigenspezifische $\mathrm{CD}^{+}$- und $\mathrm{CD}^{+}$-T-Zellen werden aktiviert. Die antigenpräsentierenden Zellen induzieren gemeinsam mit $\mathrm{CD}^{+}-\mathrm{T}-$ Zellen die Differenzierung von naiven CD8 ${ }^{+}-\mathrm{T}-Z$ Zellen zu zytotoxischen T-Lymphozyten (Keene und Forman 1982; Schultze et al. 1996; Sharpe 1995). Die zytotoxischen T-Zellen können nun in peripheren Geweben Tumorzellen anhand ihrer spezifischen Antigene identifizieren und lysieren.

\subsubsection{Tumorantigene}

Die Erkennung maligne entarteter Zellen durch zytotoxische T-Zellen basiert auf der Präsentation von Tumorantigenen über MHC-Klasse-I-Moleküle der Tumorzellen (Dunn et al. 2004). Die Vielfalt dieser Antigene wird auf Größenordnungen vergleichbar mit der Vielfalt der Immunrezeptoren geschätzt, wobei jede einzelne Tumorzelle eine Vielzahl unterschiedlicher Antigene präsentieren kann (Wortzel et al. 1983). Bei der Suche nach Zielstrukturen für Tumor-Impfstoffe wurde eine große Anzahl relevanter Tumorantigene beschrieben und von verschiedenen Autoren in unterschiedliche Klassifikationssysteme eingeordnet (Boon und van der Bruggen 1996; Cheever et al. 2009; Dunn et al. 2004; Old 2003; Parmiani et al. 2007; Rosenberg 1999).

Gemeinsame Tumorantigene sind Antigene, die von vielen Tumorzellen unterschiedlicher Ausgangsgewebe, nicht aber von normalen Zellen exprimiert werden (Boel et al. 1995; De Plaen et al. 1994; Ioannides et al. 1993 a; Van den Eynde et al. 1995; van der Bruggen et al. 1991). Ihr Erscheinen beruht auf der Transkription normalerweise nicht exprimierter Gene sowie der Aktivierung normalerweise inaktiver Promotoren, die zur Expression alternativer Leserahmen ubiquitär exprimierter Gene führen (Guilloux et al. 1996). Ebenfalls tumorübergreifend ist die Präsentation von Peptidanteilen, die in normalen Zellen durch Glykosylierung verborgen sind, bei Unterglykosylierung im Tumor allerdings eine Immunreaktion auslösen können (Ioannides et al. 1993 b; Takahashi et al. 1994).

Im Gegensatz zu diesen, nur von Tumorzellen präsentierten Antigenen gibt es weitere Tumorantigene, die auch von normalen Zellen exprimiert werden. Tumorzellen unterscheiden sich hier vom Normalgewebe durch eine deutliche Steigerung der Expression (Fisk et al. 1994; Ioannides et al. 1993 c; Peoples et al. 1995; Yoshino et al. 1994). 
Differenzierungsantigene werden ebenfalls von normalen und maligne entarteten Zellen eines Gewebes exprimiert. Die Entstehung eines malignen Tumors kann zu einer Immunantwort zytotoxischer T-Lymphozyten gegen diese Peptide führen (Anichini et al. 1993).

Tumorspezifische Antigene sind individuelle Antigene, die sich von Tumor zu Tumor unterscheiden (Prehn 1970). Sie beruhen auf zufälligen Punktmutationen (De Plaen et al. 1988; Lurquin et al. 1989; Mandelboim et al. 1994; Monach et al. 1995), die entweder direkt zu Veränderungen in der Aminosäuresequenz des präsentierten Epitops führen oder durch Veränderungen der Splicingeigenschaften der mRNA die Entstehung neuer immunogener Epitope verursachen (Coulie et al. 1995; Lupetti et al. 1998). Ebenso kann ein durch eine Punktmutation verursachter Aminosäureaustausch zur Entstehung eines Ankers führen, über den ein sonst nicht präsentationsfähiges Peptid an MHC-Klasse-I-Moleküle binden kann (Robbins et al. 1996). Auch die bei chromosomalen Translokationen entstehenden FusionsProteine können zur Bildung neuer antigener Epitope führen (Bosch et al. 1996). Eine besondere Untergruppe der tumorspezifischen Antigene bilden die mutierten Onkogene wie CDK-4 (Wolfel et al. 1995), p53 (Nijman et al. 1994; Noguchi et al. 1994) und ras (Fossum et al. 1995; Gedde-Dahl et al. 1994; Van Elsas et al. 1995), die neben ihrer Immunogenität auch onkogene Eigenschaften besitzen.

Zusätzlich zu diesen immunogenen Veränderungen der zelleigenen Proteinbiosynthese können bei virusinduzierten Tumoren auch virale Peptide die Erkennung der Tumorzellen durch das Immunsystem ermöglichen. Beispiel ist hier die Aktivierung zytotoxischer Zellen durch Epstein-Barr-nukleäres-Antigen auf EBV-positiven Tumoren (Rickinson und Moss 1997).

Die Mehrzahl der oben beschriebenen Tumorantigene ist von der Präsentation durch MHC-Klasse-I-Moleküle abhängig, es existieren aber auch MHC-unabhängige Erkennungsmerkmale, wie zum Beispiel verschiedene NKG2D-Liganden, die zur Abstoßung von Tumoren bei Mensch und Maus führen (Diefenbach et al. 2000; Groh et al. 1999; Jinushi et al. 2003; Vetter et al. 2002). Außerdem können Tumorzellen, die nur sehr geringe Mengen an MHC-Klasse-I-Molekülen exprimieren, durch NK-Zellen erkannt und lysiert werden (Whiteside und Herberman 1995).

\subsubsection{Immune-Escape-Mechanismen}

Anhand von Rekombinase-Aktivierendes-Gen-(RAG)-2-Knock-Out-Mäusen, die keine Bund T-Zellen bilden können, wurde gezeigt, dass das Immunsystem nicht nur die Entstehung von Malignomen unterdrückt, sondern auch, durch Selektion wenig immunogener Zellen, den Tumor selbst verändert. Bei der Tumortransplantation aus immundefizienten in immunkompetente Mäuse wird ein Teil der Tumoren vom Empfängerimmunsystem erkannt und abgestoßen (Shankaran et al. 2001). Die Tumoren der immundefizienten Tiere sind immunogener als die der immunkompetenten Tiere. Auch bei selektiver T-Zell-Defizienz (Svane et al. 1996) und Perforin-Defizienz (Smyth et al. 2000) entwickeln sich deutlich immunogenere Tumoren als in immunkompetenten Tieren. Dieser Einfluss des Immunsystems auf die immunogenen Eigenschaften eines Tumors findet in der Weiterentwicklung des Tumorkontrollmodells von Burnet und Thomas zum CancerImmunoediting-Model nach Schreiber Berücksichtigung (Dunn et al. 2002; Dunn et al. 2004). Es beschreibt drei Phasen der Interaktion von Tumor und Immunsystem: 


\section{Elimination}

Die Eliminationsphase beschreibt die Aktivierung der unspezifischen Immunabwehr und die Entstehung einer lokalen Entzündungsreaktion, bedingt durch Tumorwachstum und mögliche Invasion. Freigesetzte Zytokine induzieren gleichzeitig die Aktivierung tumorspezifischer zytotoxischer T-Zellen, die dann gemeinsam mit der unspezifischen Immunantwort den Tumor eliminieren können, bevor er klinisch präsent wird.

\section{Gleichgewicht}

Bei diesem vermutlich längsten Stadium der Tumorentwicklung besteht ein Gleichgewicht zwischen der ständigen Elimination von Tumorzellen durch das Immunsystem und der Bildung von Immune-Escape-Mechanismen aufgrund des starken, durch die Immunabwehr verursachten, Selektionsdrucks. Die Entwicklung von Tumoren, welche der Entdeckung und Elemination durch das Immunsystem entgehen können, wird dabei durch die genetische Instabilität der Tumorzellen begünstigt (Lengauer et al. 1998).

\section{Entkommen}

Das letzte Stadium beschreibt das unkontrolliert Wachstum von Tumorzellen, die der Detektion oder Elemination durch das Immunsystem entgehen und $\mathrm{zu}$ klinisch fassbaren Malignomen führen.

Dieses Drei-Phasen-Modell beschreibt, wie die Selektion durch das Immunsystem und die genetische Instabilität der Tumorzellen zur Entwicklung von Tumoren führen, die der unspezifischen und der adaptiven Immunantwort entgehen können. Die Entwicklung von Abwehrmechanismen gegenüber den Angriffen zytotoxischer Zellen ist essentiell für Tumorentstehung und Tumorwachstum (Smyth et al. 2001).

Ein wichtiger Immune-Escape-Mechanismus ist die Begrenzung der den Tumor umgebenden Entzündungsreaktion durch Expression immunsuppressiver Zytokine wie TGF- $\beta$ und IL-10 (Elgert et al. 1998). Diese reduzieren zum einen die Aktivität der den Tumor infiltrierenden Lymphozyten, zum anderen führen sie, durch Suppression von Entzündungsmediatoren, auch zur Unterdrückung der Reifung dendritischer Zellen, die zur Initiation einer suffizienten Immunabwehr notwendig sind (Wang et al. 2004). Eine ähnliche Wirkung hat auch die Förderung der Aktivierung und Proliferation immunsuppressiver T-Zell-Populationen wie zum Beispiel regulatorischer CD4 ${ }^{+}-\mathrm{CD} 25^{+}-\mathrm{T}$-Zellen (Liyanage et al. 2002; Woo et al. 2001) oder IL-13-produzierender NKT-Zellen (Terabe et al. 2000) durch Tumorzellen.

Ein weiterer Immune-Escape-Mechanismus ist die direkte Inhibition der den Tumor infiltrierende T-Zellen durch Sekretion spezifischer T-Zell-Inhibitoren wie Galectin 1 (Rubinstein et al. 2004) und Indolamin-2,3-Dioxygenase (IDO) (Uyttenhove et al. 2003). Auch die Sekretion von löslichen NKG2D-Liganden führt über eine NKG2DRezeptorverminderung auf den T-Zellen zur Reduktion ihrer Zytotoxizität (Groh et al. 2002). Darüber hinaus können Tumorzellen durch Expression apoptoseinduzierender Oberflächenmoleküle wie FAS-Liganden infiltrierende Lymphozyten auch direkt töten (Walker et al. 1998). 
Neben der Suppression der bereits stattfindenden Immunreaktion führt auch eine verringerte Immunogenität zur positiven Selektion der Tumorzellen. Die verminderte Expression von Genen, die für Tumorantigene kodieren (Dunn et al. 2002; Khong et al. 2004), führt ebenso, wie die Reduktion der Expression von MHC-Klasse-I-Molekülen zu einer geringeren Abstoßungsreaktion (Algarra et al. 2000; Khong et al. 2004; Marincola et al. 2000). Auch Defekte der Moleküle der Antigenprozessierung wie TAP1, LMP2 und LMP7 (Seliger et al. 2000), sowie eine verminderte Stimulierbarkeit der MHC-Klasse-I-Molekül-Expression der Tumorzellen durch Interferon- $\gamma$ (Kaplan et al. 1998; Wong et al. 1997), können einen Schutz vor der adaptiven Immunantwort darstellen.

Über diese Mechanismen hinaus entwickeln einige Tumorzellen auch Mechanismen, die es ihnen erlauben, auch bei Erkennung durch das Immunsystem zu überleben. Durch Expression des Proteaseinhibitors PI-9 schützen sich neben Lymphozyten (Bird et al. 1998) und dendritischen Zellen (Medema et al. 2001) auch Tumorzellen (Medema et al. 2001) vor der Apoptoseinduktion durch Granzym B. Auch Veränderungen der Zellmembran, die zu erschwerter Einlagerung von Perforin führen, dienen einigen Tumorzellen als effektiver Schutzmechanismus (Lehmann et al. 2000).

\subsection{Fragestellung}

Im Rahmen dieser Arbeit wurde untersucht, ob die Cathepsin-B-Expression durch Tumorzellen einen weiteren Immune-Escape-Mechanismus darstellt. Zytotoxische Zellen exprimieren nach Ausschüttung ihrer zytotoxischen Granula oberflächengebundenes Cathepsin B, welches freigesetztes Perforin spalten kann und die zytotoxischen T-Zellen so vor der Autolyse schützt (Balaji et al. 2002). Eine ähnliche membranassoziierte Expression von Cathepsin B ist auch von vielen Tumorzellen beschrieben und könnte, in analoger Weise, neben der Lösung der Tumorzellen aus dem Zellverband zur Metastasierung, auch dem Schutz der Tumorzellen vor der Lyse durch zytotoxische T-Zellen dienen (Balaji et al. 2002).

Die Inhibition von auf der Oberfläche von RMA-Lymphomzellen gebundenem Cathepsin B durch den zellmembranimpermeablen Cathepsin-B-Inhibitor CA-074 erhöht die Empfindlichkeit der Tumorzellen gegenüber zytotoxischen T-Zellen im ChromFreisetzungs-Test (Ensslen 2009). Außerdem werden auch embryonale Fibroblasten aus Mäusen mit Cathepsin-B-Defizienz im Chrom-Freisetzungs-Test besser lysiert als Fibroblasten der Wildtyp-Kontrollmäuse (Ensslen 2009). Untersucht wurde in dieser Arbeit daher, ob eine Überexpression von Cathepsin B, wie sie in Tumorzellen beschrieben ist, die Empfindlichkeit von Zielzellen gegenüber zytotoxischen T-Zellen reduzieren kann. Im Chrom-Freisetzungs-Test wurde der Einfluss verschiedener Cathepsin-BExpressionsvektoren auf die peptidspezifische Lyse von RMA-Zellen durch zytotoxische T-Zellen untersucht. 


\section{Material und Methoden}

\subsection{Material}

\subsubsection{Biologisches Material}

\subsubsection{Bakterienstämme}

Zur Gewinnung und Vermehrung von Plasmid-DNA wurden E. coli-Bakterien des Stammes TOP10 von Life technologies ${ }^{\mathrm{TM}}$ mit dem Genotyp

F- $m c r \mathrm{~A} \Delta(m r r-h s d \mathrm{RMS}-m c r \mathrm{BC}) \varphi 80$ lacZ $\Delta \mathrm{M} 15 \Delta \mathrm{lacX} 74$ recA1 araD139 $\Delta($ ara-leu $) 7697$ gal $\mathrm{U}$ galK rps $\mathrm{L}$ end $\mathrm{A} 1$ nup $\mathrm{G}$

verwendet. Der Stamm ließ sich mit hoher Effizienz transformieren (2.2.1.3, S. 33) und eignete sich besonders für die Vermehrung von high-copy Plasmiden. Aufgrund des hsdRGenotyps konnte der Stamm auch mit unmethylierten PCR-Produkten transformiert werden. Außerdem ist der Stamm Rekombinase-defizient (recA1) und zeigt daher kein Austausch zwischen eingebrachten Plasmiden und der Wirtszell-DNA.

\subsubsection{Zelllinien}

Als Zielzellen zellulärer Zytotoxizität wurden RMA-Zellen verwendet. Die RMA-Zelllinie geht auf ein durch das Rauscher-Virus induziertes T-Zell-Lymphom in C57BL/6-Mäusen (Haplotyp H2 ${ }^{\text {b }}$ ) zurück (Karre et al. 1986).

\subsubsection{Versuchstiere}

\subsection{OT-I Mäuse}

OT-I-Mäuse gehen auf den C57BL/6-Stamm (Haplotyp H2 ${ }^{\text {b }}$ zurück und exprimieren einen transgenen T-Zell-Rezeptor V $\alpha 2 \mathrm{~V} \beta 5$, der spezifisch an $\mathrm{H}_{2} \mathrm{~K}^{\mathrm{b}}$ gebundenes SIINFEKL-Peptid des Ovalbumins (Aminosäuren 257 - 264) erkennt (Hogquist et al. 1994). Aus Milzen der Mäuse wurden zytotoxische T-Lymphozyten gewonnen (2.2.4.11.3, S. 48) und zur Lyse SIINFEKL-präsentierender RMA-Zielzellen im Chrom-Freisetzungs-Test verwendet.

\subsection{Ratten}

Zur Gewinnung von zytokinreichem Concanavalin-A-Überstand (2.2.4.11.2, S. 47) wurden die Milzen aus Ratten der Stämme BUF (Haplotyp RT1 ${ }^{\mathrm{b}}$ ) und LOU/C (Haplotyp RT1 ${ }^{\mathrm{u}}$ ) verwendet.

\subsubsection{Gene}

Tabelle 1 zeigt eine Liste der Gene, die zur Herstellung der in dieser Arbeit verwendeten Konstrukte genutzt wurden. Die Cathepsin-B-cDNA wurde von OriGene Technologies Inc. in einem transformationsfähigen pCMV6-Vektor bezogen. Die bestellte cDNA BC006656 unterschied sich in einem Nukleotid an Stelle 1196 von der NCBI-Referenz-Sequenz. Dieser Unterschied lag außerhalb des verwendeten offenen Leserahmens und erforderte daher keine Beachtung. Der zur Plasmid-Herstellung verwendete CAG-PEGFP-1-Vektor wird unter 2.1.3 (S. 20) eingehend beschrieben. 
Tabelle 1: Verwendete Gene und DNA-Sequenzen

\begin{tabular}{|c|c|c|c|c|}
\hline Name & Quelle & Gene ID & Bereich & Beschreibung \\
\hline \multirow{3}{*}{ Maus Cathepsin B } & $\begin{array}{l}\text { OriGene } \\
\text { Technologies } \\
\text { Inc. }\end{array}$ & ВС006656 & $\begin{array}{l}\text { Cathepsin-B- } \\
\text { cDNA }\end{array}$ & $\begin{array}{l}\text { In transformationsfähigem } \\
\text { pCMV6-Vektor bezogen }\end{array}$ \\
\hline & \multirow[b]{2}{*}{ NCBI } & \multirow[b]{2}{*}{13030} & cDNA & $\begin{array}{ll}\text { Referenzsequenz } & \text { der } \\
\text { Cathepsin-B-cDNA } & \end{array}$ \\
\hline & & & $\begin{array}{l}\text { Nukleotide } \\
242-984\end{array}$ & $\begin{array}{l}\text { Entspricht den Aminosäuren 80- } \\
333 \text { (Swiss-Prot: P10605.2) und } \\
\text { somit der einkettigen reifen } \\
\text { Form, wie sie auch auf der } \\
\text { Oberfläche zytotoxischer Zellen } \\
\text { beschrieben ist (Balaji et al. } \\
\text { 2002). }\end{array}$ \\
\hline \multirow[b]{2}{*}{ Maus H2K } & \multirow[b]{2}{*}{ NCBI } & \multirow[b]{2}{*}{14972} & $\begin{array}{l}\text { Nukleotide } \\
77-139 \\
\text { (Leadersequenz) } \\
\end{array}$ & $\begin{array}{l}\text { Leitet den Transport von } \mathrm{H} 2 \mathrm{~K} \\
\text { zur Zelloberfläche }\end{array}$ \\
\hline & & & $\begin{array}{l}\text { Nukleotide } \\
962-1070 \\
\text { (Transmembran- } \\
\text { domäne) }\end{array}$ & $\begin{array}{l}\text { Transmembrananteil von } \mathrm{H} 2 \mathrm{~K} \\
\text { inklusive eines kurzen } \\
\text { intrazellulären Ankers und einer } \\
\text { extrazellulären } \\
\text { Verbindungssequenz }\end{array}$ \\
\hline HA-Tag & & & $\begin{array}{l}\text { 5'-TACCCATAC } \\
\text { GACGTTCCAG } \\
\text { ACTACGCT-3' }\end{array}$ & $\begin{array}{l}\text { Zur Markierung verwendetes } \\
\text { Epitop (YPYDVPDYA) des } \\
\text { Hämagglutinin des humanen } \\
\text { Influenza-Virus }\end{array}$ \\
\hline Kozak-Sequenz & & & $5^{\prime}-\mathrm{GCCGCC}-3^{\prime}$ & $\begin{array}{l}\text { Unspezifische } \\
\text { transkriptionssteigernde } \\
\text { Sequenz (Kozak 1987) }\end{array}$ \\
\hline $\begin{array}{l}\text { pTriEx 1.1- } \\
\text { Vektor }\end{array}$ & $\begin{array}{l}\text { Merck } \\
\text { Biosciences } \\
\text { GmbH } \\
\end{array}$ & $70848-3$ & $\begin{array}{l}\text { Nukleotide } \\
1079-1726 \\
\text { (CAG-Promotor) } \\
\end{array}$ & $\begin{array}{l}\text { Aus diesem Plasmid wurde nur } \\
\text { der CAG-Promotor (Niwa et al. } \\
\text { 1991) verwendet. }\end{array}$ \\
\hline PEGFP-1-Vektor & $\begin{array}{l}\text { Clontech } \\
\text { Laboratories } \\
\text { Inc. }\end{array}$ & CB7404649 & & $\begin{array}{l}\text { Plasmidgrundgerüst mit eGFP- } \\
\text { Gen und } \mathrm{Neo}^{\mathrm{r}}-\mathrm{Gen}\end{array}$ \\
\hline pMA-Vektor & $\begin{array}{l}\text { Life } \\
\text { Technologies }^{\text {TM }}\end{array}$ & & & $\begin{array}{l}\text { Transportvektor } \\
\text { MCBG-Inserts }\end{array}$ \\
\hline pCMV6-Kan/Neo & $\begin{array}{l}\text { OriGene } \\
\text { Technologies } \\
\text { Inc. }\end{array}$ & & & $\begin{array}{l}\text { Transportvektor } \\
\text { Cathepsin-B-cDNA }\end{array}$ \\
\hline
\end{tabular}

\subsubsection{Der CAG-PEGFP-1- Expressionsvektor}

Zur Überexpression von Cathepsin B wurden zwei Konstrukte entwickelt, die für unterschiedliche Cathepsin-B-Fusionsproteine kodierten. Beide Konstrukte basierten auf dem PEGFP-1-Vektor, in den im Rahmen einer anderen Arbeit bereits der CAG-Promotor des pTriEx 1.1-Vektors einkloniert wurde (Abb. 1). Der CAG-Promotor ist ein zusammengesetzter Promotor, der aus dem immediate-early-enhancer des CMV-Promotors und dem core-promotor des chicken-beta-actin-Promotors besteht. Das erste dem Promotor folgende Intron entstammt ebenfalls dem chicken-beta-actin-Promotor (Niwa et al. 1991). Durch diese Zusammensetzung wurden in Vertebraten besonders gute Transfektionseffizienz sowie hohe und stabile Expressionsraten erreicht (Xu et al. 2001). 


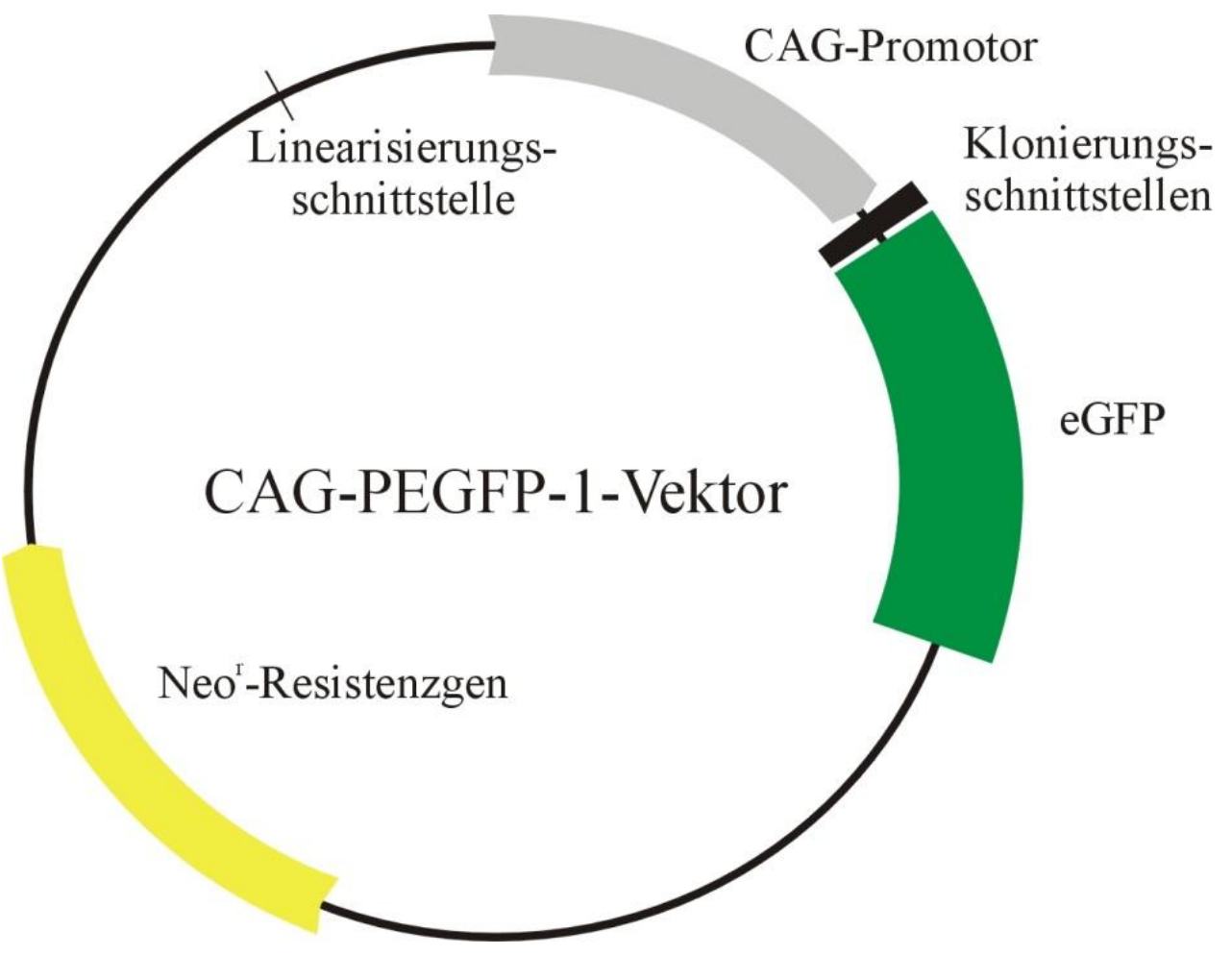

Abb. 1: Schema des CAG-PEGFP-1-Vektors

Der PEGFP-1-Vektor enthält in 3'-Richtung hinter den Klonierungsschnittstellen das eGFPGen. Beide Cathepsin-B-Fusionsproteine beinhalteten so das eGFP-Protein, da im jeweiligen kodierenden Insert auf ein Stopp-Codon verzichtet und bei der Klonierung auf Erhalt des Leserasters geachtet wurde. Außerdem enthält der PEGFP-1-Vektor das Neomycin-Geneticin-Resistenzgen $\left(\mathrm{Neo}^{\mathrm{r}}\right)$. Die kodierte Aminoglykosid-Phosphotransferase (APT) phosphoryliert und inaktiviert Geneticin und Kanamycin.

\subsubsection{Oligonukleotide}

Die Oligonukleotide wurden von der Firma Metabion international AG synthetisiert und als Primer zur Polymerase-Kettenreaktion (2.2.2.5, S. 36) sowie zur Sequenzierung (2.2.2.6, S. 38) verwendet.

Tabelle 2: Oligonukleotide

\begin{tabular}{|l|l|l|}
\hline Name & Sequenz & Schmelztemperatur \\
\hline Primer-CBG-fwd & 5'-ATGAGCTCGCCGCCATGTGGTGGTCCTTGAT-3' & $69,0^{\circ} \mathrm{C}$ \\
\hline Primer-CBG-rev & 5'-GCGAATTCCGAATCTTCCCCAGTACTGGTC-3' & $63,4^{\circ} \mathrm{C}$ \\
\hline $\begin{array}{l}\text { Seq-Primer- } \\
\text { PEGFP-1-fwd }\end{array}$ & 5'-GTATTACCGCCATGCATTAGTTATTAC-3` & $54,2^{\circ} \mathrm{C}$ \\
\hline $\begin{array}{l}\text { Seq-Primer- } \\
\text { PEGFP-1-rev }\end{array}$ & $5^{`}$-GAACTTGTGGCCGTTTACGTCG-3` & $58,7^{\circ} \mathrm{C}$ \\
\hline
\end{tabular}




\subsubsection{Enzyme}

\subsubsection{Restriktionsenzyme}

Tabelle 3 Restriktionsenzyme

\begin{tabular}{|c|c|c|}
\hline Name & Sequenz & Hersteller \\
\hline ApaLI & $5^{6}-\mathrm{G}^{\sim} \mathrm{TGCAC}-3^{6}$ & New England Biolabs GmbH \\
\hline BamHI & $5^{\circ}-\mathrm{G}^{\circ} \mathrm{GATCC}-3^{6}$ & Promega GmbH \\
\hline BglII & $5^{6}-\mathrm{A}^{\circ} \mathrm{GATCT}-3^{6}$ & Promega GmbH \\
\hline EcoRI & $5^{6}-\mathrm{G}^{2} \mathrm{AATTC}-3^{6}$ & Promega $\mathrm{GmbH}$ \\
\hline HindIII & $5^{6}-\mathrm{A}^{2} \mathrm{AGCTT}-3^{6}$ & Promega GmbH \\
\hline SacI & $5^{6}-\mathrm{G}^{2} \mathrm{AGCTC}-3^{6}$ & Promega GmbH \\
\hline
\end{tabular}

\subsubsection{Weitere Enzyme}

Tabelle 4 Weitere Enzyme

\begin{tabular}{|l|l|}
\hline Name & Hersteller \\
\hline BigDye $\left.^{(}\right)$Direct Cycle Sequencing Polymerase & Life Technologies $^{\mathrm{IM}}$ \\
\hline Phusion ${ }^{(8)}$ Hot Start High-Fidelity DNA-Polymerase & Finnzymes Oy \\
\hline Taq DNA-Polymerase & New England Biolabs GmbH \\
\hline T4 DNA-Ligase & Promega GmbH \\
\hline Alkaline Phosphatase, Calf Intestinal (CIP) & Promega GmbH \\
\hline
\end{tabular}

\subsubsection{Antikörper}

\subsubsection{Primärantikörper}

Tabelle 5 zeigt die verwendeten Primärantikörper. Der Farbstoff Phycoerythrin (PE) konnte bei $488 \mathrm{~nm}$ angeregt werden und zeigte eine Emission bei $578 \mathrm{~nm}$. Überstrahlungseffekte mit eGFP mussten in der Durchflusszytometrie (2.2.4.8, S. 44) durch Kompensation ausgeglichen werden.

Tabelle 5 Primärantikörper

\begin{tabular}{|c|c|c|c|c|c|c|}
\hline Name & gegen & Klon & Hersteller & Spezies & Isotyp & Kopplung \\
\hline anti-Cathepsin B & Cathepsin B & polyklonal & $\begin{array}{l}\text { R \& D Systems } \\
\text { GmbH }\end{array}$ & Ziege & IgG & \\
\hline anti-HA-Tag & HA-Epitop & $\begin{array}{l}\text { Hybridoma- } \\
\text { Überstand }\end{array}$ & $\begin{array}{l}\text { zur Verfügung } \\
\text { gestellt von } \\
\text { Prof. Dr. Sigried } \\
\text { Hoyer-Fender, } \\
\text { Georg August } \\
\text { Universität Göttingen, } \\
\text { Institut für Zoologie } \\
\text { und Anthropologie, } \\
\text { abteilung } \\
\text { Entwicklungsbiologie }\end{array}$ & Maus & $\mathrm{IgG}$ & \\
\hline anti-HSC70 & HSC70 & 1B5 & $\begin{array}{l}\text { Stressgen } \\
\text { Bioreagents }\end{array}$ & Ratte & $\operatorname{IgG} 2 \mathrm{a}$ & \\
\hline anti-H2K ${ }^{b}-P E$ & $\mathrm{H} 2 \mathrm{~K}^{\mathrm{b}}$ & AF6-88.5 & BioLegend & Maus & IgG2a & $\mathrm{PE}$ \\
\hline
\end{tabular}




\subsubsection{Sekundärantikörper und Isotypenkontrollen}

Die verwendeten Sekundärantikörper sind in Tabelle 6 aufgeführt. Der Tri-Color ${ }^{\circledR}$-markierte Antikörper wurde in der Durchflusszytometrie (2.2.4.8, S. 44) eingesetzt. Seine Fluoreszenz zeigte bei Anregung bei $488 \mathrm{~nm}$ eine Emissionswellenlänge von $670 \mathrm{~nm}$ und wurde daher von eGFP nicht beeinflusst. Die horseradish-peroxydase-(HRPO)-gekoppelten Antikörper wurden zur Immunfärbung im Westernblot (2.2.3.4, S. 42) eingesetzt und katalysierten eine Farbreaktion mit der DAB-Färbelösung.

Tabelle 6 Sekundärantikörper und Isotypenkontrollen

\begin{tabular}{|c|c|c|c|c|c|c|}
\hline Name & gegen & Klon & Hersteller & Spezies & Isotyp & Kopplung \\
\hline anti-goat-IgG & goat $\operatorname{IgG}(\mathrm{H}+\mathrm{L})$ & polyklonal & $\begin{array}{l}\text { Dianova } \\
\text { Vertriebs- } \\
\text { GmbH }\end{array}$ & Maus & $\mathrm{IgG}$ & \\
\hline $\begin{array}{l}\text { anti-mouse- } \\
\text { IgG-TC }\end{array}$ & mouse $\operatorname{IgG}(\mathrm{H}+\mathrm{L})$ & polyklonal & $\begin{array}{l}\text { Caltag } \\
\text { Laboratories }\end{array}$ & Ziege & $F\left(a b^{c}\right) 2$ & Tri-Color ${ }^{\circledR}$ \\
\hline $\begin{array}{l}\text { anti-mouse- } \\
\text { IgG-HRPO }\end{array}$ & mouse $\operatorname{IgG}(\mathrm{H}+\mathrm{L})$ & polyklonal & $\begin{array}{l}\text { Dianova } \\
\text { Vertriebs- } \\
\text { GmbH }\end{array}$ & Ziege & $\mathrm{IgG}$ & HRPO \\
\hline $\begin{array}{l}\text { anti-rat- } \\
\text { IgG-HRPO }\end{array}$ & rat $\operatorname{IgG}(\mathrm{H}+\mathrm{L})$ & polyklonal & $\begin{array}{l}\text { Dianova } \\
\text { Vertriebs- } \\
\text { GmbH }\end{array}$ & Ziege & $\mathrm{IgG}$ & HRPO \\
\hline $\begin{array}{l}\text { mIgG2a- } \\
\text { Isotypen- } \\
\text { kontrolle }\end{array}$ & & 713 & $\begin{array}{l}\text { ImmunoTools } \\
\text { GmbH }\end{array}$ & Maus & $\operatorname{IgG} 2 \mathrm{a}$ & $\mathrm{PE}$ \\
\hline
\end{tabular}

\subsubsection{Puffer und Stammlösungen}

Sofern nicht anders angegeben, wurden alle Lösungen in $\mathrm{dH}_{2} \mathrm{O}$ angesetzt und der $\mathrm{pH}-$ Wert wurde mit $\mathrm{NaOH}$ und $\mathrm{HCl}$ eingestellt.

Tabelle 7 Puffer und Stammlösungen

\begin{tabular}{|c|c|}
\hline \multicolumn{2}{|l|}{ Nukleinsäurepräparation } \\
\hline Lysispuffer P2 & $\begin{array}{l}200 \mathrm{mM} \mathrm{NaOH} \\
1 \%(\mathrm{w} / \mathrm{v}) \mathrm{SDS}\end{array}$ \\
\hline Neutralisationspuffer P3 & $\begin{array}{l}3 \mathrm{M} \mathrm{KCH}_{3} \mathrm{COO} \\
\text { pH } 5,5\end{array}$ \\
\hline Resuspensionspuffer P1 & $\begin{array}{l}100 \mu \mathrm{g} / \mathrm{ml} \text { RNase } \mathrm{A} \\
50 \mathrm{mM} \text { Tris/HCl } \\
10 \mathrm{mM} \text { EDTA } \\
\text { pH } 8,0\end{array}$ \\
\hline \multicolumn{2}{|l|}{ Agarosegelelektrophorese } \\
\hline $6 \times$ Ladepuffer & $\begin{array}{l}0,09 \%(\mathrm{w} / \mathrm{v}) \text { Bromphenolblau } \\
60 \%(\mathrm{v} / \mathrm{v}) \text { Glycerin } \\
60 \mathrm{mM} \text { EDTA }\end{array}$ \\
\hline Agarosegel & $\begin{array}{l}1 \%(\mathrm{w} / \mathrm{v}) \text { Agarose } \\
0,1 \mu \mathrm{g} / \mathrm{ml} \text { Ethidiumbromid } \\
\text { in TAE-Puffer }\end{array}$ \\
\hline
\end{tabular}




\begin{tabular}{|c|c|}
\hline TAE-Puffer & $\begin{array}{l}40 \mathrm{mM} \text { Tris/Acetat } \\
1 \mathrm{mM} \text { EDTA } \\
\text { pH } 8,0\end{array}$ \\
\hline \multicolumn{2}{|l|}{ SDS-Page } \\
\hline Blotpuffer & $\begin{array}{l}15 \%(\mathrm{w} / \mathrm{v}) \text { Tris/HCl } \\
72 \%(\mathrm{w} / \mathrm{v}) \text { Glycin } \\
20 \%(\mathrm{v} / \mathrm{v}) \text { Methanol } \\
0,1 \%(\mathrm{w} / \mathrm{v}) \mathrm{SDS} \\
\mathrm{pH} 8,3\end{array}$ \\
\hline DAB-Färbelösung & $\begin{array}{l}50 \mathrm{ml} \text { PBS-Tween } \\
25 \mathrm{mg} \text { DAB } \\
50 \mu \mathrm{l} 30 \% \mathrm{H}_{2} \mathrm{O}_{2}\end{array}$ \\
\hline Laufpuffer & $\begin{array}{l}15 \%(\mathrm{w} / \mathrm{v}) \text { Tris/HCl } \\
72 \%(\mathrm{w} / \mathrm{v}) \text { Glycin } \\
0,1 \%(\mathrm{w} / \mathrm{v}) \mathrm{SDS} \\
\mathrm{pH} 8,3\end{array}$ \\
\hline NP 40-Lysispuffer & $\begin{array}{l}140 \mathrm{mM} \mathrm{NaCl} \\
1,5 \mathrm{mM} \mathrm{MgCl} 2 \\
10 \mathrm{mM} \mathrm{Tris} / \mathrm{HCl} \\
0,5 \%(\mathrm{v} / \mathrm{v}) \mathrm{NP} 40 \\
\mathrm{pH} 8,0\end{array}$ \\
\hline PBS-Tween & $\begin{array}{l}0,05 \%(\mathrm{v} / \mathrm{v}) \text { Tween-20 } \\
\text { in PBS }\end{array}$ \\
\hline Ponceau-Rot-Färbelösung & $\begin{array}{l}0,5 \%(\mathrm{w} / \mathrm{v}) \text { Ponceau } \mathrm{S} \\
5 \%(\mathrm{v} / \mathrm{v}) \text { Essigsäure }\end{array}$ \\
\hline Probenpuffer & $\begin{array}{l}20 \mathrm{mM} \text { Tris/HCl } \\
20 \%(\mathrm{v} / \mathrm{v}) \mathrm{Glycerin} \\
2 \%(\mathrm{w} / \mathrm{v}) \mathrm{SDS} \\
2 \mathrm{mM} \text { EDTA } \\
10 \%(\mathrm{v} / \mathrm{v}) 2-\beta-\text { Mercaptoethanol } \\
0,1 \%(\mathrm{v} / \mathrm{v}) \text { Bromphenolblau } \\
\mathrm{pH} 8,0\end{array}$ \\
\hline Sammelgel & 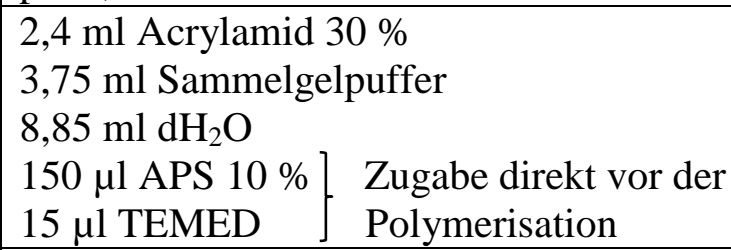 \\
\hline Sammelgelpuffer & $\begin{array}{l}0,5 \mathrm{M} \mathrm{Tris} / \mathrm{HCl} \\
0,4 \%(\mathrm{w} / \mathrm{v}) \mathrm{SDS} \\
\mathrm{pH} 6,8\end{array}$ \\
\hline Trenngel & 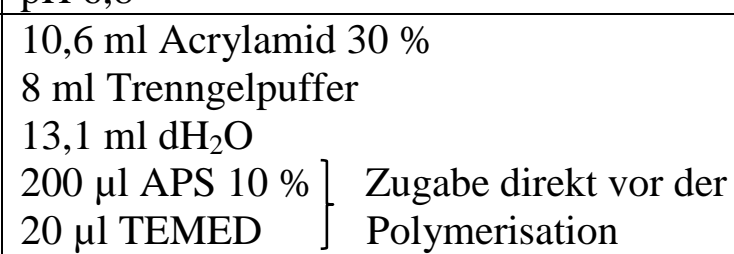 \\
\hline Trenngelpuffer & $\begin{array}{l}1,5 \mathrm{M} \text { Tris/HCl } \\
0,4 \%(\mathrm{w} / \mathrm{v}) \mathrm{SDS} \\
\mathrm{pH} 8,8\end{array}$ \\
\hline
\end{tabular}




\begin{tabular}{|c|c|}
\hline \multicolumn{2}{|l|}{ Durchflusszytometrie } \\
\hline PBS-Propidiumiodid & $\begin{array}{l}1 \mu \mathrm{g} / \mathrm{ml} \text { Propidiumiodid } \\
\text { in PBS }\end{array}$ \\
\hline PBS-Saponin & $\begin{array}{l}0,25 \%(\mathrm{v} / \mathrm{v}) \text { Saponin } \\
\text { in PBS }\end{array}$ \\
\hline \multicolumn{2}{|l|}{ Zellkultur } \\
\hline Einfriermedium Eukaryoten & $\begin{array}{l}80 \%(\mathrm{v} / \mathrm{v}) \text { FBS } \\
20 \%(\mathrm{v} / \mathrm{v}) \text { DMSO }\end{array}$ \\
\hline Trypanblau & $\begin{array}{l}0,2 \%(\mathrm{v} / \mathrm{v}) \text { Trypanblau } \\
4,25 \%(\mathrm{w} / \mathrm{v}) \mathrm{NaCl}\end{array}$ \\
\hline \multicolumn{2}{|l|}{ Chrom-Freisetzungs-Test } \\
\hline EGTA/MgCl 2 & 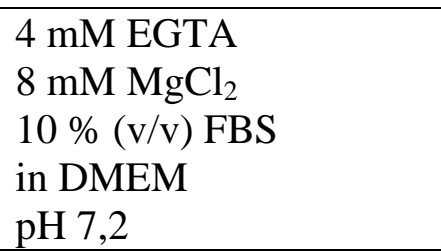 \\
\hline Erythrozyten-Lyse-Puffer & $\begin{array}{l}155 \mathrm{mM} \mathrm{NH}_{4} \mathrm{Cl} \\
10 \mathrm{mM} \mathrm{KHCO}_{3} \\
0,1 \mathrm{mM} \mathrm{EDTA} \\
\text { pH } 7,2-7,4\end{array}$ \\
\hline Triton-Lyse-Puffer & $\begin{array}{l}10 \%(\mathrm{v} / \mathrm{v}) \text { Triton X-100 } \\
\text { in PBS }\end{array}$ \\
\hline
\end{tabular}

\subsubsection{Kulturmedien}

\subsubsection{Medien zur Kultur prokaryoter Zellen}

Die Medien zur Bakterienkultur wurden in $\mathrm{dH}_{2} \mathrm{O}$ angesetzt und autoklaviert. Zur Selektion wurde den Medien bei Bedarf Kanamycin in einer Konzentration von $100 \mu \mathrm{g} / \mathrm{ml}$ nach dem Autoklavieren zugesetzt.

Tabelle 8 Medien zur Bakterienkultur

\begin{tabular}{|l|l|}
\hline Name & Zusammensetzung \\
\hline LB-Agarplatten & $1,5 \%(\mathrm{w} / \mathrm{v})$ Agar in LB-Medium \\
\hline \multirow{3}{*}{ LB-Medium (Luria-Bertani-Medium) } & $0,5 \%(\mathrm{w} / \mathrm{v})$ Hefeextrakt \\
& $1 \%(\mathrm{w} / \mathrm{v})$ Pepton \\
& $0,5 \%(\mathrm{w} / \mathrm{v}) \mathrm{NaCl}$ \\
\hline & $2 \%(\mathrm{w} / \mathrm{v})$ Trypton \\
& $0,5 \%(\mathrm{w} / \mathrm{v}) \mathrm{Hefeextrakt}$ \\
S.O.C.-Medium & $10 \mathrm{mM} \mathrm{MgCl}$ \\
& $10 \mathrm{mM} \mathrm{MgSO}_{4}$ \\
& $10 \mathrm{mM} \mathrm{NaCl}$ \\
& $2,5 \mathrm{mM} \mathrm{KCl}$ \\
& $20 \mathrm{mM} \mathrm{Glucose}$ \\
\hline
\end{tabular}

\subsubsection{Medien zur Kultur eukaryoter Zellen}

Als Basis der Kulturmedien eukaryoter Zellen wurde Dulbeccos modifiziertes Eagle Medium (DMEM, GlutaMAX' ${ }^{\mathrm{TM}}$, +4,5 g/l Glucose, +Pyruvat) der Firma Life Technologies ${ }^{\mathrm{TM}}$ verwendet. 
Tabelle 9 Medien zur Kultur eukaryoter Zellen

\begin{tabular}{|l|l|}
\hline Name & Zusammensetzung \\
\hline DMEM mit FBS & $10 \%(\mathrm{v} / \mathrm{v})$ FBS \\
& in DMEM \\
\hline \multirow{2}{*}{ DMEM mit FBS und PenStrep } & $10 \%(\mathrm{v} / \mathrm{v})$ FBS \\
& $5 \%(\mathrm{v} / \mathrm{v})$ Penicillin-Streptomycin \\
& in DMEM \\
$\begin{array}{l}\text { DMEM mit FBS und PenStrep und } \\
\text { Geneticin }\end{array}$ & $10 \%(\mathrm{v} / \mathrm{v})$ FBS \\
& $\begin{array}{l}5 \%(\mathrm{v} / \mathrm{v}) \text { Penicillin-Streptomycin } \\
\text { in DMEM }\end{array}$ \\
\hline
\end{tabular}

\subsubsection{Chemikalien}

Tabelle 10 Chemikalien

\begin{tabular}{|c|c|}
\hline Name & Hersteller \\
\hline 2- $\beta$-Mercaptoethanol & Sigma-Aldrich Chemie GmbH \\
\hline Agar & AppliChem GmbH \\
\hline Agarose & PEQLAB Biotechnologie GmbH \\
\hline Ammoniumacetat $\left(\mathrm{NH}_{4} \mathrm{CH}_{3} \mathrm{COO}\right)$ & Roth GmbH \& Co. \\
\hline Ammoniumchlorid $\left(\mathrm{NH}_{4} \mathrm{Cl}\right)$ & Merck Bioscience GmbH \\
\hline Ammoniumpersulfat (APS) & Sigma-Aldrich Chemie GmbH \\
\hline Bromphenolblau & Roth GmbH \& Co. \\
\hline Concanavalin A & Sigma-Aldrich Chemie GmbH \\
\hline Diaminobenzidin (DAB) & Sigma-Aldrich Chemie GmbH \\
\hline DMEM GlutaMAX ${ }^{\mathrm{TM}}+4,5 \mathrm{~g} / 1$ Glucose + Pyruvat & Life Technologies ${ }^{\mathrm{TM}}$ \\
\hline DNA Polymerization Mix 10mM (dNTP-Mix) & GeneCraft $\left.{ }^{(}\right)$Ares Bioscience GmbH \\
\hline DNA-Ladder $1 \mathrm{~kb}$ & New England Biolabs GmbH \\
\hline Essigsäure & Merck Bioscience GmbH \\
\hline Ethanol & AppliChem GmbH \\
\hline Ethidiumbromid & Roth GmbH \& Co. \\
\hline Ethylendiamin-Tetraacetat (EDTA) & Roth GmbH \& Co. \\
\hline $\begin{array}{l}\text { Ethylenglycol-bis(2-aminoethylether)-N,N,N',N'- } \\
\text { Tetraacetat (EGTA) }\end{array}$ & Roth GmbH \& Co. \\
\hline fetales bovines Serum (FBS) & Life Technologies ${ }^{\mathrm{TM}}$ \\
\hline Geneticin (G 418) & Biochrom AG \\
\hline Glucose & Merck Bioscience GmbH \\
\hline Glycerin & Merck Bioscience GmbH \\
\hline Glycin & Roth GmbH \& Co. \\
\hline Hefeextrakt & Roth GmbH \& Co. \\
\hline Hoechst 33342 & Immunochemistry Technologies LLC \\
\hline Isopropanol & Merck Bioscience GmbH \\
\hline Kaliumacetat $\left(\mathrm{KCH}_{3} \mathrm{COO}\right)$ & Roth GmbH \& Co. \\
\hline Kaliumchlorid $(\mathrm{KCl})$ & Roth GmbH \& Co. \\
\hline Kaliumhydrogencarbonat $\left(\mathrm{KHCO}_{3}\right)$ & Roth GmbH \& Co. \\
\hline Kanamycin & PAN-Biotech GmbH \\
\hline Lipopolysaccharid (LPS) & Sigma-Aldrich Chemie GmbH \\
\hline Magnesiumchlorid $\left(\mathrm{MgCl}_{2}\right)$ & Merck Bioscience GmbH \\
\hline
\end{tabular}




\begin{tabular}{|l|l|}
\hline Magnesiumsulfat $\left(\mathrm{MgSO}_{4}\right)$ & Roth GmbH \& Co. \\
\hline Methanol & AppliChem GmbH \\
\hline N,N,N',N'-Tetramethylethylendiamin (TEMED) & AppliChem GmbH \\
\hline Natriumacetat $\left(\mathrm{NaCH}_{3} \mathrm{COO}\right)$ & Roth GmbH \& Co. \\
\hline Natriumchlorid $\left(\mathrm{NaCl}^{\text {) }}\right)$ & Merck Bioscience GmbH \\
\hline Natriumchromat $\mathrm{Na}_{2} \mathrm{CrO}_{4}$ (radioaktiv) & Hartmann Analytic GmbH \\
\hline Natriumdodecylsulfat (SDS) & Roth GmbH \& Co. \\
\hline Natriumhydroxid (NaOH) & Merck Bioscience GmbH \\
\hline Nonidet P 40 (NP 40) & AppliChem GmbH \\
\hline Paraformaldehyd & Roth GmbH \& Co. \\
\hline Penicillin-Streptomycin & Life Technologies \\
\hline Pepton & Roth GmbH \& Co. \\
\hline Phosphatgepufferte Salzlösung (PBS) & Biochrom AG \\
\hline $\begin{array}{l}\text { Polyoxyethylen(20)-sorbitan-monolaureat } \\
\text { (Tween-20) }\end{array}$ & AppliChem GmbH \\
\hline Ponceau S & Sigma-Aldrich Chemie GmbH \\
\hline Propidiumiodid & AppliChem GmbH \\
\hline Proteinmarker 30.000 - 200.000 Da & Sigma-Aldrich Chemie GmbH \\
\hline rekombinantes murines Interleukin-2 (rm IL-2) & R \& D Systems GmbH \\
\hline RNase A & Roche Diagnostics GmbH \\
\hline Rotiphorese Gel 30 \% (Acrylamid) & Roth GmbH \& Co. \\
\hline Salzsäure (HCl) & Merck Bioscience GmbH \\
\hline Saponin & Roth GmbH \& Co. \\
\hline SIINFEKL (Ovalbumin Aminosäuren 257 - 264) & Bachem Distribution Services GmbH \\
\hline Szintillator Optiphase HiSafe 3 & PerkinElmer Wallac GmbH \\
\hline Tris-(hydroxymethyl)-aminomethan (Tris) & Roth GmbH \& Co. \\
\hline Triton X-100 & Sigma-Aldrich Chemie GmbH \\
\hline Trypanblau & Sigma-Aldrich Chemie GmbH \\
\hline Trypton & Roth GmbH \& Co. \\
\hline Wasserstoffperoxid 30 \% (H $\left.{ }_{2} \mathrm{O}_{2}\right)$ & Merck Bioscience GmbH \\
\hline
\end{tabular}

\subsubsection{Gebrauchsfertige Reaktionssysteme}

Tabelle 11 Gebrauchsfertige Reaktionssysteme

\begin{tabular}{|l|l|}
\hline Name & Hersteller \\
\hline EndoFree-Plasmid-Maxi-Kit & QIAGEN GmbH \\
\hline Zymoclean ${ }^{\text {TM}}$-Gel-DNA-Recovery-Kit & Zymo Research Corp. \\
\hline Magic-Red $^{\text {TM}}$-Cathepsin-B-Detection-Kit & Immunochemistry Technologies LLC \\
\hline
\end{tabular}




\subsubsection{Gebrauchswaren}

Tabelle 12 Gebrauchswaren

\begin{tabular}{|l|l|}
\hline Name & Hersteller \\
\hline Whatmanpapier GB 003 & Whatman GmbH \\
\hline Reaktionsgefäße & $\begin{array}{l}\text { Eppendorf AG } \\
\text { Sarstedt AG \& Co. } \\
\text { Greiner Bio-One GmbH }\end{array}$ \\
\hline FACS-Gefäß BD Falcon 5 ml & Becton Dickinson GmbH \\
\hline Gefriergefäß Cryo Tube Vialis 1,8 ml & Nunc GmbH \& Co. Kg \\
\hline $\begin{array}{l}\text { Gewebekultur-Petrischale } \\
\text { unbeschichtet 100x20 mm }\end{array}$ & Sarstedt AG \& Co. \\
\hline Klebefolie Top Seal-A 96 & PerkinElmer Wallac GmbH \\
\hline $\begin{array}{l}\text { Mikrotiterplatten } \\
\text { 96 well Flach- und Rundboden }\end{array}$ & Sarstedt AG \& Co. \\
\hline Nitrozellulosemembran & Schleicher \& Schuell GmbH \\
\hline Pipetten und Pipettenspitzen & Sarstedt AG \& Co. \\
\hline Sterilfilter & Sarstedt AG \& Co. \\
\hline $\begin{array}{l}\text { Wallac-Messplatte 96-Loch mit } \\
\text { TopSeal }{ }^{\circledR} \text {-A-Folie }\end{array}$ & PerkinElmer Wallac GmbH \\
\hline Zentrifugationsgefäß 13 ml, 15 ml & Sarstedt AG \& Co. \\
\hline Objektträger & $\begin{array}{l}\text { Waldemar Knittel Glasbearbeitungs- } \\
\text { GmbH }\end{array}$ \\
\hline Parafilm ${ }^{\circledR}$ & Pechiney Plastic Packaging Inc. \\
\hline
\end{tabular}

\subsubsection{Geräte}

Tabelle 13 Geräte

\begin{tabular}{|l|l|l|}
\hline Gerät & Typ & Hersteller \\
\hline Agarosegelkammer & PerfectBlue Gelsystem & $\begin{array}{l}\text { PEQLAB Biotechnologie } \\
\text { GmbH }\end{array}$ \\
\hline Autoklav & Dampfsterilisator FVS & Integra Biosciences GmbH \\
\hline Blotkammer & $\begin{array}{l}\text { Large Semiphor Transphor } \\
\text { Unit 80-6211-86 }\end{array}$ & GE Healthcare Europe GmbH \\
\hline Durchflusszytometer & FACSCalibur & Becton Dickinson GmbH \\
\hline $\begin{array}{l}\text { Elektroporations- } \\
\text { Impulsgenerator }\end{array}$ & $\begin{array}{l}\text { Gene Pulser } \\
\text { Capacitance Extender }\end{array}$ & Bio-Rad Laboratories GmbH \\
\hline Hamiltonspritze & Hamilton Mikroliter Spritze & Hamilton Medical AG \\
\hline Inkubator & HERAcell & $\begin{array}{l}\text { (hermo Fischer Scientific } \\
\text { Germany Ltd. \& Co. KG }\end{array}$ \\
\hline $\begin{array}{l}\text { Laser-Scanning } \\
\text { Mikroskop }\end{array}$ & LSM 510 Axioplan 2 & Carl Zeiss AG \\
\hline Magnetrührer, beheizbar & IKAMAG RET & IKA Werke GmbH \& Co. KG \\
\hline Mikroskop & Axiovert 35 & Carl Zeiss AG \\
\hline Neubauer Zählkammer & Neubauer improved & Krannich GmbH \& Co. KG \\
\hline pH-Meter & CG-837 & Schott AG \\
\hline Photometer & BioPhotometer & Eppendorf AG \\
\hline
\end{tabular}




\begin{tabular}{|c|c|c|}
\hline Pipetten & $\begin{array}{l}\begin{array}{l}\text { Eppendorf Research }^{\circledR} \\
\text { (verschiedene Größen) }\end{array} \\
\text { Multipette }^{\circledast} \text { plus }\end{array}$ & Eppendorf AG \\
\hline Pipettierhilfen & Pipetboy pro & Integra Bioscience $\mathrm{GmbH}$ \\
\hline Schutzwerkbank & HERASave $^{\circledR}$ & $\begin{array}{l}\text { Thermo Fischer Scientific } \\
\text { Germany Ltd. \& Co. KG }\end{array}$ \\
\hline SDS-Gelkammer & Hoefer $^{\text {IM }}$ SE 600 Ruby $^{\text {IM }}$ & GE Healthcare Europe GmbH \\
\hline Cell-Sorter & FACSVantage ${ }^{\mathrm{IM}} \mathrm{SE}$ & Becton Dickinson GmbH \\
\hline Spannungsquelle & $\begin{array}{l}\text { Elektrophoresis Power } \\
\text { Supply EPS } 301\end{array}$ & GE Healthcare Europe GmbH \\
\hline Szintillationszähler & MicroBeta Trilux 1450 & PerkinElmer Wallac GmbH \\
\hline Tenbroeck-Homogenisator & Tenbroek & Schütt Labortechnik GmbH \\
\hline \multirow{2}{*}{ Thermoblock } & $\begin{array}{l}\text { Stuart Block Heater } \\
\text { SBH130 }\end{array}$ & Bibby Scientific Ltd. \\
\hline & Thermomixer comfort & Eppendorf AG \\
\hline \multirow[t]{2}{*}{ Thermocycler } & $\begin{array}{l}\text { GeneAmp }{ }^{\circledR} \text { PCR System } \\
2700\end{array}$ & Life Technologies $^{\mathrm{TM}}$ \\
\hline & TPersonal 48 & Biometra GmbH \\
\hline UV-Gel-Imager & Gel Imager & $\begin{array}{l}\text { Intas Science Imaging } \\
\text { Instruments GmbH }\end{array}$ \\
\hline Vortex-Schüttler & MS1 Minishaker & IKA $^{\circledR}$-Werke GmbH \& Co.KG \\
\hline Waagen & ACCULAB Vicon & Sartorius AG \\
\hline Wasserbad & $\begin{array}{l}\text { Inkubations-/ } \\
\text { Inaktivierungsbad } 1003\end{array}$ & $\begin{array}{l}\text { Gesellschaft für Labortechnik } \\
\mathrm{mbH}\end{array}$ \\
\hline \multirow{4}{*}{ Zentrifugen } & Kühlzentrifuge $3 \mathrm{~K} 30$ & $\begin{array}{l}\text { SIGMA Laborzentrifugen } \\
\text { GmbH }\end{array}$ \\
\hline & Minizentrifuge MCF-2360 & $\begin{array}{l}\text { LMS Consult GmbH \& Co. } \\
\text { KG }\end{array}$ \\
\hline & Multifuge $1 \mathrm{~b}$ & \multirow{2}{*}{ Heraeus Holding GmbH } \\
\hline & Multifuge 3 SR & \\
\hline
\end{tabular}




\subsubsection{Datenbanken und Software}

Tabelle 14 Datenbanken und Software

\begin{tabular}{|l|l|l|}
\hline Programm & Verwendung & Hersteller \\
\hline CellQuest & Steuerung Durchflusszytometer & Becton Dickinson GmbH \\
\hline CorelDRAW 9.397 & Grafikprogramm & Corel Corporation \\
\hline Endnote X1.0.1 & Literaturverwaltungsprogramm & Thomson Reuters \\
\hline FACSDiva Version 6.1.2 & Steuerung Cell-Sorter & Life Technologies \\
\hline Gentle 1.9.4 & $\begin{array}{l}\text { Molekularbiologische } \\
\text { Anwendung }\end{array}$ & $\begin{array}{l}\text { Magnus Manske } \\
\text { Universität Köln } \\
\text { GLP 2003 }\end{array}$ \\
\hline $\begin{array}{l}\text { LSM Image Browser } \\
\text { 3,5,0,359 }\end{array}$ & Bildverarbeitung & CarlZeiss AG \\
\hline MicroBeta & Szintillationszählersteuerung & PerkinElmer Wallac GmbH \\
\hline Microsoft Excel 2010 & $\begin{array}{l}\text { Tabellenkalkulation und } \\
\text { graphische Auswertung }\end{array}$ & $\begin{array}{l}\text { Microsoft Deutschland } \\
\text { GmbH }\end{array}$ \\
\hline Microsoft Word 2010 & Textverarbeitungsprogramm & $\begin{array}{l}\text { Microsoft Deutschland } \\
\text { GmbH }\end{array}$ \\
\hline NCBI & Nukleotiddatenbank & $\begin{array}{l}\text { National Center for } \\
\text { Biotechnology Information } \\
\text { (NCBI) }\end{array}$ \\
\hline NEB-Cutter & Restriktionssimulation & $\begin{array}{l}\text { New England Biolabs } \\
\text { GmbH }\end{array}$ \\
\hline OligoAnalyzer 3.1 & Oligonukleotidanalyse & $\begin{array}{l}\text { Integrated DNA } \\
\text { Technologies Inc. }\end{array}$ \\
\hline Swiss-Prot & Proteindatenbank & EMBL-EBI \\
\hline WinMDI 2.9 & Analyse der & Joseph Trotter \\
\hline
\end{tabular}

\subsubsection{Hersteller}

Tabelle 15 Hersteller

\begin{tabular}{|l|l|}
\hline Hersteller & Adresse \\
\hline AppliChem GmbH & Ottoweg 10b, 64291 Darmstadt \\
\hline Bachem Distribution Services GmbH & $\begin{array}{l}\text { Hegenheimer Str. 5, } \\
\text { 79576 Weil am Rhein }\end{array}$ \\
\hline Becton Dickinson GmbH & Tullastr. 8-12, 69126 Heidelberg \\
\hline Bibby Scientific Ltd. & $\begin{array}{l}\text { Beacon Road, Stone, } \\
\text { Staffordshire ST15 0SA, UK }\end{array}$ \\
\hline Biochrom AG & Leonorenstr. 2-6, 12247 Berlin \\
\hline BioLegend & $\begin{array}{l}\text { 11080 Roselle St, } \\
\text { San Diego, CA 92121, USA }\end{array}$ \\
\hline Biometra GmbH & $\begin{array}{l}\text { Rudolf-Wissel-Straße 30, } \\
\text { 37079 Göttingen }\end{array}$ \\
\hline Bio-Rad Laboratories GmbH & $\begin{array}{l}\text { Heidemannstrasse 164, } \\
\text { 80901 München }\end{array}$ \\
\hline Caltag Laboratories & Brauhausstieg 15-17, 22041 Hamburg \\
\hline
\end{tabular}




\begin{tabular}{|c|c|}
\hline Carl Zeiss AG & $\begin{array}{l}\text { Carl-Zeiss-Straße 22, } \\
73447 \text { Oberkochen }\end{array}$ \\
\hline Clontech Laboratories Inc. & $\begin{array}{l}1290 \text { Terra Bella Ave } \\
\text { Mountain View, CA 94043, USA }\end{array}$ \\
\hline Corel Corporation & Edisonstr. 6, 85716 Unterschleißheim \\
\hline Dianova Vertriebs-GmbH & Warburgstr. 45, 20354 Hamburg \\
\hline EMBL-EBI & $\begin{array}{l}\text { Hinxton, } \\
\text { Cambridgeshire CB10 } 1 \text { SD, UK }\end{array}$ \\
\hline Eppendorf AG & Barkhausenweg 1, 22339 Hamburg \\
\hline Finnzymes Oy & Ratastie 2, 01620 Vantaa, Finland \\
\hline GE Healthcare Europe GmbH & $\begin{array}{l}\text { Oskar-Schlemmer-Str.11, } \\
80807 \text { München }\end{array}$ \\
\hline GeneCraft $^{(\mathbb{}}$ Ares Bioscience GmbH & Graeffstrasse 5, 50823 Köln \\
\hline Gesellschaft für Labortechnik mbH & $\begin{array}{l}\text { Schulze-Delitzsch-Straße 4, } \\
30938 \text { Burgwedel }\end{array}$ \\
\hline Greiner Bio-One GmbH & $\begin{array}{l}\text { Maybachstrasse } 2 \\
72636 \text { Frickenhausen }\end{array}$ \\
\hline Hamilton Medical AG & Via Crusch 8, 7402 Bonaduz, $\mathrm{CH}$ \\
\hline Hartmann Analytic GmbH & Inhoffenstr. 7, 38124 Braunschweig \\
\hline Heraeus Holding GmbH & Heraeusstraße 12-14, 63450 Hanau \\
\hline IKA $^{(}-$Werke GmbH \& Co.KG & Janke \& Kunkel-Str. 10, 79219 Staufen \\
\hline Immunochemistry Technologies LLC & $\begin{array}{l}9401 \text { James Ave, S \#155, } \\
\text { Bloomington, MN 55431, USA }\end{array}$ \\
\hline ImmunoTools GmbH & Altenoyther Str. 10, 26169 Friesoythe \\
\hline Intas Science Imaging Instruments $\mathrm{GmbH}$ & $\begin{array}{l}\text { Florenz-Sartorius-Str. 14, } \\
37079 \text { Göttingen }\end{array}$ \\
\hline Integra Biosciences $\mathrm{GmbH}$ & Ruhberg 4, 35463 Fernwald \\
\hline Integratd DNA Technologies Inc. & $\begin{array}{l}\text { BVBA Interleuvenlaan 12A, } \\
3001 \text { Leuven, B }\end{array}$ \\
\hline Krannich GmbH \& Co. KG & Elliehäuser Weg 17, 37079 Göttingen \\
\hline Life Technologies & Frankfurter Str.129b, 64293 Darmstadt \\
\hline LMS Consult GmbH \& Co. KG & $\begin{array}{l}\text { Robert-Bosch-Straße 14, } \\
63303 \text { Dreieich }\end{array}$ \\
\hline Merck Biosciences GmbH & Ober der Roeth 4, 65824 Schwalbach \\
\hline Metabion international AG & $\begin{array}{l}\text { Lena-Christ-Strasse 44/1, } \\
82151 \text { Martinsried }\end{array}$ \\
\hline Microsoft Deutschland GmbH & $\begin{array}{l}\text { Konrad-Zuse-Straße 1, } \\
\text { 85716 Unterschleißheim }\end{array}$ \\
\hline $\begin{array}{l}\text { National Center for Biotechnology Information } \\
\text { (NCBI) }\end{array}$ & $\begin{array}{l}8600 \text { Rockville Pike, } \\
\text { Bethesda, MD 20894, USA }\end{array}$ \\
\hline New England Biolabs GmbH & Brüningstr. 50, 65926 Frankfurt a. M. \\
\hline Nunc GmbH \& Co. Kg & $\begin{array}{l}\text { Robert-Bosch-Straße 1, } \\
\text { 63505 Langenselbold }\end{array}$ \\
\hline OriGene Technologies Inc. & $\begin{array}{l}\text { Bockenheimer Landstraße 17/19, } \\
60325 \text { Frankfurt a. M. }\end{array}$ \\
\hline PAN-Biotech GmbH & $\begin{array}{l}\text { Am Gewerbepark 13, } \\
94501 \text { Aidenbach }\end{array}$ \\
\hline Pechiney Plastic Packaging Inc. & $\begin{array}{l}8770 \text { W. Bryn Mawr Ave, } \\
\text { Chicago, IL 60631,USA }\end{array}$ \\
\hline
\end{tabular}




\begin{tabular}{|l|l|}
\hline PEQLAB Biotechnologie GmbH & Carl-Thiersch-Str. 2b, 91052 Erlangen \\
\hline PerkinElmer Wallac GmbH & $\begin{array}{l}\text { Am Langen Bangert 8, } \\
\text { 69518 Abtsteinach Mackenheim }\end{array}$ \\
\hline Promega GmbH & Schildkrötstraße 15, 68199 Mannheim \\
\hline QIAGEN GmbH & QIAGEN Strasse 1, 40724 Hilden \\
\hline R \& D Systems GmbH & $\begin{array}{l}\text { Borsigstr. 7, } \\
\text { 65205 Wiesbaden-Nordenstadt }\end{array}$ \\
\hline Roche Diagnostics GmbH & $\begin{array}{l}\text { Emil-Barell-Str. 1, } \\
\text { 79639 Granzlach-Wyhlen }\end{array}$ \\
\hline Roth GmbH \& Co. & Schoemperlenstr. 1-5, 76185 Karlsruhe \\
\hline Sarstedt AG \& Co. & Sarstedtstrasse, 51582 Nümbrecht \\
\hline Sartorius AG & $\begin{array}{l}\text { Weender Landstraße 94-108, } \\
\text { 37075 Göttingen }\end{array}$ \\
\hline Schleicher \& Schuell GmbH & Hahnestrasse 3, 37586 Dassel \\
\hline Schott AG & Hattenbergstr. 10, 55122 Mainz \\
\hline Schütt Labortechnik GmbH & $\begin{array}{l}\text { Rudolf-Wissell-Str. 11, } \\
\text { 37079 Göttingen }\end{array}$ \\
\hline SIGMA Laborzentrifugen GmbH & $\begin{array}{l}\text { Postfach 1713, } \\
\text { 37507 Osterode am Harz }\end{array}$ \\
\hline Sigma-Aldrich Chemie GmbH & Eschenstrasse 5, 82024 Taufkirchen \\
\hline Stressgen Bioreagents & Voortstraat 49, 1910 Kampenhout, B \\
\hline $\begin{array}{l}\text { Thermo Fischer Scientific Germany Ltd. \& Co. } \\
\text { KG }\end{array}$ & Adenauerallee 113, 53113 Bonn \\
\hline $\begin{array}{l}\text { Thomson Reuters über } \\
\text { Adept Scentific GmbH }\end{array}$ & $\begin{array}{l}\text { Varrentrappstraße 40 - 42, } \\
\text { 60486 Frankfurt a. M. }\end{array}$ \\
\hline Waldemar Knittel Glasbearbeitungs GmbH & $\begin{array}{l}\text { Varrentrappstr. 3-5, } \\
\text { 38224 Braunschweig }\end{array}$ \\
\hline Whatman GmbH & Hahnestr. 3, 37586 Dassel \\
\hline Zymo Research Corp. & $\begin{array}{l}\text { 17062 Murphy Ave, } \\
\text { Irvine, CA 92614, USA }\end{array}$ \\
\hline & \\
\hline
\end{tabular}

\subsection{Methoden}

Die Sequenzen der Expressionsplasmide $\mathrm{LV}^{2}, \mathrm{CBG}^{3}$ und $\mathrm{MCBG}^{3}$ wurden zunächst mit dem Programm GENtle in silico geplant. Der PEGFP-1-Vektor mit CAG-Promotor wurde als Grundlage der Plasmide ausgewählt und die Inserts des CBG- und des MCBG-Konstrukts so entworfen, dass sie in den Bereich der Klonierungsschnittstellen des PEGFP-1-Vektors eingefügt werden konnten. Das CBG-Insert wurde durch PCR-Amplifikation selbst hergestellt, das MCBG-Konstrukt wurde durch die Firma Life technologies ${ }^{\text {TM }}$ synthetisiert. Beide Plasmide wurden in TOP10 E. coli-Bakterien vermehrt und in RMA-Zellen transfiziert. Je Plasmid wurden zwei Klone stabiler Expression ausgewählt, ihre Cathepsin-B-Expression analysiert und ihre Lyse durch zytotoxische T-Zellen in ChromFreisetzungs-Tests bestimmt.

\footnotetext{
${ }^{2}$ Als LV-Expressionsplasmid wird der unter 2.1.3, S. 20 beschriebene CAG-PEGFP-1-Expressionsvektor ohne Insert bezeichnet.

${ }^{3}$ Die Expressionsplasmide $\mathrm{CBG}$ und MCBG basieren auf dem CAG-PEGFP-1-Expressionsvektor und enthalten unterschiedliche Cathepsin-B-Inserts. Die Plasmide sind in den Abschnitten 3.1 (S. 50) und 3.2 (S. 53) detailliert beschrieben.
} 


\subsubsection{Mikrobiologische Methoden}

Alle Arbeiten mit Bakterien wurden mit autoklavierten Materialien an einer Schutzbank ausgeführt und streng von allen Arbeiten in der Zellkultur getrennt.

\subsubsection{Lagerung und Anzucht von E. coli}

TOP10 E. coli-Bakterien wurden bei $-80{ }^{\circ} \mathrm{C}$ in LB-Medium mit $20 \%$ Glycerin gelagert.

Zum Einfrieren wurden $800 \mu \mathrm{l}$ einer Suspensionskultur in logarithmischem Wachstum (ca. $10^{9}$ Zellen/ $\mu$ l) mit $200 \mu 1$ Glycerin mit dem Vortex-Schüttler gründlich vermischt. Der Glycerinstock wurde sofort bei $-80{ }^{\circ} \mathrm{C}$ eingefroren und gelagert.

Zur Anzucht gelagerter Bakterienstämme wurde mit einer Pipettenspitze eine kleine Menge des Glycerinstocks abgekratzt und in die gewünschte Menge LB-Medium übertragen. Dabei musste der Glycerinstock vor dem Auftauen geschützt werden. Nach Inkubation bei $37^{\circ} \mathrm{C}$ im Schüttler über Nacht konnte die Bakteriensuspension nun verwendet werden. Transformierte Bakterienkolonien mit Kanamycin-Resistenz wurden direkt in Medium mit $100 \mu \mathrm{g} / \mathrm{ml}$ Kanamycin-Zusatz aufgenommen.

\subsubsection{Herstellung elektrokompetenter Bakterien}

Zur Transformation (2.2.1.3) wurden Bakterien in der exponentiellen Wachstumsphase in einer Lösung mit geringem Salzgehalt verwendet.

$2 \mathrm{ml}$ LB-Medium wurden mit TOP10 E. coli beimpft und bei $37{ }^{\circ} \mathrm{C}$ im Schüttler über Nacht inkubiert. $1 \mathrm{ml}$ dieser Kultur wurde in $500 \mathrm{ml}$ LB-Medium übertragen und so lange bei $37{ }^{\circ} \mathrm{C}$ im Flachbettschüttler inkubiert, bis die optische Dichte bei $595 \mathrm{~nm}$ Wellenlänge einen Wert von 0,4-0,7 erreichte. Die Bakterien wurden bei $500 \mathrm{x}$ g und $4{ }^{\circ} \mathrm{C}$ pelletiert und

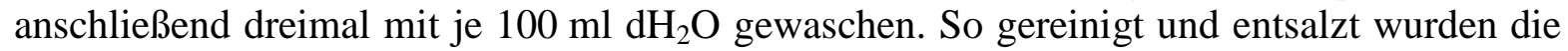
Bakterien in $5 \mathrm{ml}$ kaltem $\mathrm{dH}_{2} \mathrm{O}$ mit $10 \%$ (v/v) Glycerin aufgenommen. Bereit zur Transformation konnten die Bakterien in $50-\mu$ l-Aliquots bei $-80{ }^{\circ} \mathrm{C}$ gelagert werden.

\subsubsection{Transformation durch Elektroporation}

Die Einbringung von Plasmiden in elektrokompetente TOP10 E. coli-Bakterien erfolgte mittels Elektroporation. Der DNA-Syntheseapparat der Bakterien konnte so zur massenhaften und exakten Amplifikation der Plasmide genutzt werden und reparierte sogar Einzelstrangbrüche, wie sie beispielsweise bei der Ligation mit dephosphoryliertem Vektor auftraten.

$50 \mu 1$ elektrokompetenter Bakterien wurden langsam auf Eis aufgetaut und zusammen mit $100 \mathrm{ng}$ Plasmid beziehungsweise $10 \mu \mathrm{l}$ Ligationsansatz in eine Elektroporationsküvette gegeben. Bei $1.600 \mathrm{~V}$ wurden die Bakterien $3 \mathrm{~ms}$ elektroporiert. Anschließend wurden unverzüglich $200 \mu$ l S.O.C.-Medium hinzugegeben und der Ansatz bei $37{ }^{\circ} \mathrm{C}$ im Schüttler für $1 \mathrm{~h}$ inkubiert. $25 \mu \mathrm{l}$ des Ansatzes wurden auf Kanamycin-haltigen LB-Agarplatten ausplattiert. Nur transfizierte Bakterien erhielten durch das Plasmid eine KanamycinResistenz und konnten auf dem Agarboden wachsen.

Nach $24 \mathrm{~h}$ bei $37^{\circ} \mathrm{C}$ waren mit bloßem Auge Bakterienkolonien sichtbar. Zur besseren Identifizierung wurden diese mit einer kleinen Pipettenspitze auf eine weitere Kanamycinhaltige LB-Agarplatten mit nummerierten Feldern übertragen. Die hierzu verwendeten 
Spitzen wurden auch als Template zur Kolonie-PCR (2.2.2.5.3, S. 37) verwendet. Nach 6 - 8 h konnten von der nummerierten Platte Suspensionskulturen zur weiteren Testung und Lagerung angeimpft werden.

\subsubsection{Molekularbiologische Methoden}

\subsubsection{Nukleinsäurepräparation}

\subsection{Qualitative Nukleinsäurepräparation (modifiziert nach Birnboim und Doly 1979)}

Die qualitative Nukleinsäurepräparation diente der Gewinnung von Plasmid-DNA aus kleinen Bakteriensuspensionskulturen. Die Bakterien wurden alkalisch lysiert, RNA, Proteine und genomische DNA entfernt und die Plasmid-DNA anschließend gefällt und gewaschen.

Zunächst wurde eine 2-ml-Bakterienkultur in LB-Medium angeimpft und über Nacht im Schüttler bei $37^{\circ} \mathrm{C}$ inkubiert. Die Bakterien wurden bei $18.000 \mathrm{x}$ g in 5 min pelletiert und in $200 \mu 1$ Resuspensionspuffer P1 aufgenommen. Durch Zugabe von $200 \mu$ l Lysispuffer P2 wurden die Bakterien in 8 min bei Raumtemperatur lysiert. Proteine und genomische DNA wurden durch Zugabe von $200 \mu 1$ Neutralisationspuffer P3 ausgefällt. Die Zugabe von $2 \mu 1$ Chloroform optimierte die Fällung und Pelletierung bei $18.000 \mathrm{x} \mathrm{g}$ und $4{ }^{\circ} \mathrm{C}$ in $15 \mathrm{~min}$. Der Überstand enthielt die Plasmid-DNA und wurde in ein neues Reaktionsgefäß überführt. Nach Zugabe von $500 \mu \mathrm{l}$ Isopropanol fiel die DNA aus. Sie wurde bei $18.000 \mathrm{x} \mathrm{g}$ und $4{ }^{\circ} \mathrm{C}$ 15 min zentrifugiert und das entstehende Pellet im Anschluss mit $70 \%$ Ethanol gewaschen. Bei $37{ }^{\circ} \mathrm{C}$ wurde die gewonnene Plasmid-DNA getrocknet und in $20 \mu \mathrm{l} \mathrm{dH}_{2} \mathrm{O}$ aufgenommen. DNA-Konzentration und -Reinheit konnten im Anschluss in der Absorptionsspektrometrie (2.2.2.4, S. 35) bestimmt werden.

\subsection{Quantitative Nukleinsäurepräparation}

Größere Mengen endotoxinfreier Plasmid-DNA wurden durch modifizierte alkalische Lyse mit einem QIAGEN EndoFree-Plasmid-Maxi-Kit gewonnen. Das Verfahren basierte wie die qualitative Nukleinsäurepräparation (2.2.2.1.1) auf alkalischer Lyse der Bakterien. Die anschließende Aufreinigung der DNA erfolgte mit einer Ionenaustauschersäule. Die präparierten Plasmidlösungen waren endotoxinfrei und so für die Anwendung in der Zellkultur geeignet.

$200 \mathrm{ml}$ LB-Medium mit $100 \mu \mathrm{g} / \mathrm{ml}$ Kanamycin wurden mit den plasmidtragenden Bakterien beimpft und bei $37^{\circ} \mathrm{C}$ im Schüttler über Nacht inkubiert. Anschließend wurden die Bakterien bei $4.500 \mathrm{x}$ g und $4{ }^{\circ} \mathrm{C}$ in 15 min pelletiert und in $10 \mathrm{ml}$ P1-Puffer mit LyseBlueReagenz resuspendiert. Nach Zugabe von $10 \mathrm{ml}$ P2 färbte sich die Lösung nach mehrmaligem Schwenken homogen blau. Bei Raumtemperatur wurde diese nun 10 min inkubiert. $10 \mathrm{ml}$ kalter P3-Puffer wurden hinzugefügt und das Gemisch so lange geschwenkt, bis es sich wieder vollständig entfärbte. Die Lösung wurde in eine Filterspritze überführt und nach 10 min Inkubation unter leichtem Druck filtriert. Durch Zugabe von 2,5 ml ER-Puffer, vorsichtiges Schwenken und anschließende Inkubation auf Eis für 30 min wurden Endotoxine enzymatisch entfernt. In dieser Zeit wurde die Ionenaustauschersäule durch Zugabe von $10 \mathrm{ml}$ QBT-Puffer vorbereitet. Das filtrierte und endotoxinfreie Gemisch wurde nun auf die Ionenaustauschersäule gegeben und floss durch die Schwerkraft durch sie hindurch. Im Anschluss wurde die Säule zweimal mit $30 \mathrm{ml}$ QC-Puffer gewaschen und die 
Plasmid-DNA mit $15 \mathrm{ml}$ QN-Puffer gelöst. Die Plasmid-DNA wurde nun mit 10,5 ml eiskaltem Isopropanol gefällt, bei $25.000 \mathrm{xg}$ und $4{ }^{\circ} \mathrm{C}$ in $30 \mathrm{~min}$ pelletiert und mit endotoxinfreiem $70 \%$ Ethanol gewaschen. Das entstehende Pellet wurde bei Raumtemperatur getrocknet und in endotoxinfreiem $\mathrm{dH}_{2} \mathrm{O}$ in einer Konzentration von $1 \mu \mathrm{g} / \mu \mathrm{l}$ aufgenommen. Die DNA-Konzentration wurde hierzu absorptionsspektrometrisch (2.2.2.4) bestimmt.

\subsubsection{Nukleinsäureaufreinigung}

Zur Reinigung und zur Konzentration der DNA in Lösungen wurde diese alkoholisch gefällt. Nach Zugabe von Salzen fiel die DNA in alkoholischer Lösung aus, da ihr die Hydrathülle entzogen wurde. Viele niedermolekulare wasserlösliche Verunreinigungen blieben jedoch in Lösung und konnten mit dem Überstand verworfen werden.

Zur Standardnukleinsäureaufreinigung wurde die Natriumazetatfällung verwendet. Die DNA fiel in $300 \mathrm{mM}$ Natriumacetatlösung mit einem $\mathrm{pH}$-Wert von 4,8 nach Zugabe der 2,5-fachen Menge $-20^{\circ} \mathrm{C}$ kalten Ethanols innerhalb von 15 min Inkubation aus. Nach 20 min Zentrifugation bei $25.000 \mathrm{xg}$ wurde die pelletierte DNA noch einmal mit $70 \%$ Ethanol gewaschen, bei $37{ }^{\circ} \mathrm{C}$ getrocknet und in der gewünschten Konzentration in Wasser aufgenommen.

Um Plasmid-DNA auch von einzelnen dNTPs und Oligonukleotiden zu trennen, wurde zur Fällung statt Natriumazetat Ammoniumazetat in $250 \mathrm{mM}$ Konzentration eingesetzt. Kurze DNA-Moleküle blieben bei der Fällung in Lösung und konnten mit dem Überstand verworfen werden.

Große DNA-Mengen wurden ebenfalls mit Natrium- oder Ammoniumazetat gefällt. Als Alkohol wurde hier aber Isopropanol im 0,7-fachen Volumen der Salzlösung eingesetzt. Die präzipitierte DNA wurde wie bei Ethanolfällungen pelletiert, mit $70 \%$ Ethanol gewaschen, getrocknet und in einer Konzentration von $1 \mu \mathrm{g} / \mu \mathrm{l}$ in $\mathrm{dH}_{2} \mathrm{O}$ aufgenommen.

\subsubsection{DNA-Extraktion aus Agarosegelen}

Zur Extraktion von DNA-Fragmenten aus dem Agarosegel nach der Agarosegelelektrophorese (2.2.2.10, S. 40) wurde das Zymo-Clean ${ }^{\mathrm{TM}}$ Gel DNA Recovery Kit verwendet. Die DNA-Bande wurde mit dem Skalpell ausgeschnitten und im dreifachen Volumen ADB-Puffer bei $55^{\circ} \mathrm{C}$ aufgelöst. Im Anschluss wurde die Lösung bei $25.000 \mathrm{x} \mathrm{g}$ durch eine Zymo-Spin ${ }^{\mathrm{TM}}$-Ionenaustauschersäule zentrifugiert, an deren innere Oberfläche sich die DNA anlagerte. Die Säule wurde zweimal mit je $200 \mu 1$ Waschpuffer gespült und im Anschluss die DNA mit $50 \mu 1 \mathrm{dH}_{2} \mathrm{O}$ in 1 min bei $25.000 \mathrm{x}$ g aus der Säule gelöst. Die gewonnene Lösung wurde zur Entfernung von Agaroseresten mit Natriumacetat gefällt (2.2.2.2).

\subsubsection{Absorptionsspektrometrische DNA-Konzentrationsbestimmung}

Die Konzentrationen verschiedener DNA-Lösungen wurden durch Absorptionsspektrometrie bestimmt. Nukleinsäuren absorbieren Licht von $260 \mathrm{~nm}$ Wellenlänge. Aus der optischen Dichte der DNA-Lösung bei dieser Wellenlänge wurde die Menge an Nukleotiden in der Lösung berechnet. Nach Kalibrierung des Photometers mit reinem Wasser wurde das Absorptionsspektrum der DNA-Lösung bestimmt. Die Konzentration errechnete sich nach folgender Formel: 


$$
\text { Konzentration }[\mu \mathrm{g} / \mu \mathrm{l}]=\frac{\mathrm{OD}_{260} \cdot \text { Verdünnungsfaktor } \cdot \mathrm{F}_{\mathrm{dsDNA}}[\mu \mathrm{g}]}{1.000[\mu \mathrm{l}]}
$$

$\mathrm{OD}_{260}$ bezeichnet hierbei die Optische Dichte bei $260 \mathrm{~nm}$ Wellenlänge und $\mathrm{F}_{\mathrm{dsDNA}}$ einen konstanten Faktor der bei doppelsträngiger DNA 50 beträgt. Durch die parallele Bestimmung des Verhältnisses von optischer Dichte bei $260 \mathrm{~nm}$ und $280 \mathrm{~nm}$ Wellenlänge konnte auch die Verunreinigung der Lösung mit Protein abgeschätzt werden, wobei eine reine DNA-Lösung einem Verhältnis von 1,8 bis 2,0 entsprach.

\subsubsection{Polymerase-Kettenreaktion (PCR) (Saiki et al. 1985)}

Die Polymerase-Kettenreaktion ist ein molekularbiologisches Standardverfahren zur Vermehrung von DNA-Abschnitten. Auch die Kolonie-PCR (2.2.2.5.3, S. 37) und die DNASequenzierung (2.2.2.6, S. 38) beruhten auf dem gleichen Prinzip der spezifischen DNAVermehrung.

Zunächst wurde die als Doppelstrang vorliegende DNA denaturiert. Zugegebene kurze Oligonukleotid-Primer (2.2.2.5.1) banden spezifisch an zwei Stellen der nun vorliegenden Einzelstränge. Eine DNA-Polymerase füllte diese Bereich der Einzelstränge der Vorlagen-DNA zu Doppelsträngen auf, indem sie an die gebundenen Oligonukleotide am jeweiligen 3'-Ende freie dNTPs anfügte. Durch zyklische Veränderungen der Temperatur wurden die Schritte der Denaturierung der Doppelstränge, der Anlagerung der Oligonukleotide und der Strangsynthese durch die Polymerase mehrfach wiederholt. Da die Synthese am Führungs- und am Folgestrang erfolge und auch die Kopien beim nächsten Zyklus als Vorlage zur DNA-Synthese dienten, wurde die Anzahl der Kopien des amplifizierten DNA-Bereichs theoretisch mit jedem Zyklus verdoppelt.

\subsection{Primer}

Als Primer wurden einzelsträngige Oligonukleotide von 20 bis 30 bp Länge verwendet. Sie bildeten durch komplementäre Anlagerung an eine bestimmte Stelle des VorlagenEinzelstrangs den Startkomplex. Die Auswahl der Nukleotidsequenzen der Primer bestimmte ihre Hybridisierungsstellen und somit auch Beginn und Ende des amplifizierten Abschnitts der DNA-Vorlage.

Die Primer wurden so gestaltet, dass sie spezifisch an nur eine Stelle der DNA-Vorlage banden. Ihre Schmelztemperatur war bei Vorwärts- und Rückwärts-Primer besonders ähnlich. Auch wurde durch sorgfältige in-silico-Prüfung vermieden, dass sich die Primer an sich selbst, an sich gegenseitig oder an sich untereinander komplementär anlagern konnten.

Da die 5'-Enden der Oligonukleotid-Primer nicht zwangsläufig komplementär zur DNAVorlage sein mussten, konnten an den komplementär bindenden Teil des Primers in 5'-Richtung kurze zusätzliche Nukleotidsequenzen angefügt werden. Diese wurden bei jedem Zyklus mitamplifiziert und so an die Sequenz des ausgewählten Bereichs der DNAVorlage angefügt. Die Sequenzen der verwendeten Oligonukleotid-Primer sind in Tabelle 2 (S. 21) angegeben. 


\subsection{Durchführung der Polymerase-Kettenreaktion}

Der Reaktionsansatz zur Polymerase-Kettenreaktion setzte sich wie folgt zusammen:

$10 \mu 1 \quad 5 \times$ Phusion $^{\circledR}$-HF-Puffer

$0,5 \mu \mathrm{l} \quad$ Phusion $^{\circledR}$ Hot Start High-Fidelity DNA-Polymerase

$2 \mu 1 \quad 5 \mu \mathrm{M}$ Vorwärts-Primer

$2 \mu 1 \quad 5 \mu \mathrm{M}$ Rückwärts-Primer

$400 \mathrm{ng} \quad$ DNA-Vorlage

$1 \mu \mathrm{l} \quad 10 \mathrm{mM}$ dNTP-Mix

ad $50 \mu \mathrm{l} \quad \mathrm{dH}_{2} \mathrm{O}$

Um die Fehlerraten bei der Amplifikation möglichst gering zu halten, wurde die Phusion ${ }^{\circledR}$ Hot Start High-Fidelity DNA-Polymerase verwendet. Durch ihre 3'-5'-Exonukleaseaktivität korrigierte sie falsch eingesetzte Basen selbst (proofreading).

Zur Vermeidung unspezifischer DNA-Polymerisationen wurde der Ansatz auf Eis pipettiert und dann in den bereits vorgeheizten Thermocycler gegeben. Die DNA-Vermehrung erfolgte durch zyklische Änderungen der Reaktionstemperatur. Die Anlagerungstemperatur wurde $5{ }^{\circ} \mathrm{C}$ unter der oben angegebenen Schmelztemperatur der Primer gewählt. Die Synthesedauer wurde der Länge des zu amplifizierenden Fragments angepasst.

$\left.\begin{array}{lll}\text { Initiale Denaturierung } & 98^{\circ} \mathrm{C} & 2,5 \mathrm{~min} \\ \hline \text { Denaturierung } & 98^{\circ} \mathrm{C} & 25 \mathrm{sec} \\ \hline \text { Primeranlagerung } & 45^{\circ} \mathrm{C}-72{ }^{\circ} \mathrm{C} & 25 \mathrm{sec} \\ \hline \text { Strangsynthese } & 72^{\circ} \mathrm{C} & 30 \mathrm{sec} / 1.000 \mathrm{bp}\end{array}\right]=30 \mathrm{x}$

Nach der Amplifikation wurden die DNA-Abschnitte durch Natriumazetatfällung (2.2.2.2, S. 35) vom PCR-Puffer und der Polymerase gereinigt.

\subsection{Kolonie-Polymerase-Kettenreaktion}

Die Kolonie-PCR diente als schnelle und sensitive Methode zur ersten Selektion plasmidenthaltender Bakterienkolonien nach der Transformation. Durch die initiale Erhitzung wurden die Bakterienzellwände zerstört und die in den Bakterien enthaltenen Plasmide als Vorlage zur Polymerase-Kettenreaktion zugänglich. Über spezifische Primer konnte nun ein definierter Bereich des gewünschten Plasmids amplifiziert und anschließen in der Agarosegelelektrophorese (2.2.2.10, S. 40) nachgewiesen werden. Da hierfür die korrekte Amplifikation der Sequenz des DNA-Abschnitts irrelevant war, konnte statt der Phusion ${ }^{\circledR}$ Hot Start High-Fidelity DNA-Polymerase die wesentlich günstigere Taq DNAPolymerase verwendet werden. Der Reaktionsansatz setzte sich wie folgt zusammen:

$\begin{array}{ll}2,5 \mu \mathrm{l} & 10 \times \text { Taq-DNA-Polymerase-Puffer } \\ 0,5 \mu \mathrm{l} & \text { Taq DNA-Polymerase } \\ 0,5 \mu \mathrm{l} & 5 \mu \mathrm{M} \text { Vorwärts-Primer } \\ 0,5 \mu \mathrm{l} & 5 \mu \mathrm{M} \text { Rückwärts-Primer } \\ 1 & \text { Abstrich der Bakterienkolonie } \\ 0,5 \mu \mathrm{l} & 10 \mathrm{mM} \text { dNTP-Mix } \\ 20,5 \mu \mathrm{l} & \mathrm{dH}_{2} \mathrm{O}\end{array}$


Zur Vermeidung unspezifischer Polymeraseaktivität wurde bis zur Erhitzung im Thermocycler auf Eis gearbeitet. Auch hier wurde die Anlagerungstemperatur um $5{ }^{\circ} \mathrm{C}$ niedriger als die Primerschmelztemperatur gewählt. Die Strangsynthese erfolgte langsamer als mit der Phusion ${ }^{\circledR}$-Polymerase.

$\left.\begin{array}{lll}\text { Initiale Denaturierung } & 94^{\circ} \mathrm{C} & 5 \mathrm{~min} \\ \hline \text { Denaturierung } & 94^{\circ} \mathrm{C} & 30 \mathrm{sec} \\ \hline \text { Primeranlagerung } & 45^{\circ} \mathrm{C}-72^{\circ} \mathrm{C} & 25 \mathrm{sec} \\ \hline \text { Strangsynthese } & 72^{\circ} \mathrm{C} & 60 \mathrm{sec} / 1.000 \mathrm{bp}\end{array}\right]=30 \mathrm{x}$

Da die Bakterien beim Ausstreichen auf die Agarplatten noch vom Ligationsansatz umgeben waren und die Insert-DNA daher auf der gesamten Platte in sehr geringer Konzentration vorhanden war, konnten auch in Abstrichen untransformierter Kolonien das gewünschte Plasmid nachgewiesen werden. Dies führte zu häufig falsch-positiven Plasmid-Nachweisen. Die Sensitivität der Methode sorgte allerdings für einen hohen negativ-prädiktiven Wert. War eine Kolonie in der Kolonie-PCR negativ, so war sie mit großer Sicherheit nicht korrekt transformiert und musste nicht weiter untersucht werden.

\subsubsection{Sequenzierung (Sanger et al. 1977)}

Zur Sequenzierung wurde eine nicht radioaktive automatische Variante der Kettenabbruchsequenzierung nach Sanger (Sanger et al. 1977) am Deutschen Primatenzentrum Göttingen durchgeführt.

Ähnlich wie bei der PCR (2.2.2.5, S. 36) fügte eine Polymerase dNTPs an einen Primer an, der an einen Strang der denaturierten DNA-Vorlage gebunden war. Der Nukleotidmix enthielt neben den dNTPs zur Kettenverlängerung noch verschiedenfarbig fluoreszenzmarkierte Didesoxynukleotide, welche ebenfalls in den neu synthetisierten Strang eingebaut wurden. An sie konnte die Polymerase keinen weiteren Nukleotide anfügen, sodass der synthetisierte Strang mit dem fluoreszenzmarkierten Nukleotid abbrach. Im Unterschied zur PCR wurde immer nur ein Primer pro Ansatz verwendet, sodass die lineare Amplifikation immer nur eines Strangs erfolgte. Der Reaktionsansatz setzte sich wie folgt zusammen:

$2 \mu 1 \quad$ BigDye $^{\circledR}$-Direct-Cycle-Sequencing-Polymerase-Puffer

$1 \mu 1 \quad$ BigDye $^{\circledR}$ Direct Cycle Sequencing Polymerase

$1 \mu \mathrm{l} \quad 10 \mu \mathrm{M}$ Sequenzierprimer

$3 \mu \mathrm{l} \quad$ Plasmid-DNA $(100 \mathrm{ng} / \mu \mathrm{l})$

$3 \mu \mathrm{l} \quad \mathrm{dH}_{2} \mathrm{O}$

Die Sequenzierreaktion erfolgte unter zyklischen Temperaturveränderungen nach folgendem Schema:

$\left.\begin{array}{lll}\text { Initiale Denaturierung } & 96^{\circ} \mathrm{C} & 2 \mathrm{~min} \\ \hline \text { Denaturierung } & 96^{\circ} \mathrm{C} & 30 \mathrm{sec} \\ \hline \begin{array}{l}\text { Primeranlagerung und } \\ \text { Strangsynthese }\end{array} & 50^{\circ} \mathrm{C} & 15 \mathrm{sec} \\ \hline \text { Finale Strangsynthese } & 60^{\circ} \mathrm{C} & \end{array}\right]=0 \mathrm{~m}$


Das entstehende Gemisch verschiedenlanger Ketten, die an ihrem Ende entsprechend ihrer letzten Base fluoreszenzmarkiert waren, wurde mit Ammoniumazetat gefällt (2.2.2.2, S. 35) und mit $70 \%$ Ethanol gewaschen. Die getrockneten Pellets wurden elektrophoretisch nach der Größe aufgetrennt. Die anschließende Bestimmung der Fluoreszenzen erlaubte die Bestimmung der DNA-Sequenz der Vorlage. Alle Sequenzen wurden nach der automatischen Erkennung der Basenfolge anhand der aufgezeichneten Fluoreszenzmuster nachkontrolliert und mit den erwarteten Sequenzen verglichen.

\subsubsection{Restriktionsenzymatische Spaltung von DNA-Lösungen (modifiziert nach Brooks 1987)}

Restriktionsenzyme sind Endo-Nukleasen, die DNA-Doppelstränge an spezifischen palindromischen Sequenzen schneiden. Dabei können Überhänge des 3'- oder des 5'-Endes oder keine Überhänge entstehen.

Zum Verdau wurde die DNA mit dem Restriktionsenzym im dazugehörenden Puffer bei $37{ }^{\circ} \mathrm{C}$ inkubiert. Die Menge an DNA bestimmte die Menge des benötigten Enzyms, wobei $1 \mathrm{u}$ des Enzyms $1 \mu \mathrm{g}$ DNA in $1 \mathrm{~h}$ verdaute. Die Dauer der Inkubation wurde nach Herstellerempfehlung gewählt. DNA konnte auch gleichzeitig mit mehreren Enzymen verdaut werden, wenn diese im gleichen Puffer aktiv waren.

Nach dem Verdau wurde die DNA von Enzym und Puffer durch Natrium- oder Ammoniumazetatfällung getrennt (2.2.2.2, S. 35).

\subsubsection{Dephosphorylierung von Vektoren}

Zur Verhinderung der Re-Ligation eines durch Restriktionsverdau geöffneten Vektors wurde dieser nach der enzymatischen Aufspaltung dephosphoryliert. Die alkalische Phosphatase entfernte die zur Ligation notwendigen Phosphatgruppen an den jeweiligen 5'-Enden der komplementären Stränge. Eine Ligation (2.2.2.9) dieser Schnittstellen konnte so nur noch mit nicht-dephosphorylierter DNA wie beispielsweise dem Insert erfolgen. Hier wurde allerdings auch jeweils nur das phosphatgruppentragenden $5^{6}$-Ende des Inserts mit dem jeweiligen 3 '-Ende des Vektors verknüpft, sodass Einzelstrangbrüche entstanden, die nach der Transformation (2.2.1.3, S. 33) von Nukleinsäure-Reparaturmechanismen der Bakterien repariert werden mussten.

Die Dephosphorylierung erfolgte bei $37^{\circ} \mathrm{C}$ für eine Stunde in folgendem Reaktionsansatz:

$\begin{array}{ll}20 \mu \mathrm{l} & \text { Restriktionsverdaute DNA (100 ng/ } \mu \mathrm{l}) \\ 3 \mu \mathrm{l} & \text { Alkaline Phosphatase, Calf Intestinal (CIP) } \\ 5 \mu \mathrm{l} & 10 \mathrm{x} \text { CIP-Puffer } \\ 17 \mu \mathrm{l} & \mathrm{dH}_{2} \mathrm{O}\end{array}$

Im Anschluss wurden Phosphatase und Puffer mittels Natriumazetatfällung (2.2.2.2, S. 35) entfernt.

\subsubsection{Ligation (Dugaiczyk et al. 1975; Sgaramella et al. 1970)}

T4 DNA-Ligase verbindet aneinander gelagerte DNA-Stränge unter Abspaltung 5'-terminaler Phosphatgruppen kovalent miteinander. Hierbei arbeitete die Ligase besonders effektiv, wenn sie DNA-Stränge verknüpft, deren Enden sich komplementär überlappen. 
Zur Ligation eines Insert in einen Vektor musste deren optimales Massenverhältnis nach folgender Formel verwendet werden:

$$
\frac{\text { Insertmasse }[\mathrm{ng}]}{\text { Insertgröße [bp] }}=5 \cdot \frac{\text { Vektormasse }[\mathrm{ng}]}{\text { Vektorgröße }[\mathrm{bp}]}
$$

Eine gute Ligationseffizienz wurde mit dem unten beschriebenen Ligationsansatz bei $10 \mathrm{~h}$ Inkubation bei $8{ }^{\circ} \mathrm{C}$ erreicht:

$$
\begin{array}{ll}
3 \mu \mathrm{l} & 10 \times \text { T4-DNA-Ligase-Puffer } \\
1 \mu \mathrm{l} & \text { T4 DNA-Ligase } \\
200 \mathrm{ng} & \text { Insert und Vektor nach Formel } \\
\text { ad } 30 \mu \mathrm{l} & \mathrm{dH}_{2} \mathrm{O}
\end{array}
$$

Der Ligationsansatz konnte nun ohne weitere Aufreinigung direkt zur Transformation (2.2.1.3, S. 33) verwendet werden.

\subsubsection{Agarosegelelektrophorese}

Die Agarosegelelektrophorese wurde zur Auftrennung von DNA-Fragmenten entsprechend ihrer Länge verwendet. Je $25 \mu \mathrm{l}$ der DNA-Lösung wurden mit $5 \mu 16$ x Ladepuffer versetzt und in Taschen eines $1 \%$ Agarosegels aufgetragen. Im elektrischen Feld diffundierte die negativ geladene DNA durch das Gel in Richtung der Anode. Die Diffusionsgeschwindigkeit hing hierbei vor allem von der Länge des DNA-Fragments ab. Die Auftrennung erfolgte bei $100 \mathrm{~V}$ in 30 - 60 min. Die Färbung mit Ethidiumbromid machte die DNA-Fragmente im Gel unter UV-Licht sichtbar. Ihre Längen wurden im Vergleich mit der DNA-Ladder 1 kb mit Fragmenten bekannter Längen abgeschätzt.

Aufgetrennte DNA-Fragmente konnten aus dem Gel auch extrahiert und weiter verwendet werden (2.2.2.3, S. 35). Eine intensive Bestrahlung mit UV-Licht musste dann allerdings vermieden werden.

\subsubsection{Proteinbiochemische Methoden}

Zum Nachweis von Proteinen in Zelllysaten wurden diese zunächst in einem SDS-Polyacrylamdigel entsprechend ihrer Größe aufgetrennt. In einem zweiten Schritt wurden die getrennten Proteine auf eine Nitrozellulosemembran geblottet und mit Antikörpern spezifisch markiert.

Zur Kontrolle unspezifischer Antikörperbindungen wurden jeweils zwei Analysen durchgeführt, wobei ein Proteinnachweis ohne Primärantikörper blieb und so der Kontrolle unspezifischer Markierungen diente.

\subsubsection{Zelllysate}

Zunächst wurden die zellulären Proteine aus den Zellen gelöst und aufgereinigt. Je Probe wurden $5 \cdot 10^{5}$ Zellen zweimal mit PBS gewaschen und in $20 \mu$ l eiskaltem NP 40-Lysispuffer aufgenommen. Nach $20 \mathrm{~min}$ Inkubation auf Eis wurden DNA, RNA und Membranbestandteile bei $1.500 \mathrm{x}$ g bei $4{ }^{\circ} \mathrm{C}$ in $20 \mathrm{~min}$ pelletiert. Der Überstand enthielt nun die zellulären Proteine zur gelelektrophoretischen Auftrennung. Da streng auf Eis gearbeitet wurde, konnte auf die Zugabe von Protease-Inhibitoren verzichtet werden. 


\subsubsection{SDS-Polyacrylamid-Gelelektrophorese (SDS-PAGE) (Laemmli 1970)}

Mit Hilfe der diskontinuierlichen SDS-Polyacrylamid-Gelelektrophorese nach Laemmli (Laemmli 1970) wurden denaturierte Proteine ihrem Molekulargewicht entsprechend aufgetrennt. Proteine bekannter Masse wurden als Größenmarker verwendet.

Die Zelllysate (2.2.3.1, S. 40) wurden durch Zugabe des SDS- und Mercaptoethanolhaltigen Probenpuffers denaturiert. Das im Überschuss eingesetzte SDS verursachte eine gleichmäßige negative Ladung aller Proteine, das Reduktionsmittel Mercaptoethanol löste Tertiärstrukturen wie zum Beispiel Disulfidbrücken. Im Sammelgel wurden die Proteine bei 20 mA Stromstärke zunächst zu einer einheitlichen Lauffront aufkonzentriert. Nach Übertritt in das Trenngel wurde die Stromstärke auf $40 \mathrm{~mA}$ erhöht. Hier trennten sich die Proteine aufgrund ihrer unterschiedlichen Laufgeschwindigkeiten auf. Die Diffusionsgeschwindigkeit eines Proteins im Gel hing hierbei vom seinem Molekulargewicht ab. Die Zugabe von Bromphenolblau zum Probenpuffer ermöglichte die Beobachtung der Lauffront während der Elektrophorese.

\subsubsection{Westernblot (Burnette 1981; Towbin et al. 1979)}

Zur spezifischen Färbung der entsprechend ihres Molekulargewichts aufgetrennten Proteine mit Antikörpern wurden diese im Semi-Dry-Blot-Verfahren aus dem SDS-Gel auf eine Nitrozellulosemembran übertragen.

Das SDS-Gel wurde nach der Elektrophorese in Blotpuffer äquilibriert und wie in Abb. 2 dargestellt in eine Semy-Dry-Blotkammer gegeben. Hierbei musste besonders darauf geachtet werden, dass alle Schichten ausreichend mit Blotpuffer getränkt waren und keine Luftblasen zwischen SDS-Gel und Nitrozellulosemembran entstanden.

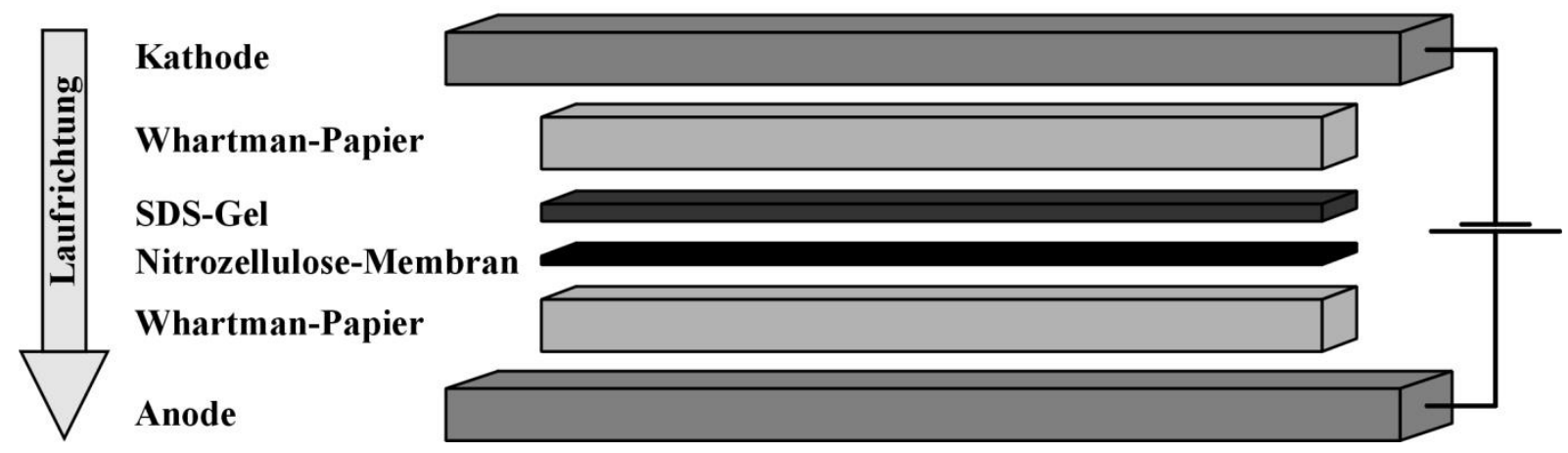

Abb. 2: Aufbau des Westernblots

Unter Druck wurde eine senkrechte Spannung so angelegt, dass die negativ geladenen Proteine aus dem Gel auf die Nitrozellulose diffundierten, wo sie aufgrund hydrophober Wechselwirkungen hafteten. Nach einer Stunde bei $16 \mathrm{~V}$ und $240 \mathrm{~mA}$ wurde die Nitrozellulose aus dem Blot genommen, die Proteine befanden sich nun auf der Nitrozellulosemembran.

Zur Kontrolle der Proteinauftragung und zur Färbung des Längenstandards wurde die Nitrozellulose kurz in ein Bad der Ponceau-Rot-Färbelösung gegeben. Der rote Farbstoff band reversibel an positiv geladenen Aminogruppen der Proteine und konnte nach Anzeichnung des Längenstandards und der Lauflinien leicht mit PBS-Tween ausgewaschen werden. 


\subsubsection{Immunfärbung}

Die Nitrozellulosemembran wurde nach dem Blot mit PBS-Tween gewaschen und für $8 \mathrm{~h}$ bei $4{ }^{\circ} \mathrm{C}$ im Schüttler mit $5 \mu 1$ Antikörper gegen Cathepsin B und als Ladekontrolle mit $5 \mu 1$ Antikörper gegen HSC70 in $10 \mathrm{ml}$ PBS-Tween inkubiert. Sowohl das endogene Cathepsin B als auch beide auf Cathepsin B basierenden Konstrukte CBG und MCBG konnten durch Immunreaktion mit dem anti-Cathepsin-B-Antikörper markiert werden. Der überschüssige Primärantikörper wurde durch dreimaliges Waschen mit PBS-Tween entfernt und die Nitrozellulose im Anschluss mit 2,5 $\mu$ l Sekundärantikörper (anti-goat-IgG) in $10 \mathrm{ml}$ PBS-Tween für 2 Stunden bei Raumtemperatur im Schüttler inkubiert. Erneut wurde ungebundener Antikörper mit PBS-Tween entfernt und die Membran mit 2,5 $\mu \mathrm{l}$ der Peroxidase-gekoppelten Nachweisantikörper (anti-mouse-IgG-HRPO, anti-rat-IgG-HRPO) in $10 \mathrm{ml}$ PBS-Tween für weitere 2 Stunden bei Raumtemperatur im Schüttler inkubiert. Anschließend wurde die Membran mehrfach mit PBS-Tween gewaschen und mit DAB-Lösung entwickelt. Die gebundenen Antikörper mit Peroxidase-Aktivität katalysierten eine Farbstoffreaktion der DAB-Lösung. Braune Streifen markierten die Positionen proteingebundener Antikörper. Auch die DAB-Färbelösung wurde mit PBS-Tween gründlich abgewaschen, um ein späteres Nachdunkeln zu vermeiden.

Alle Cathepsin-B-haltigen Proteine in den Zelllysaten waren nun als braune Banden angefärbt. Ihr Molekulargewicht konnten durch Vergleich mit dem vorher eingezeichneten Längenstandard ermittelt werden. Zur Kontrolle der aufgetragenen Proteinmengen wurde der Nachweis des konstitutiv exprimierten Proteins HSC70 verwendet.

\subsubsection{Zellbiologische Methoden}

\subsubsection{Allgemeines zur Arbeit mit Zellkulturen}

Alle Arbeiten an Zellkulturen wurden unter sterilen Bedingungen mit einzeln verpackten Einwegmaterialien in einem separaten für die Kultur von Zellen reservierten Raum unter einer Schutzwerkbank durchgeführt. Alle Medien und Lösungen wurden, soweit nicht anders beschrieben, vor der Verwendung im Wasserbad auf $37{ }^{\circ} \mathrm{C}$ vorgewärmt. Die Zellen wurden in ausschließlich für die Zellkultur verwendeten Inkubatoren bei $37^{\circ} \mathrm{C}$ unter $5 \%$ $\mathrm{CO}_{2}$ inkubiert. Medien, Puffer und Zusätze wurden in einem separaten Kühlschrank bei $4{ }^{\circ} \mathrm{C}$ gelagert.

Als Kulturmedium diente DMEM mit FBS und PenStrep. Transfizierte Zellen wurden durch Zusatz von $1 \mathrm{mg} / \mathrm{ml}$ Geneticin zum Nährmedium unter ständigem Selektionsdruck gehalten.

\subsubsection{Kultivierung von Suspensionszellen}

RMA-Zellen wuchsen in Suspensionskultur. Bis $\mathrm{zu} 10^{7}$ Zellen wurden in einer Suspensionskulturschale mit Deckel in $10 \mathrm{ml}$ DMEM mit FBS und PenStrep inkubiert. Die Zelldichte wurde täglich lichtmikroskopisch überprüft. Bei einer Dichte von $10^{6}$ Zellen $/ \mathrm{ml}$, mindestens jedoch alle 3 Tage, wurden die Zellen geteilt. Je Schale wurden $10^{6}$ Zellen in Medium entnommen und bei $300 \mathrm{xg}$ pelletiert. Die Zellen wurden in $10 \mathrm{ml}$ Medium resuspendiert und in eine neue Suspensionskulturschale überführt. So befanden sich die Zellen kontinuierlich in der exponentiellen Wachstumsphase und konnten für Experimente jederzeit entnommen werden. 


\subsubsection{Einfrieren und Auftauen von Zellen}

Nicht in Kultur benötigte Zellen wurden zur Lagerung bei $-140{ }^{\circ} \mathrm{C}$ eingefroren. Sie waren so über längere Zeiträume haltbar und konnten innerhalb weniger Tage wieder in Kultur genommen werden.

\subsection{Einfrieren}

Etwa $10^{6}$ Zellen im exponentiellen Wachstum wurden in Medium in ein 13-ml-Gefäß überführt, bei $300 \mathrm{x}$ g für 5 min pelletiert und in $500 \mu \mathrm{l}$ Geneticin-freiem DMEM mit FBS und PenStrep resuspendiert. In 2-ml-Kryoröhrchen wurden je $500 \mu \mathrm{l}$ Einfriermedium vorgelegt und die Zellen hinzugegeben. Da das Einfriermedium toxisch war, mussten die Zellen nun unverzüglich aber trotzdem langsam in einer Styroporbox auf $-140{ }^{\circ} \mathrm{C}$ abgekühlt werden.

\subsection{Auftauen}

Bei $-140{ }^{\circ} \mathrm{C}$ gelagerte Zellen wurden in ihren Kryoröhrchen erwärmt, bis ein schwimmender Eiskern entstand. Der gesamte Inhalt des Röhrchens wurde dann sofort in $5 \mathrm{ml} 37^{\circ} \mathrm{C}$ warmes DMEM gegeben und bei $300 \mathrm{x}$ g für 5 min zentrifugiert. Das Zellpellet wurde in $10 \mathrm{ml}$ DMEM mit FBS und PenStrep resuspendiert und die Zelllösung in Kulturschalen überführt. Transfizierte Zellen wurden direkt in DMEM mit FBS und PenStrep und Geneticin aufgenommen.

\subsubsection{Bestimmung der Zellzahl}

Die Bestimmung der Zellkonzentration einer Lösung erfolgte durch Auszählung mit einer Neubauer-improved-Zählkammer. Die Zählkammer bestand aus einem Objektträger, auf dem 4 Quadrate mit je $1 \mathrm{~mm}$ Kantenlänge markiert waren. Ein Deckgläschen wurde so auf dem Objektträger platziert, dass darunter ein Flüssigkeitsfilm von 0,1 mm Dicke entstand. Auf jedem Quadrat befand sich so $0,1 \mu 1$ Zellsuspension. Die Anzahl der Zellen innerhalb dieser definierten Flüssigkeitsmenge konnte mittels Durchlichtmikroskopie bestimmt werden. Die Konzentration der Zellen wurde nach folgender Formel berechnet:

$$
\text { Zellen/ml }=\text { Zellen/Quadrat } \cdot 10^{4}
$$

Zum Ausschluss toter Zellen konnten die Zellsuspension 1:10 mit Trypanblau verdünnt werden. Der Farbstoff reicherte sich in toten Zellen an und färbte diese blau. Lebende Zellen blieben ungefärbt und konnten so gezählt werden. Der Verdünnungsfaktor musste bei der Ermittlung der ursprünglichen Zellkonzentration berücksichtig werden.

\subsubsection{Transfektion mittels Elektroporation}

Durch einen elektrischen Puls wurden RMA-Zellen dazu gebracht, DNA aus ihrer Umgebung aufzunehmen.

$10^{7}$ Zellen in exponentiellem Wachstum wurden in $800 \mu \mathrm{l}$ PBS aufgenommen und $60 \mu \mathrm{g}$ linearisiertes, endotoxinfreies Plasmid hinzugegeben. Nach 5 min Ko-Inkubation in der Elektroporationsküvette wurde die Membran der Zellen durch Elektroporation mit $250 \mathrm{~V}$ bei einer Kapazität von $960 \mu \mathrm{F}$ permeabilisiert, was zur Aufnahme der DNA in die Zellen führte. Der komplette Ansatz wurde nach der Elektroporation für weitere $3 \mathrm{~min}$ bei 
Raumtemperatur inkubiert und im Anschluss mit 10 ml DMEM mit FBS und PenStrep aber noch ohne Geneticin in Suspensionskulturschalen überführt.

\subsubsection{Selektion}

Zur Selektion transfizierter Zellen wurde $24 \mathrm{~h}$ nach der Transfektion $1 \mathrm{mg} / \mathrm{ml}$ Geneticin zum Zellkulturmedium gegeben. Geneticin inhibiert die Proteinbiosynthese eukaryoter Zellen durch Hemmung der Elongation an 80S-Ribosomen (Bar-Nun et al. 1983). Transfizierte Zellen waren durch das im Vektor enthaltene Resistenzgen $\mathrm{Neo}^{\mathrm{r}}$ unempfindlich, da die kodierte Aminoglykosid-Phosphotransferase (APT) Geneticin phosphoryliert und inaktiviert (Haas und Dowding 1975). Untransfizierte Zellen, die dieses Resistenzgen nicht exprimierten, wurden durch Inhibition der Proteinbiosynthese getötet. Obwohl Geneticin sich nicht zur vollständigen Abtötung untransfizierter Zellen eignete, so reichte seine Toxizität doch zur Aufrechterhaltung eines ausreichenden Selektionsdruckes aus, um die überschießende Vermehrung untransfizierter Zellen zu verhindern (Paludan et al. 1989).

\subsubsection{Vereinzelung / Herstellung von Klonen}

Um verlässliche Tests zur Funktion der verschiedenen Zelllinien durchzuführen war es notwendig, konstante Expressionsraten aller Plasmide über längere Zeiträume zu erhalten. Dies wurde erreicht, indem klonale Zelllinien erzeugt wurden, die jeweils nur auf eine einzelne transfizierte Zelle zurückzuführen waren.

Zur Vereinzelung wurden Verdünnungsreihen in DMEM mit FBS und PenStrep und Geneticin durchgeführt. Eine klonale Aussaat wurde ab einer Verdünnung angenommen, in der nur noch in maximal jeder dritten Kultur Zellwachstum nachweisbar war. Nach durchflusszytometrischer Kontrolle der eGFP-Expression (2.2.4.8.4, S. 46) wurden die klonalen Zellen zu drei Zeitpunkten eingefroren (2.2.4.3.1, S. 43).

\subsubsection{Durchflusszytometrie}

Die Durchflusszytometrie erlaubte die Bestimmung der Fluoreszenz einzelner Zellen nach Anregung durch einen Laser. Die Fluoreszenz des eGFP-Proteins konnte direkt angeregt werden, andere Zellstrukturen wurden über fluoreszenzmarkierte Antikörper nachgewiesen. Durch gleichzeitiges Messen der Vorwärtsstreuung FSC als Maß der Zellgröße sowie der Seitwärtsstreuung SSC als Maß der Granularität wurden Zelltrümmer schon während der Messung ausgeschlossen.

Bei allen Messungen wurden je 10.000 Zellen analysiert und die arithmetischen Mittelwerte der betrachteten Fluoreszenzen automatisch errechnet.

\subsection{Nachweis toter Zellen in der Durchflusszytometrie}

Wenn immer die Kombination der Fluoreszenzfarbstoffe es ermöglichte, wurde eine Färbung mit Propidiumiodid (Absorption: $535 \mathrm{~nm}$; Emission: $617 \mathrm{~nm}$ ) durchgeführt. $10^{5}$ Zellen wurden mit PBS gewaschen und in $200 \mu \mathrm{l}$ PBS-Propidiumiodid-Lösung aufgenommen. Propidiumiodid ist ein rot fluoreszierender Farbstoff, der tote Zellen anfärbt, indem er ihre Zellmembran durchdringt und in die DNA interkaliert. Lebende Zellen entfernten den Farbstoff aktiv aus ihrem Inneren und blieben daher ungefärbt. Tote Zellen konnten so von der Messung ausgeschlossen werden. Die Fluoreszenzen von eGFP und 
Propidiumiodid beeinflussten sich bei geeigneter Einstellung des Durchflusszytometers gegenseitig nicht.

\subsection{Nachweis von Oberflächenmolekülen in der Durchflusszytometrie}

Zum Nachweis von oberflächengebundenen Molekülen in der Durchflusszytometrie wurden diese durch fluoreszierende Antikörper markiert und im Vergleich zu unmarkierten Zellen betrachtet.

Je $10^{6}$ Zellen wurden in einem FACS-Gefäß zweimal mit PBS gewaschen und in der zurücklaufenden Flüssigkeit resuspendiert. Zu den entsprechenden Proben wurden $2 \mu 1$ des Primärantikörpers hinzugegeben. Nach 45 min Inkubation bei $4{ }^{\circ} \mathrm{C}$ unter Lichtabschluss wurden alle Proben zweimal mit je $1 \mathrm{ml}$ PBS gewaschen und die Zellen in je $200 \mu \mathrm{PBS}$ resuspendiert.

Zur Messung der $\mathrm{H} 2 \mathrm{~K}^{\mathrm{b}}$-Expression wurde der fluoreszenzmarkierte Primärantikörper anti-H2 $\mathrm{K}^{\mathrm{b}}-\mathrm{PE}$ verwendet. Normalisiert wurde hier jeweils gegen die mIgG2a-Isotypenkontrolle.

Die Messung von oberflächengebundenem Cathepsin B sowie der HA-Tag-Nachweis erfolgten mit nicht fluoreszenzmarkierten Primärantikörpern. Der anti-HA-Tag-Antikörper konnte in einem zweiten Inkubations- und Waschschritt über den Sekundärantikörper anti-mouse-IgG-TC markiert werden. Zum Nachweis des anti-Cathepsin-B-Antikörpers wurde der nicht fluoreszenzmarkierte Sekundärantikörper anti-goat-IgG verwendet, der in einem dritten Inkubationsschritt mit dem Tertiärantikörper anti-mouse-IgG-TC dargestellt wurde. Die Normalisierung erfolgte in beiden Fällen gegen Sekundärantikörperkontrollen ohne Primärantikörper.

Zur Quantifizierung der Bindung des Primärantikörpers wurde die spezifische mittlere Fluoreszenzintensität (sMFI) als Differenz der mittleren Fluoreszenzintensitäten von Primärantikörperfärbung und der jeweiligen Kontrollmessung bestimmt.

\subsection{Nachweis von intrazellulären Molekülen in der Durchflusszytometrie}

Auch intrazelluläre Moleküle konnte in der Durchflusszytometrie durch Bindung eines fluoreszenzmarkierten Antikörpers nachgewiesen werden. Damit der Antikörper die intrazellulären Strukturen erreichen konnte, mussten die Zellen vor der Färbung mit Paraformaldehyd fixiert und ihre Membranen mit Saponin permeabilisiert werden.

Wie beim Nachweis von Oberflächenmolekülen (2.2.4.8.2) wurden $10^{6}$ Zellen in einem FACS-Gefäß zweimal mit PBS gewaschen. Anschließend wurden die Zellen in $500 \mu 11 \%$ Paraformaldehyd resuspendiert und $10 \mathrm{~min}$ bei Raumtemperatur inkubiert. Nach einem weiteren Waschschritt mit PBS wurden die Membranen mit 0,25\% (w/v) Saponin in PBS permeabilisiert. Die Antikörperfärbungen wurden wie in 2.2.4.8.2 beschrieben durchgeführt. Statt mit reinem PBS wurde allerdings immer mit 0,25\% (w/v) Saponin in PBS gewaschen. Vor der Messung erfolgte ein zusätzlicher Waschschritt mit reinem PBS. Daraufhin wurden die fixierten Zellen in $200 \mu$ l PBS resuspendiert und ihre Fluoreszenz gemessen. Wie unter 2.2.4.8.2 beschrieben wurden auch hier Sekundärantikörperkontrollen durchgeführt und die spezifische mittlere Fluoreszenzintensität (sMFI) berechnet. 


\subsection{Nachweis von eGFP in der Durchflusszytometrie}

Das eGFP-Protein konnte sowohl in freier Form als auch als Bestandteil der CBG- und MCBG-Fusionsproteine durch Anregung bei $488 \mathrm{~nm}$ zur Fluoreszenz mit einem Maximum der Emission bei $509 \mathrm{~nm}$ angeregt werden und war daher in der Durchflusszytometrie wie auch in der Laser-Scanning-Mikroskopie (2.2.4.10) leicht darstellbar. $10^{5}$ der zu untersuchenden Zellen und nicht eGFP-exprimierender Kontrollzellen wurden in je ein FACS-Gefäß überführt und zweimal in je $1 \mathrm{ml}$ PBS gewaschen. Anschließend wurden die Zellen in $200 \mu \mathrm{l}$ PBS aufgenommen und vorsichtig resuspendiert. Die eGFP-Expression wurde gegen die Kontrollzellen normalisiert betrachtet

\subsubsection{Zell-Sortierung}

Wie bei der Durchflusszytometrie (2.2.4.8.4) wurden Zellen einzeln mit einem Laserstrahl angeregt und anhand ihrer eGFP-Fluoreszenz sortiert.

$10^{7}$-Zellen wurden mit PBS gewaschen und in $500 \mu 1$ PBS aufgenommen. Die Zell-Sortierung selbst wurde in der zentralen Service-Einheit Cell-Sorting der Universitätsmedizin Göttingen durchgeführt. Die zunächst bestimmte Fluoreszenz untransfizierter RMA-Zellen wurde als Bereich eGFP-negativer Zellen definiert. Alle Zellen mit größerer Fluoreszenzintensität wurden als erfolgreich transfizierte Zellen gesammelt und in DMEM mit FBS und PenStrep und Geneticin aufgenommen.

\subsubsection{Konfokale Laser-Scanning-Mikroskopie}

Mittels konfokaler Laser-Scanning-Mikroskopie wurde die Verteilung von Farbstoffen innerhalb einzelner Zellkompartimente analysiert. Die Messung erfolgte an lebenden unfixierten Zellen.

Die katalytische Aktivität von Cathepsin B wurde innerhalb lebender Zellen mit Hilfe des Magic-Red ${ }^{\mathrm{TM}}$-Cathepsin-B-Detection-Kits nachgewiesen. Das Fluorophor Magic Red ${ }^{\mathrm{TM}}$ war an ein Cathepsin-B-spezifisches Substrat gekoppelt und konnte so die Membranen lebender Zellen durchdringen. Erst nach der Entfernung des Substrats durch enzymatisch aktives Cathepsin B fluoreszierte das freigesetzte Magic Red ${ }^{\mathrm{TM}}$. Die Verteilung der Cathepsin-BAktivität konnte so anhand der roten Fluoreszenz bestimmt werden. Das Magic-Red ${ }^{\text {TM }}$ Cathepsin-B-Detection-Kit war laut Herstellerangaben für Cathepsin B hochspezifisch und stellte keine Cathepsin-B-Vorstufen oder andere Cathepsine dar.

Parallel wurden die Zellen auch mit Hoechst 33342 gefärbt, welches in die DNA interkalierte und so Zellkerne sichtbar machte. Seine intensive Fluoreszenz erleichterte das Auffinden von Zellen, außerdem ermöglichte die Darstellung des Chromatins des Zellkerns eine erste Aussage zur Vitalität betrachteter Zellen. Die Messung der Verteilung des eGFP erforderte keine spezielle Vorbereitung.

$10^{6}$ Zellen in der exponentiellen Wachstumsphase wurden in $500 \mu 1$ DMEM mit FBS und PenStrep aufgenommen und $20 \mu \mathrm{l} 26 \times$ Magic-Red $^{\mathrm{TM}_{-}-C a t h e p s i n-B-w o r k i n g-s o l u t i o n}$ hinzugegeben. Nach 45 min Inkubation unter regelmäßigem Schwenken bei $37^{\circ} \mathrm{C}$ und $5 \%$ $\mathrm{CO}_{2}$ wurde in jede Probe 2,5 $\mu 1$ Hoechst 33342 hinzugegeben und der gesamte Ansatz weitere $15 \mathrm{~min}$ inkubiert. Je $15 \mu \mathrm{l}$ Zellsuspension wurden auf einem Objektträger ausgestrichen und mit einem Deckgläschen abgedeckt. Das Deckgläschen wurde auf dem Objektträger mit Nagellack luftdicht verklebt. 
Bei jeder Messung wurde zunächst das gesamte Präparat betrachtet. Mindestens fünf repräsentative Zellen wurden ausgewählt und ihre Fluoreszenzmuster gescannt. Die verschiedenen Farbstoffe wurden durch Laser unterschiedlicher Wellenlängen nacheinander angeregt und ihre Fluoreszenzmuster bestimmt. Zum Schutz vor Ausbleichung wurde zuerst mit langwelligem und danach mit kurzwelligem Licht angeregt. Mit dem LSM Image Browser wurden im Anschluss Helligkeit und Kontrast der Einzelbilder optimiert.

\subsubsection{Chrom-Freisetzungs-Test}

Zur Messung der zellvermittelten Zytolyse wurde der Chrom-Freisetzungs-Test eingesetzt. Zielzellen wurden mit Killerzellen gemeinsam inkubiert und im Anschluss der Anteil lysierter Zielzellen als Maß der zytotoxischen Reaktion bestimmt. Die Zielzellen wurden dazu vor dem Test mit radioaktivem ${ }^{51} \mathrm{Cr}$ markiert, welches sie aus ihrer Umgebung aufnahmen und erst nach ihrer Lyse wieder freisetzten. Durch Präsentation des im Inkubationsmedium enthaltenen SIINFEKL-Peptids auf $\mathrm{H} 2 \mathrm{~K}^{\mathrm{b}}$ auf ihrer Oberfläche aktivierten die RMA-Zielzellen den transgenen T-Zell-Rezeptor der zuvor peptidspezifisch stimulierten zytotoxischen T-Zellen aus OT-I-Mäusen. Diese lysierten die Zielzellen nun durch Freisetzung von Perforin und Granzymen durch Exozytose ihrer zytotoxischen Granula.

\subsection{Präparation von Milzen}

Zur Gewinnung zytotoxischer T-Zellen wurden Mausmilzen steril präpariert, homogenisiert und im Anschluss T-Zell-spezifisch stimuliert. Auch Rattenmilzen wurden präpariert, um aus den Lymphozytensuspensionen nach Stimulation mit Concanavalin A zytokinhaltigen Überstand zu gewinnen.

Zur Präparation der Milz wurden das jeweilige Tier zunächst durch $\mathrm{CO}_{2}$-Inhalation und anschließenden Genickbruch getötet. Der Körper wurde mit Nadeln auf einem Korkbrett befestigt und das Fell mit $70 \%$ Ethanol gereinigt. Nach medianem abdominalem Hautschnitt wurde die Bauchhaut stumpf gelöst und nach lateral abpräpariert. Das Peritoneum wurde steril eröffnet. Die Milz wurde im linken Oberbauch vorsichtig mobilisiert, am Hilus abgetrennt und in $5 \mathrm{ml}$ DMEM mit FBS und PenStrep aufgenommen. Lymphozyten und Erythrozyten wurden mit dem Tenbroeck-Homogenisator aus dem Gewebeverband gelöst.

\subsection{Herstellung von Concanavalin-A-Überstand aus Rattenmilzen}

Durch Stimulation mit Concanavalin A wurden die Lymphozytensuspensionen aus Rattenmilzen zur Produktion von Zytokinen angeregt. Die homogenisierten Rattenmilzen wurden bei $300 \mathrm{xg}$ für $5 \mathrm{~min}$ zentrifugiert. Das Zellpellet wurde in $40 \mathrm{ml}$ DMEM aufgenommen. Durch Zugabe von $200 \mu \mathrm{l}$ Concanavalin A $(1 \mathrm{mg} / \mathrm{ml})$ wurden die Lymphozyten unspezifisch stimuliert. Nach $4 \mathrm{~h}$ Inkubation bei $37{ }^{\circ} \mathrm{C}$ und $5 \% \mathrm{CO}_{2}$ wurden die zellulären Bestandteile erneut herunterzentrifugiert und in $20 \mathrm{ml}$ DMEM mit FBS und PenStrep aufgenommen. Die stimulierten Lymphozyten produzierten nun Zytokine, die sie in das Medium abgaben. Nach $24 \mathrm{~h}$ bei $37^{\circ} \mathrm{C}$ und $5 \% \mathrm{CO}_{2}$ wurden durch Zentrifugation bei 1.500 x g für 10 min die Rattenlymphozyten pelettiert. Der zytokinreiche DMEM-Überstand wurde abgenommen, aliquotiert und bei $-20{ }^{\circ} \mathrm{C}$ gelagert. 


\subsection{Stimulation zytotoxischer T-Zellen}

Vor dem Einsatz im Chrom-Freisetzungs-Test wurden die zytotoxischen T-Zellen aus den präparierten Lymphozytensuspensionen der OT-I-Mäuse aufbereitet und peptidspezifisch stimuliert.

Die in $10 \mathrm{ml}$ DMEM mit FBS und PenStrep gelösten Lymphozytensuspensionen wurden zunächst zentrifugiert $(300 \mathrm{x} \mathrm{g}, 5 \mathrm{~min})$ und das entstehende Pellet in $5 \mathrm{ml}$ ErythrozytenLyse-Puffer resuspendiert. Nach vollständiger Lyse der Erythrozyten wurden zunächst $5 \mathrm{ml}$ DMEM mit FBS hinzugegeben und die Zellen im Anschluss mit $10 \mathrm{ml}$ DMEM gewaschen. Die Zellen wurden bei $300 \mathrm{x}$ g pelletiert und in $20 \mathrm{ml}$ DMEM mit FBS und PenStrep mit $4 \mathrm{ml}$ Concanavalin-A-Überstand, $20 \mu \mathrm{l}$ LPS $(1 \mathrm{mg} / \mathrm{ml})$ und $2 \mu \mathrm{l}$ SIINFEKL-Peptid $(10 \mu \mathrm{g} / \mathrm{ml})$ zur antigenspezifischen Stimulation der OT-I-T-Zellen aufgenommen. In einer 96-well-Platte mit runden Böden wurden $200 \mu$ l Zellensuspension/well für 4 Tage bei $37^{\circ} \mathrm{C}$ und $5 \% \mathrm{CO}_{2}$ inkubiert, bevor die zytotoxischen T-Zellen geerntet und im ChromFreisetzungs-Test verwendet werden konnten.

\subsection{Durchführung des Chrom-Freisetzungs-Tests}

Zur Vorbereitung der Zielzellen wurden $10^{6}$ Zellen in $100 \mu$ FBS aufgenommen und $8 \mu 1$ radioaktives $\mathrm{Na}_{2} \mathrm{CrO}_{4}$ mit einer Aktivität von etwa $50 \mu \mathrm{Ci}{ }^{51} \mathrm{Cr}$ hinzugegeben. Die Aufnahme des radioaktiven Chroms erfolgte in einer Stunde bei $37{ }^{\circ} \mathrm{C}$ und $5 \% \mathrm{CO}_{2}$. Extrazellulär verbliebenes Chrom wurde durch dreimaliges Waschen der Zellen mit je $10 \mathrm{ml}$ DMEM entfernt. Im Anschluss wurden die Zellen in $10 \mathrm{ml}$ DMEM mit FBS und PenStrep resuspendiert und so eine Zielzellkonzentration von $10^{5}$ Zellen/ml eingestellt.

Die aus Mausmilzen gewonnen stimulierten zytotoxischen T-Zellen (2.2.4.11.3) wurden in 10 ml DMEM mit FBS und PenStrep aufgenommen und mit Trypanblau gezählt (2.2.4.4, S. 43). Eine Konzentration lebender Killerzellen von $8 \cdot 10^{6}$ Zellen/ml wurde eingestellt.

Killerzellen und Zielzellen wurden wie in Abb. 3 gezeigt auf eine 96-well Platte mit runden Böden verteilt. Jede Reaktion wurde als Triplet angesetzt. In jeder Reaktionskammer wurden $10^{4}$ chromierte Zielzellen und je nach Killer-Zielzell-Verhältnis $2 \cdot 10^{5}$ bis $3 \cdot 10^{3}$ Killerzellen eingesetzt. Zeile $\mathrm{H}$ verblieb zur Messung der Spontanfreisetzung ohne Killerzellen. Die zytotoxische Reaktion erfolgte in DMEM mit FBS und PenStrep und $0,25 \mu \mathrm{g} / \mathrm{ml}$ SIINFEKL-Peptid.

Bei jedem Test wurde auch eine Positivkontrolle mit untransfizierten RMA-Zellen zur Ermittlung eines Normalwertes der zytotoxischen Funktion der Killerzellen durchgeführt. Außerdem erfolgten bei jedem Test Negativkontrollen ohne SIINFEKL-Peptid und mit SIINFEKL-Peptid in Gegenwart des Calciumchelators EGTA/ $\mathrm{MgCl}_{2}$ (4 mM EGTA/8 mM $\mathrm{MgCl}_{2}$ ). Die Messung in Abwesenheit des SIINFEKL-Peptids diente dem Ausschluss einer nicht-peptidspezifischen Lyse. Der Calciumchelator EGTA/ $\mathrm{MgCl}_{2}$ entzog das zur Exozytose zytotoxischer Granula notwendige freie Calcium. Diese Kontrolle diente der Identifizierung nicht-Granula-vermittelter Zytotoxizität. Beide Negativkontrollen wurden jeweils nur mit den drei höchsten Killer-Zielzell-Verhältnissen durchgeführt. 


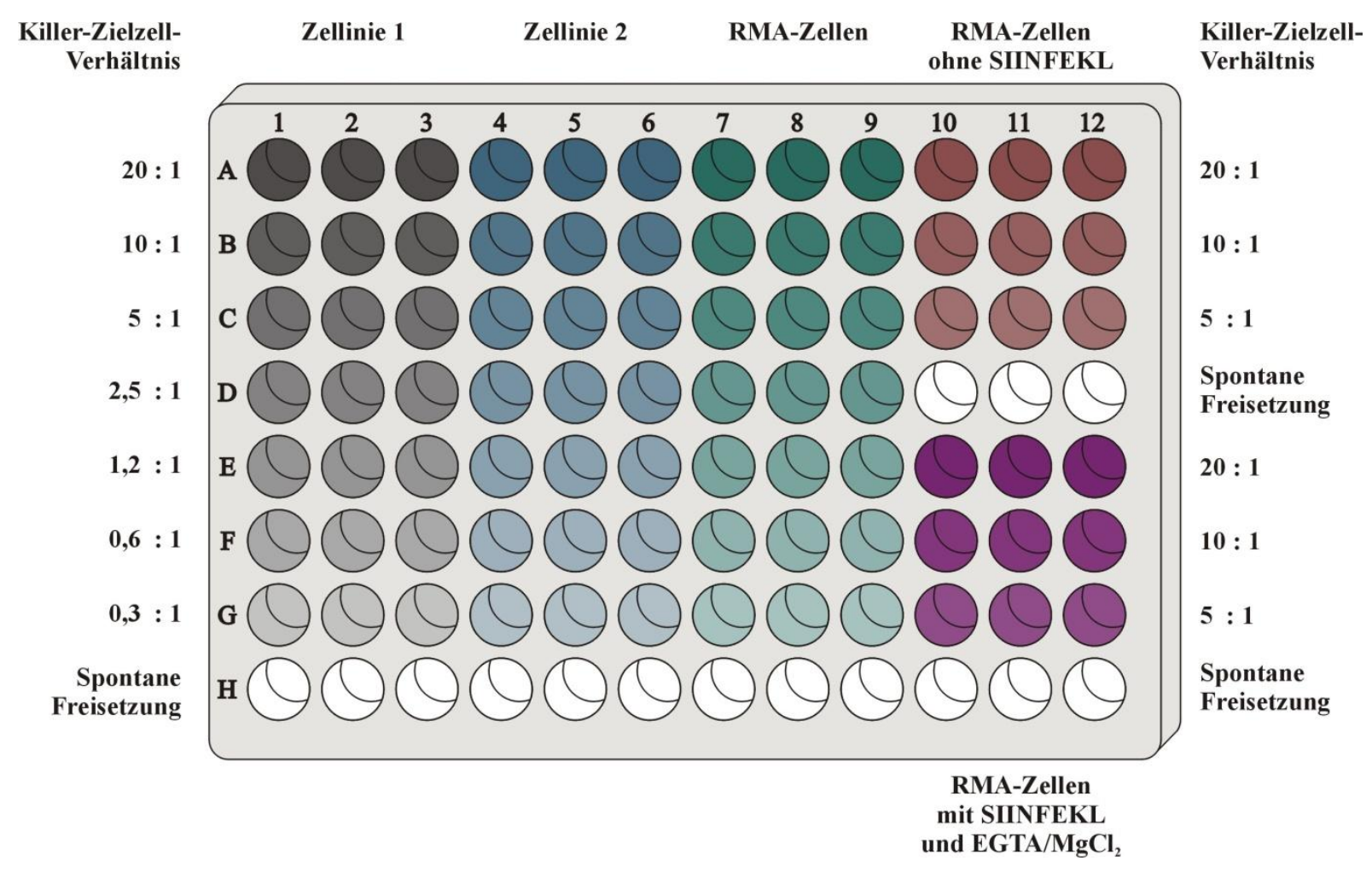

Abb. 3: Pipettierschema des Chrom-Freisetzungs-Test

Zytotoxische Zellen und Zielzellen wurden durch kurzes anzentrifugieren bei $300 \mathrm{x} g$ am runden Boden der Wells in Kontakt gebracht. Die zytotoxische Reaktion erfolgte bei $37{ }^{\circ} \mathrm{C}$ und $5 \% \mathrm{CO}_{2}$ über $4 \mathrm{~h}$. Zur Ermittlung der Lyse wurden Zellen und Zellreste durch Zentrifugation für $5 \mathrm{~min}$ bei $300 \mathrm{x}$ g sedimentiert. Freigesetztes Chrom wurde in $50 \mu 1$ des zellfreien Überstandes bestimmt. Nach Abnahme des Überstands wurden die sedimentierten Zellen durch Zugabe von $10 \mu 1$ Triton-Lyse-Puffer lysiert. Die Summe aus zellulär gebundenem und freigesetztem Chrom wurde in $50 \mu \mathrm{l}$ der lysierten Sedimente bestimmt. Die Proben wurden in Wallac-Messplatten überführt, mit je $200 \mu 1$ Szintillator überschichtet und mit TopSeal ${ }^{\circledR}$-A-Folie verschlossen. Durch kurzes Schütteln wurde der Szintillator mit den zu messenden Flüssigkeiten vermischt und mit dem Szinztillationszähler die Aktivität der Proben bestimmt. Mit der folgenden Formel wurde die prozentuale Lyse errechnet:

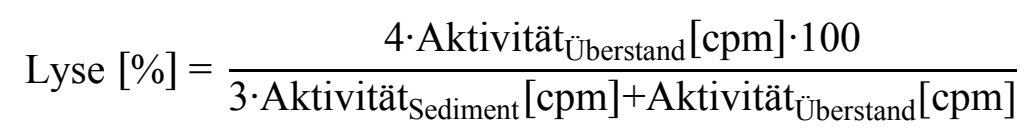

Zur Berücksichtigung der spontanen Lyse wurde nun nach folgender Formel die spezifische, durch die Killerzellen verursachte Lyse bestimmt:

$$
\text { Lyse }_{\text {spezifisch }}=\text { Lyse }_{\text {Probe }} \text { Lyse }_{\text {spontan }}
$$

Zur besseren Vergleichbarkeit verschiedener Tests wurde die relative Lyse der Zielzellklone im Vergleich zu untransfizierten RMA-Zellen der Positivkontrolle bestimmt. Die relative Lyse entsprach dem Quotient aus spezifischer Lyse des betrachteten Messwerts und maximaler Lyse von RMA-Zellen beim größten Killer-Zielzell-Verhältnis von 20:1. Der Anteil lysierter Zellen konnte nun unabhängig von der Qualität der Killerzellen mit anderen Tests verglichen werden. Die Berechnung und Auswertung sowie die graphische Darstellung erfolgten mit Microsoft Excel 2010. 


\section{Ergebnisse}

Die Cathepsin-B-Expression von RMA-Zellen wurde durch Expression der CBG- und MCBG-Fusionsproteine verändert. In Zytotoxizitätstests wurde untersucht, ob diese Veränderungen Einfluss auf die Lyse der Zellen durch zytotoxische T-Lymphozyten hatten.

Bei allen Messungen wurden zur Erfassung nicht Cathepsin-B-spezifischer Effekte der Transfektion immer zwei RMA-Klone verwendet, die durch Transfektion mit dem CAG-PEGFP-1-Vektor eGFP exprimierten, in ihrer Cathepsin-B-Expression aber nicht verändert waren. Diese wurden als Klon LV-2 und Klon LV-5 bezeichnet. Beide Klone waren bereits vorhanden.

Zur Übersicht wurden in den folgenden Abbildungen untransfizierte RMA-Zellen in violett, LV-Klone in grau, CBG-Klone in rot und MCBG-Klone in blau dargestellt.

\subsection{Herstellung der CBG-Klone}

Zur Untersuchung, ob die Überexpression von lysosomalem Cathepsin B die Lyse von Tumorzellen durch zytotoxische T-Zellen beeinflusst, wurden RMA-Zellen mit dem CBGKonstrukt transfiziert. Das Konstrukt enthielt ein Fusionsgen aus Cathepsin B und eGFP, das durch den CAG-Promotor reguliert wurde.

Der offene Leserahmen des murinen Cathepsin B wurde in den CAG-PEGFP-1-Vektor einkloniert. Durch PCR mit den überhängenden Primern Primer-CBG-fwd und Primer-CBG-rev wurden Restriktionsschnittstellen und eine Kozak-Sequenz an den offenen Leserahmen der Cathepsin-B-cDNA angefügt. Im Anschluss wurden durch Restriktionsverdau des PCR-Produkts und des CAG-PEGFP-1-Vektors mit EcoRI und SacI an beiden Enden Schnittstellen mit überhängenden Enden erzeugt. Diese entsprachen sich bei Insert und Vektor so, dass bei der anschließenden Ligation das Insert nur in korrekter Orientierung in den Vektor eingefügt werden konnte. Um zu verhindern, dass der Vektor auch mit sich selbst ligieren konnte, wurde er vor der Ligation dephosphoryliert. In Abb. 4 ist eine Agarosegelelektrophorese von Vektor und Insert dargestellt.

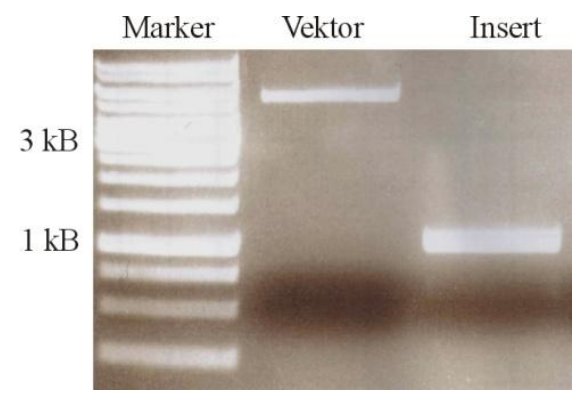

Abb. 4: Agarosegelelektrophorese von Vektor und Insert des CBG-Konstrukts

Die Agarosegelelektrophorese zeigt Vektor und Insert vor der Ligation. Die DNA-Ladder $1 \mathrm{~kb}$ diente dem Größenvergleich. Der aufgeschnittene Vektor hatte eine Größe von 5.500 bp, das Insert eine Größe von ca. $1.000 \mathrm{bp}$.

Mit dem CBG-Plasmid wurden nun mittels Elektroporation elektrokompetente TOP10 E. coli-Bakterien transformiert. Unter Kanamycin-Selektion konnten erfolgreich transformierte Bakterienklone als Kolonien geerntet und analysiert werden. Zunächst wurden Kanamycin-resistente Kolonien mittels Kolonie-PCR auf das Vorliegen des Inserts 
getestet. Im Anschluss wurde die DNA aus Flüssigkulturen der positiv getesteten Kolonien isoliert und mit den zur Klonierung verwendeten Restriktionsenzymen EcoRI und SacI verdaut. Das Insert konnte so in der Agarosegelelektrophorese nachgewiesen werden (Abb. 5). Um auch die Orientierung des Inserts im Vektor zu überprüfen, wurde außerdem ein Restriktionsverdau mit BglII durchgeführt, welches so in Insert und Vektor schnitt, dass das entstehende Bandenmuster im Agarosegel Aufschluss über die Orientierung des Inserts gab (nicht dargestellt).

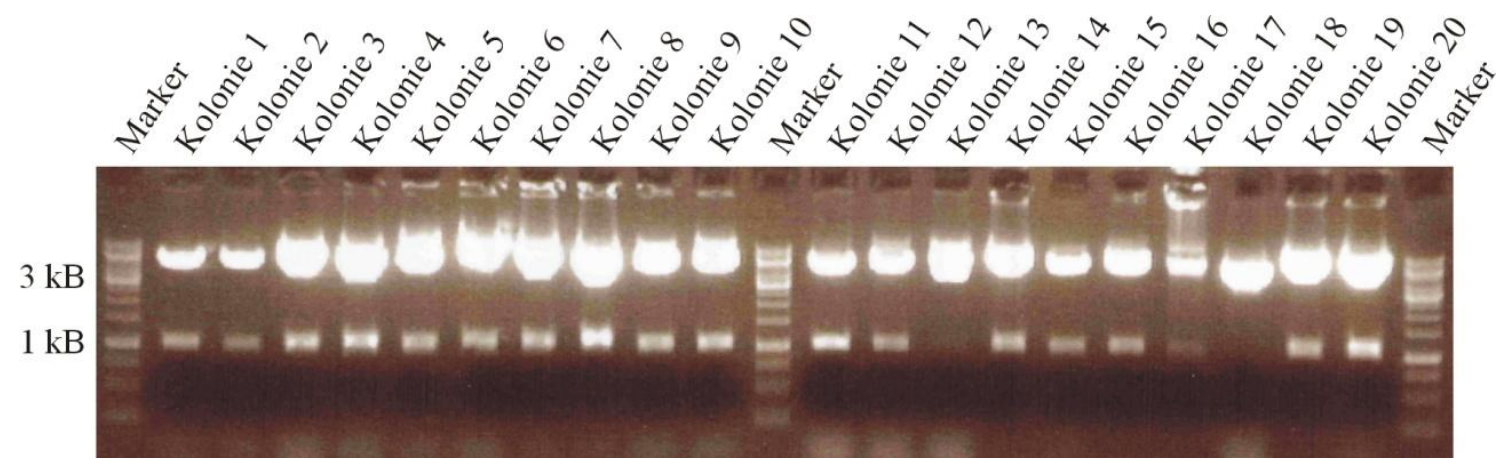

Abb. 5: Agarosegelelektrophorese des Testverdaus des CBG-Plasmids

Dargestellt ist der Testverdau aufgereinigter Plasmide von 20 in der Kolonie-PCR positiven Flüssigkulturen mit den zur Klonierung verwendeten Restriktionsenzymen EcoRI und SacI. Die DNA-Ladder $1 k b$ diente der Größenbestimmung. Alle Kolonien zeigten im Bereich von 5.500 bp den CAG-PEGFP-1-Vektor ohne Insert. Dem Insert entsprach die Bande bei $1 \mathrm{~kb}$ der Kolonien 1-12, 14-16 sowie 19 und 20. Zur weiteren Plasmidpräparation wurde die Kolonie 11 verwendet.

Alle Kolonien, die das Plasmid mit Insert in korrekter Orientierung enthielten, wurden eingefroren. Eine Kolonie wurde ausgewählt, um größere Mengen endotoxinfreier Plasmid-DNA durch quantitative Nukleinsäurepräparation herzustellen. Zum Ausschluss eventueller Mutationen wurde das Plasmid anschließend sequenziert. Die verwendeten Sequenzierprimer Seq-Primer-PEGFP-1-fwd und Seq-Primer-PEGFP-1-rev lagen vor und hinter dem Insert, sodass von beiden Seiten jeweils ein Teil der Klonierungsschnittstellen des Vektors, die verwendete Restriktionsschnittstelle und das Insert selbst analysiert werden konnten. Die kontrollierten Sequenzen überschnitten sich in der Mitte, sodass sowohl die gesamte Sequenz des Inserts als auch die Orientierung des Inserts im Vektor überprüft wurden. Das Insert lag bei dem zur Transfektion verwendeten Plasmid mutationsfrei und in korrekter Orientierung im Vektor. Abb. 6 zeigt ein Schema des endgültigen Aufbaus des CBG-Expressionsplasmids. 


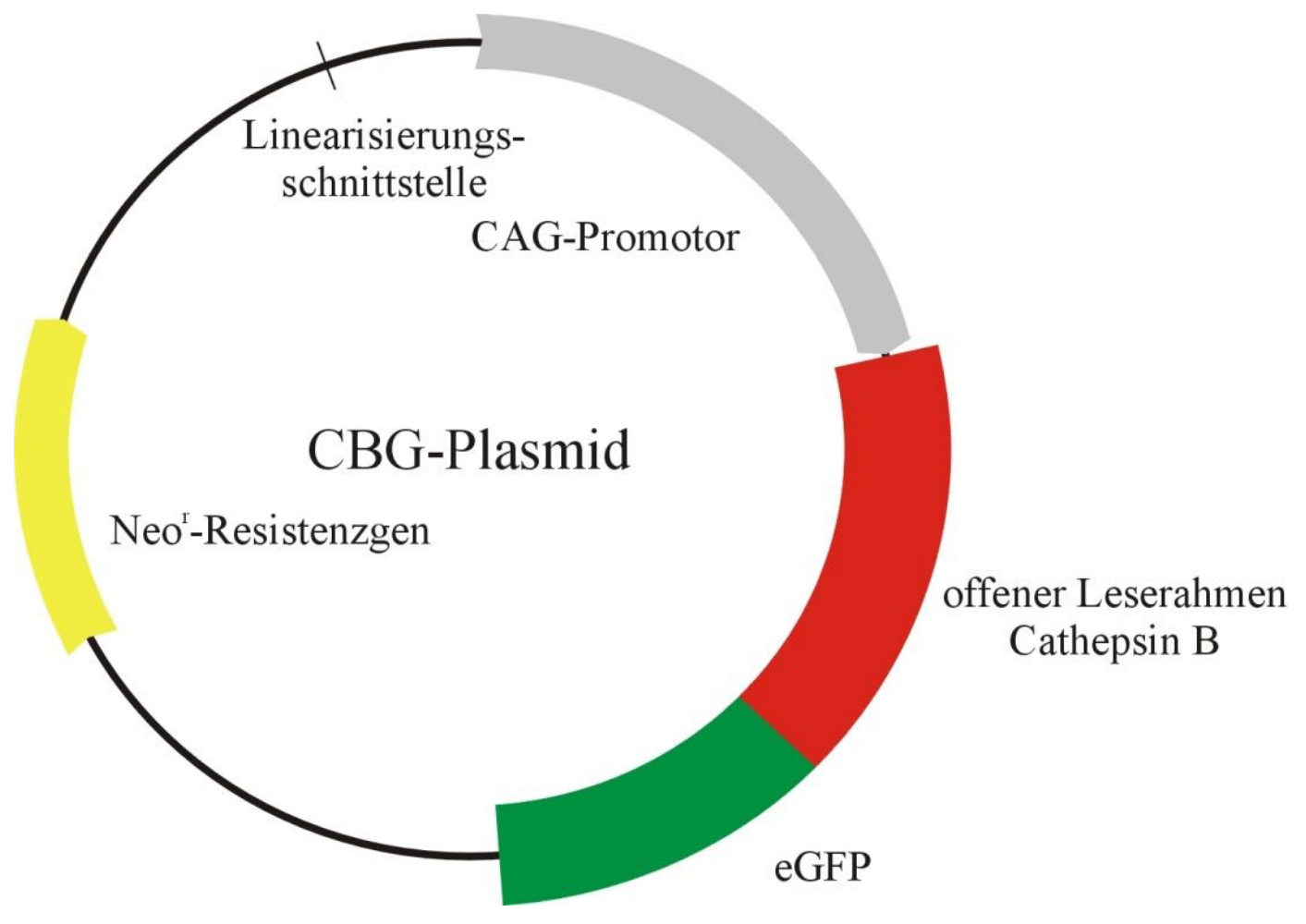

Abb. 6: Schema des CBG-Expressionsplasmids

Das CBG-Expressionsplasmid basiert auf dem PEGFP-1-Vektor. Der CAG-Promotor (grau) kontrollierte die Expression eines Fusionsproteins aus Cathepsin B (rot) und eGFP (grün). Außerdem enthielt das Plasmid die Geneticin-Resistenz Neo ${ }^{\mathrm{r}}$. Ebenfalls dargestellt ist die ApaLI-Linearisierungsschnittstelle.

Vor der Transfektion wurde das Plasmid durch Restriktionsverdau mit ApaLI linearisiert, um die Integration des Konstrukts in das Genom zu erleichtern. Die Transfektion selbst erfolgte durch Elektroporation exponentiell wachsender RMA-Zellen in Anwesenheit des linearisierten Konstrukts. Die Selektion transfizierter Zellen, die das CBG-Fusionsprotein exprimierten, erfolge durch Zugabe von Geneticin zum Kulturmedium. Die Transfektionsrate konnte durchflusszytometrisch als Anteil eGFP-exprimierender Zellen bestimmt werden.

Selbst durch umfangreiche Optimierungsversuche der Elektroporationsbedingungen konnten nur geringe Transfektionsraten erreicht werden. Daher wurden, im Anschluss an die Transfektion, eGFP-exprimierende Zellen durch Sortierung angereichert. Das Ergebnis der Sortierung ist in Abb. 7 dargestellt. 


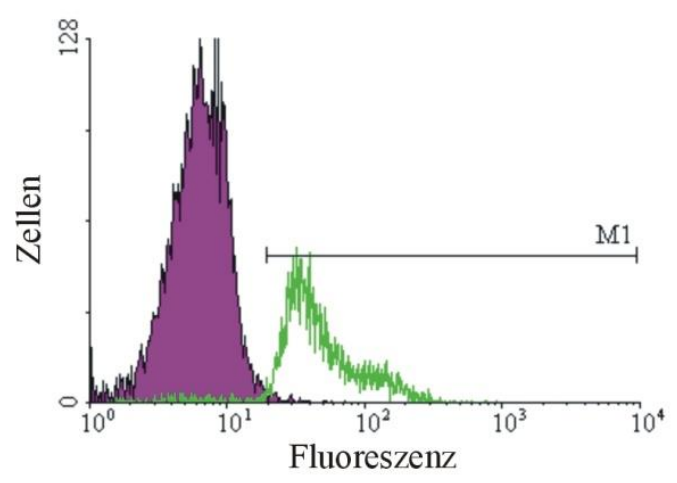

Abb. 7: Durchflusszytometrische Bestimmung der eGFP-Fluoreszenz vor und nach der Sortierung Zur Anreicherung von Zellen, die das CBG-Konstrukt exprimierten, wurden die Zellen nach der Transfektion sortiert. Die violett Kurve beschreibt die eGFP-Fluoreszenz von 10.000 Zellen vor der Sortierung; die grüne Kurve beschreibt die eGFP-Fluoreszenz von 5.000 eGFP-positiv sortierter Zellen. Der Marker M1 zeigt das zur Sortierung verwendete Gate.

Mit den angereicherten eGFP-exprimierenden Zellen konnten durch Grenzverdünnungsreihen (limiting dilution) Zelllinien hergestellt werden, die nur auf eine einzige transfizierte Zelle zurückgingen. Bei allen so erhaltenen Klonen wurde die Expressionsstärke des CBGFusionsproteins durch durchflusszytometrische Messung der eGFP-Fluoreszenz bestimmt. Die Klone CBG-3 und CBG-5 wurden für die weitere Charakterisierung der Cathepsin-BExpression sowie anschließende funktionelle Tests ausgewählt.

\subsection{Herstellung der MCBG-Klone}

Zur Expression von membrangebundenem Cathepsin B wurde das MCBG-Konstrukt in RMA-Zellen eingebracht.

Das MCBG-Konstrukt basiert, wie das CBG-Konstrukt, auf dem PEGFP-1-Vektor mit CAG-Promotor. Das Insert besteht hier aus einem Gen, das für ein Fusionsprotein aus Cathepsin B und der Transmembrandomäne des H2K-Moleküls kodiert. Eine reife Form des Cathepsin B wurde über eine Verbindungssequenz mit der Transmembrandomäne des H2KMoleküls verbunden, mit dem Ziel, die Protease auf der Außenseite der Zellmembran zu verankern. Eine vorgeschaltete Leader-Sequenz, ebenfalls aus dem H2K-Molekül, sollte das Fusionsprotein zur Zelloberfläche leiten.

Zur selektiven Detektierbarkeit des MCBG-Fusionsproteins auf der Zelloberfläche wurde eine Nukleotidsequenz eingefügt, die für eine am extrazellulären $\mathrm{N}$-Terminus der Cathepsin-B-Kette hängende Aminosäuresequenz des Hämagglutinins (HA-Tag) kodierte. Außerdem enthielt das in Abb. 8 dargestellte MCBG-Konstrukt, wie schon das CBG-Konstrukt, das eGFP-Gen des PEGFP-1-Vektors am 3'-Ende des offenen Leserasters. 


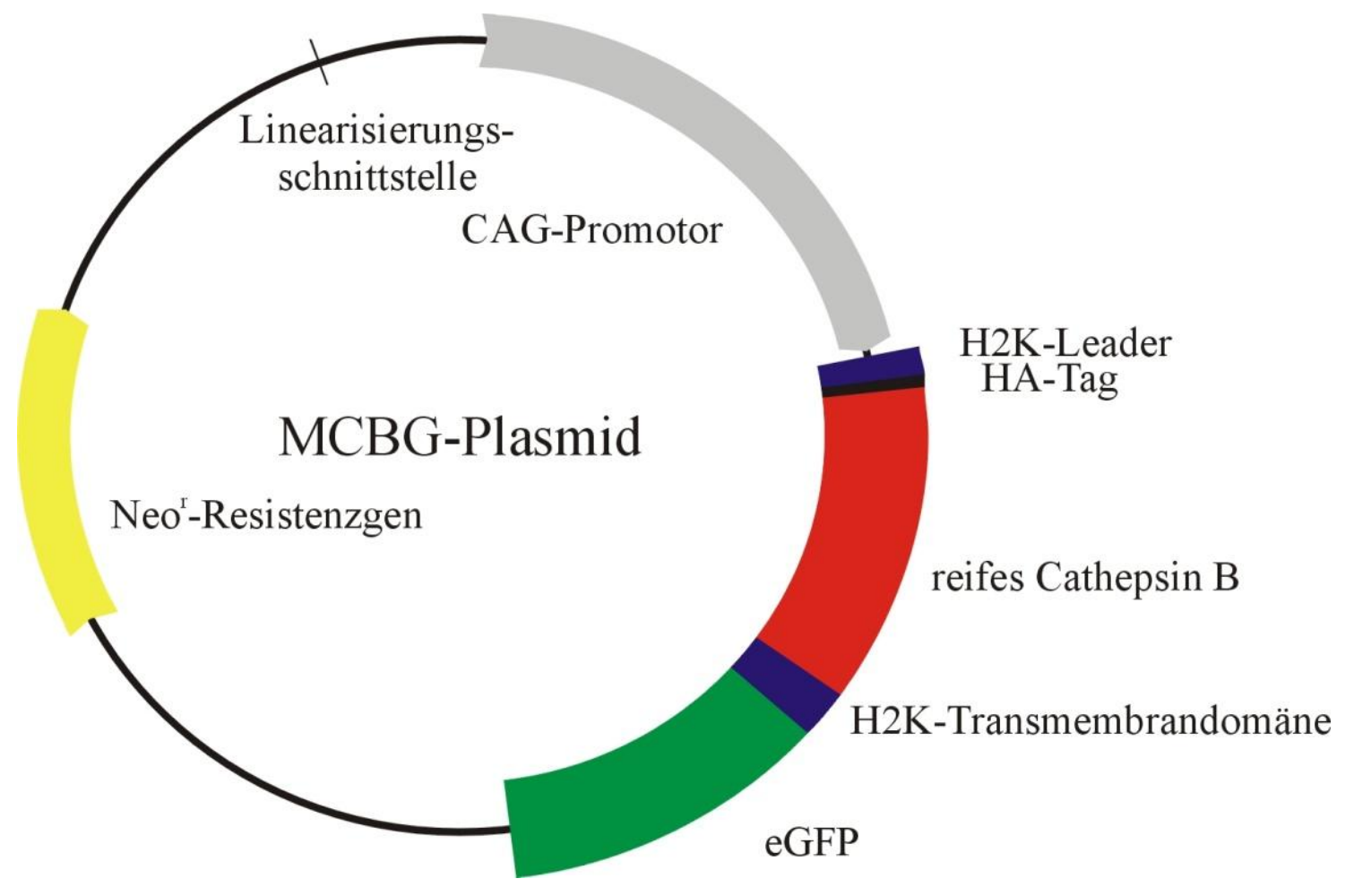

Abb. 8: Schema des MCBG-Expressionsplasmids

Das MCBG-Expressionsplasmid basierte auf dem PEGFP-1-Vektor mit CAG-Promotor (grau). Der für eine einkettige aktive Form von Cathepsin B kodierende Bereich des Cathepsin-B-Gens (rot) wurde mit Teilen des H2K-Gens (blau) sowie dem eGFP-Gen (grün) verbunden. Eine H2K-Leadersequenz am C-Terminus markierte das MCBG-Fusionsprotein zum Transport zur Zellmembran. Der eingefügte HA-Tag (schwarz) diente als extrazelluläre Erkennungssequenz. Als weiteren wichtigen Bestandteil enthielt der Vektor das Geneticin-Resistenzgen Neo ${ }^{\mathrm{r}}$ (gelb). Ebenfalls dargestellt ist die ApaLI-Linearisierungsschnittstelle.

Aufgrund der Komplexität des Inserts wurde darauf verzichtet, es selbst zu klonieren. Mit dem Programm GENtle wurde unter Verwendung der NCBI-Datenbanken eine klonierungsfähige DNA-Sequenz inklusive Restriktionsschnittstellen und Kozak-Sequenz erstellt. Diese wurde zur Expression im Mausmodell optimiert und von der Firma Life Technologies $^{\mathrm{TM}}$ synthetisiert. Die bestellte Sequenz wurde als Teil eines transformationsfertigen Plasmids geliefert.

Nach Transformation in TOP10 E. coli-Bakterien wurde das gelieferte Plasmid durch qualitative Nukleinsäurepräparation aus einer Flüssigkultur isoliert. Mit Hilfe der zur Klonierung eingefügten Restriktionsschnittstellen von HindIII und BamHI wurde die synthetisierte Sequenz aus dem pMA-Vektor ausgeschnitten und im Agarosegel dargestellt. Nach anschließender Rückgewinnung der DNA aus dem Agarosegel wurde auch der CAG-PEGFP-1-Vektor mit den gleichen Restriktionsenzymen so verdaut, dass die Ligation wiederum nur in korrekter Orientierung ablaufen konnte. Der Vektor wurde zur Verhinderung der Selbstligation außerdem dephosphoryliert. Insert und Vektor sind im Agarosegel in Abb. 9 dargestellt. 


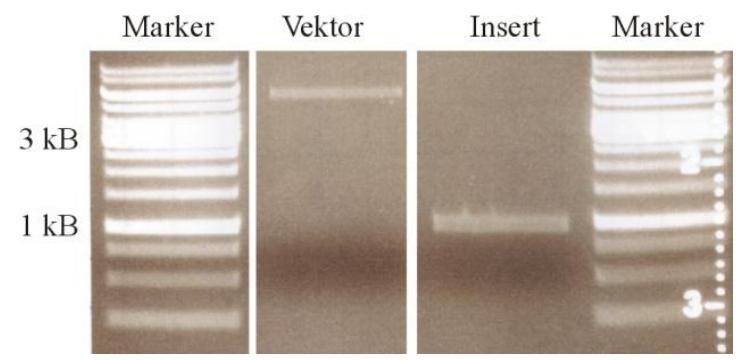

Abb. 9: Agarosegelelektrophorese von Insert und Vektor des MCBG-Konstrukts

Die Agarosegelelektrophorese zeigt Insert und Vektor vor der Ligation. Die DNA-Ladder $1 \mathrm{~kb}$ diente dem Größenvergleich. Der mit HindIII und BamHI aufgeschnittene Vektor hatte eine Größe von 5.500 bp, das Insert eine Größe von ca. 1.000 bp.

Das ligierte MCBG-Plasmid wurde nun, wie schon bei der Herstellung der CBG-Klone beschrieben, in TOP10 E. coli-Bakterien vermehrt und nach Sequenzkontrolle in RMA-Zellen transfiziert. Abb. 10 zeigt 20 Bakterienkolonien nach der Transformation im Testverdau.

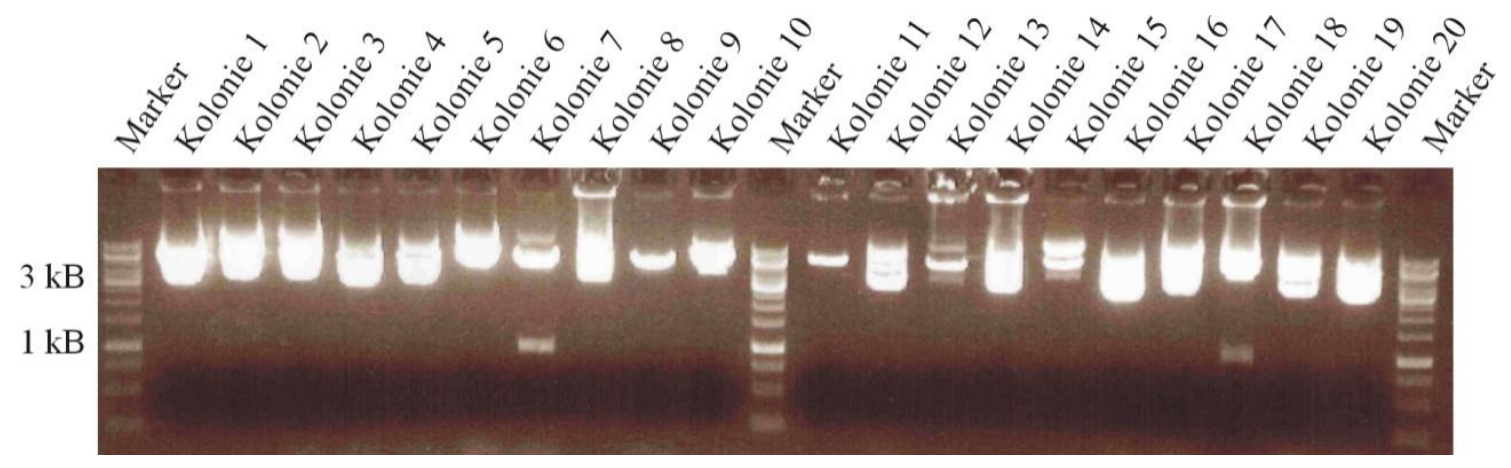

Abb. 10: Agarosegelelektrophorese des Testverdaus des MCBG-Plasmids

Dargestellt ist der Testverdau aufgereinigter Plasmide von 20 Flüssigkulturen mit den zur Klonierung verwendeten Restriktionsenzymen HindIII und BamHI. Die DNA-Ladder $1 \mathrm{~kb}$ diente der Größenbestimmung. Alle Kolonien zeigten im Bereich von 5.500 bp den CAG-PEFGP-1-Vektor ohne Insert. Dem Insert entsprach die Bande bei 1.000 bp der Kolonien 7 und 18. Zur weiteren Plasmidpräparation wurde Kolonie 7 verwendet.

Die nach Optimierung der Elektroporationsbedingungen erreichten Transfektionsraten ermöglichten die Herstellung stabiler Klone durch Grenzverdünnungsreihen, auch ohne vorangehende Sortierung (Abb. 11). Für die weitere Analyse sowie die Zytotoxizitätstests wurden die Klone MCBG-2 und MCBG-4 ausgewählt. 
A

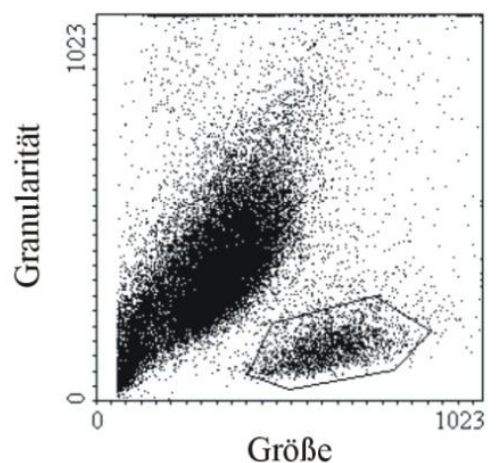

B

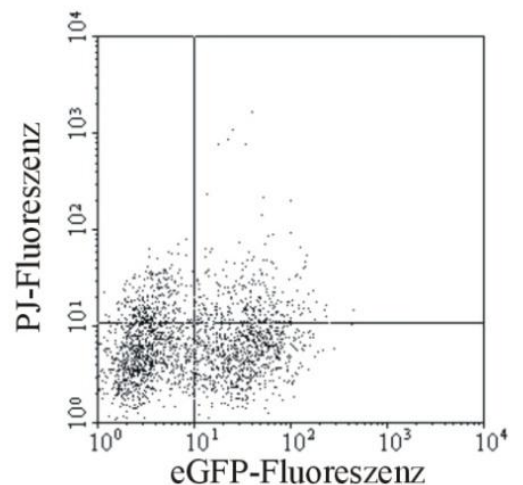

Abb. 11: Durchflusszytometrische Analyse der eGFP-Fluoreszenz der mit dem MCBG-Konstrukt transfizierten Zellen

Drei Tage nach der Transfektion mit dem MCBG-Konstrukt wurde, direkt vor der klonalen Vereinzelung, die eGFP-Fluoreszenz der überlebenden Zellen durchflusszytometrisch ermittelt.

A Durch Bestimmung von Granularität und Größe wurde zunächst die Population lebender Zellen ausgewählt (Gate). Die anderen Messungen entsprachen Zellen, die entweder bei der Transfektion oder danach im Geneticin-haltigen Medium gestorben waren.

B Auftragung der Propidiumiodid-Fluoreszenz gegenüber der eGFP-Fluoreszenz der in A gegateten Zellen. Vitale Zellen wiesen nur eine geringe Propidiumiodid-Fluoreszenz auf (beide unteren Quadranten). Unter den lebenden Zellen mit geringer Propidiumiodid-Fluoreszenz waren $43 \%$ eGFP-positiv (unterer rechter Quadrant). 


\subsection{Durchflusszytometrische Untersuchungen}

\subsubsection{Nachweis der durch das LV-Konstrukt induzierten eGFP-Expression}

Das LV-Konstrukt sowie die beiden Cathepsin-B-enthaltenden Konstrukte CBG und MCBG enthielten das eGFP-Gen. Daher konnte über die eGFP-Expression der transfizierten Zellen die Abschätzung der Expressionsstärke der Konstrukte erfolgen. Die eGFP-Fluoreszenz der Zellen wurde im Vergleich zur Fluoreszenz untransfizierter RMA-Zellen bestimmt.

Die Expression des durch das LV-Konstrukt kodierten eGFP-Proteins in den Zellen der Klone LV-2 und LV-5 konnte durch eine deutliche eGFP-Fluoreszenz dieser Zellen nachgewiesen werden (Abb. 12). Sie wurden in den folgenden Messungen als Kontrollzelllinien zum Ausschluss unspezifischer Einflüsse der Transfektion und der eGFP-Expression verwendet.

A

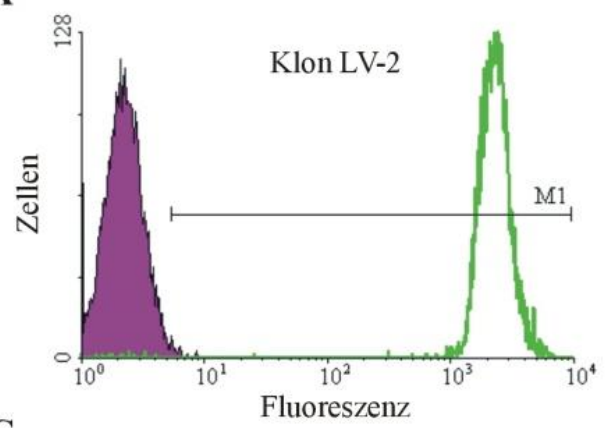

C

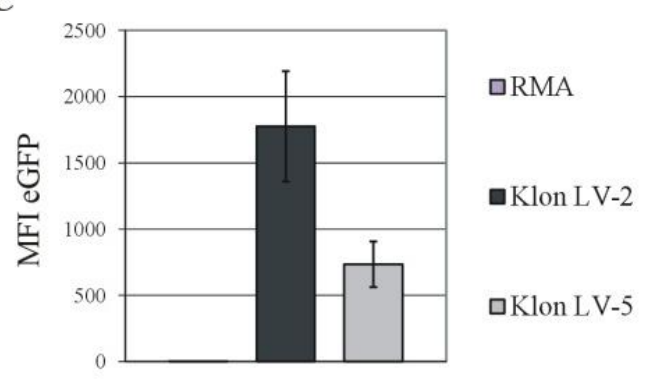

B

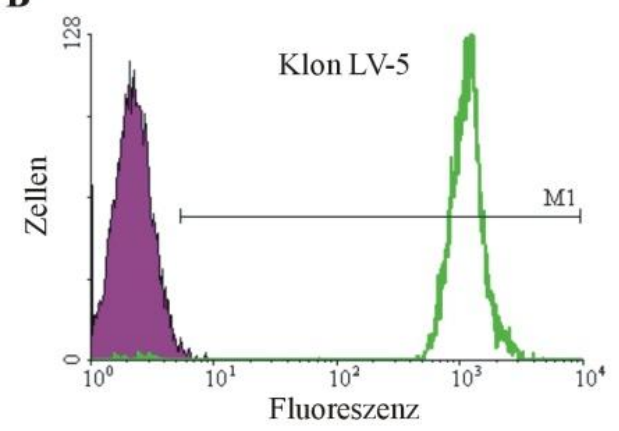

Abb. 12: Durchflusszytometrische Analyse der eGFP-Expression von Zellen der Klone LV-2 und LV-5 Die Darstellung zeigt 10.000 Zellen, entsprechend ihrer Fluoreszenzintensität aufgetragen. Die Autofluoreszenz untransfizierter Zellen wurde im Bereich $10^{0}$ bis $10^{1}$ eingestellt. Der Marker M1 beschreibt den Fluoreszenzbereich, der als eGFP-positiv definiert wurde. Weniger als 0,5\% der untransfizierten Zellen lagen in diesem Bereich.

A Bei gleicher Einstellung wie bei den untransfizierten Zellen zeigte sich bei Zellen des Klons LV-2 eine knapp drei Zehnerpotenzen größere Fluoreszenzintensität. Der Anteil eGFP-positiver Zellen betrug mehr als $99 \%$.

B Auch Zellen des Klons LV-5 zeigten eine gesteigerte Fluoreszenzintensität. Die Veränderung betrug hier mehr als zwei Zehnerpotenzen. Es waren ebenfalls mehr als $99 \%$ der Zellen eGFP-positiv.

C Dargestellt sind Mittelwert und Standardabweichung von 15 unabhängigen Messungen der mittleren eGFP-Fluoreszenzintensität (MFI eGFP) von untransfizierten RMA-Zellen sowie von Zellen der Klone LV-2 und LV-5. Die mittlere Fluoreszenzintensität der untransfizierten RMA-Zellen war so gering, dass sie im Maßstab der Abbildung nicht sichtbar ist. 


\subsubsection{Nachweis der Expression des CBG-Fusionsproteins}

Die Expression des CBG-Fusionsproteins wurde in der Durchflusszytometrie dargestellt. Die im Vergleich zu untransfizierten RMA-Zellen erhöhte eGFP-Fluoreszenz war auf den eGFP-Teil des CBG-Fusionsproteins zurückzuführen. Zellen beider Klone zeigten eine ähnliche Expressionsstärke. Ihre Fluoreszenzintensität war gegenüber den Kontrollzellen um etwas mehr als eine Zehnerpotenz erhöht. Abb. 13 zeigt eine beispielhafte Messung sowie die Zusammenfassung von insgesamt 15 unabhängigen Messungen.

A

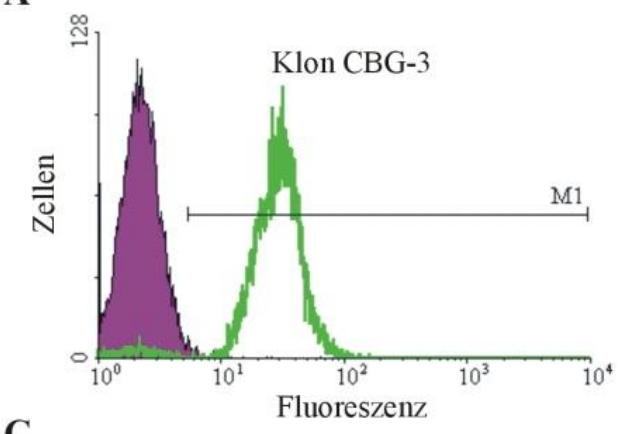

C

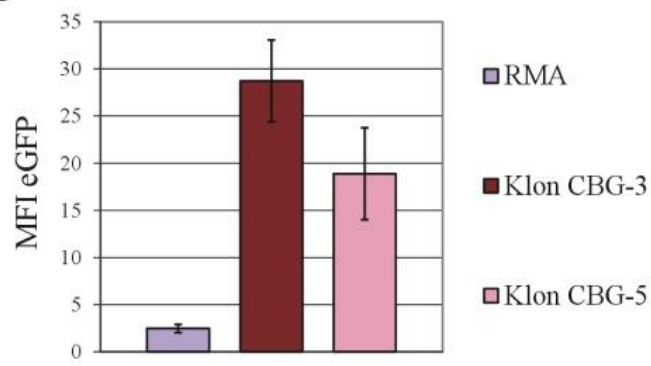

B

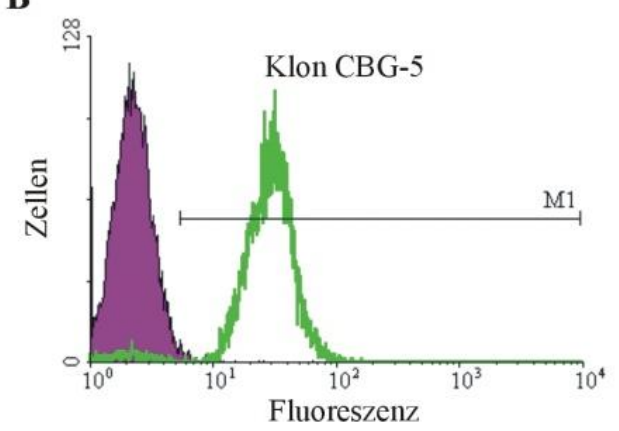

Abb. 13: Durchflusszytometrische Analyse der eGFP-Expression von Zellen der Klone CBG-3 und CBG-5

Die Darstellung zeigt 10.000 Zellen, entsprechend ihrer eGFP-Fluoreszenzintensität aufgetragen.

A Zellen des Klons CBG-3 zeigten eine gesteigerte Fluoreszenzintensität im Vergleich zu untransfizierten Zellen. Der Anteil eGFP-positiver Zellen betrug über $99 \%$.

B Auch Zellen des Klons CBG-5 fluoreszierten deutlich stärker als die Kontrollzellen. Der Anteil eGFP-positiver Zellen lag ebenfalls bei über $99 \%$.

C Das Diagramm zeigt Mittelwert und Standardabweichung von 15 unabhängigen Messungen der mittleren eGFP-Fluoreszenzintensität (MFI eGFP) untransfizierter RMA-Zellen sowie von Zellen der Klone CBG-3 und CBG-5.

\subsubsection{Nachweis der Expression des MCBG-Fusionsproteins}

Die Expression des durch das MCBG-Konstrukt kodierten MCBG-Fusionsproteins in den Zellen der Klone MCBG-2 und MCBG-4 wurde durch durchflusszytometrische Bestimmung der eGFP-Fluoreszenz im Vergleich $\mathrm{zu}$ untransfizierten RMA-Zellen untersucht. Die Expressionsstärke der Zellen beider Klone war in etwa gleich. Eine ausgewählte Messung und die Gesamtauswertung sind in Abb. 14 gezeigt. 
A

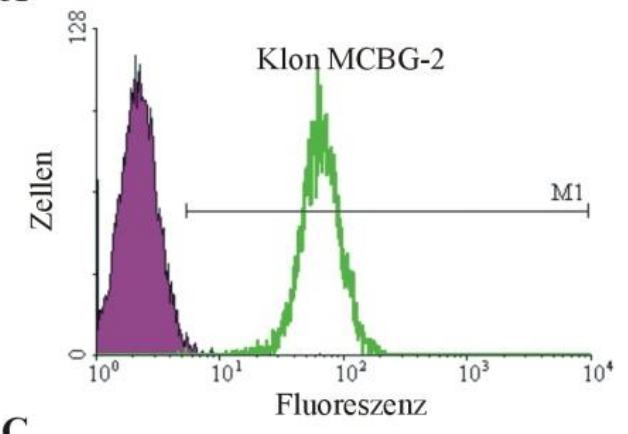

C

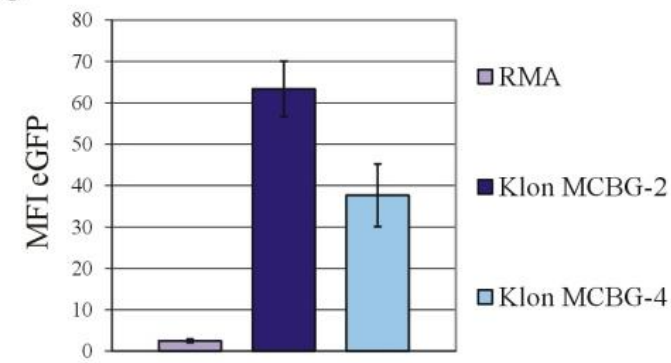

B

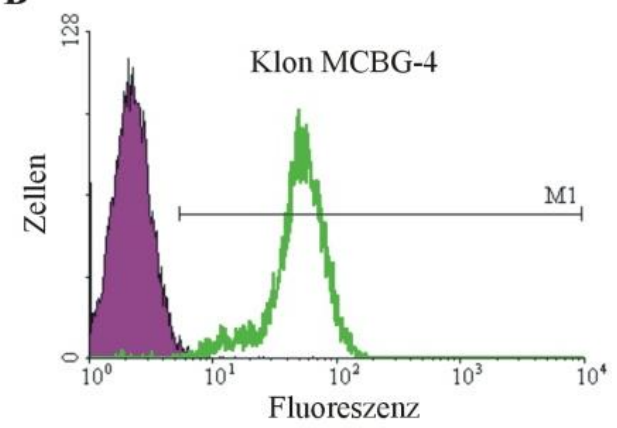

Abb. 14: Durchflusszytometrische Analyse der eGFP-Expression von Zellen der Klone MCBG-2 und MCBG-4

Die Darstellung zeigt 10.000 Zellen, entsprechend ihrer eGFP-Fluoreszenzintensität aufgetragen.

A Zellen des Klons MCBG-2 zeigten eine gesteigerte Fluoreszenzintensität im Vergleich zu untransfizierten Zellen. Der Anteil eGFP-positiver Zellen betrug über $99 \%$.

B Auch Zellen des Klons MCBG-4 fluoreszierten deutlich stärker als die Kontrollzellen. Der Anteil der eGFP-positiven Zellen lag bei über $99 \%$.

C Das Diagramm zeigt Mittelwert und Standardabweichung aus 15 unabhängigen Messungen der mittleren eGFP-Fluoreszenzintensität (MFI eGFP) untransfizierter RMA-Zellen sowie von Zellen der Klone MCBG-2 und MCBG-4.

\subsubsection{Gesteigerte zelluläre Cathepsin-B-Expression in Zellen der CBG- und MCBG-Klone}

Zur direkten Untersuchung der Cathepsin-B-Expression wurde die Bindung eines Antikörpers gegen Cathepsin B in fixierten und permeabilisierten Zellen bestimmt. Der eingesetzte Antikörper reagierte sowohl mit endogenem Cathepsin B als auch mit den Fusionsproteinen CBG und MCBG. Durchflusszytometrisch wurde die mittlere Fluoreszenzintensität eines Tri-Color ${ }^{\circledR}$-markierten Sekundärantikörpers gemessen. Bei jeder Messung wurden außerdem die Autofluoreszenz und die Fluoreszenz nur mit Sekundärantikörper behandelter Zellen erfasst. Die Differenz der mittleren Fluoreszenzintensitäten mit und ohne Primärantikörper wurde als spezifische mittlere Fluoreszenzintensität (sMFI) berechnet.

Die durchflusszytometrische Bestimmung der Cathepsin-B-Expression wurde mit Zellen beider LV-Klone, beider CBG-Klone und auch beider MCBG-Klone durchgeführt. In den Zellen der LV-Klone war endogenes Cathepsin B nachweisbar. Die im Vergleich zu den Zellen der LV-Klone verstärkte Antikörperbindung in Zellen der Klone CBG-2 und CBG-5 sowie in Zellen der Klone MCBG-2 und MCBG-4 zeigte eine Steigerung der Cathepsin-BMenge in den Zellen der CBG- und MCBG-Klone. Es wurden drei unabhängige Messungen durchgeführt. Abb. 15 zeigt eine beispielhafte Messung und die Gesamtauswertung aller Messungen. 
A

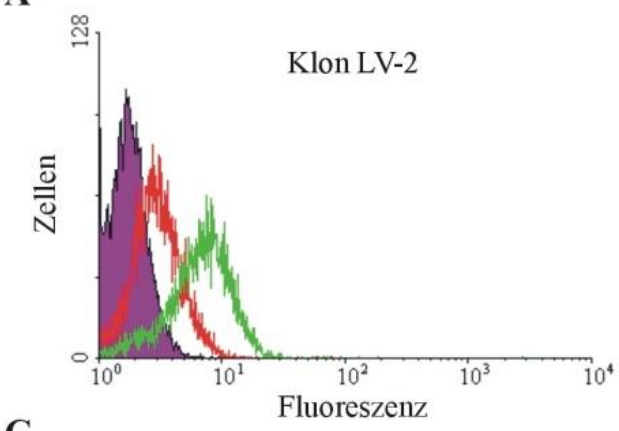

C

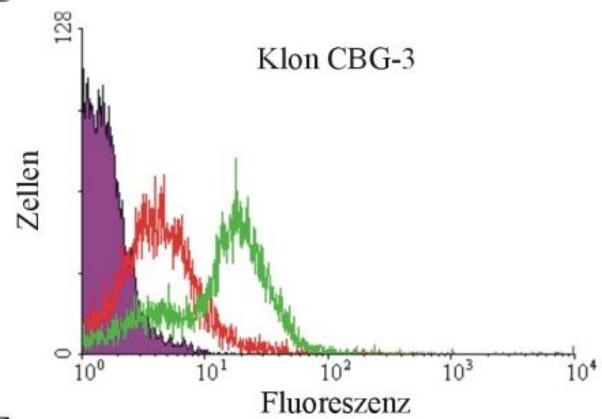

E

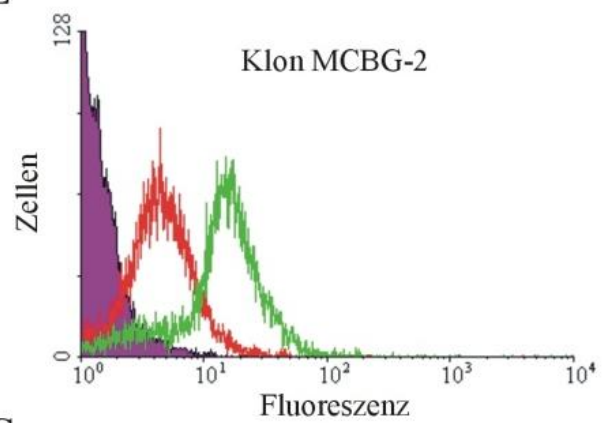

G

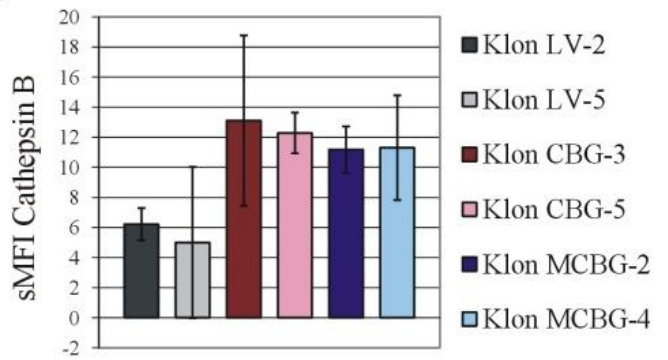

B

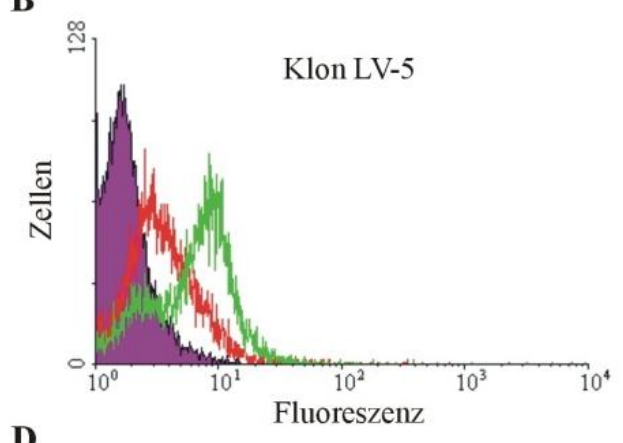

D

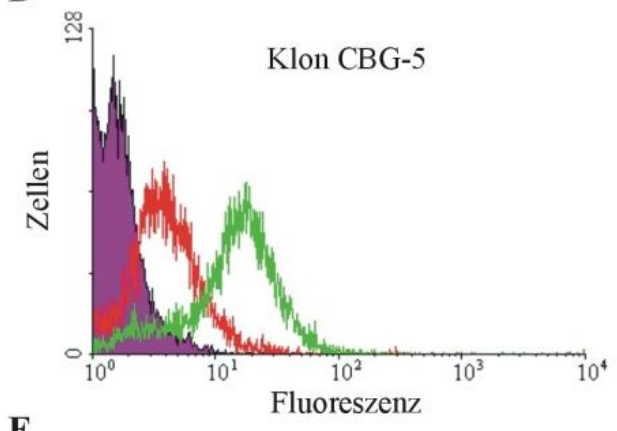

F

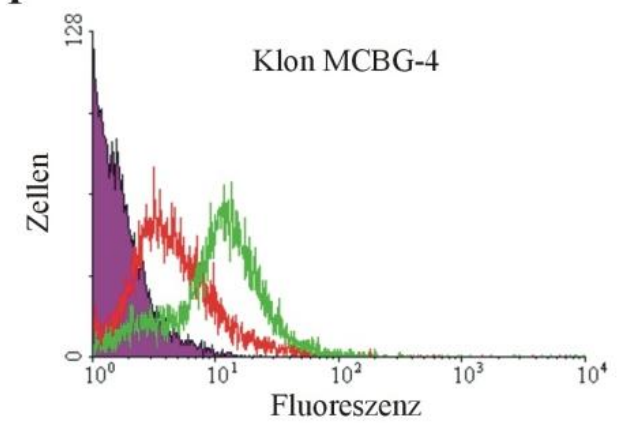

Abb. 15: Durchflusszytometrische Analyse der Cathepsin-B-Expression an permeabilisierten Zellen

Im Histogramm sind die Zellen nach ihrer Fluoreszenzintensität sortiert aufgetragen. Violett gefüllt ist die Eigenfluoreszenz der Zellen ohne Antikörper dargestellt, Rot zeigt die Fluoreszenz der Sekundärantikörperkontrollen und Grün die Fluoreszenz mit Primär- und Sekundärantikörper. Der Unterschied zwischen roter und grüner Kurve gibt die Bindung des Primärantikörpers in den Zellen an.

A und B Die mit Primärantikörper behandelten Zellen der Klone LV-2 und LV-5 wiesen eine höhere Fluoreszenzintensität als die Sekundärantikörperkontrollen auf.

C und D Die Messung von Zellen der Klone CBG-3 und CBG-5 zeigte ebenfalls eine Erhöhung der Fluoreszenzintensität der Zellen der Primärantikörperfärbungen gegenüber den Sekundärantikörperkontrollen.

$\mathbf{E}$ und $\mathbf{F}$ Auch bei Zellen der Klone MCBG-2 und MCBG-4 wurde die Bindung des Antikörpers gegen Cathepsin B im Vergleich von Primärantikörperfärbung und Sekundärantikörperkontrolle gezeigt.

G Die spezifischen mittleren Fluoreszenzintensitäten (sMFI) von Zellen der LV-Klone (grau), der CBG-Klone (rot) und der MCBG-Klone (blau) sind als Mittelwerte mit Standardabweichungen aus drei unabhängigen Messungen angegeben. 


\subsubsection{Geringgradig gesteigerte oberflächengebundene Cathepsin-B-Expression von Zellen der CBG- und MCBG-Klone}

Neben dem Einfluss einer veränderten Cathepsin-B-Gesamtmenge sollte auch der Einfluss von zellmembrangebundenem Cathepsin B auf die Lyse durch zytotoxische T-Zellen bestimmt werden. Besonders die MCBG-Klone dienten dem Ziel der Expression von Cathepsin B auf der Zelloberfläche, aber auch die Oberflächenexpression von Cathepsin B an den Zellen der CBG-Klone wurde untersucht.

Extrazellulär gebundenes Cathepsin B wurde durch Immunfärbung nicht permeabilisierter Zellen nachgewiesen. Der eingesetzte Antikörper reagierte sowohl mit dem endogenen Cathepsin B als auch mit den Cathepsin-B-Anteilen der CBG- und MCBG-Fusionsproteine. Als Vergleich dienten die Messungen des extrazellulären Cathepsin B auf der Oberfläche von Zellen der LV-Klone.

Unspezifische Bindungen des fluoreszenzmarkierten Sekundärantikörpers führten zu starker Fluoreszenz der Sekundärantikörperkontrollen und erschwerten die Messungen. Auf der Oberfläche der Zellen der LV-Klone war keine Bindung des anti-Cathepsin-B-Antikörpers nachweisbar, eine oberflächenassoziierte Cathepsin-B-Expression konnte bei den Zellen der LV-Klone durchflusszytometrisch nicht gezeigt werden. Die Zellen der CBG- und MCBG-Klone wiesen hingegen eine schwache spezifische Fluoreszenz auf, sodass hier eine geringe oberflächenassoziierte Cathepsin-B-Expression dargestellt werden konnte. Die Zellen der MCBG-Klone zeigten dabei keine stärkere membrangebundene Cathepsin-BExpression als die Zellen der CBG-Klone. Abb. 16 zeigt das Beispiel einer Messung und die Gesamtauswertung der spezifischen Fluoreszenzen. 
A

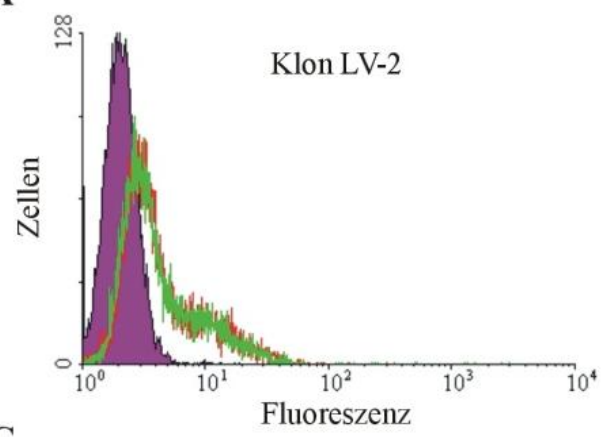

C

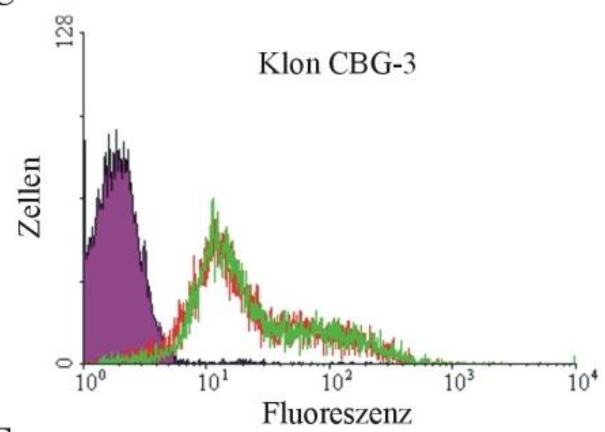

$\mathbf{E}$

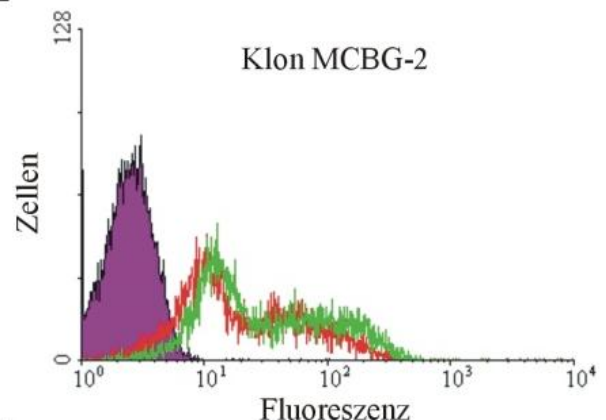

G

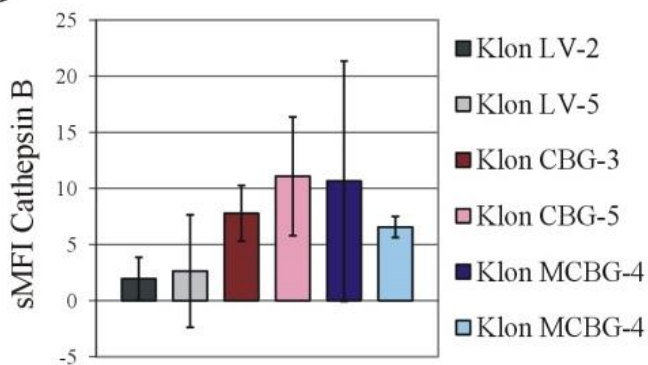

B
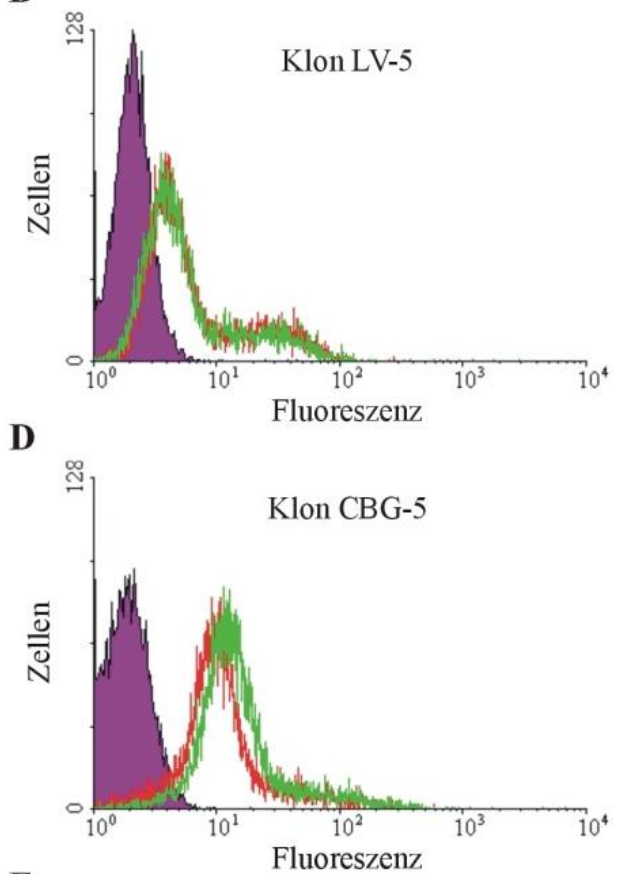

$\mathbf{F}$

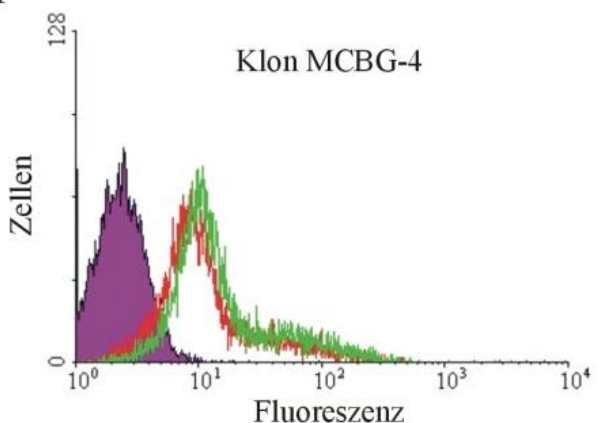

Abb. 16: Durchflusszytometrische Analyse der Cathepsin-B-Oberflächenexpression

Im Histogramm sind die Zellen nach ihrer Fluoreszenzintensität sortiert aufgetragen. Violett gefüllt ist die Eigenfluoreszenz der Zellen ohne Antikörper dargestellt, Rot zeigt die Fluoreszenz der Sekundärantikörperkontrollen und Grün die Fluoreszenz mit Primär- und Sekundärantikörper. Der Unterschied zwischen roter und grüner Kurve gibt die Bindung des Primärantikörpers auf der Oberfläche der Zellen an.

A und B Bei den Zellen der Klone LV-2 und LV-5 bestanden keine Unterschiede der Fluoreszenzintensitäten der Primärantikörperfärbungen und der Sekundärantikörperkontrollen.

C und D Die Messung mit Zellen der Klone CBG-3 und CBG-5 zeigte eine geringe Erhöhung der Fluoreszenzintensitäten der Zellen der Primärantikörperfärbungen gegenüber denen der Sekundärantikörperkontrollen. Allerdings war die Fluoreszenz der Sekundärantikörperkontrollen sehr stark.

$\mathbf{E}$ und $\mathbf{F}$ Auch bei Zellen der Klone MCBG-2 und MCBG-4 waren die Fluoreszenzen der Primärantikörperfärbungen größer als die der Sekundärantikörperkontrollen. Diese waren allerdings auch hier wieder sehr stark.

G Angegeben sind Mittelwerte und Standardabweichungen der spezifischen mittleren Fluoreszenzintensitäten (sMFI) aus je drei unabhängigen Messungen von Zellen beider LV-Klone (grau), beider CBG-Klone (rot) und beider MCBG-Klone (blau). 


\subsubsection{Kein Nachweis einer oberflächengebundenen Expression des MCBG- Fusionsproteins mit Hilfe des HA-Tags}

Da die oberflächengebundene Cathepsin-B-Expression auf den Zellen der MCBG-Klone nachgewiesen werden konnte, diese aber nicht stärker war als die oberflächenassoziierte Cathepsin-B-Expression der Zellen der CBG-Klone, wurde nun direkt die oberflächengebundene Expression des MCBG-Fusionsproteins untersucht. Am N-terminalen extrazellulären Ende des Cathepsin-B-Anteils enthielt das MCBG-Fusionsprotein zu diesem Zweck die Aminosäuresequenz YPYDVPDYA des Hämagglutinins, die mit einem anti-HA-Tag-Antikörper spezifisch nachgewiesen werden sollte. Die Zellen der LV-Klone exprimierten keinen HA-Tag und dienten als Negativkontrollen.

Die Zellen beider MCBG-Klone zeigten wie die Zellen der LV-Klone keine Bindung des anti-HA-Tag-Antikörpers auf ihrer Oberfläche. Die oberflächengebundene Expression des MCBG-Fusionsproteins war mit Hilfe des HA-Tags in der Durchflusszytometrie nicht nachweisbar. In Abb. 17 ist eine exemplarische Messung und die Zusammenfassung aller Messungen dargestellt. 
A

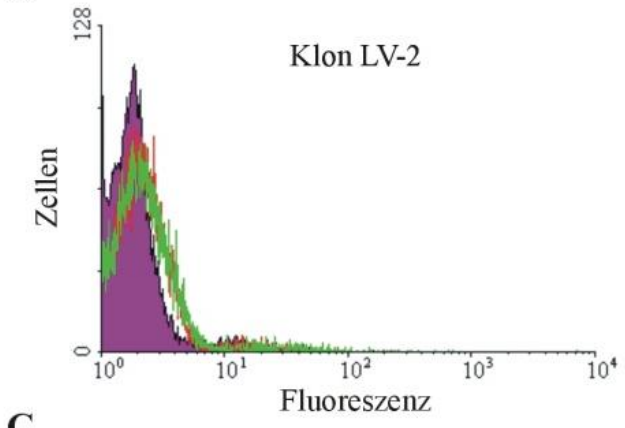

C

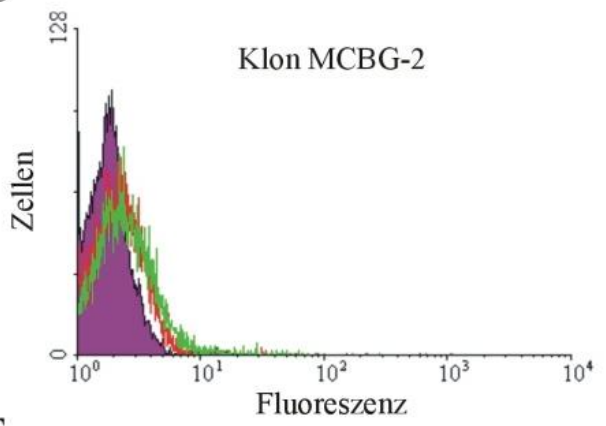

$\mathbf{E}$

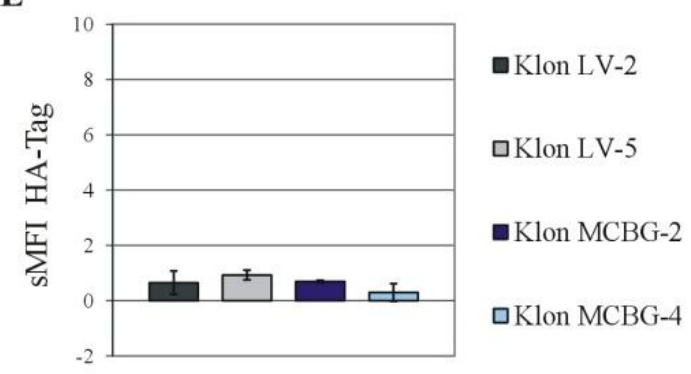

B

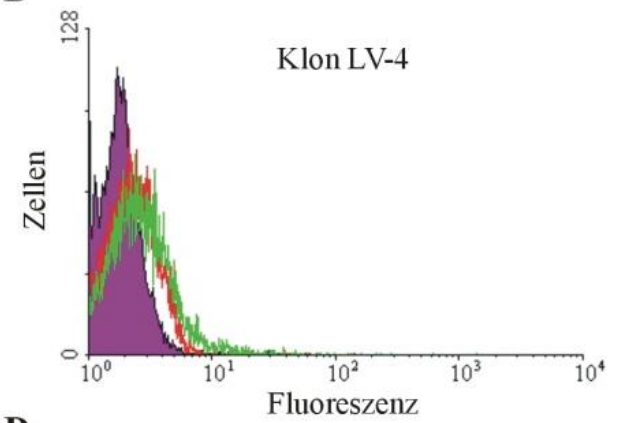

D

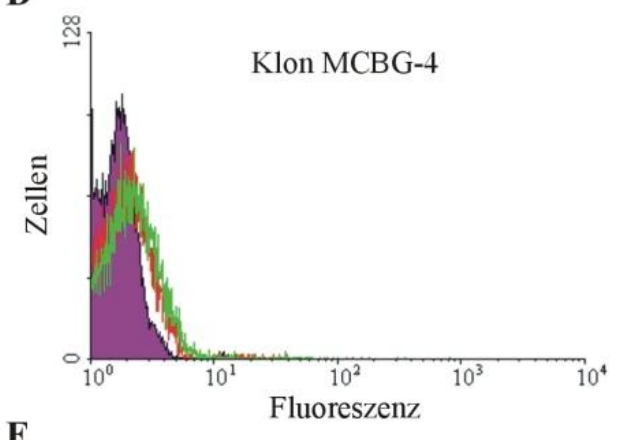

$\mathbf{F}$

Abb. 17: Durchflusszytometrische Analyse der oberflächengebundenen Expression des MCBGFusionsproteins mit Hilfe des HA-Tags

Im Histogramm sind die Zellen nach ihrer Fluoreszenzintensität sortiert aufgetragen. Violett gefüllt ist die Eigenfluoreszenz der Zellen ohne Antikörper dargestellt, Rot zeigt die Fluoreszenz der Sekundärantikörperkontrollen und Grün die Fluoreszenz mit Primär- und Sekundärantikörper. Der Unterschied zwischen roter und grüner Kurve gibt die Bindung des Primärantikörpers auf den Zellen an.

A und B Bei den Zellen der Klone LV-2 und LV-5 bestanden praktisch keine Unterschiede der Fluoreszenzintensitäten der mit Primärantikörper markierten Zellen und der Sekundärantikörperkontrollen.

C und D Auch bei den Zellen der MCBG-Klone zeigten sich keine Unterschiede zwischen Primär- und Sekundärantikörperkontrollen.

F Die spezifischen Fluoreszenzen waren sowohl bei den Zellen der LV-Klone (grau) als auch bei den Zellen der MCBG-Klone (rot) nur sehr gering. Die Grafik zeigt Mittelwerte und Standardabweichungen der spezifischen mittleren Fluoreszenzintensitäten (sMFI) aus drei unabhängigen Messungen. 


\subsection{Immunoblots}

\subsubsection{Nachweis des CBG-Fusionsproteins im Westernblot}

Durch Auftrennung der zellulären Proteine nach dem Molekulargewicht konnte im Immunoblot gezeigt werden, dass die Zellen der CBG-Klone zusätzlich zu endogenem Cathepsin B das CBG-Fusionsprotein exprimierten. Mit einer errechneten Größe von $59 \mathrm{kDa}$ war das CBG-Fusionsprotein größer als die endogenen reifen Cathepsin-B-Formen mit ca. $31 \mathrm{kDa}$ und auch größer als das ebenfalls dargestellte Pro-Cathepsin B mit ca. $45 \mathrm{kDa}$.

Der Vergleich mit der Darstellung des Klon LV-5 zeigte das CBG-Fusionsprotein in den Messungen der Klone CBG-3 und CBG-5 als Bande bei $59 \mathrm{kDa}$ (Abb. 18). Das Molekulargewicht entsprach der Größe der einkettigen aktiven Form des Cathepsin B zuzüglich des angehängten eGFP. Höhermolekulare Pre- und Pro-Formen des CBG-Fusionsproteins waren nicht nachweisbar. Nicht-eGFP-verknüpftes Cathepsin B und Pro-Cathepsin B waren in Zelllysaten aller Klone darstellbar. Die Zellen der CBG-Klone exprimierten neben endogenen Cathepsin B auch das CBG-Fusionsprotein, welches in den Zellen zur reifen Form prozessiert wurde. Durch einen identischen Blot ohne Primärantikörper wurden unspezifische Bindungen der Sekundär- und Tertiärantikörper ausgeschlossen (nicht dargestellt).

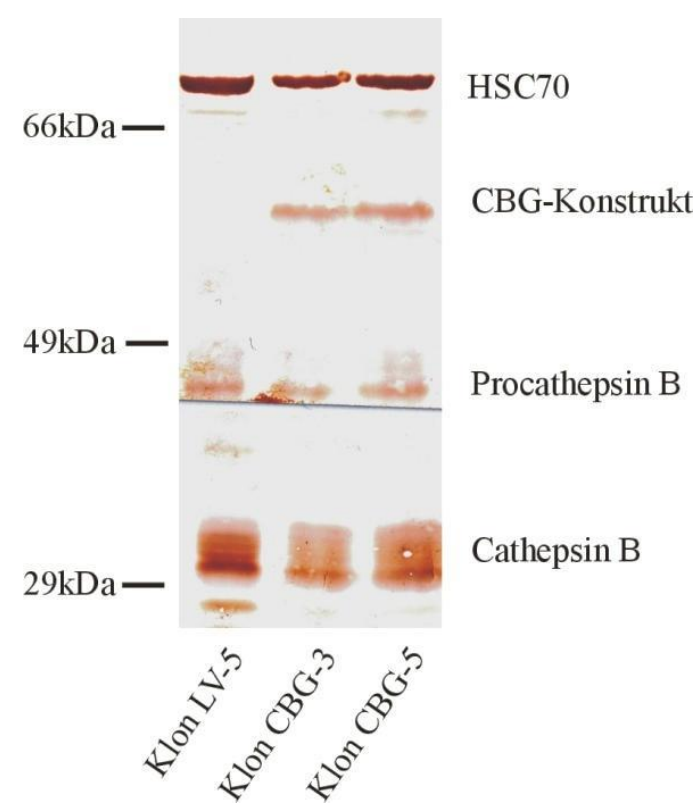

Abb. 18: Cathepsin-B-Immunoblot von Zellen der Klone LV-5, CBG-3 und CBG-5

Der Westernblot diente dem Nachweis des CBG-Fusionsproteins in Zellen beider CBG-Klone durch Reaktion mit einem Antikörper gegen Cathepsin B. Als Vergleichszelllinie wurde der Klon LV-5 verwendet. Als Ladekontrolle diente der Nachweis des konstitutiv exprimierten HSC70. Die in allen Zelllysaten nachweisbaren Banden um $31 \mathrm{kDa}$ entsprachen verschiedenen Formen des endogenen Cathepsin B. Pro-Cathepsin B war ebenfalls in Zellen aller Klone bei $45 \mathrm{kDa}$ nachweisbar. Zusätzliche Banden bei $59 \mathrm{kDa}$ in den Lysaten der CBG-Klone entsprachen dem CBG-Konstrukt. Die schwarze Linie ist ein für die Auswertung irrelevanter Schnitt in der Nitrozellulosemembran. 


\subsubsection{Nachweis des MCBG-Fusionsproteins im Westernblot}

Zur Bestätigung der Expression wurde das MCBG-Fusionsprotein mit einem Antikörper gegen Cathepsin B im Immunoblot nachgewiesen. Das MCBG-Fusionsprotein wurde in Lysaten von Zellen beider MCBG-Klone bei $61 \mathrm{kDa}$ dargestellt. Das Molekulargewicht entsprach der errechneten Größe des MCBG-Fusionsproteins.

Mit dem Antikörper gegen Cathepsin B wurde auch endogenes Cathepsin B und Pro-Cathepsin B in den Zelllysaten der MCBG-Klone und des LV-5-Klons nachgewiesen (Abb. 19). Negativkontrollen ohne Primärantikörper zeigten keine unspezifischen Bindungen von Sekundär- und Tertiärantikörper (nicht dargestellt).

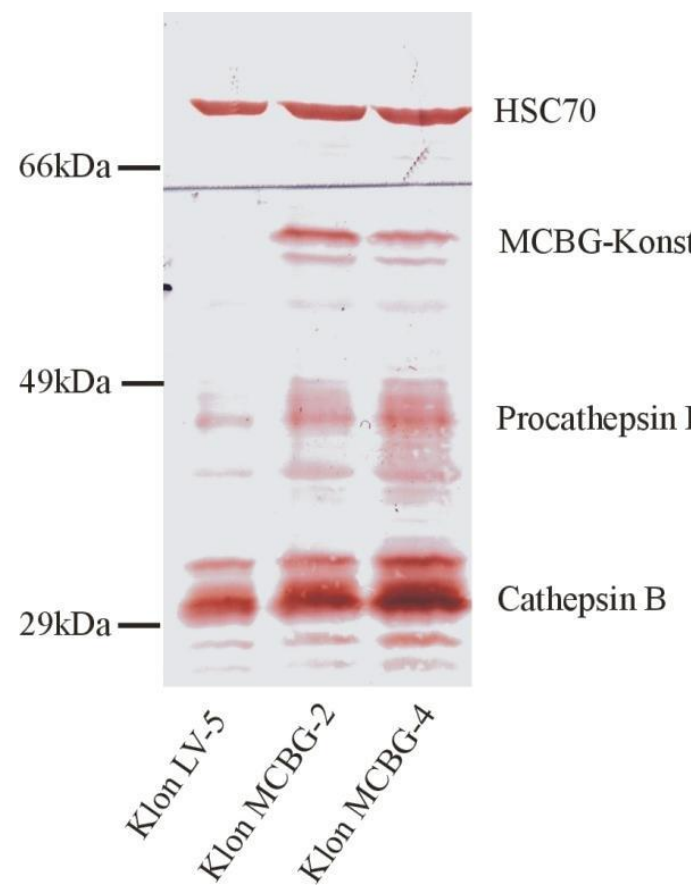

Abb. 19: Cathepsin-B-Immunoblot von Zellen der Klone LV-5, MCBG-2 und MCBG-4

Dargestellt ist der Westernblot der Klone LV-5, MCBG-2 und MCBG-4 mit einem Antikörper gegen Cathepsin B. Als Ladekontrolle diente der Nachweis von HSC70. In allen Zelllinien erfolgte der Nachweis von endogenem Cathepsin B bei $31 \mathrm{kDa}$ und von ebenfalls endogenem Pro-Cathepsin B bei $45 \mathrm{kDa}$. Die im Vergleich zum Klon LV-5 zusätzlichen Banden bei $61 \mathrm{kDa}$ entsprachen dem MCBG-Fusionsprotein. Die schwarze Linie ist ein für die Auswertung irrelevanter Schnitt in der Nitrozellulosemembran.

\subsection{Konfokale Laser-Scanning-Mikroskopie}

Zur Untersuchung des Einflusses von Cathepsin B auf die Lyse von Zielzellen zytotoxischer Zellen war nicht nur die Cathepsin-B-Expression in den Zellen interessant, auch die Verteilung seiner katalytischen Aktivität innerhalb der Zellen aller Klone wurde betrachtet.

In der Laser-Scanning-Mikroskopie konnte mit Hilfe des Magic-Red ${ }^{\mathrm{TM}_{-} \text {Cathepsin-B- }}$ Detection-Kits die Verteilung der Cathepsin-B-Aktivität in einzelnen Zellen bestimmt werden. Zusätzlich wurde die Lokalisation der CBG- und MCBG-Fusionsproteine anhand der Fluoreszenz des eGFP-Anteils untersucht und beide Verteilungen miteinander verglichen. 


\subsubsection{Perinukleäre, vesikuläre und membrangebundene Cathepsin-B-Aktivität bei diffuser zytoplasmatischer Verteilung von eGFP in den Zellen der LV-Klone}

Zur Beurteilung der natürlichen Verteilung der Cathepsin-B-Aktivität sowie zur Kontrolle der Verteilung von freiem eGFP wurden Zellen beider LV-Klone betrachtet.

Die Zellen beider LV-Klone zeigten Cathepsin-B-Aktivität an der Kernmembran, in perinukleären Vesikeln und geringer auch an der Zelloberfläche. Freies eGFP war in allen Zellen diffus im gesamten Zytoplasma verteilt. Die die Cathepsin-B-Aktivität-beinhaltenden Vesikel zeigten keine eGFP-Fluoreszenz. Alle betrachteten Zellen wiesen einen runden Zellkern mit grobscholliger Verteilung des Heterochromatins als Zeichen der Vitalität auf. Je Klon wurden mindestens fünf verschiedene Zellen genauer betrachtetet. Alle zeigten eine ähnliche Verteilung von Cathepsin-B-Aktivität und eGFP, wenngleich die Stärke der Cathepsin-B-Aktivität in Kernmembran und Zellmembran auch unter den Zellen des jeweiligen Klons nicht einheitlich war. Exemplarisch wurde in Abb. 20 je eine Zelle jedes Klons dargestellt, wobei die Zelle des Klons LV-2 ein Beispiel für eine Zelle mit geringer membranassoziierter Cathepsin-B-Aktivität ist. Die Zelle des Klons LV-5 weist eine im Vergleich stärkere membranassoziierte Cathepsin-B-Aktivität auf.
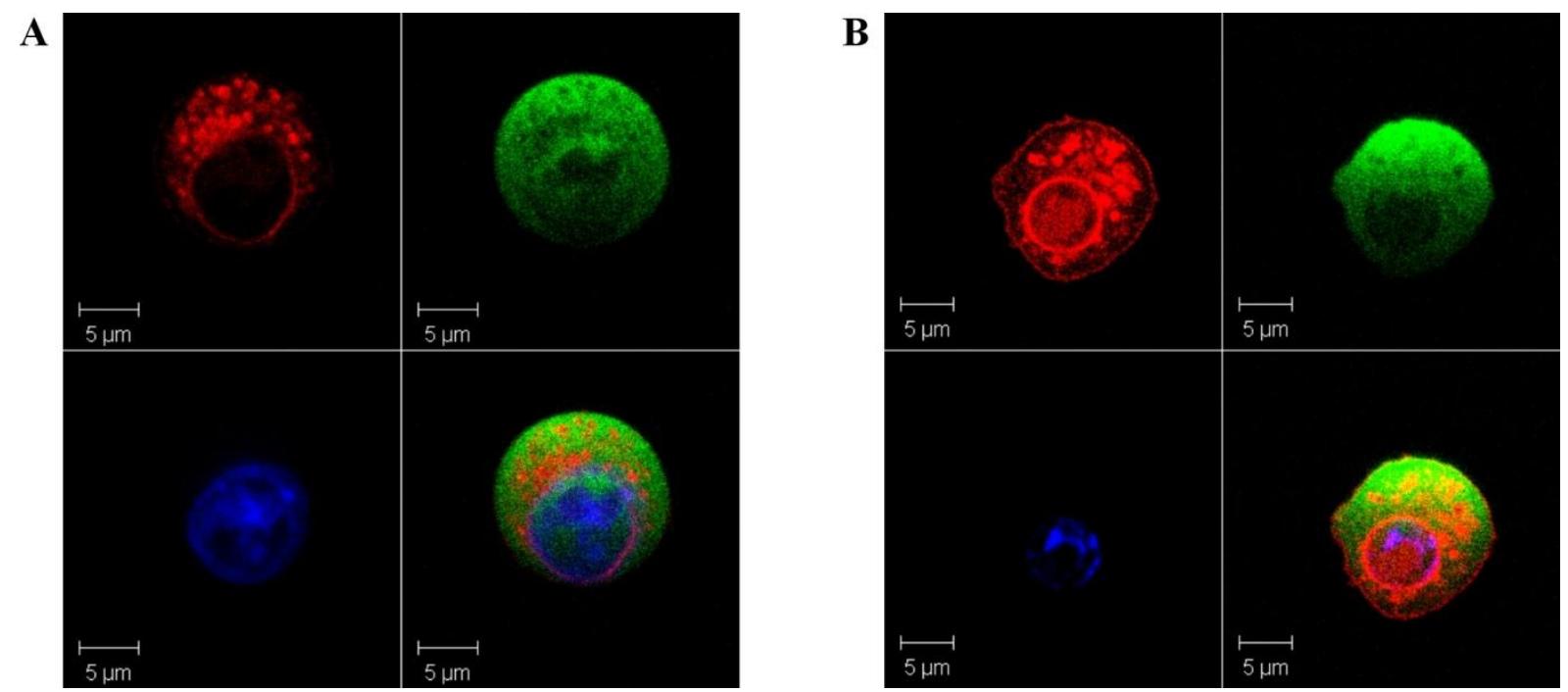

Abb. 20: Fluoreszenzmikroskopische Bestimmung der Verteilung von Cathepsin-B-Aktivität und eGFPFluoreszenz in Zellen der Klone LV-2 und LV-5

Oben links ist als rote Fluoreszenz die mittels Magic-RedTM-Cathepsin-B-Detection-Kit bestimmte Cathepsin-B-Aktivität dargestellt, oben rechts die im Anschluss bestimmte Fluoreszenz des freien eGFP. Unten links ist das Chromatin des Zellkerns nach Hoechst 33324-Färbung und unten rechts die Projektion aller Fluoreszenzen übereinander gezeigt. Da eGFP nur wenig photostabil ist, verblasste sein Signal währen der zeilenweisen Abtastung von oben nach unten deutlich.

A Gezeigt ist die Messung einer Zelle des Klons LV-2. Sie ist Beispiel einer Zelle mit geringer membranassoziierter Cathepsin-B-Aktivität.

B Die hier dargestellte Zelle des Klons LV-5 ist Beispiel einer Zelle mit stärkerer Membranassoziation der Cathepsin-B-Aktivität. 


\subsubsection{Intrazelluläre Kolokalisation des CBG-Fusionsproteins und der Cathepsin-B- Aktivität in den Zellen der CBG-Klone}

Mit Hilfe der Laser-Scanning-Mikroskopie wurde nun untersucht, ob durch Expression des CBG-Fusionsproteins neben der Steigerung der Cathepsin-B-Menge auch die Verteilung der Cathepsin-B-Aktivität in den Zellen verändert wurde. Die Cathepsin-B-Aktivität wurde wieder mit Hilfe des Magic-Red ${ }^{\text {TM}}$-Cathepsin-B-Detection-Kit bestimmt und mit der Verteilung der Fluoreszenz des eGFP-Anteils des CBG-Fusionsproteins verglichen.

In allen Zellen der CBG-Klone war die Cathepsin-B-Aktivität besonders in der Region der Kernmembran, in perinukleären Vesikeln und in der Zellmembran sichtbar. Das eGFPSignal des Fusionsproteins lag in exakt gleicher Verteilung vor. Dies wurde besonders durch die Überlagerung aller Fluoreszenzmuster im selben Bild deutlich.

Eine deutliche Veränderung der Lokalisation der Cathepsin-B-Expression in den Zellen der CBG-Klone im Vergleich zu den Zellen der LV-Klone war nicht darstellbar. Insbesondere war keine Verschiebung der Cathepsin-B-Aktivität zur Zellmembran sichtbar. Die Darstellung der Cathepsin-B-Aktivität mittels des Magic-Red ${ }^{\mathrm{TM}_{-}}$Cathepsin-B-Detection-Kits erlaubte keine Quantifizierung der Cathepsin-B-Aktivität der gesamten Zelle.

Je Klon wurden mindestens fünf Zellen mit intaktem Zellkern genauer betrachtet. Alle wiesen ein ähnliches Verteilungsmuster der Cathepsin-B-Aktivität und der eGFPFluoreszenz auf. In Abb. 21 ist je Klon eine exemplarische Aufnahme dargestellt.
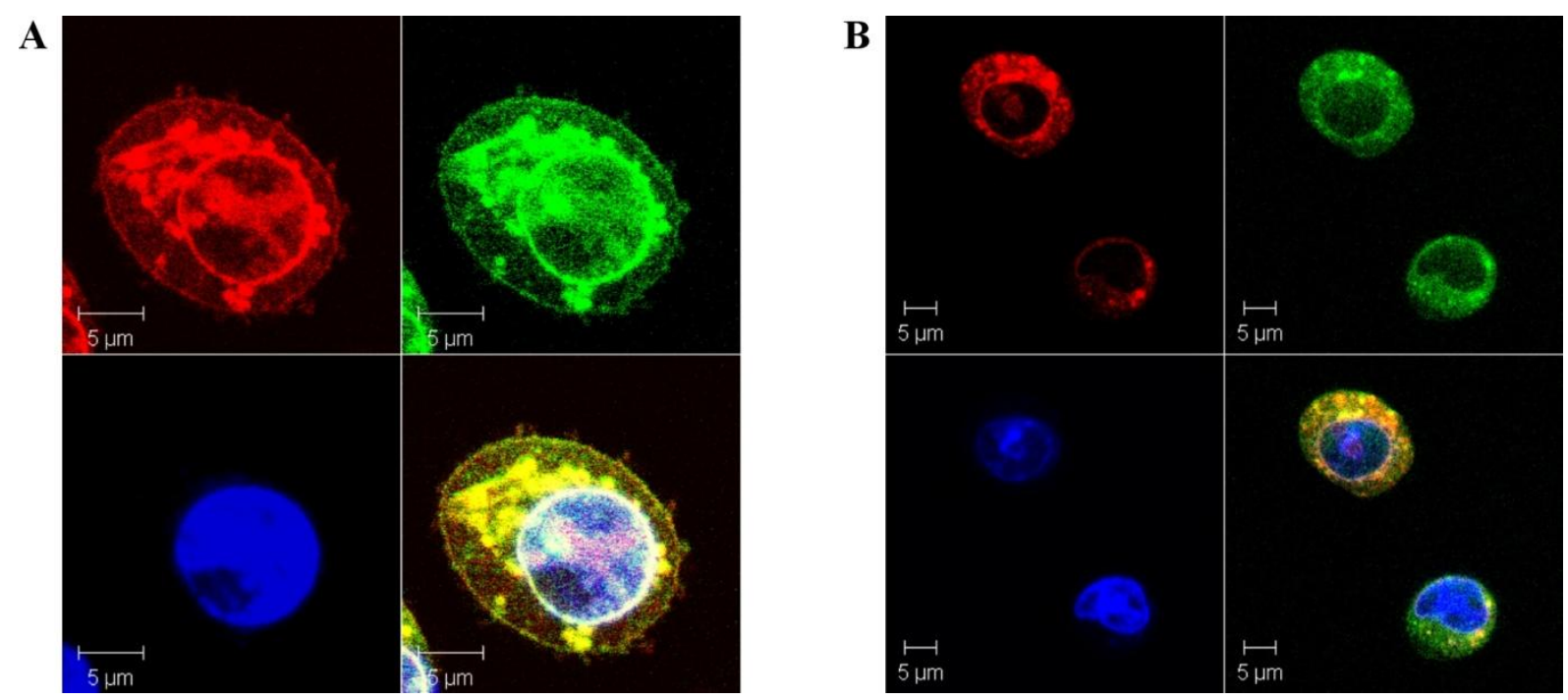

Abb. 21: Fluoreszenzmikroskopische Bestimmung der Verteilung von Cathepsin-B-Aktivität und eGFPFluoreszenz in Zellen der Klone CBG-3 und CBG-5

Die Cathepsin-B-Aktivität ist als rote Fluoreszenz im oberen linken Bild dargestellt. Die eGFP-Fluoreszenz des CBG-Fusionsproteins ist als grünes Signal oben rechts gezeigt. Mit Hoechst 33342 wurde das Chromatin des intakten Zellkerns (unten links) gefärbt. Durch die Überlagerung aller Fluoreszenzen (unten rechts) wurde die übereinstimmende Lokalisation von Cathepsin-B-Aktivität und eGFP-Fluoreszenz des CBGFusionsproteins besonders deutlich.

A Dargestellt ist die Fluoreszenz einer Zelle des Klons CBG-3.

B Das Bild zeigt zwei Zellen des Klons CBG-5. 


\subsubsection{Intrazelluläre Kolokalisation des MCBG-Fusionsproteins und der Cathepsin-B- Aktivität in den Zellen der MCBG-Klone}

Auch die Verteilung der Cathepsin-B-Aktivität in den Zellen der MCBG-Klone wurde in der Laser-Scanning-Mikroskopie untersucht und mit der Lokalisation des MCBGFusionsproteins verglichen. Dieses konnte, wie das CBG-Fusionsprotein, anhand der Fluoreszenz seines eGFP-Anteils nachgewiesen werden.

Die Cathepsin-B-Aktivität war in den Zellen der MCBG-Klone vor allem in der Kernmembran und in perinukleären Vesikeln lokalisiert und unterschied sich somit nicht von der Verteilung der Cathepsin-B-Aktivität in den Zellen der LV- und CBG-Klone. An der Zellmembran ließ sich nur geringe Cathepsin-B-Aktivität nachweisen. Das MCBGFusionsprotein selbst war vor allem in der Kernmembran und in perinukleären Vakuolen nachweisbar. Es reicherte sich nicht in der Zellmembran an. Seine Verteilung entsprach der Verteilung der Cathepsin-B-Aktivität. Auch hier erlaubte die Darstellung keine Aussage zur Quantität der Cathepsin-B-Aktivität.

Je Klon wurden mindestens fünf Zellen mit intaktem Zellkern genauer betrachtet. Exemplarisch ist in Abb. 22 je ein Bild einer Zelle beider MCBG-Klone gezeigt.
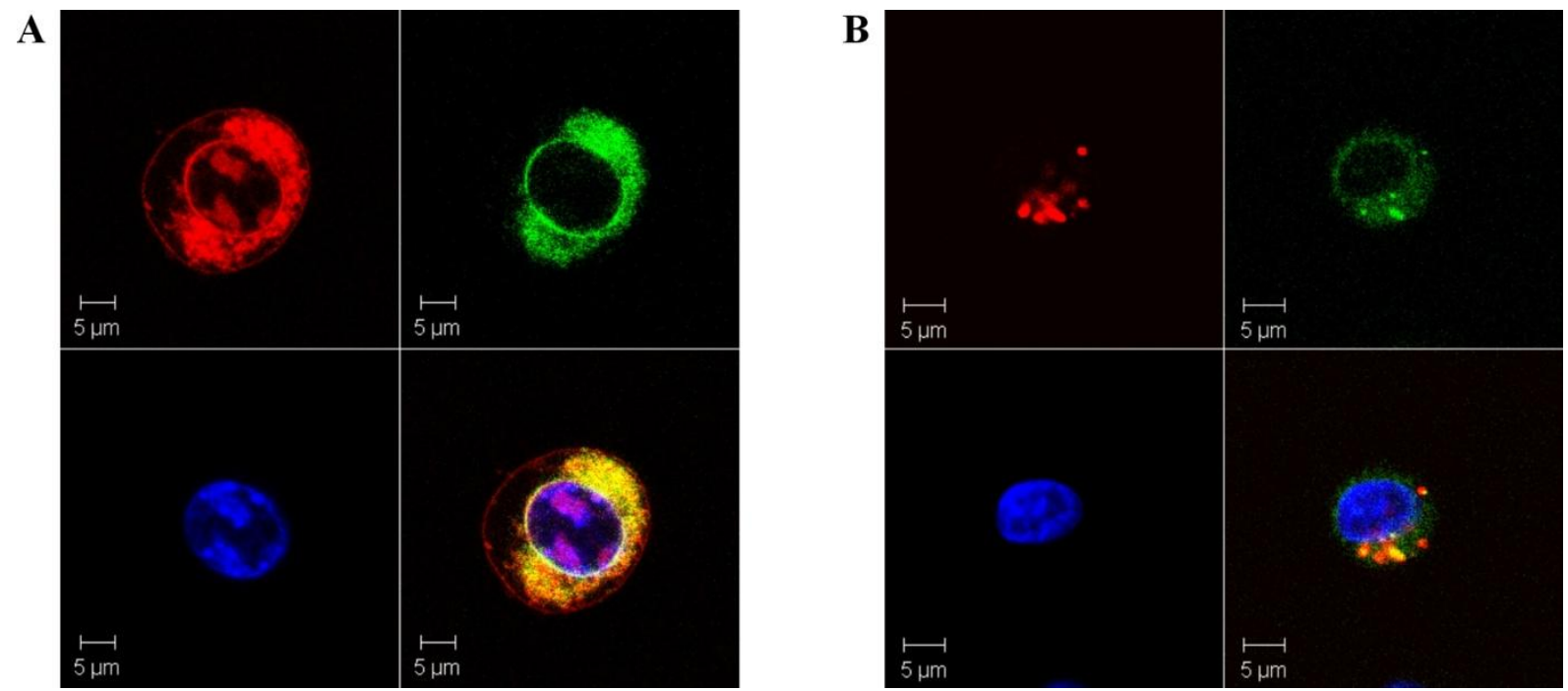

Abb. 22: Fluoreszenzmikroskopische Bestimmung der Verteilung von Cathepsin-B-Aktivität und eGFPFluoreszenz in Zellen der Klone MCBG-2 und MCBG-4

Die Aufnahme zeigt die Lokalisation der Cathepsin-B-Aktivität (rot, oben links) und der eGFP-Fluoreszenz des MCBG-Fusionsproteins (grün, oben rechts). Der Zellkern der Zelle wurde mittels Hoechst 33342 (blau, unten links) dargestellt. Unten rechts ist die Überlagerung aller Fluoreszenzsignale gezeigt.

A Gezeigt sind die Fluoreszenzen einer exemplarisch ausgewählten Zelle des Klons MCBG-2.

B Hier sind die Fluoreszenzen einer Zelle des Klons MCBG-4 dargestellt.

\subsection{Zytotoxizitätstests}

Der Einfluss von Cathepsin B auf die Lyse von Zielzellen zytotoxischer T-Zellen wurde untersucht, indem die Freisetzung radioaktiven Chroms durch die Zielzellen nach Kontakt mit zytotoxischen T-Zellen bestimmt wurde. Die verwendeten zytotoxischen T-Lymphozyten lysierten die Zielzellen durch Exozytose ihrer zytotoxischen Granula mit Freisetzung von Perforin und Granzymen. Zur Normierung wurden untransfizierte RMAZellen verwendet, die LV-Klone dienten als Kontrollzelllinien. 


\subsubsection{Vergleichbare oberflächenassoziierte $\mathbf{H} 2 \mathbf{K}^{\mathbf{b}}$-Expressionen auf den Zellen aller Klone}

Die Funktion zytotoxischer T-Zellen ist abhängig von der Antigenpräsentation der Zielzellen. Die eingesetzten zytotoxischen T-Zellen aus OT-I-Mäusen lysierten spezifisch Zielzellen, die das SIINFEKL-Peptid des Ovalbumins auf $\mathrm{H} 2 \mathrm{~K}^{\mathrm{b}}$-Molekülen präsentierten. Für eine Messung der Lyse war also die Expression von $\mathrm{H} 2 \mathrm{~K}^{\mathrm{b}}$ durch die Zielzellen essentiell.

Mit einem fluoreszenzmarkierten Antikörper gegen $\mathrm{H} 2 \mathrm{~K}^{\mathrm{b}}$ wurde die Expression dieses MHC-Moleküls auf den Zellen der LV-Klone, der CBG-Klone und der MCBG-Klone bestimmt und mit der Expressionsstärke auf untransfizierten RMA-Zellen verglichen. Für die Bestimmung der spezifischen Fluoreszenzintensitäten wurden unspezifische Bindungen durch Isotypenkontrollen bestimmt und subtrahiert.

Die $\mathrm{H} 2 \mathrm{~K}^{\mathrm{b}}$-Expression der Zellen aller Klone unterschied sich nicht von der untransfizierter RMA-Zellen. Lediglich die Zellen des Klons MCBG-4 wiesen eine etwas geringere $\mathrm{H} 2 \mathrm{~K}^{\mathrm{b}}$-Expression auf. Abb. 23 zeigt die mittlere $\mathrm{H}_{2} \mathrm{~K}^{\mathrm{b}}$-Expression der Zellen aller Klone aus jeweils fünf Messungen.

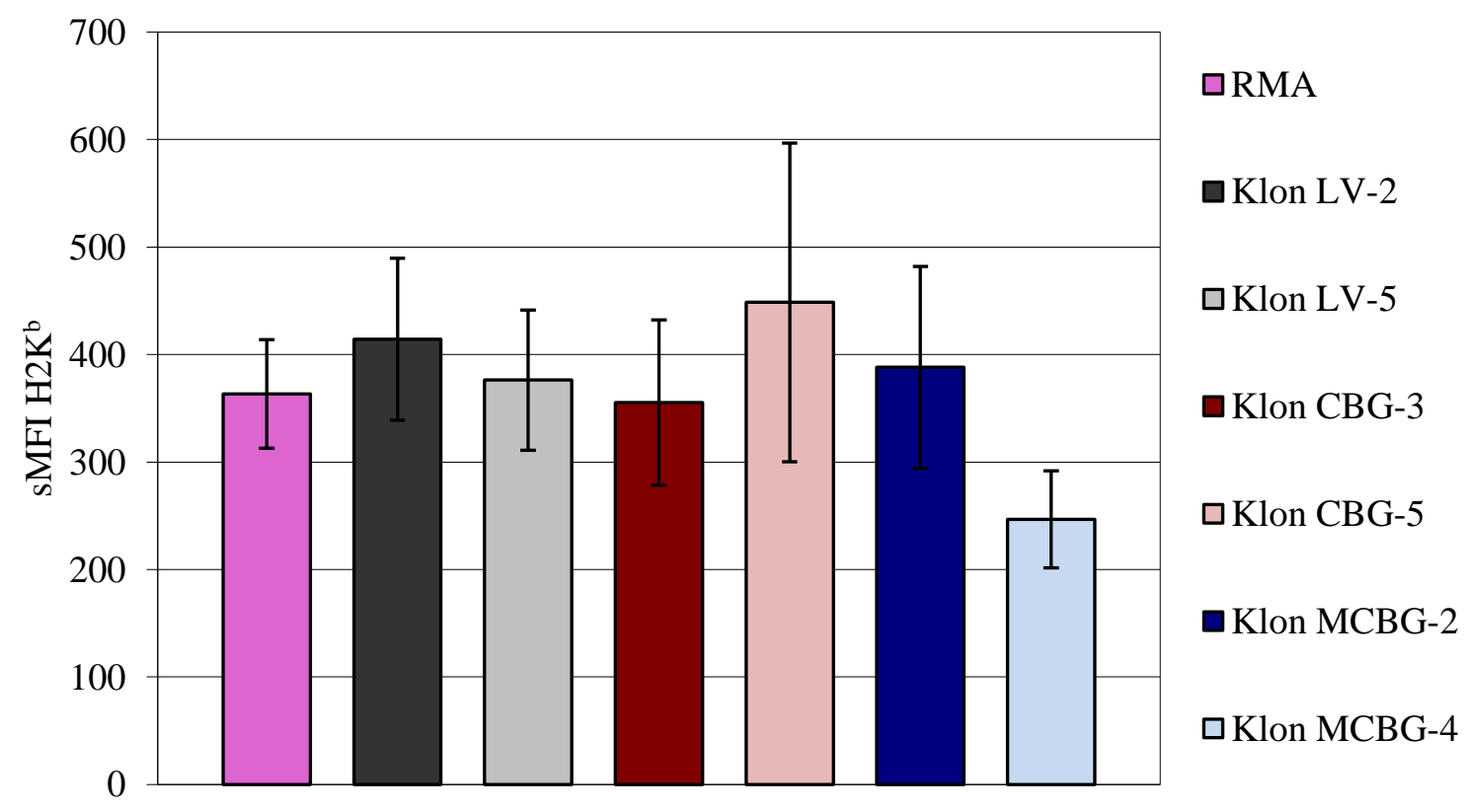

Abb. 23: Durchflusszytometrische Analyse der $\mathbf{H}^{2} \mathrm{~K}^{\mathrm{b}}$-Expression

Das Diagramm zeigt die durchflusszytometrische Bestimmung der $\mathrm{H} 2 \mathrm{~K}^{\mathrm{b}}$-Expression. Dargestellt sind die spezifischen mittleren Fluoreszenzintensitäten (sMFI) eines gegen $\mathrm{H}_{2} \mathrm{~K}^{\mathrm{b}}$ gerichteten Antikörpers als Mittelwerte und Standardabweichungen aus sechs Messungen.

\subsubsection{Unveränderte Lyse der Zellen der CBG-Klone}

Es wurde gezeigt, dass durch Expression des CBG-Fusionsproteins die Cathepsin-B-Menge in den Zellen der CBG-Klone gesteigert werden konnte. Der Einfluss der erhöhten Cathepsin-B-Expression auf die Lyse durch zytotoxische Zellen konnte nun im ChromFreisetzungs-Test untersucht werden. Der Anteil lysierter Zellen der CBG-Klone wurde bei unterschiedlichen Killer-Zielzell-Verhältnissen mit dem Anteil lysierter Zellen der LV-Klone und dem untransfizierter RMA-Zellen verglichen. 
Alle Zellen wurden von zytotoxischen T-Lymphozyten antigenspezifisch über den GranulaExozytose-Weg lysiert. Die Kontrollen untransfizierter RMA-Zellen ohne Zusatz von SIINFEKL zeigten, dass ohne antigenspezifische Aktivierung keine spezifische Lyse auftrat. Ebenso wurden nach Unterbindung der Granula-Exozytose durch Entzug freien Calciums mittels EGTA/ $\mathrm{MgCl}_{2}$ keine Zellen durch andere Mechanismen lysiert.

Bei allen Klonen nahm mit sinkendem Verhältnis von Killerzellen zu Zielzellen der Anteil lysierter Zielzellen ab. Zur besseren Vergleichbarkeit verschiedener Experimente wurde die relative Lyse der Klone im Vergleich zur Lyse untransfizierter RMA-Zellen bei einem Killer-Zielzell-Verhältnis von 20:1 bestimmt. Für die Gesamtauswertung wurden Mittelwerte und Standardabweichungen aller durchgeführten Tests betrachtet.

Es zeigte sich keine Reduktion der Lyse der Zellen der CBG-Klone im Vergleich zu den Zellen der LV-Klone und $\mathrm{zu}$ untransfizierten RMA-Zellen. Die Expression des CBG-Fusionsproteins hatte keinen Einfluss auf die Empfindlichkeit von RMA-Zellen gegenüber der Granula-Exozytose zytotoxischer T-Zellen. Abb. 24 zeigt einen exemplarischen Test sowie die Gesamtauswertung als Vergleich der relativen Lyseraten. 


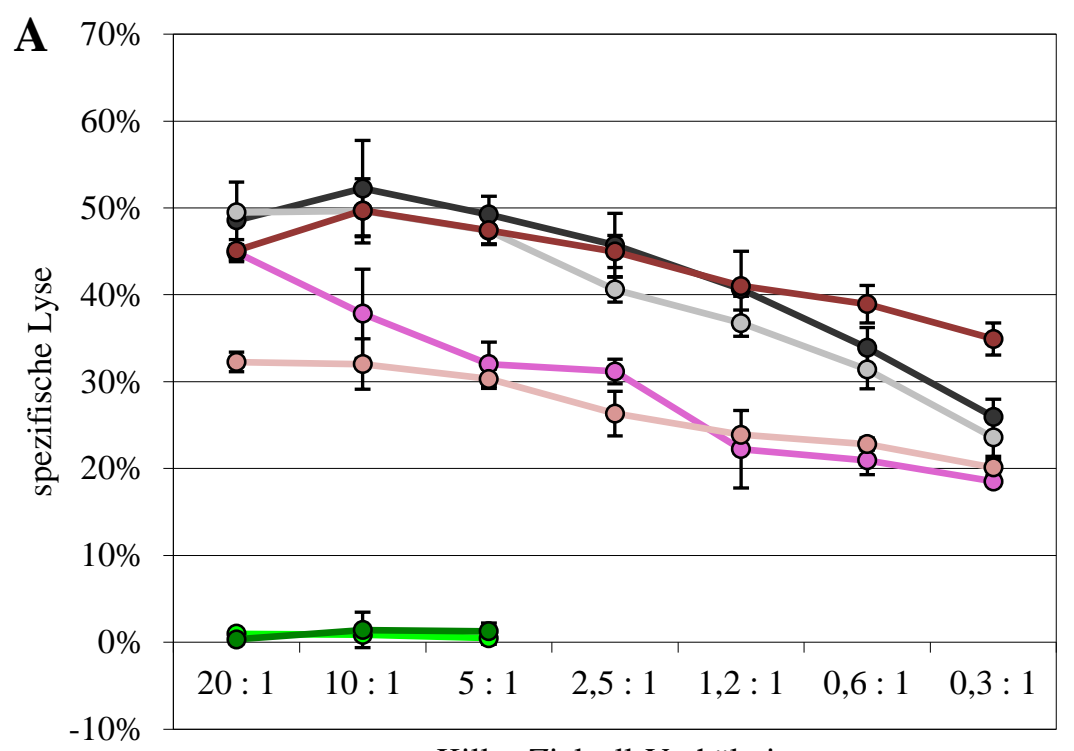

- - RMA

$\longrightarrow$ Klon LV-2

o- Klon LV-5

- - Klon CBG-3

o- Klon CBG-5

O- RMA ohne SIINFEKL

RMA mit EGTA/MgCl2 und SIINFEKL

Killer-Zielzell-Verhältnis

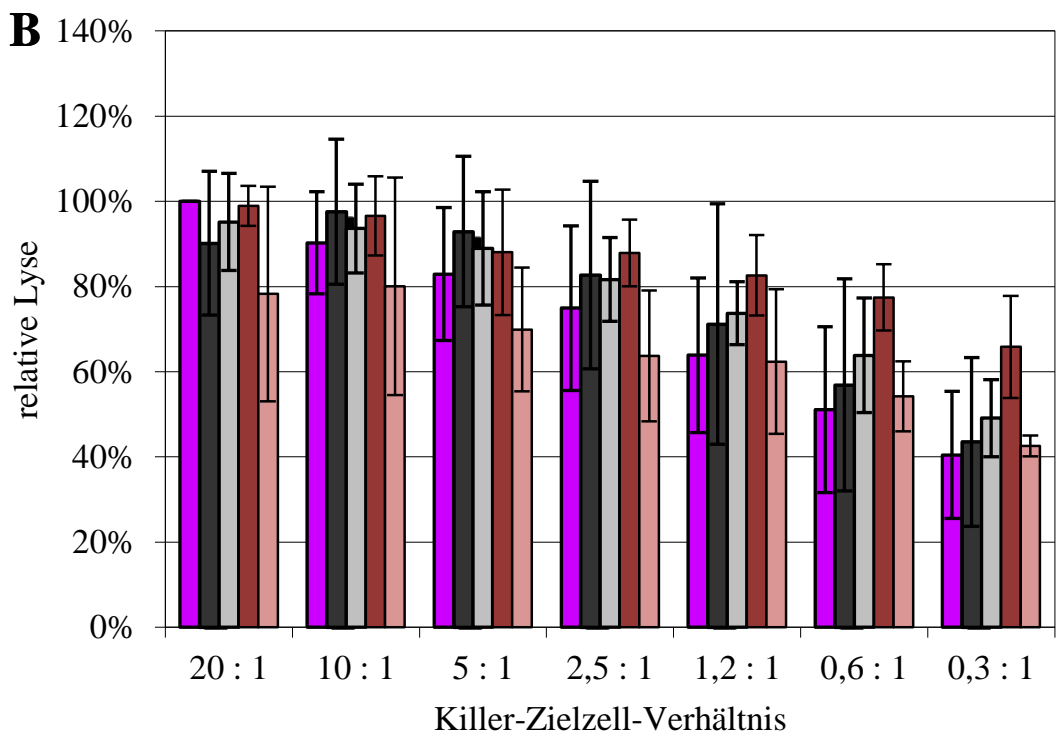

口RMA (n=7)

aKlon LV-2 (n=5)

$\square$ Klon LV-5 (n=5)

$\square$ Klon CBG-3 (n=6)

$\square$ Klon CBG-5 (n=3)

Abb. 24: Chrom-Freisetzungs-Tests der CBG-Klone

A Dargestellt ist ein exemplarischer Chrom-Freisetzungs-Tests mit untransfizierten Zellen (violett), Zellen beider LV-Klone (grau) und Zellen beider CBG-Klone (rot). Die spezifische Lyse entspricht dem Anteil der Zielzellen, der spezifisch durch die zytotoxischen T-Lymphozyten lysiert wurde. Angegeben sind Mittelwerte und Standardabweichungen je eines Triplets. Die Kontrollmessungen von untransfizierten RMA-Zellen ohne SIINFEKL-Peptid und bei Zusatz von EGTA/ $\mathrm{MgCl}_{2}$ mit SIINFEKL-Peptid (grün) zeigten keine Lyse.

B Die Abbildung zeigt Mittelwerte und Standardabweichungen der relativen Lysen der Zellen der einzelnen Klone im Vergleich zu untransfizierten RMA-Zellen bei einem Killer-Zielzell-Verhältnis von 20:1 (100 \%). 


\subsubsection{Unveränderte Lyse der Zellen der MCBG-Klone}

Zur Funktion von Perforin bei der Lyse von Zellen durch die Exozytose zytotoxischer Granula existieren verschiedene Modelle. Übereinstimmend beschreiben sie den Wirkort von Perforin an der Plasmamembran oder an Membranen intrazellulärer Kompartimente. Da das CBG-Fusionsprotein keinen Einfluss auf die Lyse der Zielzellen über den GranulaExozytose-Weg hatte, wurde nun untersucht, ob die Expression des MCBG-Fusionsproteins die Lyse der Zielzellen beeinflusste. Die durch das MCBG-Fusionsprotein erreichte Steigerung der oberflächengebundenen Cathepsin-B-Menge war zwar so gering, dass ein Einfluss auf die Lyse der Zellen fraglich war, doch auch eine mögliche Bindung des MCBG-Fusionsproteins durch seine Transmembrandomäne an intrazellulären Membranen könnte die Empfindlichkeit der Zielzellen gegenüber Granula-vermittelter Zytotoxizität verändern.

Die Lyse der Zellen der MCBG-Klone war im Vergleich zur Lyse der Zellen der LV-Klone und zur Lyse untransfizierter RMA-Zellen nicht vermindert. Die RMA-Zellen wurden durch die Expression des MCBG-Fusionsproteins nicht vor der Lyse durch zytotoxische T-Zellen geschützt.

Abb. 25 zeigt einen exemplarisch ausgewählten Test sowie die Gesamtauswertung. Zur besseren Vergleichbarkeit verschiedener Tests wurden wiederum die relative Lyse im Vergleich zu untransfizierten RMA-Zellen bei größtem Killer-Zielzell-Verhältnis bestimmt und Mittelwerte und Standardabweichungen aller Tests dargestellt. 

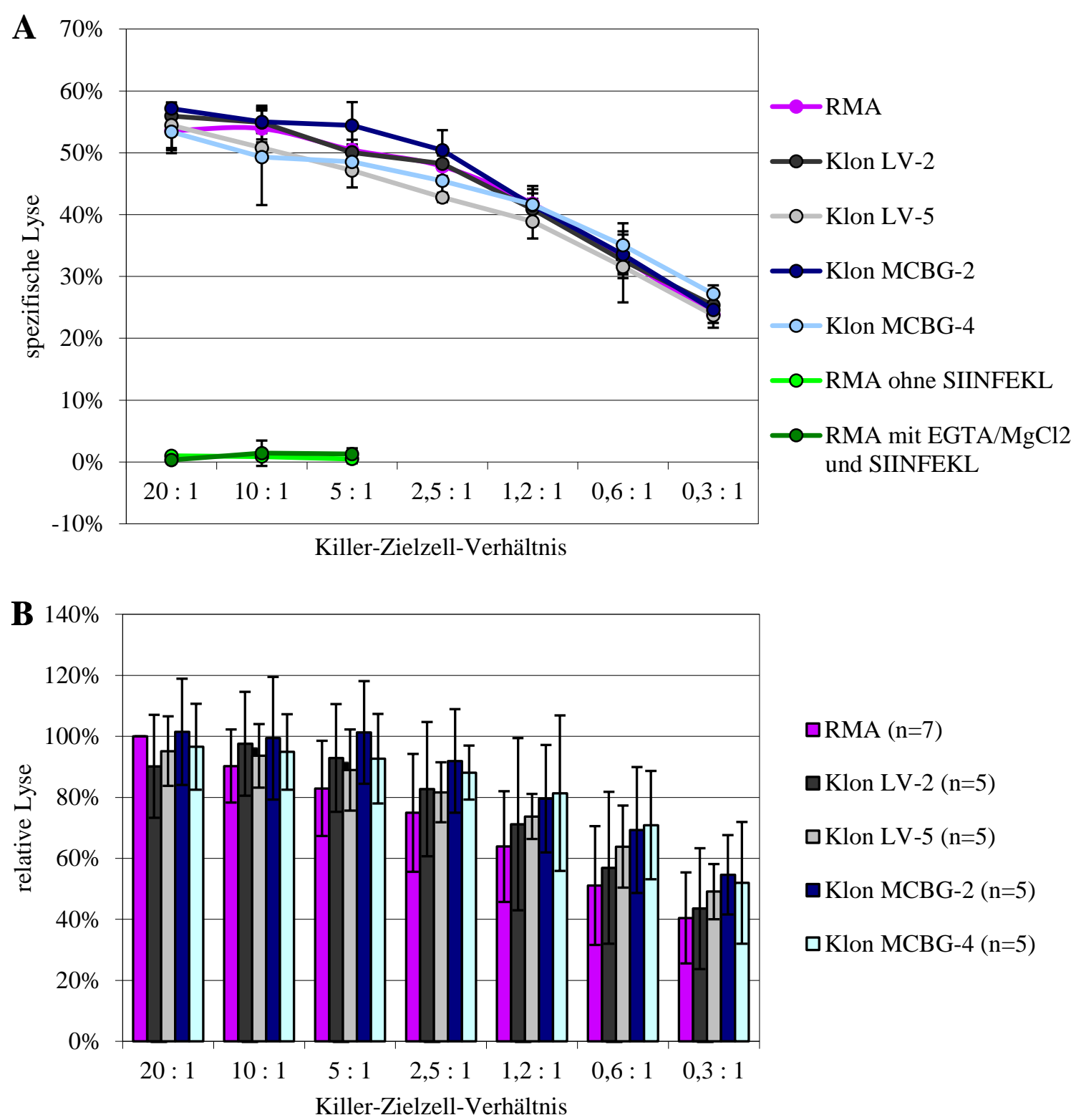

Abb. 25: Chrom-Freisetzungs-Tests der MCBG-Klone

A Dargestellt ist ein exemplarischer Chrom-Freisetzungs-Tests mit untransfizierten Zellen (violett), Zellen beider LV-Klone (grau) und Zellen beider MCBG-Klone (blau). Die spezifische Lyse entspricht dem Anteil der Zielzellen, der spezifisch durch die zytotoxischen T-Lymphozyten lysiert wurde. Angegeben sind Mittelwerte und Standardabweichungen je eines Triplets. Die Kontrollmessungen von RMA-Zellen ohne SIINFEKL-Peptid und in Anwesenheit des Chelatkomplexes EGTA/ $\mathrm{MgCl}_{2}$ mit SIINFEKL-Peptid (grün) zeigten keine spezifische Lyse.

B Die Abbildung zeigt Mittelwerte und Standardabweichungen der relativen Lysen der Zellen der einzelnen Klone im Vergleich zu untransfizierten RMA-Zellen bei einem Killer-Zielzell-Verhältnis von 20:1 (100\%). 


\section{Diskussion}

Zytotoxische T-Zellen werden bei der Lyse von Zielzellen nicht selbst lysiert (Rothstein et al. 1978). Sie sind zwar prinzipiell empfindlich gegenüber den Inhaltsstoffen ihrer zytotoxischen Granula (Schick und Berke 1990) und können sich auch gegenseitig über den Granula-Exozytose-Weg lysieren (Dutz et al. 1992; Su et al. 1993; Walden und Eisen 1990), im Rahmen der Lyse von Zielzellen zeigen sie sich allerdings unempfindlich gegenüber den in den Spalt der immunologischen Synapse freigesetzten zytotoxischen Substanzen (Rothstein et al. 1978). Einige Untersuchungen führen diese Resistenz auf die lokale Expression von zellmembranassoziiertem Cathepsin B zurück (Balaji et al. 2002). Die Protease lysosomalen Ursprungs ist in den zytotoxischen Granula enthalten und erscheint nach deren Exozytose auf der Oberfläche der Killerzellen (Balaji et al. 2002). Die zytoprotektive Funktion von Cathepsin B wurde durch Hemmung der Protease während der Induktion der Granula-Exozytose dargestellt. Es zeigte sich eine Granula-vermittelte Autolyse derjenigen zytotoxischen T-Zellen, deren membranassoziierte Cathepsin-BAktivität gehemmt war (Balaji et al. 2002). Als Mechanismus der Resistenz wurde eine Inaktivierung von Perforin beschrieben, da dieser essentielle Bestandteil der Granulavermittelten Zytotoxizität in vitro durch Cathepsin B gespalten werden kann (Balaji et al. 2002). Die membranassoziierte Expression von Cathepsin B scheint somit einen Schutzmechanismus gegenüber Granula-assoziierter Zytotoxizität darzustellen, der zytotoxische T-Zellen vor der Autolyse durch Perforin und Granzyme schützt.

Schutzmechanismen gegenüber zellulärer Zytotoxizität spielen auch bei der Entwicklung maligner Tumoren eine entscheidende Rolle (Burnet 1970). Die Erkennung und Lyse von entarteten Zellen durch zytotoxische T-Zellen ist ein wichtiger Mechanismus des Organismus zur Unterdrückung der Entstehung von Tumoren (Smyth et al. 2001). Durch ständige Interaktion mit dem Immunsystem erfolgt bei der Entwicklung manifester Tumore eine Selektion solcher entarteter Zellen, welche Mechanismen entwickelt haben, der Erkennung oder der Lyse durch zytotoxische T-Zellen zu entgehen (Dunn et al. 2002). Einen derartigen Immune-Escape-Mechanismus könnte auch die Überexpression von Cathepsin B darstellen.

Viele Tumore unterschiedlicher Ursprungsgewebe zeigen eine Steigerung der Cathepsin-BExpression (Campo et al. 1994; Ebert et al. 1994; Emmert-Buck et al. 1994; Froehlich et al. 2001; Hazen et al. 2000; Hughes et al. 1998; Krepela et al. 1989; Kusunoki et al. 1995; Lah et al. 1995; Liu Y et al. 1998; Rempel et al. 1994; Scorilas et al. 2002; Sheahan et al. 1989; Shuja et al. 1991; Sivaparvathi et al. 1995) oder exprimieren die Protease auf ihrer Zelloberfläche (Arkona und Wiederanders 1996; Demchik et al. 1999; Rozhin et al. 1987; Sameni et al. 1995; Sinha et al. 2001; Sloane et al. 1994). Diese veränderte Cathepsin-BExpression ist vergleichbar mit der Cathepsin-B-Expression auf degranulierten zytotoxischen T-Zellen und könnte durch Spaltung von Perforin zu einer verminderten Immunabwehr entarteter Zellen und somit zur Entstehung von Malignomen beitragen. Um einen solchen Cathepsin-B-assoziierten Immune-Escape-Mechanismus zu untersuchen, sind bereits Versuche mit Cathepsin-B-Inhibitoren und Cathepsin-B-defizienten Zellen durchgeführt worden. Im Chrom-Freisetzungs-Test zeigten die Zellen mit verminderter Cathepsin-B-Aktivität auf der Zelloberfläche in beiden Fällen auch eine signifikant größere Empfindlichkeit gegenüber der Granula-vermittelten Lyse durch zytotoxische T-Zellen (Ensslen 2009). 
Ziel dieser Arbeit war es daher zu untersuchen, ob eine Steigerung der Cathepsin-BExpression, wie sie in Tumorzellen verschiedener Ursprungsgewebe beschrieben ist, die Empfindlichkeit von RMA-Lymphomzellen gegenüber der Granula-vermittelten Lyse durch zytotoxische T-Zellen vermindert. Ein möglicher zytoprotektiver Effekt einer Überexpression von Cathepsin B sollte als verringerte Lyse der in der Cathepsin-BExpression veränderten Zielzellen im Chrom-Freisetzungs-Test dargestellt werden.

Um den Einfluss einer Überexpression von Cathepsin B auf die Lyse durch zytotoxische T-Zellen zu untersuchen, wurden zwei unterschiedliche Konstrukte kloniert und in RMA-Lymphomzellen transfiziert. Das CBG-Konstrukt kodierte für ein Fusionsprotein aus Pre-Pro-Cathepsin B und dem Fluorophor eGFP. Dieses CBG-Fusionsprotein sollte aufgrund der erhaltenen Pre- und Pro-Region wie endogenes Cathepsin B prozessiert und in der Zelle verteilt werden, lediglich die Expression sollte durch Verwendung des CAG-Promotors deutlich gesteigert werden. Dieser Fusionspromotor aus CMV-Promotor und chicken-beta-actin-Promotor (Niwa et al. 1991) zeichnet sich durch besonders hohe Expressionsraten und stabile Transfektionsergebnisse in eukaryoten Zellen aus (Xu et al. 2001). Klone von RMA-Zellen, die dieses Fusionsprotein stabil und kräftig exprimierten, wurden zur Untersuchung der in vielen Tumorzellen beschriebenen Überexpression von lysosomalem Cathepsin B verwendet.

Da die zytoprotektive Funktion von Cathepsin B in zytotoxischen T-Zellen auf eine membranassoziierte Form der Protease zurückgeführt wurde (Balaji et al. 2002) und auch in einigen Tumorzellen membranassoziierte Formen von Cathepsin B beschrieben sind (Arkona und Wiederanders 1996; Demchik et al. 1999; Rozhin et al. 1987; Sameni et al. 1995; Sinha et al. 2001; Sloane et al. 1994), wurde ein weiteres Konstrukt zur Untersuchung der Funktion von membranassoziiertem Cathepsin B entworfen. Dieses MCBG-Konstrukt kodierte für ein Fusionsprotein aus $\mathrm{H} 2 \mathrm{~K}$ und einem Teil des Cathepsin B. Die Transmembrandomäne des $\mathrm{H} 2 \mathrm{~K}$ wurde verwendet, um eine $31 \mathrm{kDa}$ große einkettige aktive Form von Cathepsin B in der Zellmembran der Zielzellen zu verankern. Die Ausrichtung der Protease zeigte dabei nach extrazellulär. Ein HA-Tag am N-Terminus der Cathepsin-B-Kette wurde zum selektiven Nachweis des Fusionsproteins auf der Zellmembran angefügt. Für den Transport zur Zellmembran wurde außerdem die Leader-Sequenz der H2K-cDNA am 5'-Ende ergänzt. Um auch das MCBG-Fusionsprotein stabil und kräftig zu exprimieren, wurde es wie das CBG-Fusionsprotein in den CAG-PEGFP-1-Vektor kloniert. Durch Erhalt des Leserasters wurde dabei die eGFP-Sequenz des Vektors zur Markierung an das intrazelluläre 3'-Ende des MCBG-Konstrukts angefügt.

Nach der Klonierung beider Konstrukte wurden diese in TOP10 E. coli-Bakterien vermehrt, sequenzkontrolliert und per Elektroporation in RMA-Zellen transfiziert. Durch Verdünnungsreihen wurden stabil transfizierte Zelllinien monoklonalen Ursprungs erzeugt. Um unspezifische klonale Effekte ausschließen zu können, wurden je Konstrukt zwei Zelllinien vergleichbarer Expressionsstärke zur weiteren Analyse verwendet. Als Kontrollzelllinien wurden zwei weitere klonale RMA-Zelllinien eingesetzt. Sie exprimierten durch Transfektion mit dem CAG-PEGFP-1-Vektor ohne Insert freies eGFP und dienten der Bestimmung Cathepsin-B-unabhängiger Veränderungen der Zelleigenschaften, die auf die Expression von eGFP sowie unspezifische Transfektionsfolgen zurückzuführen waren.

Da alle transfizierten Konstrukte das eGFP-Gen enthielten, konnte die Expression der Fusionsproteine über den Nachweis der Fluoreszenz ihres eGFP-Anteils bestimmt werden. Es handelte sich um eine für die Fusionsproteine spezifische Darstellung, für die nur sehr 
wenige Zellen benötigt wurden. Daher konnte mit dieser Methode bei allen Klonen in regelmäßigen Abständen und im Rahmen aller durchgeführten Experimente die Expression der Fusionsproteine bestimmt werden. Eine kräftige Expression der einklonierten Proteine wurde über den gesamten Zeitraum der Versuche gezeigt. Eine Reduktion der Expressionsstärke fand auch nach mehreren Zellteilungen nicht statt. Die Transfektion war bei allen verwendeten Klonen stabil.

Da die CBG- und MCBG-Klone der Analyse verschiedener Formen der Überexpression von Cathepsin B dienten, wurde die Cathepsin-B-Menge in den Zellen der eingesetzten Klone über die Bindung eines gegen Cathepsin B gerichteten Antikörpers durchflusszytometrisch bestimmt. Das Epitop, mit welchem der Antikörper spezifisch reagierte, war sowohl in beiden Fusionsproteinen als auch in endogenem Cathepsin B enthalten, sodass die Messung die Summe der Mengen des endogenen Cathepsin B und des jeweiligen Fusionsproteins zeigte. Die Zellen wurden vor der Messung fixiert und permeabilisiert, so erreichte der Antikörper Proteine in der gesamten Zelle sowie auch an der Zellmembran. Als Referenzwert wurde die Cathepsin-B-Menge in Zellen der LV-Klone bestimmt. Diese entsprach der endogenen Cathepsin-B-Expression von RMA-Zellen. Einflüsse der eGFPExpression auf die Messung wurden durch Verwendung der LV-Klone als Referenzzellen ebenfalls berücksichtigt.

Die Bestimmung der Menge des zellulären Cathepsin B erfolgte über die Berechnung der spezifischen mittleren Fluoreszenzintensität (sMFI) als Differenz der Mittelwerte der Fluoreszenzintensitäten mit und ohne Primärantikörper. Eine gesteigerte Cathepsin-BMenge in Zellen der CBG- und MCBG-Klone im Vergleich zu den Zellen der LV-Klone ließ sich in allen Einzelmessungen sowie auch in der Gesamtauswertung darstellen. Die Expression der Konstrukte führte somit zur gewünschten Steigerung der Cathepsin-BExpression.

Die Steigerung der Empfindlichkeit der RMA-Zielzellen gegenüber zytotoxischen T-Zellen bei extrazellulärer Inhibition von Cathepsin B (Ensslen 2009) war bereits ein indirekter Hinweis auf eine membrangebundene Expression von Cathepsin B auf RMALymphomzellen, welche nun auch durchflusszytometrisch untersucht werden sollte. Bei einer solchen membrangebundenen Expression von Cathepsin B konnte auch eine Steigerung der intrazellulären Cathepsin-B-Menge durch Expression des CBG-Fusionsproteins zu verstärkter membrangebundener Cathepsin-B-Expression auf den Zellen der CBG-Klone führen. Analog zur Bestimmung der intrazellulären Cathepsin-BMenge wurde daher die oberflächengebundene Cathepsin-B-Expression der Zellen der CBG-Klone in der Durchflusszytometrie analysiert. Es wurde der gleiche anti-Cathepsin-BAntikörper eingesetzt, die Zellen wurden vor der Reaktion jedoch nicht fixiert und permeabilisiert, sodass der Antikörper nur Proteine binden konnte, die extrazellulär mit der Zellmembran verbunden waren.

Durchflusszytometrisch konnte eine membrangebundene Cathepsin-B-Expression auf den Zellen der LV-Klone nicht nachgewiesen werden. Die Verteilung der Cathepsin-B-Aktivität in den Zellen der LV-Klone wurde daher später in der Laser-Scanning-Mikroskopie untersucht. Die Zellen der CBG-Klone hingegen zeigten eine geringe Bindung des anti-Cathepsin-B-Antikörpers auf der Zelloberfläche. Dies könnte ein Hinweis auf einen Transport des endogenen Cathepsin B oder des CBG-Fusionsproteins zur Zellmembran der RMA-Lymphomzellen sein. Auch hier erfolgte eine weitergehende Analyse der Verteilung der Cathepsin-B-Aktivität sowie auch der Verteilung des CBG-Fusionsproteins mit Hilfe der 
Laser-Scanning-Mikroskopie Außerdem wurde eine Analyse der Prozessierung des CBG-Fusionsproteins im Immunoblot angeschlossen.

Auch bei den Zellen der MCBG-Klone wurde die zellmembranassoziierte Cathepsin-BExpression durchflusszytometrisch untersucht. Die MCBG-Klone wurden speziell zur Untersuchung der Funktion von zellmembrangebundenem Cathepsin B hergestellt, wobei das MCBG-Fusionsprotein über die angefügte H2K-Leadersequenz direkt zur Zellmembran geführt und dort mit der H2K-Transmembrandomäne verankert werden sollte. Die beschriebene zellmembranassoziierte Cathepsin-B-Expression von Tumorzellen und zytotoxischen T-Zellen sollte so nachgebildet werden. Die Messung der oberflächengebundenen Cathepsin-B-Menge erfolgte wie bei den Zellen der LV- und der CBG-Klone. Eine membranassoziierte Cathepsin-B-Expression war auf den Zellen beider MCBG-Klone nachweisbar, diese war allerdings geringer als erwartet und in der Intensität vergleichbar mit der oberflächenassoziierten Cathepsin-B-Expression der Zellen der CBG-Klone.

Zur Untersuchung, ob diese membrangebundene Cathepsin-B-Expression auf das MCBG-Fusionsprotein oder auf endogenes Cathepsin B zurückzuführen war, wurde daher der spezifische Nachweis des Fusionsproteins über den HA-Tag angeschlossen. Die membrangebundene Expression des MCBG-Fusionsproteins sollte so unabhängig von anderen membrangebundenen Proteinen dargestellt werden. Außerdem sollte die N-terminale Lage des HA-Tags im MCBG-Fusionsprotein eine gute extrazelluläre Exposition gegenüber dem eingesetzten Antikörper zulassen. Eine Beeinträchtigung der Antikörperbindung durch andere Teile des Fusionsproteins oder durch die Membranassoziation selbst, wie sie bei Verwendung des anti-Cathepsin-B-Antikörpers nicht ausgeschlossen werden konnte, war daher unwahrscheinlich. Zellen der LV-Klone exprimierten keinen HA-Tag und dienten so als Negativkontrollen.

Die durchflusszytometrische Messung der Fluoreszenz unpermeabilisierter Zellen ergab sowohl bei den Zellen der LV-Klone als auch bei den Zellen der MCBG-Klone keinen Nachweis einer extrazellulären Bindung des anti-HA-Tag-Antikörpers. Das MCBG-Fusionsprotein konnte über seinen HA-Tag nicht auf der Oberfläche der Zellen der MCBG-Klone nachgewiesen werden. Auch die Expression des MCBG-Fusionsproteins wurde daher im Immunoblot und in der Laser-Scanning-Mikroskopie weiter untersucht.

Im Immunoblot wurden die Proteine aus den Zelllysaten der verschiedenen Klone elektrophoretisch ihrem Molekulargewicht entsprechend aufgetrennt und auf eine Nitrozellulosemembran geblottet. Die Cathepsin-B-haltigen Proteine wurden im Anschluss über eine Immunreaktion mit einem anti-Cathepsin-B-Antikörper nachgewiesen. Aufgrund der Größenunterschiede zwischen den Fusionsproteinen und den endogenen Cathepsin-BFormen konnte eine unabhängige Betrachtung der Expression dieser Proteine erfolgen. Auch die Prozessierung der Proteine konnte orientierend beurteilt werden, da sich die Molekulargewichte der verschiedenen Prozessierungsstufen des endogenen Cathepsin B wie auch des CBG-Fusionsproteins unterschieden.

Mit Zelllysaten des Klons LV-5 wurde die regelhafte Expression von endogenem Cathepsin B dargestellt. Sie dienten in der vergleichenden Analyse als Referenz unveränderter Cathepsin-B-Expression. Der Immunoblot zeigte Cathepsin B in seinen reifen Formen sowie auch das etwas größere Pro-Cathepsin B. 
Die Lysate von Zellen der CBG-Klone wiesen neben endogenem Cathepsin B zusätzlich auch das CBG-Konstrukt als Cathepsin-B-haltiges Protein auf. Es konnte als einzelne Bande bei $59 \mathrm{kDa}$ dargestellt werden und entsprach somit der erwarteten Größe der reifen einkettigen Cathepsin-B-Form mit angehängtem eGFP. Dies zeigte einerseits, dass Pre- und Pro-Peptid des Cathepsin-B-Anteils des CBG-Fusionsproteins wie erwartet abgespalten wurden, andererseits blieb hierbei der eGFP-Anteil mit der Cathepsin-B-Kette verbunden. Die Prozessierung des Fusionsproteins erfolgte auch mit angefügtem eGFP analog zu der des endogenen Cathepsin B. Der Nachweis von unprozessiertem CBG-Fusionsprotein mit erhaltenem Pro-Peptid bei etwa $73 \mathrm{kDa}$ fehlte, was möglicherweise auf einer schnellen und effektiven Abspaltung des Pro-Peptids vom CBG-Fusionsprotein beruhte. Außerdem konnte gezeigt werden, dass die Zellen auch weiterhin nicht eGFP-markiertes, also endogenes, Pro-Cathepsin B und Cathepsin B enthielten.

Eine gleichartige Analyse wurde auch mit Zelllysaten der MCBG-Klone durchgeführt. Aufgrund der nur geringen zellmembranassoziierten Cathepsin-B-Expression bei gleichzeitiger deutlicher Steigerung der eGFP-Fluoreszenz sowie der intrazellulären Cathepsin-B-Menge sollte insbesondere eine unerwünschte Spaltung des Fusionsproteins im Bereich der Transmembrandomäne ausgeschlossen werden. Neben einer leichten Steigerung der Intensität der Banden von Cathepsin B und Pro-Cathepsin B konnte in den Zelllysaten beider Klone auch das MCBG-Fusionsprotein als klare Bande bei $61 \mathrm{kDa}$ dargestellt werden. Eine ebenfalls nur in den Zellen der MCBG-Klone vorkommende sehr feine Bande etwas geringerer Molekülgröße entsprach möglichweise einer gespaltenen Form des Fusionsproteins, war jedoch in ihrer Intensität deutlich geringer. Ein Teil des MCBGFusionsproteins lag somit in intakter Form in den Zellen vor. Die nur geringe membrangebundene Cathepsin-B-Expression sowie auch der fehlende Nachweis des HA-Tags auf der Membran der Zellen der MCBG-Klone war nicht auf eine fehlerhafte Prozessierung oder auf einen Abbau des MCBG-Fusionsproteins zurückzuführen. Die zelluläre Verteilung des MCBG-Fusionsproteins musste daher weiter untersucht werden.

Da die Expression beider Fusionsproteine sowohl in der Durchflusszytometrie als auch im Immunoblot nachgewiesen war, der zelluläre Transport der Fusionsproteine innerhalb der Zellen aber noch unbekannt blieb, erfolgte die Analyse der intrazellulären Verteilung der Fusionsproteine mit Hilfe der Laser-Scanning-Mikroskopie. Gleichzeitig wurde auch die Verteilung der Cathepsin-B-Aktivität in den betrachteten Zellen analysiert. Die Fusionsproteine wurden anhand der Fluoreszenz ihres eGFP-Anteils dargestellt, der Nachweis der Cathepsin-B-Aktivität erfolgte mit Hilfe des Magic-Red ${ }^{\mathrm{TM}}$-Cathepsin-BDetection-Kits. Das roten Fluorophor Magic Red ${ }^{\mathrm{TM}}$ drang in gebundener, nichtfluoreszierender Form in die Zellen ein, lokale Cathepsin-B-Aktivität katalysierte dann innerhalb der einzelnen Zellkompartimente die Freisetzung des Magic-Red ${ }^{\mathrm{TM}}$-Farbstoffs, dessen rote Fluoreszenz in der Laser-Scanning-Mikroskopie dargestellt wurde. Die Freisetzung von Magic Red ${ }^{\mathrm{TM}}$ erfolgte laut Herstellerangaben spezifisch nur durch aktives Cathepsin B. Einerseits konnten so Veränderungen der Cathepsin-B-Aktivität in Zellen der Klone die die Fusionsproteine exprimierten dargestellt und direkt den entsprechenden Zellkompartimenten zugeordnet werden, andererseits konnte der Vergleich der Verteilung von Cathepsin-B-Aktivität und eGFP-Fluoreszenz auch Hinweise auf die enzymatische Aktivität der Fusionsproteine liefern.

Die zunächst betrachteten LV-Zellen dienten als Vergleichszellen unveränderter Cathepsin-B-Expression, da ihre Cathepsin-B-Aktivität ausschließlich auf endogenes Cathepsin B zurückzuführen war. Außerdem sollte auch eine eventuelle membranassoziierte 
Cathepsin-B-Expression, wie sie aufgrund von Untersuchungen zur Lyse von RMA-Zellen in Anwesenheit von zellmembranimpermeablen Cathepsin-B-Inhibitoren vermutet wurde (Ensslen 2009), untersucht werden.

Die Cathepsin-B-Aktivität in den Zellen der LV-Klone konzentrierte sich auf die Kernmembran, perinukleäre Vesikel und geringer auch auf den Bereich der Zellmembran. Sie entsprach damit der beschriebenen Verteilung der Cathepsin-B-Aktivität in Tumorzellen (Spiess et al. 1994). Die membrangebundene Cathepsin-B-Expression vor RMA-Zellen war hier, anders als in der Durchflusszytometrie, darstellbar.

Neben der Verteilung der Cathepsin-B-Aktivität wurde auch die Verteilung von freiem eGFP untersucht. Dieses verteilte sich diffus im Zytoplasma und sparte die beschriebenen Kompartimente der Cathepsin-B-Aktivität aus. Eine artifizielle Assoziation von eGFP-Fluoreszenz und mittels Magic Red ${ }^{\mathrm{TM}}$ nachgewiesener Cathepsin-B-Aktivität konnte so ausgeschlossen werden.

Die Bestimmung der Verteilung des CBG-Fusionsproteins sowie der Cathepsin-B-Aktivität in Zellen der CBG-Klone erfolgte analog. Da eine C-terminale Verknüpfung eines Proteins mit eGFP in der Regel weder seine Aktivität noch seine intrazelluläre Verteilung beeinflusst (Cygler et al. 1996), wurde erwartet, dass sich das CBG-Fusionsprotein wie endogenes Cathepsin B im endoplasmatischen Retikulum und perinukleären Lysosomen nachweisen ließ. Auch der durchflusszytometrische Nachweis von zellmembranassoziiertem Cathepsin B an den Zellen der CBG-Klone sollte in der Laser-Scanning-Mikroskopie bestätigt werden.

Die intrazelluläre Verteilung des Fusionsproteins entsprach exakt der erwarteten Verteilung in zellkernassoziierten Membranen, perinukleären Vesikeln und auch an der Zellmembran. Diese korrelierte außerdem mit der Verteilung der Cathepsin-B-Aktivität der betrachteten Zellen, welche sich wiederum nicht von der Verteilung der Cathepsin-B-Aktivität in Zellen der LV-Klone unterschied. Da sich das CBG-Fusionsprotein somit genau wie das ebenfalls in den Zellen vorhandene endogene Cathepsin B verhielt und da die Untersuchung keine quantitative Aussage zur Cathepsin-B-Aktivität erlaubte, konnte eine Veränderung der zellulären Cathepsin-B-Aktivität durch das Fusionsprotein nicht beurteilt werden. Die enzymatische Aktivität des Fusionsproteins konnte nicht sicher bestätigt werden, wenngleich sich kein Hinweis auf eine eingeschränkte Aktivität des Fusionsproteins ergab. Eine über die eGFP-Fluoreszenz nachgewiesene Anreicherung des CBG-Fusionsproteins ohne gleich lokalisierte Cathepsin-B-Aktivität wurde nicht beobachtet.

Auch die Verteilung des MCBG-Fusionsproteins wurde in der Laser-Scanning-Mikroskopie untersucht. Die kräftige Expression des Fusionsproteins war sowohl in der Durchflusszytometrie als auch im Immunoblot nachweisbar. Dennoch führte seine Expression nur zu einer leichten Steigerung der membrangebundenen Cathepsin-B-Menge und das Fusionsprotein selbst war durchflusszytometrisch über seinen HA-Tag nicht auf der Zellmembran darstellbar. In der Laser-Scanning-Mikroskopie sollte nun eine direkte Detektion des Fusionsproteins anhand der Fluoreszenz seines eGFP-Anteils unabhängig von der Interaktion mit Antikörpern erfolgen. Auch die Verteilung der Cathepsin-B-Aktivität in den Zellen der MCBG-Klone wurde in der Laser-Scanning-Mikroskopie dargestellt.

Das MCBG-Fusionsprotein war in zellkernassoziierten Membranen sowie in perinukleären Vesikeln nachweisbar. Seine Anreicherung an der Zellmembran war nur sehr gering. Obwohl der Cathepsin-B-Anteil des MCBG-Fusionsproteins kein Pre- und kein Pro-Peptid 
enthielt und tumorzellassoziierte Cathepsin-B-Varianten ohne Pre- und Pro-Peptid das vesikuläre Zellkompartiment nicht erreichen sollten (Frosch et al. 1999), entsprach die Verteilung des MCBG-Fusionsproteins der des CBG-Fusionsproteins sowie auch der des endogenen Cathepsin B. Der H2K-Leader führte nicht $\mathrm{zu}$ einem Transport des Fusionsproteins zur Zellmembran.

Wie bei dieser Verteilung des MCBG-Fusionsproteins zu erwarten war, zeigte auch die Verteilung der Cathepsin-B-Aktivität keine Unterschiede zur beschriebenen Verteilung in den Zellen der LV-Klone und in den Zellen der CBG-Klone. Die Verteilung der Cathepsin-B-Aktivität korrelierte mit der Verteilung des Fusionsproteins; da sie allerdings wiederum auch der erwarteten Verteilung der endogenen Cathepsin-B-Aktivität entsprach, erlaubte dieses Ergebnis wie beim CBG-Fusionsprotein keine Aussage zur enzymatischen Aktivität des MCBG-Fusionsproteins.

Zusammenfassend ließ sich die Cathepsin-B-Expression der transfizierten RMA-Zellen wie folgt charakterisieren: Die LV-Klone zeigten neben der Expression von freiem eGFP geringe Cathepsin-B-Aktivität an der Zellmembran. Die Zellen der CBG- wie auch der MCBG-Klone wiesen im Vergleich dazu eine deutliche Steigerung der intrazellulären Cathepsin-B-Menge sowie eine geringgradige Steigerung der zellmembranassoziierten Expression von Cathepsin B auf. Das MCBG-Fusionsprotein verteilte sich wie endogenes Cathepsin B und wie das CBG-Fusionsprotein in den Zellen. Seine Expression auf der Zelloberfläche war nicht nachweisbar. Der Einfluss der beschriebenen Überexpression von Cathepsin B in den Zellen der CBG- und MCBG-Klone auf die Lyse durch zytotoxische T-Zellen wurde nun im Chrom-Freisetzungs-Test untersucht. Eine zytoprotektive Funktion der Cathepsin-B-Expression in Tumorzellen sollte sich als verminderte Lyse dieser Zellen im Vergleich zu Zellen der LV-Klone darstellen.

Zur Untersuchung des Einflusses von Cathepsin B auf die Lyse von Tumorzellen wurde der Chrom-Freisetzungs-Test mit den beschriebenen RMA-Zielzellen und zytotoxischen OT-I-T-Zellen als Killerzellen verwendet. Die zytotoxischen T-Zellen lysierten die RMA-Zielzellen in Anwesenheit des SIINFEKL-Peptids spezifisch durch Exozytose ihrer zytotoxischen Granula. Das Verhältnis von lysierten und intakten Zielzellen konnte nach vierstündiger Ko-Inkubation mit den Killerzellen anhand des Verhältnisses von freigesetztem $\mathrm{zu}$ zellulär gebundenem radioaktivem Chrom bestimmt werden. Unter Berücksichtigung der spontanen Chromfreisetzung der Zellen konnte so die Empfindlichkeit der Zielzellen gegenüber Granula-vermittelter Zytotoxizität ermittelt werden.

Da im Chrom-Freisetzungs-Test die Lyse der Zielzellen durch zytotoxische T-Zellen untersucht werden sollte, musste eine Lyse der Zielzellen durch andere Effektorzellen ausgeschlossen werden. Die Stimulation der Killerzellen erfolgte spezifisch für OT-I-T-Zellen, dennoch konnten sich weitere zytotoxische Zellen in den als Killerzellsuspensionen eingesetzten Lymphozytengemischen befinden. Die Lyse der Zielzellen durch andere Effektorzellen wurde daher in Kontrollmessungen bestimmt, bei denen kein SIINFEKL-Peptid zugesetzt wurde. Die OT-I-T-Zellen wurden so nicht aktiviert und lysierten die als Zielzellen eingesetzten untransfizierten RMA-Zellen nicht. Da die Lyseraten dieser Kontrollmessungen selbst bei hohen Killer-Zielzell-Verhältnissen der spontanen Lyse ohne Zugabe von Killerzellen entsprachen, war die dargestellte peptidspezifische Lyse der Zielzellen im Chrom-Freisetzungs-Test ausschließlich auf zytotoxische OT-I-T-Zellen zurückzuführen. 
Zytotoxische T-Zellen können Zielzellen über unterschiedliche Mechanismen der Zelltodinduktion lysieren (Kagi et al. 1994 a; Kagi et al. 1996). Die beschriebene Protektion zytotoxischer T-Zellen durch zellmembranassoziiertes Cathepsin B bezieht sich jedoch nur auf den Schutz vor den Inhaltsstoffen zytotoxischer Granula im Spalt der immunologischen Synapse (Balaji et al. 2002). Auch ein möglicher Cathepsin-B-vermittelter Immune-EscapeMechanismus von Tumorzellen sollte daher hauptsächlich einen Schutz gegenüber Granulaassoziierter Zytotoxizität darstellen. Um einen zytoprotektiven Effekt der Überexpression von Cathepsin B zu untersuchen, musste daher auch im Chrom-Freisetzungs-Test die Lyse der Zielzellen auf der Exozytose zytotoxischer Granula beruhen. Eine nicht Granulavermittelte Zytotoxizität durch die eingesetzten OT-I-T-Zellen wurde in Kontrollmessungen ausgeschlossen. Durch den Zusatz von EGTA/ $\mathrm{MgCl}_{2}$ zum Kulturmedium wurde freies Calcium entzogen, was die Exozytose zytotoxischer Granula inhibierte. Die Granulavermittelte Zytotoxizität war so unterbunden und andere Mechanismen der Zelltodinduktion durch OT-I-T-Zellen, wie beispielsweise die direkte Zytotoxizität durch Aktivierung von Todesrezeptoren durch Expression des FAS-Liganden konnten quantifiziert werden. Auch bei hohem Killer-Zielzell-Verhältnis unterschied sich die Lyserate untransfizierter RMAZellen bei EGTA/ $\mathrm{MgCl}_{2}$-Zugabe nicht von der spontanen Lyserate ohne die Einwirkung der Killerzellen. Die spezifische Lyse im Chrom-Freisetzungs-Test beruhte ausschließlich auf peptidspezifischer Granula-vermittelter Zytotoxizität durch die eingesetzten OT-I-TKillerzellen.

In einem Test wurden die gleichen Killerzellen für alle getesteten Zelllinien verwendet. Die spezifischen Lyseraten unterschiedlicher Zelllinien bei gleichem Killer-Zielzell-Verhältnis konnten daher direkt miteinander verglichen werden. Da die Tests aber mehrfach wiederholt und für jeden Test neue Killerzellen präpariert und stimuliert wurden, musste zusätzlich zur spezifischen Lyse als Differenz aus Lyserate mit und ohne Killerzellzugabe auch immer die relative Lyse als Verhältnis zur Lyse untransfizierter RMA-Zellen bei höchstem KillerZielzell-Verhältnis bestimmt werden. Die Ergebnisse verschiedener Tests konnten so in einer Gesamtauswertung dargestellt und die Lyseraten der Zelllinien testübergreifend und unabhängig von der jeweiligen Aktivität der Killerzellen verglichen werden.

Bei jedem Test musste außerdem sichergestellt werden, dass die eingesetzten Zellen eine ausreichende Fähigkeit zur Präsentation des SIINFEKL-Peptids aufwiesen. Das SIINFEKL-Peptid diente der Aktivierung der eingesetzten OT-I-T-Zellen über ihren transgenen T-Zell-Rezeptor, die das Protein bei Präsentation auf $\mathrm{H} 2 \mathrm{~K}^{\mathrm{b}}$ erkannten. Nur bei ausreichender $\mathrm{H} 2 \mathrm{~K}^{\mathrm{b}}$-Expression auf allen Zelllinien war sichergestellt, dass mögliche Unterschiede in der Lyse durch zytotoxische OT-I-T-Zellen auch tatsächlich auf die induzierten Veränderungen in der Cathepsin-B-Expression zurückzuführen waren. Insbesondere wurde gezeigt, dass auch die Expression des MCBG-Fusionsproteins mit seinem $\mathrm{H} 2 \mathrm{~K}$-Anteil die Expression von $\mathrm{H} 2 \mathrm{~K}^{\mathrm{b}}$ auf der Zellmembran nicht beeinflusste. Alle Zelllinien wiesen eine deutliche $\mathrm{H} 2 \mathrm{~K}^{\mathrm{b}}$-Expression auf und konnten so das zugegebene SIINFEKL-Peptid präsentieren.

Neben dem Ausschluss von Einschränkungen der SIINFEKL-Präsentation mussten weitere Cathepsin-B-unabhängige Einflüsse auf das Überleben der Zellen im Chrom-FreisetzungsTest ausgeschlossen werden. So konnte beispielsweise die Expression von eGFP oder auch die vorherige Kultivierung der CBG- und MCBG-Zelllinien in Geneticin-haltigem Medium mit einer damit einhergehenden möglichen Beeinträchtigung der Proteinbiosynthese Einfluss auf das Überleben der Zellen im Test haben. Um solche Verfälschungen auszuschließen wurden bei allen Chrom-Freisetzungs-Tests neben einer Positivkontrolle mit untransfizierten 
RMA-Zellen auch Kontrollmessungen mit Zellen beider LV-Klone durchgeführt. Sie exprimierten ebenfalls eGFP, waren klonal und wurden in Geneticin-haltigem Medium kultiviert. Sie konnten somit zur quantitativen Analyse dieser Einflüsse genutzt werden. Alle genannten Faktoren hatten keinen Einfluss auf die Lyse der RMA-Zellen. Die relative Lyse der Zellen beider LV-Klone entsprach bei allen Killer-Zielzell-Verhältnissen in etwa der Lyse untransfizierter RMA-Zellen.

Zur Untersuchung, ob eine gesteigerte lysosomale Cathepsin-B-Expression Einfluss auf die Lyse der Zellen durch zytotoxische T-Zellen hat, wurde die Lyse der Zellen der CBG-Klone im Chrom-Freisetzungs-Test ermittelt und mit der Lyse von untransfizierten RMA-Zellen sowie mit der Lyse von Zellen der LV-Klone verglichen. Die Expression des CBG-Fusionsproteins beeinflusste den Anteil lysierter Zellen auch bei verschiedenen KillerZielzell-Verhältnissen nicht. Die Steigerung der lysosomalen Cathepsin-B-Menge durch Expression des CBG-Fusionsproteins stellte somit keinen Immune-Escape-Mechanismus dar.

Der von Perforin abhängige Schritt der Granula-vermittelten Zytotoxizität ist die Freisetzung von unabhängig von Perforin in die Zielzelle eingedrungenen Granzymen aus intrazellulären Kompartimenten (Pinkoski et al. 1998). Das MCBG-Fusionsprotein verteilte sich wie endogenes Cathepsin B innerhalb der Zelle und führte nur zu einem geringen Anstieg der extrazellulär bestimmten Cathepsin-B-Menge. Möglicherweise lagerte es sich mit seiner erhaltenen Transmembrandomäne in intrazellulären Membranen ein. Seine Cathepsin-BAktivität könnte daher Perforin direkt am Ort seiner zelltodvermittelnden Wirkung inaktivieren und so einen möglichen Immune-Escape-Mechanismus von Tumorzellen abbilden.

Die Ermittlung der Lyse der Zellen der MCBG-Klone zeigte allerdings, dass die Expression des MCBG-Fusionsproteins keinen Einfluss auf die Empfindlichkeit von RMA-Zellen gegenüber zytotoxischen OT-I-T-Zellen hatte. Sie wurden in gleicher Stärke wie untransfizierte RMA-Zellen und wie Zellen der LV- und CBG-Klone lysiert. Da auch hier durch Negativkontrollen eine nicht durch Granula verursachte Lyse sowie eine nicht-peptidspezifische Lyse der Zielzellen ausgeschlossen war, wurde so gezeigt, dass auch die Expression des MCBG-Fusionsproteins die Zellen nicht vor Granula-vermittelter Zytotoxizität durch T-Zellen schützte.

Die beschriebenen Experimente lieferten keinen Hinweis auf eine zytoprotektive Funktion veränderter Cathepsin-B-Expression in Zielzellen zytotoxischer T-Zellen. Die RMA-Zielzellen wurden unabhängig von der Expression der Fusionsproteine lysiert, obwohl die Zellen der CBG-Klone wie auch die der MCBG-Klone eine deutliche Cathepsin-BÜberexpression aufwiesen und sich beide Fusionsproteine auch ähnlich dem endogenen Cathepsin B in den Zellen verteilten.

Dies könnte einerseits darauf zurückzuführen sein, dass ein solcher Mechanismus initial überschätzt wurde (Balaji et al. 2002). Andererseits konnte nicht ausgeschlossen werden, dass CBG- und MCBG-Klone die Cathepsin-B-Überexpression in Tumorzellen nicht ausreichend abbildeten und so ein darauf beruhender Immune-Escape-Mechanismus in den durchgeführten Experimenten nicht nachgewiesen werden konnte.

Ursache einer fehlenden Darstellbarkeit eines Cathepsin-B-vermittelten Immune-EscapeMechanismus könnte eine veränderte Aktivität der Fusionsproteine gewesen sein. Ein zytoprotektiver Effekt der Fusionsproteine konnte nur erwartet werden, wenn nicht nur ihre 
Verteilung innerhalb der Zellen sondern auch ihre enzymatische Aktivität der des Cathepsin B in Tumorzellen entsprach.

Eine gegenseitige Beeinflussung der verschiedenen Bestandteile stellt ein generelles Problem bei der Arbeit mit Fusionsproteinen dar und könnte auch bei den CBG- und MCBG-Fusionsproteinen zu verminderter enzymatischer Aktivität der Cathepsin-B-Anteile geführt haben. Bei der Planung beider Fusionsproteine wurde die Auswahl und Kombination der einzelnen Elemente daher so gewählt, dass die Wahrscheinlichkeit relevanter Wechselwirkungen minimiert wurde. Zur Fluoreszenzmarkierung beider Fusionsproteine wurde das eGFP-Fluorophor gewählt. In der Literatur ist beschrieben, dass die C-terminale Verknüpfung eines Proteins mit eGFP die Eigenschaften des Ursprungsproteins in der Regel nicht verändert (Cygler et al. 1996). Speziell das CBG-Fusionsprotein sollte daher keine relevanten intramolekularen Wechselwirkungen aufweisen.

Die Gestaltung des MCBG-Fusionsproteins war deutlich komplexer, aber auch hier wurde eine Interaktion der Einzelbestandteile soweit möglich bereits bei der Konstruktion ausgeschlossen. Die eGFP-Markierung erfolgte durch intrazelluläre Verknüpfung mit der H2K-Transmembrandomäne, die wiederum extrazellulär mit der Cathepsin-B-Kette verbunden war. Eine gegenseitige Beeinflussung von Cathepsin B und eGFP war daher bei Einlagerung des Fusionsproteins in eine Membran nahezu ausgeschlossen und auch die Einlagerung der Transmembrandomäne in die Zellmembran sollte durch das angefügte eGFP nicht beeinträchtigt sein (Simonova et al. 1999). Durch flexible Verbindung der Cathepsin-B-Kette mit der Transmembrandomäne über eine kurze zwischengeschaltete Sequenz wurde auch die Wahrscheinlichkeit einer Hemmung des Cathepsin-B-Anteils durch die direkte Nachbarschaft zur Zellmembran minimiert. Als weiterer Bestandteil des Fusionsproteins lag der HA-Tag am N-Terminus der Cathepsin-B-Kette. Bei korrekter Faltung des Cathepsin B befand er sich daher deutlich außerhalb des aktiven Zentrums (Musil et al. 1991). Hier war ein Einfluss seinerseits auf die enzymatische Aktivität des Fusionsproteins auch aufgrund seiner geringen Größe von nur neun Aminosäuren unwahrscheinlich.

Neben der reinen Aktivität konnte aber auch die Prozessierung der Fusionsproteine durch die angefügten weiteren Bestandteile beeinträchtigt sein. Beim CBG-Konstrukt wurden Pre- und Pro-Peptid erhalten, da diese auch bei natürlichem Cathepsin B möglicherweise zur korrekten Faltung der Cathepsin-B-Kette beitragen (McGrath 1999). Zur Aktivierung mussten sie am endoplasmatischen Retikulum beziehungsweise in den Lysosomen abgespalten werden (Mort und Buttle 1997). Eine Beeinflussung dieser Prozessierung durch das angehängte eGFP war unwahrscheinlich, da die Abspaltung des Pre-Peptids von Cathepsin B bereits kotranslational erfolgt (Mort und Buttle 1997) und die Abspaltung des Pro-Peptids durch verschiedene Proteasen und sogar als unimolekulare Autoprozessierung erfolgen kann (Rowan et al. 1992). Auch die Darstellung der Molekülgröße im Immunoblot deutete auf eine korrekte Prozessierung des CBG-Fusionsproteins hin. Da Cathepsin B nach Abspaltung des Pro-Peptids ohne weitere Umlagerungen direkt in seiner einkettigen enzymatisch aktiven Form vorliegt (Cygler et al. 1996; Takio et al. 1983), gab es auch für das CBG-Fusionsprotein keinen Hinweis, dass nach der Abspaltung des Pro-Peptids eine weitere Prozessierung zur Erlangung der enzymatischen Aktivität erforderlich war. Auch Untersuchungen an einem Fusionsprotein aus eGFP und dem strukturell dem MausCathepsin B sehr ähnlichen Cathepsin B der Ratte unterstützen diese Annahme. Die Eigenschaften dieses Fusionsproteins glichen denen des CBG-Fusionsproteins sowohl im Immunoblot als auch in der Laser-Scanning-Mikroskopie. Für dieses Protein konnte in 
einem Enzymassay der Erhalt der enzymatischen Aktivität von Cathepsin B auch bei Verknüpfung mit eGFP gezeigt werden (Linke et al. 2002).

Beim MCBG-Fusionsprotein erfolgte keine Aktivierung der Cathepsin-B-Kette. Da das Fusionsprotein durch Verknüpfung mit dem H2K-Leader und der H2K-Transmembrandomäne nicht wie endogenes Cathepsin B in den Lysosomen aktiviert werden konnte, musste die Protease so in das Fusionsprotein integriert werden, dass sie auch ohne Prozessierung in enzymatisch aktiver Form vorlag. Aus diesem Grund wurde nur der Bereich der Cathepsin-B-cDNA verwendet, der für den Teil von Cathepsin B kodierte, der als einkettige aktive Form auf der Oberfläche zytotoxischer T-Zellen nach der Degranulation nachgewiesen war (Balaji et al. 2002). Der Cathepsin-B-Teil des MCBG-Fusionsproteins sollte daher auch ohne Prozessierung in einer enzymatisch aktiven Form vorliegen, die der Form entsprach, die auch bei zytotoxischen T-Lymphozyten den Schutz vor der Lyse durch die eigenen zytotoxischen Granula vermittelt.

Eine fehlende Aktivität beider Fusionsproteine als Ursache einer Unterschätzung der zytoprotektiven Funktion von Cathepsin B im Chrom-Freisetzungs-Test war aus den oben genannten Gründen unwahrscheinlich, nicht aber vollkommen auszuschließen. Darüber hinaus war es auch denkbar, dass ein Schutz der RMA-Zellen durch die Fusionsproteine zwar existierte, aufgrund einer zu geringen Steigerung der Cathepsin-B-Expression durch die Fusionsproteine in den durchgeführten Tests aber nicht nachweisbar war. Zytotoxische T-Zellen schützen sich durch lokale und transiente Expression von Cathepsin B am Ort der Immunologischen Synapse (Balaji et al. 2002). Ein Schutz der gesamten Zelle erforderte daher möglicherweise eine wesentlich höhere Steigerung der Cathepsin-B-Expression, als mit den Fusionsproteinen erreicht wurde, obwohl diese unter Kontrolle des speziell wegen seiner sehr hohen Expressionsraten verwendeten CAG-Promotors standen (Xu et al. 2001). Eine zu geringe Expressionsstärke der Fusionsproteine könnte auch durch eine mögliche kompensatorische Gegenregulation der endogenen Cathepsin-B-Synthese nach der Transfektion noch verstärkt worden sein. Eine deutliche Reduktion der Menge von nicht eGFP-markiertem Pro-Cathepsin B und Cathepsin B in den Zelllysaten der CBG- und MCBG-Klone war im Immunoblot allerdings nicht nachweisbar.

Auch die beschriebene endogene Cathepsin-B-Expression der RMA-Zellen könnte den Nachweis eines zytoprotektiven Effekts der Fusionsproteine erschwert haben. RMA-Zellen sind Tumorzellen, die sich auch ohne Expression der Fusionsproteine bereits durch zellmembranassoziierte Cathepsin-B-Aktivität in gewissem Außmaß vor der Lyse durch zytotoxische T-Zellen schützen (Ensslen 2009). Möglicherweise bedingte diese membranassoziierte Cathepsin-B-Expression in untransfizierten RMA-Zellen bereits das Maximum eines durch Cathepsin B vermittelbaren zytoprotektiven Effekts. Eine weitere Steigerung der Cathepsin-B-Expression konnte dann keine zusätzliche Zytoprotektion mehr verursachen. Dies war allerdings unwahrscheinlich, da einerseits die auf der Zellmembran der RMA-Zellen detektierbare Cathepsin-B-Menge nur sehr gering war und andererseits auch die Hemmung der extrazellulären Cathepsin-B-Aktivität nur zu einer geringen Steigerung der Empfindlichkeit der RMA-Zellen gegenüber Granula-vermittelter Zytotoxizität führte (Ensslen 2009).

Neben diesen Aspekten musste zur Interpretation der Ergebnisse auch berücksichtigt werden, dass für Cathepsin B in anderem Zusammenhang auch proapoptotische Effekte beschrieben sind. In Prostata und Brustdrüse wirkt Cathepsin B als Effektorprotease der Apoptose (Tenniswood et al. 1992) und im Rahmen der Apoptose von Leberzellen konnte 
sogar gezeigt werden, dass ein Cathepsin-B-eGFP-Fusionsprotein, welches dem CBG-Fusionsprotein sehr ähnlich ist, in den Zellkern transportiert wurde und dort an der Apoptose beteiligt war (Roberts et al. 1997). Die fluoreszenzmikroskopischen Bilder gaben keinen Hinweis auf eine solche Funktion der Fusionsproteine in den Zellen der CBG- oder MCBG-Klone, es konnte jedoch nicht ausgeschlossen werden, dass die Expression der Fusionsproteine zu schnellerer oder effektiverer Apoptose nach der Zelltodinduktion durch zytotoxische T-Zellen führte. Auch das könnte einen zytoprotektiven Effekt der Fusionsproteine verborgen haben.

Auch wenn nicht ausgeschlossen werden konnte, dass der fehlende Nachweis eines zytoprotektiven Effekts der Überexpression von Cathepsin B in Zielzellen zytotoxischer T-Zellen auf eine unzureichende Abbildung der Cathepsin-B-Expression von Tumorzellen durch die Fusionsproteine zurückzuführen war, so führen die Ergebnisse dieser Arbeit dennoch dazu, dass die Existenz eines solchen Immune-Escape-Mechanismus kritisch betrachtet werden muss.

Die Hypothese einer zytoprotektiven Wirkung der Cathepsin-B-Überexpression von Zielzellen zytotoxischer T-Zellen beruht im Wesentlichen auf den Untersuchungen zum Selbstschutz der Killerzellen. Neuere Untersuchungen zeigen allerdings, dass dieser Selbstschutzmechanismus nicht zweifelsfrei auf Cathepsin B zurückzuführen ist. Die Autolyse zytotoxischer T-Zellen nach Granula-Exozytose war zwar bei Zugabe eines zellmembranimpermeablen Cathepsin-B-Inhibitors signifikant erhöht (Balaji et al. 2002), zytotoxische T-Zellen aus Cathepsin-B-defizienten Mäusen wurden allerdings nicht stärker lysiert als Cathepsin-B-exprimierende Kontrollzellen (Baran et al. 2006). Dieser Widerspruch ließe sich durch ein dem Cathepsin B ähnliches Enzym, welches zwar vom verwendeten Cathepsin-B-Inhibitor inaktiviert, in den Cathepsin-B-defizienten Zellen aber unvermindert exprimiert wird, erklären. Das ausschließlich von zytotoxischen Zellen exprimierte und bei der zytotoxischen Reaktion von diesen Zellen sezernierte Cathepsin W könnte ein solches alternatives Enzym darstellen (Stoeckle et al. 2009). Die Bedeutung von Cathepsin B für die Autolyse zytotoxischer T-Zellen ist daher nach wie vor unklar.

Auch zur Beurteilung eines Immune-Escape-Mechanismus von Tumorzellen durch zellmembranassoziierte Cathepsin-B-Expression liegen Experimente mit Cathepsin-BInhibitoren sowie mit einer Cathepsin-B-Knock-Out-Linie muriner embryonaler Fibroblasten vor. In beiden Untersuchungen konnte eine verstärkte Lyse derjenigen Zellen dargestellt werden, die in ihrer Cathepsin-B-Aktivität reduziert waren. Die InhibitorUntersuchungen zeigten allerdings keine eindeutige Dosis-Wirkungs-Beziehung und auch die Inhibition von intrazellulärem Cathepsin B mit einem zellmembranpermeablen Cathepsin-B-Inhibitor führte nicht zu einer Verstärkung der Lyse dieser Zielzellen im Chrom-Freisetzungs-Test (Ensslen 2009).

Diese unterschiedlichen Einflüsse der Modifikationen der Cathepsin-B-Aktivität auf die Lyse von zytotoxischen T-Zellen und Tumorzellen sind möglicherweise Resultat eines komplexen Immune-Escape-Mechanismus, bei dem die Expression von extrazellulärem Cathepsin B eine bedeutende Rolle spielen kann, nicht aber alleinige Ursache einer verminderten Empfindlichkeit der Zellen darstellt. Verschiedene Inhibitoren, der Knock-Out des Cathepsin-B-Gens sowie auch die Expression der Fusionsproteine könnten einen solchen komplexeren Immune-Escape-Mechanismus in unterschiedlicher Art beeinflussen und so die unterschiedlichen Ergebnisse der verschiedenen beschriebenen Experimente erklären. 
Die Frage nach der Bedeutung der Expression von Cathepsin B für den Selbstschutz zytotoxischer T-Zellen und vor allem die Bedeutung der Cathepsin-B-Expression als Immune-Escape-Mechanismus von Tumorzellen konnte durch Untersuchungen mit Cathepsin-B-Inhibitoren und Cathepsin-B-Knock-Out-Zellen bisher nicht eindeutig geklärt werden. In der vorliegenden Arbeit wurde daher ein experimenteller Ansatz gewählt, der die direktere Darstellung einen solchen Mechanismus in Tumorzellen ermöglichen sollte. Die Verstärkung der Cathepsin-B-Expression durch die Fusionsproteine unterschied sich von den beschriebenen Versuchen durch eine direkte Nachbildung der in Tumorzellen beschriebenen Cathepsin-B-Überexpression. Anders als bei den bisherigen Untersuchungen, die sich auf eine Reduktion der Cathepsin-B-Aktivität zur Analyse seiner Funktion beschränkten, sollte so erstmalig die Darstellung einer verminderten Lyse von Tumorzellen durch gesteigerte Cathepsin-B-Expression möglich sein. Diese konnte allerdings weder durch Expression einer lysosomalen Form von Cathepsin B noch durch die Expression eines Fusionsproteins aus Cathepsin B und einer Transmembrandomäne dargestellt werden. Die Expression der Cathepsin-B-Fusionsproteine stellte keinen Immune-Escape-Mechanismus für die eingesetzten RMA-Zellen dar. Die Überexpression von Cathepsin B hatte keinen wesentlichen Einfluss auf die Lyse der Zielzellen durch zytotoxische T-Zellen.

Untersuchungen mit weiteren zellmembranverankerten proteolytischen Enzymen oder mit Zellen mit deutlich stärkerer Überexpression von Cathepsin B können auf Grundlage der Ergebnisse dieser Arbeit erfolgen. Hierbei könnte die Verwendung von Cathepsin-Bdefizienten Zelllinien zu einer besseren Darstellbarkeit eines zytoprotektiven Effekts beitragen. 


\section{Zusammenfassung}

Das Immunsystem kann maligne Zellen erkennen und lysieren und so die Entstehung von Tumoren verhindern und das Wachstum bereits manifester Tumoren begrenzen. Einen wesentlichen Mechanismus stellt hierbei die Lyse entarteter Zellen durch zytotoxische T-Zellen dar. Diese erkennen veränderte Zellen anhand von Tumorantigenen und lysieren sie durch Freisetzung von Perforin und Granzymen aus präformierten zytotoxischen Granula. Im Rahmen der zytotoxischen Reaktion sind sowohl die Zielzellen als auch die Killerzellen den Zelltod-Mediatoren ausgesetzt, die Killerzellen überleben diesen Kontakt allerdings. Ihre Unempfindlichkeit wird auf eine lokale membrangebundene Expression der sonst lysosomalen Protease Cathepsin B am Ort der immunologischen Synapse zurückgeführt, wobei Cathepsin B die Killerzellen durch Spaltung von Perforin vor der Autolyse schützen soll.

Oberflächenassoziierte Cathepsin-B-Aktivität ist aber nicht nur bei zytotoxischen T-Zellen nach der Granula-Exozytose beschrieben. Auch verschiedene Tumorzellen exprimieren die Protease in membrangebundener Form. Erste Untersuchungen mit Cathepsin-B-Inhibitoren und Cathepsin-B-defizienten Zelllinien zeigten auch bei Tumorzellen, dass eine Reduktion zellmembranassoziierter Cathepsin-B-Aktivität ihre Empfindlichkeit gegenüber Granulaassoziierter Zytotoxizität verstärkt.

In dieser Arbeit wurde daher untersucht, ob die in Tumorzellen beschriebene Überexpression von Cathepsin B im Umkehrschluss auch einen Immune-EscapeMechanismus gegenüber Granula-assoziierter Zytotoxizität darstellt. Erstmals wurden nicht die Effekte einer Reduktion der Cathepsin-B-Aktivität auf die Lyse durch zytotoxische T-Zellen bestimmt, vielmehr wurde die Cathepsin-B-Expression von RMA-Lymphomzellen durch Transfektion mit zwei unterschiedlichen Expressionskonstrukten gesteigert und der Einfluss dieser den Tumorzellen nachempfundenen Überexpression von Cathepsin B auf die Lyse durch zytotoxische T-Zellen im Chrom-Freisetzungs-Test analysiert.

Zur Untersuchung des zytoprotektiven Effekts einer Überexpression lysosomaler Cathepsin-B-Formen wurde das CBG-Konstrukt entwickelt. Es kodierte für ein Fusionsprotein aus Cathepsin B und eGFP, wobei der Cathepsin-B-Teil endogenem Pre-Pro-Cathepsin B entsprach. Das Fusionsprotein sollte sich daher wie endogenes Cathepsin B verhalten, lediglich seine Expressionsstärke sollte durch Verwendung des CAG-Promotors gesteigert werden. Über seine eGFP-Fluoreszenz wurde die Expression des Fusionsproteins bestätigt und stabil transfizierte Zelllinien durch Grenzverdünnungsreihen erstellt. Die erwartete Steigerung der intrazellulären Cathepsin-B-Menge konnte durchflusszytometrisch ebenso dargestellt werden wie eine leichte Steigerung der membranassoziierten Cathepsin-B-Expression der transfizierten Zellen. Die Prozessierung des Fusionsproteins analog zu der des endogenen Cathepsin B wurde im Immunoblot anhand der Molekülgröße bestätigt. In der Laser-Scanning-Mikroskopie wurde gezeigt, dass die Verteilung der Cathepsin-B-Aktivität in den Zellen der CBG-Klone der Verteilung der Cathepsin-B-Expression in den Kontrollzellen entsprach und auch mit der zellulären Verteilung des Fusionsproteins übereinstimmte. Die Zellen der CBG-Klone konnten so zur Untersuchung des Effekts einer Überexpression von lysosomalem Cathepsin B auf die Lyse durch zytotoxische T-Zellen verwendet werden.

Um den Einfluss von membrangebundenem Cathepsin B auf die Lyse durch zytotoxische T-Zellen zu analysieren, wurde ein weiteres Konstrukt erstellt. Das MCBG-Konstrukt 
kodierte für ein Fusionsprotein bestehend aus der einkettigen aktiven Form von Cathepsin B und der Transmembrandomäne von H2K. Nach der Transfektion in RMA-Lymphomzellen wurden wiederum stabil transfizierte klonale Zelllinien hergestellt. Die Expression des MCBG-Fusionsproteins wurde anhand der eGFP-Fluoreszenz der Zellen in der Durchflusszytometrie bestimmt und zwei Ziellinien vergleichbarer Expressionsstärke für die anschließenden Experimente ausgewählt. Die Expression des MCBG-Fusionsproteins führte zu einer Steigerung der durchflusszytometrisch nachweisbaren intrazellulären Cathepsin-BMenge, eine Assoziation des Fusionsproteins mit der Zellmembran konnte mit Hilfe des eingefügten HA-Tags allerdings nicht gezeigt werden. Die Steigerung der zellmembranassoziierten Cathepsin-B-Menge war bei den Zellen der MCBG-Klone nur gering. Im Immunoblot wurde die kräftige Expression des Fusionsproteins bestätigt und auch eine unerwünschte Spaltung des Fusionsproteins ausgeschlossen. In der LaserScanning-Mikroskopie zeigte sich, dass sich das MCBG-Fusionsprotein wie endogenes Cathepsin B in den Zellen verteilte. Möglicherweise lagerte es sich mit seiner erhaltenen Transmembrandomäne in intrazelluläre Membranen ein.

Der Einfluss der gesteigerten Cathepsin-B-Expression auf die Lyse der RMA-Zellen durch zytotoxische T-Zellen wurde im Chrom-Freisetzungs-Test analysiert. Zellen der Klone beider Konstrukte wurden peptidspezifisch durch zytotoxische T-Zellen über den GranulaExozytose-Weg lysiert und die Stärke der zytotoxischen Reaktion am Anteil lysierter Zielzellen gemessen. Hierbei zeigte sich, dass weder die Expression des CBG-Fusionsproteins noch die möglicherweise membranassoziierte Expression des MCBG-Fusionsproteins die Lyse der RMA-Zellen beeinflusste. Die Überexpression von Cathepsin B stellte keinen Immune-Escape-Mechanismus dar.

Dieses Ergebnis war zunächst unerwartet, da wie oben beschrieben die Reduktion der zellmembranassoziierten Cathepsin-B-Aktivität von RMA-Zellen zu einer gesteigerten Empfindlichkeit dieser Zellen gegenüber Granula-assoziierter Zytotoxizität führte. Der daraufhin postulierte Cathepsin-B-assoziierte Immune-Escape-Mechanismus wurde, wie bei zytotoxischen T-Zellen beschrieben, auf die proteolytische Inaktivierung von Perforin durch zellmembranassoziiertes Cathepsin B zurückgeführt, sodass im Umkehrschluss auch eine Reduktion der Empfindlichkeit durch gesteigerte Cathepsin-B-Expression erwartet werden musste. Da jedoch weder die Überexpression von lysosomalem Cathepsin B noch die Expression des membranassoziierten Fusionsproteins einen wesentlichen Einfluss auf die Lyse der Zellen durch zytotoxische T-Zellen hatte, zeigt diese Arbeit, dass Cathepsin B allein nicht $\mathrm{zu}$ einer Inaktivierung von Zelltod-Mediatoren führt. Auch aktuelle Untersuchungen zum Selbstschutz zytotoxischer T-Zellen zeigen, dass Cathepsin B zwar zum Schutz der Zellen vor Granula-assoziierter Zytotoxizität beiträgt, für diesen aber nicht allein verantwortlich ist. Hier führt die Hemmung membrangebundener Cathepsin-BAktivität ebenfalls zu einer Autolyse zytotoxischer T-Zellen nach der Freisetzung ihrer zytotoxischen Granula, eine vollständige Cathepsin-B-Defizienz der Killerzellen beeinflusst ihren Selbstschutz allerdings nicht.

Weitere Untersuchungen zur Beschreibung eines Cathepsin-B-assoziierten Immune-EscapeMechanismus sowohl von Tumorzellen als auch von zytotoxischen T-Zellen sind daher notwendig. 


\section{Literaturverzeichnis}

Abdollahi A, Getts LA, Sonoda G, Miller PD, Taguchi T, Godwin AK, Testa JR und Hamilton TC (1999): Genome scanning detects amplification of the cathepsin B gene (CtsB) in transformed rat ovarian surface epithelial cells. J Soc Gynecol Investig $\underline{6}, 32-40$

Ackerman AL und Cresswell P (2004): Cellular mechanisms governing cross-presentation of exogenous antigens. Nat Immunol $\underline{5}, 678-684$

Albert ML, Sauter B und Bhardwaj N (1998): Dendritic cells acquire antigen from apoptotic cells and induce class I-restricted CTLs. Nature $\underline{392}, 86-89$

Algarra I, Cabrera T und Garrido F (2000): The HLA crossroad in tumor immunology. Hum Immunol $\underline{61}, 65-73$

Almeida PC, Nantes IL, Chagas JR, Rizzi CC, Faljoni-Alario A, Carmona E, Juliano L, Nader HB und Tersariol IL (2001): Cathepsin B activity regulation. Heparin-like glycosaminogylcans protect human cathepsin B from alkaline $\mathrm{pH}$-induced inactivation. J Biol Chem 276, 944951

Anichini A, Maccalli C, Mortarini R, Salvi S, Mazzocchi A, Squarcina P, Herlyn M und Parmiani G (1993): Melanoma cells and normal melanocytes share antigens recognized by HLA-A2restricted cytotoxic T cell clones from melanoma patients. J Exp Med 177, 989-998

Annabi B, Lachambre M, Bousquet-Gagnon N, Page M, Gingras D und Beliveau R (2001): Localization of membrane-type 1 matrix metalloproteinase in caveolae membrane domains. Biochem J 353, 547-553

Antia R, Schlegel RA und Williamson P (1992): Binding of perforin to membranes is sensitive to lipid spacing and not headgroup. Immunol Lett 32, 153-157

Arkona C und Wiederanders B (1996): Expression, subcellular distribution and plasma membrane binding of cathepsin B and gelatinases in bone metastatic tissue. Biol Chem $\underline{377}$, 695-702

Baici A, Lang A, Horler D, Kissling R und Merlin C (1995): Cathepsin B in osteoarthritis: cytochemical and histochemical analysis of human femoral head cartilage. Ann Rheum Dis $\underline{54}, 289-297$

Balaji KN, Schaschke N, Machleidt W, Catalfamo M und Henkart PA (2002): Surface cathepsin B protects cytotoxic lymphocytes from self-destruction after degranulation. J Exp Med 196, 493-503

Baran K, Ciccone A, Peters C, Yagita H, Bird PI, Villadangos JA und Trapani JA (2006): Cytotoxic $\mathrm{T}$ lymphocytes from cathepsin B-deficient mice survive normally in vitro and in vivo after encountering and killing target cells. J Biol Chem $\underline{281}$, 30485-30491

Bar-Nun S, Shneyour Y und Beckmann JS (1983): G-418, an elongation inhibitor of 80 S ribosomes. Biochim Biophys Acta 741, 123-127

Barry M und Bleackley RC (2002): Cytotoxic T lymphocytes: all roads lead to death. Nat Rev Immunol $\underline{2}, 401-409$

Berardi S, Lang A, Kostoulas G, Horler D, Vilei EM und Baici A (2001): Alternative messenger RNA splicing and enzyme forms of cathepsin B in human osteoarthritic cartilage and cultured chondrocytes. Arthritis Rheum 44, 1819-1831

Berquin IM, Cao L, Fong D und Sloane BF (1995): Identification of two new exons and multiple transcription start points in the 5'-untranslated region of the human cathepsin-B-encoding gene. Gene $\underline{159}, 143-149$

Berti PJ und Storer AC (1995): Alignment/phylogeny of the papain superfamily of cysteine proteases. J Mol Biol 246, 273-283 
Bird CH, Sutton VR, Sun J, Hirst CE, Novak A, Kumar S, Trapani JA und Bird PI (1998): Selective regulation of apoptosis: the cytotoxic lymphocyte serpin proteinase inhibitor 9 protects against granzyme B-mediated apoptosis without perturbing the Fas cell death pathway. Mol Cell Biol 18, 6387-6398

Birkeland SA, Storm HH, Lamm LU, Barlow L, Blohme I, Forsberg B, Eklund B, Fjeldborg O, Friedberg M, Frodin L, et al. (1995): Cancer risk after renal transplantation in the Nordic countries, 1964-1986. Int J Cancer 무, 183-189

Birnboim HC und Doly J (1979): A rapid alkaline extraction procedure for screening recombinant plasmid DNA. Nucleic Acids Res $\underline{7}, 1513-1523$

Blakely A, Gorman K, Ostergaard H, Svoboda K, Liu CC, Young JD und Clark WR (1987): Resistance of cloned cytotoxic T lymphocytes to cell-mediated cytotoxicity. J Exp Med $\underline{166}$, 1070-1083

Boel P, Wildmann C, Sensi ML, Brasseur R, Renauld JC, Coulie P, Boon T und van der Bruggen P (1995): BAGE: a new gene encoding an antigen recognized on human melanomas by cytolytic T lymphocytes. Immunity $\underline{2}, 167-175$

Bohley P und Seglen PO (1992): Proteases and proteolysis in the lysosome. Experientia 48 , 151-157

Boon T und van der Bruggen P (1996): Human tumor antigens recognized by T lymphocytes. J Exp Med 183, 725-729

Boothby M, Mora AL und Stephenson LM (2001): Lymphokine-dependent proliferation of Tlymphoid cells: regulated responsiveness and role in vivo. Crit Rev Immunol 21, 487-522

Bosch GJ, Joosten AM, Kessler JH, Melief CJ und Leeksma OC (1996): Recognition of BCR-ABL positive leukemic blasts by human $\mathrm{CD} 4+\mathrm{T}$ cells elicited by primary in vitro immunization with a BCR-ABL breakpoint peptide. Blood $\underline{88}, 3522-3527$

Bossi G und Griffiths GM (1999): Degranulation plays an essential part in regulating cell surface expression of Fas ligand in T cells and natural killer cells. Nat Med $\underline{5}, 90-96$

Brix K, Lemansky P und Herzog V (1996): Evidence for extracellularly acting cathepsins mediating thyroid hormone liberation in thyroid epithelial cells. Endocrinology 137, 1963-1974

Brooks JE (1987): Properties and uses of restriction endonucleases. Methods Enzymol 152, 113-129

Browne KA, Blink E, Sutton VR, Froelich CJ, Jans DA und Trapani JA (1999): Cytosolic delivery of granzyme B by bacterial toxins: evidence that endosomal disruption, in addition to transmembrane pore formation, is an important function of perforin. Mol Cell Biol 19, 86048615

Buck MR, Karustis DG, Day NA, Honn KV und Sloane BF (1992): Degradation of extracellularmatrix proteins by human cathepsin B from normal and tumour tissues. Biochem $\mathrm{J} \underline{282(\mathrm{Pt}}$ 1), 273-278

Burnet FM (1970): The concept of immunological surveillance. Prog Exp Tumor Res 13, 1-27

Burnett D, Abrahamson M, Devalia JL, Sapsford RJ, Davies RJ und Buttle DJ (1995): Synthesis and secretion of procathepsin $\mathrm{B}$ and cystatin $\mathrm{C}$ by human bronchial epithelial cells in vitro: modulation of cathepsin B activity by neutrophil elastase. Arch Biochem Biophys $\underline{317}$, 305310

Burnette WN (1981): "Western blotting": electrophoretic transfer of proteins from sodium dodecyl sulfate--polyacrylamide gels to unmodified nitrocellulose and radiographic detection with antibody and radioiodinated protein A. Anal Biochem $\underline{112}$, 195-203

Buttle DJ, Bonner BC, Burnett D und Barrett AJ (1988): A catalytically active high-Mr form of human cathepsin B from sputum. Biochem J 254, 693-699 
Buttle DJ, Burnett D und Abrahamson M (1990): Levels of neutrophil elastase and cathepsin B activities, and cystatins in human sputum: relationship to inflammation. Scand J Clin Lab Invest 50, 509-516

Butz EA und Bevan MJ (1998): Massive expansion of antigen-specific CD8+ T cells during an acute virus infection. Immunity $\underline{8}, 167-175$

Campo E, Munoz J, Miquel R, Palacin A, Cardesa A, Sloane BF und Emmert-Buck MR (1994): Cathepsin B expression in colorectal carcinomas correlates with tumor progression and shortened patient survival. Am J Pathol 145, 301-309

Cao L, Taggart RT, Berquin IM, Moin K, Fong D und Sloane BF (1994): Human gastric adenocarcinoma cathepsin B: isolation and sequencing of full-length cDNAs and polymorphisms of the gene. Gene $\underline{139}, 163-169$

Cavallo-Medved D und Sloane BF (2003): Cell-surface cathepsin B: understanding its functional significance. Curr Top Dev Biol 54, 313-341

Cheever MA, Allison JP, Ferris AS, Finn OJ, Hastings BM, Hecht TT, Mellman I, Prindiville SA, Viner JL, Weiner LM, et al. (2009): The prioritization of cancer antigens: a national cancer institute pilot project for the acceleration of translational research. Clin Cancer Res $\underline{15}$, 53235337

Chen Y, Plouffe C, Menard R und Storer AC (1996): Delineating functionally important regions and residues in the cathepsin B propeptide for inhibitory activity. FEBS Lett 393, 24-26

Chung CY und Erickson HP (1994): Cell surface annexin II is a high affinity receptor for the alternatively spliced segment of tenascin-C. J Cell Biol $\underline{126}, 539-548$

Clark WH, Jr., Elder DE, Guerry Dt, Braitman LE, Trock BJ, Schultz D, Synnestvedt M und Halpern AC (1989): Model predicting survival in stage I melanoma based on tumor progression. J Natl Cancer Inst $\underline{81}, 1893-1904$

Coulie PG, Lehmann F, Lethe B, Herman J, Lurquin C, Andrawiss M und Boon T (1995): A mutated intron sequence codes for an antigenic peptide recognized by cytolytic $\mathrm{T}$ lymphocytes on a human melanoma. Proc Natl Acad Sci U S A 92, 7976-7980

Cox MA, Harrington LE und Zajac AJ (2011): Cytokines and the inception of CD8 T cell responses. Trends Immunol $\underline{32}, 180-186$

Cygler M, Sivaraman J, Grochulski P, Coulombe R, Storer AC und Mort JS (1996): Structure of rat procathepsin B: model for inhibition of cysteine protease activity by the proregion. Structure $\underline{4}, 405-416$

Darmon AJ, Nicholson DW und Bleackley RC (1995): Activation of the apoptotic protease CPP32 by cytotoxic T-cell-derived granzyme B. Nature $\underline{377}$, 446-448

Davis JE, Smyth MJ und Trapani JA (2001): Granzyme A and B-deficient killer lymphocytes are defective in eliciting DNA fragmentation but retain potent in vivo anti-tumor capacity. Eur $\mathrm{J}$ Immunol $\underline{31}, 39-47$

Davis MM und Bjorkman PJ (1988): T-cell antigen receptor genes and T-cell recognition. Nature 334, 395-402

Dehrmann FM, Elliott E und Dennison C (1996): Reductive activation markedly increases the stability of cathepsins B and L to extracellular ionic conditions. Biol Chem Hoppe Seyler $\underline{377}, 391-394$

Demchik LL, Sameni M, Nelson K, Mikkelsen T und Sloane BF (1999): Cathepsin B and glioma invasion. Int J Dev Neurosci 17, 483-494

De Plaen E, Lurquin C, Van Pel A, Mariame B, Szikora JP, Wolfel T, Sibille C, Chomez P und Boon $T$ (1988): Immunogenic (tum-) variants of mouse tumor P815: cloning of the gene of tum- 
antigen P91A and identification of the tum- mutation. Proc Natl Acad Sci U S A $\underline{85}, 2274-$ 2278

De Plaen E, Arden K, Traversari C, Gaforio JJ, Szikora JP, De Smet C, Brasseur F, van der Bruggen P, Lethe B, Lurquin C, et al. (1994): Structure, chromosomal localization, and expression of 12 genes of the MAGE family. Immunogenetics $\underline{40}, 360-369$

De Stefanis D, Demoz M, Dragonetti A, Houri JJ, Ogier-Denis E, Codogno P, Baccino FM und Isidoro C (1997): Differentiation-induced changes in the content, secretion, and subcellular distribution of lysosomal cathepsins in the human colon cancer HT-29 cell line. Cell Tissue Res $289,109-117$

Devetzi M, Scorilas A, Tsiambas E, Sameni M, Fotiou S, Sloane BF und Talieri M (2009): Cathepsin B protein levels in endometrial cancer: Potential value as a tumour biomarker. Gynecol Oncol 112, 531-536

Diefenbach A, Jamieson AM, Liu SD, Shastri N und Raulet DH (2000): Ligands for the murine NKG2D receptor: expression by tumor cells and activation of NK cells and macrophages. Nat Immunol $\underline{1}, 119-126$

Dighe AS, Richards E, Old LJ und Schreiber RD (1994): Enhanced in vivo growth and resistance to rejection of tumor cells expressing dominant negative IFN gamma receptors. Immunity $\underline{1}$, $447-456$

Dressel R, von Figura K und Gunther E (2004 a): Unimpaired allorejection of cells deficient for the mannose 6-phosphate receptors Mpr300 and Mpr46. Transplantation $\underline{78}$, 758-761

Dressel R, Raja SM, Honing S, Seidler T, Froelich CJ, von Figura K und Gunther E (2004 b): Granzyme-mediated cytotoxicity does not involve the mannose 6-phosphate receptors on target cells. J Biol Chem $\underline{279}$, 20200-20210

Duan H, Orth K, Chinnaiyan AM, Poirier GG, Froelich CJ, He WW und Dixit VM (1996): ICELAP6, a novel member of the ICE/Ced-3 gene family, is activated by the cytotoxic T cell protease granzyme B. J Biol Chem 271, 16720-16724

Dugaiczyk A, Boyer HW und Goodman HM (1975): Ligation of EcoRI endonuclease-generated DNA fragments into linear and circular structures. J Mol Biol 무, 171-184

Duke RC, Persechini PM, Chang S, Liu CC, Cohen JJ und Young JD (1989): Purified perforin induces target cell lysis but not DNA fragmentation. J Exp Med 170, 1451-1456

Dunn GP, Bruce AT, Ikeda H, Old LJ und Schreiber RD (2002): Cancer immunoediting: from immunosurveillance to tumor escape. Nat Immunol $\underline{3}$, 991-998

Dunn GP, Old LJ und Schreiber RD (2004): The immunobiology of cancer immunosurveillance and immunoediting. Immunity 21, 137-148

Dutz JP, Walden PR und Eisen HN (1992): Effects of cognate peptides on cytolytic and proliferative activities of cloned cytotoxic T lymphocytes. Int Immunol 4 , 571-580

Ebert W, Knoch H, Werle B, Trefz G, Muley T und Spiess E (1994): Prognostic value of increased lung tumor tissue cathepsin B. Anticancer Res $\underline{14}, 895-899$

Ebnet K, Hausmann M, Lehmann-Grube F, Mullbacher A, Kopf M, Lamers M und Simon MM (1995): Granzyme A-deficient mice retain potent cell-mediated cytotoxicity. EMBO J $\underline{14}$, 4230-4239

Ehrlich P (1909): Über den jetzigen Stand der Karzinomforschung. Ned Tijdscr Geneeskd 므, 273290

Elder GJ, Hersey P und Branley P (1997): Remission of transplanted melanoma--clinical course and tumour cell characterisation. Clin Transplant 11, 565-568 
Eley BM und Cox SW (1991): Cathepsin B- and L-like activities at local gingival sites of chronic periodontitis patients. J Clin Periodontol 18, 499-504

Elgert KD, Alleva DG und Mullins DW (1998): Tumor-induced immune dysfunction: the macrophage connection. J Leukoc Biol 64, 275-290

Emmert-Buck MR, Roth MJ, Zhuang Z, Campo E, Rozhin J, Sloane BF, Liotta LA und StetlerStevenson WG (1994): Increased gelatinase A (MMP-2) and cathepsin B activity in invasive tumor regions of human colon cancer samples. Am J Pathol 145, 1285-1290

Ensslen M: Untersuchung zur Funktion von Cathepsin B in der durch zytotoxische T-Zellen vermittelten Lyse von Tumorzellen. Med. Diss. Göttingen 2009

Fafeur V, Tulasne D, Queva C, Vercamer C, Dimster V, Mattot V, Stehelin D, Desbiens X und Vandenbunder B (1997): The ETS1 transcription factor is expressed during epithelialmesenchymal transitions in the chick embryo and is activated in scatter factor-stimulated MDCK epithelial cells. Cell Growth Differ $\underline{8}, 655-665$

Felbor U, Kessler B, Mothes W, Goebel HH, Ploegh HL, Bronson RT und Olsen BR (2002): Neuronal loss and brain atrophy in mice lacking cathepsins B and L. Proc Natl Acad Sci U S A $\underline{99}, 7883-7888$

Fisk B, Chesak B, Pollack MS, Wharton JT und Ioannides CG (1994): Oligopeptide induction of a cytotoxic T lymphocyte response to HER-2/neu proto-oncogene in vitro. Cell Immunol $\underline{157}$, 415-427

Fong D, Chan MM, Hsieh WT, Menninger JC und Ward DC (1992): Confirmation of the human cathepsin B gene (CTSB) assignment to chromosome 8. Hum Genet $\underline{89}, 10-12$

Fossum B, Olsen AC, Thorsby E und Gaudernack G (1995): CD8+ T cells from a patient with colon carcinoma, specific for a mutant p21-Ras-derived peptide (Gly13-->Asp), are cytotoxic towards a carcinoma cell line harbouring the same mutation. Cancer Immunol Immunother $\underline{40}, 165-172$

Fraser SA, Karimi R, Michalak M und Hudig D (2000): Perforin lytic activity is controlled by calreticulin. J Immunol 164, 4150-4155

Froehlich E, Schlagenhauff B, Mohrle M, Weber E, Klessen C und Rassner G (2001): Activity, expression, and transcription rate of the cathepsins $\mathrm{B}, \mathrm{D}, \mathrm{H}$, and $\mathrm{L}$ in cutaneous malignant melanoma. Cancer 91, 972-982

Froelich CJ, Orth K, Turbov J, Seth P, Gottlieb R, Babior B, Shah GM, Bleackley RC, Dixit VM und Hanna W (1996): New paradigm for lymphocyte granule-mediated cytotoxicity. Target cells bind and internalize granzyme $\mathrm{B}$, but an endosomolytic agent is necessary for cytosolic delivery and subsequent apoptosis. J Biol Chem 271, 29073-29079

Frosch BA, Berquin I, Emmert-Buck MR, Moin K und Sloane BF (1999): Molecular regulation, membrane association and secretion of tumor cathepsin B. APMIS $\underline{107}, 28-37$

Gabrijelcic D, Gollwitzer R, Popovic T und Turk V (1988): Proteolytic cleavage of human fibrinogen by cathepsin B. Biol Chem Hoppe Seyler 369 Suppl, 287-292

Gallucci S und Matzinger P (2001): Danger signals: SOS to the immune system. Curr Opin Immunol $\underline{13}, 114-119$

Gallucci S, Lolkema M und Matzinger P (1999): Natural adjuvants: endogenous activators of dendritic cells. Nat Med $\underline{5}, 1249-1255$

Galvin JP, Spaeny-Dekking LH, Wang B, Seth P, Hack CE und Froelich CJ (1999): Apoptosis induced by granzyme B-glycosaminoglycan complexes: implications for granule-mediated apoptosis in vivo. J Immunol $\underline{162}, 5345-5350$ 
Gamen S, Hanson DA, Kaspar A, Naval J, Krensky AM und Anel A (1998): Granulysin-induced apoptosis. I. Involvement of at least two distinct pathways. J Immunol 161, 1758-1764

Gatti RA und Good RA (1971): Occurrence of malignancy in immunodeficiency diseases. A literature review. Cancer $28,89-98$

Gedde-Dahl T, 3rd, Spurkland A, Fossum B, Wittinghofer A, Thorsby E und Gaudernack G (1994): $\mathrm{T}$ cell epitopes encompassing the mutational hot spot position 61 of p21 ras. Promiscuity in ras peptide binding to HLA. Eur J Immunol 24, 410-414

Gerasimenko JV, Gerasimenko OV und Petersen OH (2001): Membrane repair: $\mathrm{Ca}(2+)$-elicited lysosomal exocytosis. Curr Biol 11, R971-974

Gong Q, Chan SJ, Bajkowski AS, Steiner DF und Frankfater A (1993): Characterization of the cathepsin B gene and multiple mRNAs in human tissues: evidence for alternative splicing of cathepsin B pre-mRNA. DNA Cell Biol 12, 299-309

Griffiths GM und Isaaz S (1993): Granzymes A and B are targeted to the lytic granules of lymphocytes by the mannose-6-phosphate receptor. J Cell Biol 120, 885-896

Groh V, Rhinehart R, Secrist H, Bauer S, Grabstein KH und Spies T (1999): Broad tumor-associated expression and recognition by tumor-derived gamma delta T cells of MICA and MICB. Proc Natl Acad Sci U S A 96, 6879-6884

Groh V, Wu J, Yee C und Spies T (2002): Tumour-derived soluble MIC ligands impair expression of NKG2D and T-cell activation. Nature $\underline{419}, 734-738$

Guilloux Y, Lucas S, Brichard VG, Van Pel A, Viret C, De Plaen E, Brasseur F, Lethe B, Jotereau F und Boon T (1996): A peptide recognized by human cytolytic T lymphocytes on HLA-A2 melanomas is encoded by an intron sequence of the $\mathrm{N}$-acetylglucosaminyltransferase $\mathrm{V}$ gene. J Exp Med 183, 1173-1183

Guinec N, Dalet-Fumeron V und Pagano M (1992): Quantitative study of the binding of cysteine proteinases to basement membranes. FEBS Lett $\underline{308}$, 305-308

Haas MJ und Dowding JE (1975): Aminoglycoside-modifying enzymes. Methods Enzymol 43, 611628

Halangk W, Lerch MM, Brandt-Nedelev B, Roth W, Ruthenbuerger M, Reinheckel T, Domschke W, Lippert H, Peters C und Deussing J (2000): Role of cathepsin B in intracellular trypsinogen activation and the onset of acute pancreatitis. J Clin Invest 106, 773-781

Hanewinkel H, Glossl J und Kresse H (1987): Biosynthesis of cathepsin B in cultured normal and Icell fibroblasts. J Biol Chem $\underline{262}, 12351-12355$

Harder T und Gerke V (1994): The annexin II2p11(2) complex is the major protein component of the triton X-100-insoluble low-density fraction prepared from MDCK cells in the presence of $\mathrm{Ca} 2+$. Biochim Biophys Acta $\underline{1223}, 375-382$

Harty JT, Tvinnereim AR und White DW (2000): CD8+ T cell effector mechanisms in resistance to infection. Annu Rev Immunol 18, 275-308

Hartz PA und Wilson PD (1997): Functional defects in lysosomal enzymes in autosomal dominant polycystic kidney disease (ADPKD): abnormalities in synthesis, molecular processing, polarity, and secretion. Biochem Mol Med $\underline{60}, 8-26$

Hazen LG, Bleeker FE, Lauritzen B, Bahns S, Song J, Jonker A, Van Driel BE, Lyon H, Hansen U, Kohler A, et al. (2000): Comparative localization of cathepsin B protein and activity in colorectal cancer. J Histochem Cytochem $\underline{48}$, 1421-1430

Higashiyama M, Doi O, Kodama K, Yokouchi H und Tateishi R (1993): Cathepsin B expression in tumour cells and laminin distribution in pulmonary adenocarcinoma. J Clin Pathol $\underline{46}, 18-22$ 
Hill PA, Buttle DJ, Jones SJ, Boyde A, Murata M, Reynolds JJ und Meikle MC (1994): Inhibition of bone resorption by selective inactivators of cysteine proteinases. J Cell Biochem $\underline{56}, 118-130$

Hogquist KA, Jameson SC, Heath WR, Howard JL, Bevan MJ und Carbone FR (1994): T cell receptor antagonist peptides induce positive selection. Cell $\underline{76}, 17-27$

Hughes SJ, Glover TW, Zhu XX, Kuick R, Thoraval D, Orringer MB, Beer DG und Hanash S (1998): A novel amplicon at 8p22-23 results in overexpression of cathepsin B in esophageal adenocarcinoma. Proc Natl Acad Sci U S A $\underline{95}$, 12410-12415

Hulkower KI, Butler CC, Linebaugh BE, Klaus JL, Keppler D, Giranda VL und Sloane BF (2000): Fluorescent microplate assay for cancer cell-associated cathepsin B. Eur J Biochem 267, 4165-4170

Ioannides CG, Fisk B, Pollack MS, Frazier ML, Taylor Wharton J und Freedman RS (1993 a): Cytotoxic T-cell clones isolated from ovarian tumour infiltrating lymphocytes recognize common determinants on non-ovarian tumour clones. Scand J Immunol 37, 413-424

Ioannides CG, Fisk B, Jerome KR, Irimura T, Wharton JT und Finn OJ (1993 b): Cytotoxic T cells from ovarian malignant tumors can recognize polymorphic epithelial mucin core peptides. $\mathbf{J}$ Immunol 151, 3693-3703

Ioannides CG, Fisk B, Fan D, Biddison WE, Wharton JT und O'Brian CA (1993 c): Cytotoxic T cells isolated from ovarian malignant ascites recognize a peptide derived from the HER-2/neu proto-oncogene. Cell Immunol 151, 225-234

Jameson SC, Hogquist KA und Bevan MJ (1995): Positive selection of thymocytes. Annu Rev Immunol $\underline{13}, 93-126$

Jans DA, Jans P, Briggs LJ, Sutton V und Trapani JA (1996): Nuclear transport of granzyme B (fragmentin-2). Dependence of perforin in vivo and cytosolic factors in vitro. J Biol Chem $\underline{271}, 30781-30789$

Jans DA, Briggs LJ, Jans P, Froelich CJ, Parasivam G, Kumar S, Sutton VR und Trapani JA (1998): Nuclear targeting of the serine protease granzyme A (fragmentin-1). J Cell Sci 111 (Pt 17), 2645-2654

Jiang SB, Ojcius DM, Persechini PM und Young JD (1990): Resistance of cytolytic lymphocytes to perforin-mediated killing. Inhibition of perforin binding activity by surface membrane proteins. J Immunol 144, 998-1003

Jinushi M, Takehara T, Tatsumi T, Kanto T, Groh V, Spies T, Kimura R, Miyagi T, Mochizuki K, Sasaki Y, et al. (2003): Expression and role of MICA and MICB in human hepatocellular carcinomas and their regulation by retinoic acid. Int J Cancer 104, 354-361

Kagi D, Vignaux F, Ledermann B, Burki K, Depraetere V, Nagata S, Hengartner H und Golstein P (1994 a): Fas and perforin pathways as major mechanisms of $\mathrm{T}$ cell-mediated cytotoxicity. Science $265,528-530$

Kagi D, Ledermann B, Burki K, Seiler P, Odermatt B, Olsen KJ, Podack ER, Zinkernagel RM und Hengartner H (1994 b): Cytotoxicity mediated by T cells and natural killer cells is greatly impaired in perforin-deficient mice. Nature $\underline{369}, 31-37$

Kagi D, Ledermann B, Burki K, Zinkernagel RM und Hengartner H (1996): Molecular mechanisms of lymphocyte-mediated cytotoxicity and their role in immunological protection and pathogenesis in vivo. Annu Rev Immunol 14, 207-232

Kaplan DH, Shankaran V, Dighe AS, Stockert E, Aguet M, Old LJ und Schreiber RD (1998): Demonstration of an interferon gamma-dependent tumor surveillance system in immunocompetent mice. Proc Natl Acad Sci U S A $\underline{95}$, 7556-7561

Karre K, Ljunggren HG, Piontek G und Kiessling R (1986): Selective rejection of H-2-deficient lymphoma variants suggests alternative immune defence strategy. Nature $\underline{319}, 675-678$ 
Kaspar AA, Okada S, Kumar J, Poulain FR, Drouvalakis KA, Kelekar A, Hanson DA, Kluck RM, Hitoshi Y, Johnson DE, et al. (2001): A distinct pathway of cell-mediated apoptosis initiated by granulysin. J Immunol 167, 350-356

Kassam G, Manro A, Braat CE, Louie P, Fitzpatrick SL und Waisman DM (1997): Characterization of the heparin binding properties of annexin II tetramer. J Biol Chem $\underline{272}$, 15093-15100

Kassam G, Choi KS, Ghuman J, Kang HM, Fitzpatrick SL, Zackson T, Zackson S, Toba M, Shinomiya A und Waisman DM (1998): The role of annexin II tetramer in the activation of plasminogen. J Biol Chem 273, 4790-4799

Keefe D, Shi L, Feske S, Massol R, Navarro F, Kirchhausen T und Lieberman J (2005): Perforin triggers a plasma membrane-repair response that facilitates CTL induction of apoptosis. Immunity $\underline{23}, 249-262$

Keene JA und Forman J (1982): Helper activity is required for the in vivo generation of cytotoxic T lymphocytes. J Exp Med 155, 768-782

Kennett CN, Cox SW und Eley BM (1997): Ultrastructural localization of cathepsin B in gingival tissue from chronic periodontitis patients. Histochem J $\underline{29}, 727-734$

Khan A, Krishna M, Baker SP, Malhothra R und Banner BF (1998): Cathepsin B expression and its correlation with tumor-associated laminin and tumor progression in gastric cancer. Arch Pathol Lab Med 122, 172-177

Khong HT, Wang QJ und Rosenberg SA (2004): Identification of multiple antigens recognized by tumor-infiltrating lymphocytes from a single patient: tumor escape by antigen loss and loss of MHC expression. J Immunother 27, 184-190

Kim K, Cai J, Shuja S, Kuo T und Murnane MJ (1998): Presence of activated ras correlates with increased cysteine proteinase activities in human colorectal carcinomas. Int $\mathrm{J}$ Cancer $\underline{79}$, 324-333

Kisielow P und von Boehmer H (1995): Development and selection of T cells: facts and puzzles. Adv Immunol 58, 87-209

Klein G (1966): Tumor antigens. Annu Rev Microbiol 20, 223-252

Kobayashi H, Schmitt M, Goretzki L, Chucholowski N, Calvete J, Kramer M, Gunzler WA, Janicke F und Graeff H (1991): Cathepsin B efficiently activates the soluble and the tumor cell receptor-bound form of the proenzyme urokinase-type plasminogen activator (Pro-uPA). J Biol Chem 266, 5147-5152

Koblinski JE, Dosescu J, Sameni M, Moin K, Clark K und Sloane BF (2002): Interaction of human breast fibroblasts with collagen I increases secretion of procathepsin B. J Biol Chem 277 , 32220-32227

Kojima H, Shinohara N, Hanaoka S, Someya-Shirota Y, Takagaki Y, Ohno H, Saito T, Katayama T, Yagita H, Okumura K, et al. (1994): Two distinct pathways of specific killing revealed by perforin mutant cytotoxic T lymphocytes. Immunity $\underline{1}, 357-364$

Kozak M (1987): An analysis of 5'-noncoding sequences from 699 vertebrate messenger RNAs. Nucleic Acids Res $\underline{15}, 8125-8148$

Kranz DM und Eisen HN (1987): Resistance of cytotoxic T lymphocytes to lysis by a clone of cytotoxic T lymphocytes. Proc Natl Acad Sci U S A $\underline{84}$, 3375-3379

Krepela E, Vicar J und Cernoch M (1989): Cathepsin B in human breast tumor tissue and cancer cells. Neoplasma $\underline{36}, 41-52$

Kuliawat R und Arvan P (1994): Distinct molecular mechanisms for protein sorting within immature secretory granules of pancreatic beta-cells. J Cell Biol 126, 77-86 
Kuliawat R, Klumperman J, Ludwig T und Arvan P (1997): Differential sorting of lysosomal enzymes out of the regulated secretory pathway in pancreatic beta-cells. J Cell Biol 137, 595-608

Kupfer A und Dennert G (1984): Reorientation of the microtubule-organizing center and the Golgi apparatus in cloned cytotoxic lymphocytes triggered by binding to lysable target cells. $\mathbf{J}$ Immunol $\underline{133}, 2762-2766$

Kusunoki T, Nishida S, Nakano T, Funasaka K, Kimoto S, Murata K und Tomura T (1995): Study on cathepsin B activity in human thyroid tumors. Auris Nasus Larynx 22, 43-48

Kuta AE, Bashford CL, Pasternak CA, Reynolds CW und Henkart PA (1991): Characterization of non-lytic cytolysin-membrane intermediates. Mol Immunol 28, 1263-1270

Laemmli UK (1970): Cleavage of structural proteins during the assembly of the head of bacteriophage T4. Nature 227, 680-685

Lah TT, Calaf G, Kalman E, Shinde BG, Russo J, Jarosz D, Zabrecky J, Somers R und Daskal I (1995): Cathepsins D, B and L in breast carcinoma and in transformed human breast epithelial cells (HBEC). Biol Chem Hoppe Seyler $\underline{376}$, 357-363

Lang A, Horler D und Baici A (2000): The relative importance of cysteine peptidases in osteoarthritis. J Rheumatol 27, 1970-1979

Lehmann C, Zeis M, Schmitz N und Uharek L (2000): Impaired binding of perforin on the surface of tumor cells is a cause of target cell resistance against cytotoxic effector cells. Blood $\underline{96}, 594-$ 600

Lengauer C, Kinzler KW und Vogelstein B (1998): Genetic instabilities in human cancers. Nature 396, 643-649

Lerch MM, Halangk W und Kruger B (2000): The role of cysteine proteases in intracellular pancreatic serine protease activation. Adv Exp Med Biol 477, 403-411

Lieberman J (2003): The ABCs of granule-mediated cytotoxicity: new weapons in the arsenal. Nat Rev Immunol $\underline{3}, 361-370$

Linebaugh BE, Sameni M, Day NA, Sloane BF und Keppler D (1999): Exocytosis of active cathepsin B enzyme activity at $\mathrm{pH} 7.0$, inhibition and molecular mass. Eur J Biochem 264, 100-109

Linke M, Herzog V und Brix K (2002): Trafficking of lysosomal cathepsin B-green fluorescent protein to the surface of thyroid epithelial cells involves the endosomal/lysosomal compartment. J Cell Sci 115, 4877-4889

Liu CC, Jiang S, Persechini PM, Zychlinsky A, Kaufmann Y und Young JD (1989): Resistance of cytolytic lymphocytes to perforin-mediated killing. Induction of resistance correlates with increase in cytotoxicity. J Exp Med 169, 2211-2225

Liu Y, Xiao S, Shi Y, Wang L, Ren W und Sloane BF (1998): Cathepsin B on invasion and metastasis of gastric carcinoma. Chin Med J (Engl) 111, 784-788

Liyanage UK, Moore TT, Joo HG, Tanaka Y, Herrmann V, Doherty G, Drebin JA, Strasberg SM, Eberlein TJ, Goedegebuure PS, et al. (2002): Prevalence of regulatory T cells is increased in peripheral blood and tumor microenvironment of patients with pancreas or breast adenocarcinoma. J Immunol 169, 2756-2761

Lorenzo K, Ton P, Clark JL, Coulibaly S und Mach L (2000): Invasive properties of murine squamous carcinoma cells: secretion of matrix-degrading cathepsins is attributable to a deficiency in the mannose 6-phosphate/insulin-like growth factor II receptor. Cancer Res $\underline{60}$, 4070-4076 
Lowin B, Beermann F, Schmidt A und Tschopp J (1994 a): A null mutation in the perforin gene impairs cytolytic T lymphocyte- and natural killer cell-mediated cytotoxicity. Proc Natl Acad Sci U S A 91, 11571-11575

Lowin B, Hahne M, Mattmann C und Tschopp J (1994 b): Cytolytic T-cell cytotoxicity is mediated through perforin and Fas lytic pathways. Nature $\underline{370}, 650-652$

Luciani MF, Brunet JF, Suzan M, Denizot F und Golstein P (1986): Self-sparing of long-term in vitro-cloned or uncloned cytotoxic T lymphocytes. J Exp Med 164, 962-967

Ludwig T, Munier-Lehmann H, Bauer U, Hollinshead M, Ovitt C, Lobel P und Hoflack B (1994): Differential sorting of lysosomal enzymes in mannose 6-phosphate receptor-deficient fibroblasts. EMBO J 13, 3430-3437

Lupetti R, Pisarra P, Verrecchia A, Farina C, Nicolini G, Anichini A, Bordignon C, Sensi M, Parmiani G und Traversari C (1998): Translation of a retained intron in tyrosinase-related protein (TRP) 2 mRNA generates a new cytotoxic T lymphocyte (CTL)-defined and shared human melanoma antigen not expressed in normal cells of the melanocytic lineage. J Exp Med $\underline{188}, 1005-1016$

Lurquin C, Van Pel A, Mariame B, De Plaen E, Szikora JP, Janssens C, Reddehase MJ, Lejeune J und Boon T (1989): Structure of the gene of tum- transplantation antigen P91A: the mutated exon encodes a peptide recognized with Ld by cytolytic T cells. Cell $\underline{58}, 293-303$

Mach L, Stuwe K, Hagen A, Ballaun C und Glossl J (1992): Proteolytic processing and glycosylation of cathepsin $\mathrm{B}$. The role of the primary structure of the latent precursor and of the carbohydrate moiety for cell-type-specific molecular forms of the enzyme. Biochem $\mathbf{J}$ $\underline{282(\mathrm{Pt} 2)}, 577-582$

Maciewicz RA, Wotton SF, Etherington DJ und Duance VC (1990): Susceptibility of the cartilage collagens types II, IX and XI to degradation by the cysteine proteinases, cathepsins B and L. FEBS Lett 269, 189-193

Mai J, Finley RL, Jr., Waisman DM und Sloane BF (2000): Human procathepsin B interacts with the annexin II tetramer on the surface of tumor cells. J Biol Chem 275, 12806-12812

Mandelboim O, Berke G, Fridkin M, Feldman M, Eisenstein M und Eisenbach L (1994): CTL induction by a tumour-associated antigen octapeptide derived from a murine lung carcinoma. Nature $\underline{369}, 67-71$

Marincola FM, Jaffee EM, Hicklin DJ und Ferrone S (2000): Escape of human solid tumors from Tcell recognition: molecular mechanisms and functional significance. Adv Immunol 74, 181273

Marten K, Bremer C, Khazaie K, Sameni M, Sloane B, Tung CH und Weissleder R (2002): Detection of dysplastic intestinal adenomas using enzyme-sensing molecular beacons in mice. Gastroenterology $\underline{122}$, 406-414

Martin SJ, Amarante-Mendes GP, Shi L, Chuang TH, Casiano CA, O'Brien GA, Fitzgerald P, Tan EM, Bokoch GM, Greenberg AH, et al. (1996): The cytotoxic cell protease granzyme B initiates apoptosis in a cell-free system by proteolytic processing and activation of the ICE/CED-3 family protease, CPP32, via a novel two-step mechanism. EMBO J 15, 24072416

McClain KL (1997): Immunodeficiency states and related malignancies. Cancer Treat Res 92, 39-61

McGrath ME (1999): The lysosomal cysteine proteases. Annu Rev Biophys Biomol Struct 28, 181204 
Medema JP, Schuurhuis DH, Rea D, van Tongeren J, de Jong J, Bres SA, Laban S, Toes RE, Toebes M, Schumacher TN, et al. (2001): Expression of the serpin serine protease inhibitor 6 protects dendritic cells from cytotoxic $\mathrm{T}$ lymphocyte-induced apoptosis: differential modulation by T helper type 1 and type 2 cells. J Exp Med 194, 657-667

Mehtani S, Gong Q, Panella J, Subbiah S, Peffley DM und Frankfater A (1998): In vivo expression of an alternatively spliced human tumor message that encodes a truncated form of cathepsin B. Subcellular distribution of the truncated enzyme in COS cells. J Biol Chem $\underline{273}$, 1323613244

Metkar SS, Wang B, Aguilar-Santelises M, Raja SM, Uhlin-Hansen L, Podack E, Trapani JA und Froelich CJ (2002): Cytotoxic cell granule-mediated apoptosis: perforin delivers granzyme B-serglycin complexes into target cells without plasma membrane pore formation. Immunity $\underline{16}, 417-428$

Metkar SS, Wang B, Ebbs ML, Kim JH, Lee YJ, Raja SM und Froelich CJ (2003): Granzyme B activates procaspase-3 which signals a mitochondrial amplification loop for maximal apoptosis. J Cell Biol $\underline{160}, 875-885$

Moin K, Day NA, Sameni M, Hasnain S, Hirama T und Sloane BF (1992): Human tumour cathepsin B. Comparison with normal liver cathepsin B. Biochem J 285 ( Pt 2), 427-434

Moin K, Cao L, Day NA, Koblinski JE und Sloane BF (1998): Tumor cell membrane cathepsin B. Biol Chem 379, 1093-1099

Monach PA, Meredith SC, Siegel CT und Schreiber H (1995): A unique tumor antigen produced by a single amino acid substitution. Immunity $2,45-59$

Mort JS und Buttle DJ (1997): Cathepsin B. Int J Biochem Cell Biol 29 , 715-720

Mort JS, Leduc MS und Recklies AD (1983): Characterization of a latent cysteine proteinase from ascitic fluid as a high molecular weight form of cathepsin B. Biochim Biophys Acta $\underline{755}$, 369-375

Motyka B, Korbutt G, Pinkoski MJ, Heibein JA, Caputo A, Hobman M, Barry M, Shostak I, Sawchuk T, Holmes CF, et al. (2000): Mannose 6-phosphate/insulin-like growth factor II receptor is a death receptor for granzyme $\mathrm{B}$ during cytotoxic $\mathrm{T}$ cell-induced apoptosis. Cell $\underline{103}, 491-500$

Mullbacher A, Ebnet K, Blanden RV, Hla RT, Stehle T, Museteanu C und Simon MM (1996): Granzyme A is critical for recovery of mice from infection with the natural cytopathic viral pathogen, ectromelia. Proc Natl Acad Sci U S A 93, 5783-5787

Muller C und Tschopp J (1994): Resistance of CTL to perforin-mediated lysis. Evidence for a lymphocyte membrane protein interacting with perforin. J Immunol 153, 2470-2478

Murali-Krishna K, Altman JD, Suresh M, Sourdive DJ, Zajac AJ, Miller JD, Slansky J und Ahmed R (1998): Counting antigen-specific CD8 T cells: a reevaluation of bystander activation during viral infection. Immunity $\underline{8}, 177-187$

Murnane MJ, Sheahan K, Ozdemirli M und Shuja S (1991): Stage-specific increases in cathepsin B messenger RNA content in human colorectal carcinoma. Cancer Res 51, 1137-1142

Musil D, Zucic D, Turk D, Engh RA, Mayr I, Huber R, Popovic T, Turk V, Towatari T, Katunuma N, et al. (1991): The refined 2.15 A X-ray crystal structure of human liver cathepsin B: the structural basis for its specificity. EMBO J $\underline{10}, 2321-2330$

Nagai A, Murakawa Y, Terashima M, Shimode K, Umegae N, Takeuchi H und Kobayashi S (2000): Cystatin C and cathepsin B in CSF from patients with inflammatory neurologic diseases. Neurology $\underline{55}, 1828-1832$ 
Nagler DK, Storer AC, Portaro FC, Carmona E, Juliano L und Menard R (1997): Major increase in endopeptidase activity of human cathepsin B upon removal of occluding loop contacts. Biochemistry $\underline{36}, 12608-12615$

Nagler-Anderson C, Verret CR, Firmenich AA, Berne M und Eisen HN (1988): Resistance of primary CD8+ cytotoxic $\mathrm{T}$ lymphocytes to lysis by cytotoxic granules from cloned $\mathrm{T}$ cell lines. J Immunol 141, 3299-3305

Naito S, Shimizu S, Matsuu M, Nakashima M, Nakayama T, Yamashita S und Sekine I (2002): Ets-1 upregulates matrix metalloproteinase-1 expression through extracellular matrix adhesion in vascular endothelial cells. Biochem Biophys Res Commun 291, 130-138

Naito Y, Saito K, Shiiba K, Ohuchi A, Saigenji K, Nagura H und Ohtani H (1998): CD8+ T cells infiltrated within cancer cell nests as a prognostic factor in human colorectal cancer. Cancer Res 묘, 3491-3494

Nijman HW, Van der Burg SH, Vierboom MP, Houbiers JG, Kast WM und Melief CJ (1994): p53, a potential target for tumor-directed T cells. Immunol Lett $\underline{40}, 171-178$

Niwa H, Yamamura K und Miyazaki J (1991): Efficient selection for high-expression transfectants with a novel eukaryotic vector. Gene 108, 193-199

Noguchi Y, Chen YT und Old LJ (1994): A mouse mutant p53 product recognized by CD4+ and CD8+ T cells. Proc Natl Acad Sci U S A 91, 3171-3175

Ojcius DM, Jiang SB, Persechini PM, Detmers PA und Young JD (1991): Cytoplasts from cytotoxic T lymphocytes are resistant to perforin-mediated lysis. Mol Immunol 28, 1011-1018

Old LJ (2003): Cancer vaccines 2003: opening address. Cancer Immun $\underline{3 \text { Suppl 2, } 1}$

Old LJ und Boyse EA (1964): Immunology of Experimental Tumors. Annu Rev Med 15, 167-186

Page AE, Warburton MJ, Chambers TJ, Pringle JA und Hayman AR (1992): Human osteoclastomas contain multiple forms of cathepsin B. Biochim Biophys Acta 1116, 57-66

Page LJ, Darmon AJ, Uellner R und Griffiths GM (1998): L is for lytic granules: lysosomes that kill. Biochim Biophys Acta 1401, 146-156

Paludan K, Duch M, Jorgensen P, Kjeldgaard NO und Pedersen FS (1989): Graduated resistance to G418 leads to differential selection of cultured mammalian cells expressing the neo gene. Gene $\underline{85}, 421-426$

Parmiani G, De Filippo A, Novellino L und Castelli C (2007): Unique human tumor antigens: immunobiology and use in clinical trials. J Immunol 178, 1975-1979

Penn I (1981): Malignant lymphomas in organ transplant recipients. Transplant Proc $\underline{13}$, 736-738

Penn I (1996 a): Malignant melanoma in organ allograft recipients. Transplantation $\underline{61,274-278}$

Penn I (1996 b): Posttransplantation de novo tumors in liver allograft recipients. Liver Transpl Surg $\underline{2}, 52-59$

Peoples GE, Goedegebuure PS, Smith R, Linehan DC, Yoshino I und Eberlein TJ (1995): Breast and ovarian cancer-specific cytotoxic $T$ lymphocytes recognize the same HER2/neu-derived peptide. Proc Natl Acad Sci U S A $\underline{92}, 432-436$

Pereira RA, Simon MM und Simmons A (2000): Granzyme A, a noncytolytic component of CD8(+) cell granules, restricts the spread of herpes simplex virus in the peripheral nervous systems of experimentally infected mice. J Virol 74, 1029-1032

Persechini PM, Young JD und Almers W (1990): Membrane channel formation by the lymphocyte pore-forming protein: comparison between susceptible and resistant target cells. J Cell Biol $\underline{110}, 2109-2116$ 
Peter ME und Krammer PH (2003): The CD95(APO-1/Fas) DISC and beyond. Cell Death Differ 10, 26-35

Pham CT und Ley TJ (1999): Dipeptidyl peptidase I is required for the processing and activation of granzymes A and B in vivo. Proc Natl Acad Sci U S A $\underline{96}, 8627-8632$

Pham SM, Kormos RL, Landreneau RJ, Kawai A, Gonzalez-Cancel I, Hardesty RL, Hattler BG und Griffith BP (1995): Solid tumors after heart transplantation: lethality of lung cancer. Ann Thorac Surg $\underline{60}$, 1623-1626

Pinkoski MJ, Hobman M, Heibein JA, Tomaselli K, Li F, Seth P, Froelich CJ und Bleackley RC (1998): Entry and trafficking of granzyme B in target cells during granzyme B-perforinmediated apoptosis. Blood 92, 1044-1054

Pipkin ME und Lieberman J (2007): Delivering the kiss of death: progress on understanding how perforin works. Curr Opin Immunol 19, 301-308

Podack ER (1999): How to induce involuntary suicide: the need for dipeptidyl peptidase I. Proc Natl Acad Sci U S A $\underline{96}, 8312-8314$

Podack ER, Young JD und Cohn ZA (1985): Isolation and biochemical and functional characterization of perforin 1 from cytolytic T-cell granules. Proc Natl Acad Sci U S A $\underline{82}$, 8629-8633

Prehn RT (1970): Analysis of antigenic heterogeneity within individual 3-methylcholanthreneinduced mouse sarcomas. J Natl Cancer Inst 45, 1039-1045

Puyraimond A, Fridman R, Lemesle M, Arbeille B und Menashi S (2001): MMP-2 colocalizes with caveolae on the surface of endothelial cells. Exp Cell Res 262, 28-36

Qian F, Bajkowski AS, Steiner DF, Chan SJ und Frankfater A (1989): Expression of five cathepsins in murine melanomas of varying metastatic potential and normal tissues. Cancer Res $\underline{49}$, $4870-4875$

Qian F, Frankfater A, Chan SJ und Steiner DF (1991): The structure of the mouse cathepsin B gene and its putative promoter. DNA Cell Biol $\underline{10}, 159-168$

Reinheckel T, Deussing J, Roth W und Peters C (2001): Towards specific functions of lysosomal cysteine peptidases: phenotypes of mice deficient for cathepsin B or cathepsin L. Biol Chem $\underline{382}, 735-741$

Rempel SA, Rosenblum ML, Mikkelsen T, Yan PS, Ellis KD, Golembieski WA, Sameni M, Rozhin J, Ziegler G und Sloane BF (1994): Cathepsin B expression and localization in glioma progression and invasion. Cancer Res $\underline{54}, 6027-6031$

Rickinson AB und Moss DJ (1997): Human cytotoxic T lymphocyte responses to Epstein-Barr virus infection. Annu Rev Immunol 15, 405-431

Robbins PF, El-Gamil M, Li YF, Kawakami Y, Loftus D, Appella E und Rosenberg SA (1996): A mutated beta-catenin gene encodes a melanoma-specific antigen recognized by tumor infiltrating lymphocytes. J Exp Med 183, 1185-1192

Roberts LR, Kurosawa H, Bronk SF, Fesmier PJ, Agellon LB, Leung WY, Mao F und Gores GJ (1997): Cathepsin B contributes to bile salt-induced apoptosis of rat hepatocytes. Gastroenterology 113, 1714-1726

Rosenberg SA (1999): A new era for cancer immunotherapy based on the genes that encode cancer antigens. Immunity $\underline{10}, 281-287$

Roshy S, Sloane BF und Moin K (2003): Pericellular cathepsin B and malignant progression. Cancer Metastasis Rev 22, 271-286 
Rothstein TL, Mage M, Jones G und McHugh LL (1978): Cytotoxic T lymphocyte sequential killing of immobilized allogeneic tumor target cells measured by time-lapse microcinematography. J Immunol 121, 1652-1656

Rowan AD, Mason P, Mach L und Mort JS (1992): Rat procathepsin B. Proteolytic processing to the mature form in vitro. J Biol Chem 267, 15993-15999

Rozhin J, Robinson D, Stevens MA, Lah TT, Honn KV, Ryan RE und Sloane BF (1987): Properties of a plasma membrane-associated cathepsin B-like cysteine proteinase in metastatic B16 melanoma variants. Cancer Res $\underline{47}$, 6620-6628

Rozhin J, Sameni M, Ziegler G und Sloane BF (1994): Pericellular pH affects distribution and secretion of cathepsin B in malignant cells. Cancer Res $\underline{54}$, 6517-6525

Rubinstein N, Alvarez M, Zwirner NW, Toscano MA, Ilarregui JM, Bravo A, Mordoh J, Fainboim L, Podhajcer OL und Rabinovich GA (2004): Targeted inhibition of galectin-1 gene expression in tumor cells results in heightened $\mathrm{T}$ cell-mediated rejection; A potential mechanism of tumor-immune privilege. Cancer Cell $\underline{5}, 241-251$

Russell JH und Dobos CB (1980): Mechanisms of immune lysis. II. CTL-induced nuclear disintegration of the target begins within minutes of cell contact. J Immunol $\underline{125}$, 1256-1261

Russell JH und Ley TJ (2002): Lymphocyte-mediated cytotoxicity. Annu Rev Immunol 20, 323-370

Russell JH, Masakowski VR und Dobos CB (1980): Mechanisms of immune lysis. I. Physiological distinction between target cell death mediated by cytotoxic $\mathrm{T}$ lymphocytes and antibody plus complement. J Immunol 124, 1100-1105

Saiki RK, Scharf S, Faloona F, Mullis KB, Horn GT, Erlich HA und Arnheim N (1985): Enzymatic amplification of beta-globin genomic sequences and restriction site analysis for diagnosis of sickle cell anemia. Science 230, 1350-1354

Sameni M, Elliott E, Ziegler G, Fortgens PH, Dennison C und Sloane BF (1995): Cathepsin B and D are Localized at the Surface of Human Breast Cancer Cells. Pathol Oncol Res 1 , 43-53

Sameni M, Moin K und Sloane BF (2000): Imaging proteolysis by living human breast cancer cells. Neoplasia $\underline{2}, 496-504$

Sameni M, Dosescu J und Sloane BF (2001): Imaging proteolysis by living human glioma cells. Biol Chem $\underline{382}, 785-788$

Sanger F, Nicklen S und Coulson AR (1977): DNA sequencing with chain-terminating inhibitors. Proc Natl Acad Sci U S A 74, 5463-5467

Sargiacomo M, Sudol M, Tang Z und Lisanti MP (1993): Signal transducing molecules and glycosyl-phosphatidylinositol-linked proteins form a caveolin-rich insoluble complex in MDCK cells. J Cell Biol 122, 789-807

Sarin A, Williams MS, Alexander-Miller MA, Berzofsky JA, Zacharchuk CM und Henkart PA (1997): Target cell lysis by CTL granule exocytosis is independent of ICE/Ced-3 family proteases. Immunity $\underline{6}, 209-215$

Schick B und Berke G (1990): The lysis of cytotoxic T lymphocytes and their blasts by cytotoxic T lymphocytes. Immunology $\underline{71}, 428-433$

Schultze J, Nadler LM und Gribben JG (1996): B7-mediated costimulation and the immune response. Blood Rev 10, 111-127

Scorilas A, Fotiou S, Tsiambas E, Yotis J, Kotsiandri F, Sameni M, Sloane BF und Talieri M (2002): Determination of cathepsin B expression may offer additional prognostic information for ovarian cancer patients. Biol Chem $\underline{383}, 1297-1303$

Seliger B, Maeurer MJ und Ferrone S (2000): Antigen-processing machinery breakdown and tumor growth. Immunol Today 21, 455-464 
Sellins KS und Cohen JJ (1991): Cytotoxic T lymphocytes induce different types of DNA damage in target cells of different origins. J Immunol 147, 795-803

Sgaramella V, Van de Sande JH und Khorana HG (1970): Studies on polynucleotides, C. A novel joining reaction catalyzed by the T4-polynucleotide ligase. Proc Natl Acad Sci U S A $\underline{67}$, 1468-1475

Shankaran V, Ikeda H, Bruce AT, White JM, Swanson PE, Old LJ und Schreiber RD (2001): IFNgamma and lymphocytes prevent primary tumour development and shape tumour immunogenicity. Nature 410, 1107-1111

Sharpe AH (1995): Analysis of lymphocyte costimulation in vivo using transgenic and 'knockout' mice. Curr Opin Immunol $\underline{7}, 389-395$

Shaw E und Dean RT (1980): The inhibition of macrophage protein turnover by a selective inhibitor of thiol proteinases. Biochem J $\underline{186}, 385-390$

Sheahan K, Shuja S und Murnane MJ (1989): Cysteine protease activities and tumor development in human colorectal carcinoma. Cancer Res $\underline{49}$, 3809-3814

Shi L, Chen G, MacDonald G, Bergeron L, Li H, Miura M, Rotello RJ, Miller DK, Li P, Seshadri T, et al. (1996): Activation of an interleukin 1 converting enzyme-dependent apoptosis pathway by granzyme B. Proc Natl Acad Sci U S A 93, 11002-11007

Shi L, Mai S, Israels S, Browne K, Trapani JA und Greenberg AH (1997): Granzyme B (GraB) autonomously crosses the cell membrane and perforin initiates apoptosis and GraB nuclear localization. J Exp Med 185, 855-866

Shi Y, Evans JE und Rock KL (2003): Molecular identification of a danger signal that alerts the immune system to dying cells. Nature $\underline{425}, 516-521$

Shortman K und Wu L (1996): Early T lymphocyte progenitors. Annu Rev Immunol 14, 29-47

Shresta S, Russell JH und Ley TJ (1997 a): Mechanisms responsible for granzyme B-independent cytotoxicity. Blood $\underline{89}, 4085-4091$

Shresta S, Goda P, Wesselschmidt R und Ley TJ (1997 b): Residual cytotoxicity and granzyme K expression in granzyme A-deficient cytotoxic lymphocytes. J Biol Chem $\underline{272}$, 20236-20244

Shresta S, Pham CT, Thomas DA, Graubert TA und Ley TJ (1998): How do cytotoxic lymphocytes kill their targets? Curr Opin Immunol 10, 581-587

Shuja S, Sheahan K und Murnane MJ (1991): Cysteine endopeptidase activity levels in normal human tissues, colorectal adenomas and carcinomas. Int J Cancer 49, 341-346

Shuja S, Cai J, Iacobuzio-Donahue C, Zacks J, Beazley RM, Kasznica JM, O'Hara CJ, Heimann R und Murnane MJ (1999): Cathepsin B activity and protein levels in thyroid carcinoma, Graves' disease, and multinodular goiters. Thyroid $\underline{9}, 569-577$

Simon MM, Hausmann M, Tran T, Ebnet K, Tschopp J, ThaHla R und Mullbacher A (1997): In vitro- and ex vivo-derived cytolytic leukocytes from granzyme A x B double knockout mice are defective in granule-mediated apoptosis but not lysis of target cells. J Exp Med 186, $1781-1786$

Simonova M, Weissleder R, Sergeyev N, Vilissova N und Bogdanov A, Jr. (1999): Targeting of green fluorescent protein expression to the cell surface. Biochem Biophys Res Commun $\underline{262}$, 638-642

Sinha AA, Gleason DF, Deleon OF, Wilson MJ und Sloane BF (1993): Localization of a biotinylated cathepsin B oligonucleotide probe in human prostate including invasive cells and invasive edges by in situ hybridization. Anat Rec 235, 233-240 
Sinha AA, Jamuar MP, Wilson MJ, Rozhin J und Sloane BF (2001): Plasma membrane association of cathepsin B in human prostate cancer: biochemical and immunogold electron microscopic analysis. Prostate $\underline{49}, 172-184$

Sivaparvathi M, Sawaya R, Wang SW, Rayford A, Yamamoto M, Liotta LA, Nicolson GL und Rao JS (1995): Overexpression and localization of cathepsin B during the progression of human gliomas. Clin Exp Metastasis $\underline{13}$, 49-56

Sloane BF, Moin K, Sameni M, Tait LR, Rozhin J und Ziegler G (1994): Membrane association of cathepsin B can be induced by transfection of human breast epithelial cells with c-Ha-ras oncogene. J Cell Sci 107 ( Pt 2), 373-384

Smyth MJ, Thia KY, Street SE, MacGregor D, Godfrey DI und Trapani JA (2000): Perforinmediated cytotoxicity is critical for surveillance of spontaneous lymphoma. J Exp Med 192, 755-760

Smyth MJ, Godfrey DI und Trapani JA (2001): A fresh look at tumor immunosurveillance and immunotherapy. Nat Immunol 2, 293-299

Spiess E, Bruning A, Gack S, Ulbricht B, Spring H, Trefz G und Ebert W (1994): Cathepsin B activity in human lung tumor cell lines: ultrastructural localization, $\mathrm{pH}$ sensitivity, and inhibitor status at the cellular level. J Histochem Cytochem $\underline{42}$, 917-929

Stahl A und Mueller BM (1995): The urokinase-type plasminogen activator receptor, a GPI-linked protein, is localized in caveolae. J Cell Biol 129, 335-344

Stepp SE, Dufourcq-Lagelouse R, Le Deist F, Bhawan S, Certain S, Mathew PA, Henter JI, Bennett M, Fischer A, de Saint Basile G, et al. (1999): Perforin gene defects in familial hemophagocytic lymphohistiocytosis. Science 286, 1957-1959

Stinchcombe JC, Barral DC, Mules EH, Booth S, Hume AN, Machesky LM, Seabra MC und Griffiths GM (2001): Rab27a is required for regulated secretion in cytotoxic T lymphocytes. J Cell Biol 152, 825-834

Stoeckle C, Gouttefangeas C, Hammer M, Weber E, Melms A und Tolosa E (2009): Cathepsin W expressed exclusively in CD8+ T cells and NK cells, is secreted during target cell killing but is not essential for cytotoxicity in human CTLs. Exp Hematol 37, 266-275

Straus SE, Sneller M, Lenardo MJ, Puck JM und Strober W (1999): An inherited disorder of lymphocyte apoptosis: the autoimmune lymphoproliferative syndrome. Ann Intern Med 130, 591-601

Street SE, Cretney E und Smyth MJ (2001): Perforin and interferon-gamma activities independently control tumor initiation, growth, and metastasis. Blood 97, 192-197

Street SE, Trapani JA, MacGregor D und Smyth MJ (2002): Suppression of lymphoma and epithelial malignancies effected by interferon gamma. J Exp Med 196, 129-134

Su MW, Walden PR, Golan DB und Eisen HN (1993): Cognate peptide-induced destruction of CD8+ cytotoxic T lymphocytes is due to fratricide. J Immunol 151, 658-667

Sukoh N, Abe S, Nakajima I, Ogura S, Isobe H, Inoue K und Kawakami Y (1994): Immunohistochemical distributions of cathepsin B and basement membrane antigens in human lung adenocarcinoma: association with invasion and metastasis. Virchows Arch $\underline{424}$, $33-38$

Suranyi MG, Hogan PG, Falk MC, Axelsen RA, Rigby R, Hawley C und Petrie J (1998): Advanced donor-origin melanoma in a renal transplant recipient: immunotherapy, cure, and retransplantation. Transplantation $\underline{66}, 655-661$

Svane IM, Engel AM, Nielsen MB, Ljunggren HG, Rygaard J und Werdelin O (1996): Chemically induced sarcomas from nude mice are more immunogenic than similar sarcomas from congenic normal mice. Eur J Immunol 26, 1844-1850 
Takahashi T, Makiguchi Y, Hinoda Y, Kakiuchi H, Nakagawa N, Imai K und Yachi A (1994): Expression of MUC1 on myeloma cells and induction of HLA-unrestricted CTL against MUC1 from a multiple myeloma patient. J Immunol 153, 2102-2109

Takio K, Towatari T, Katunuma N, Teller DC und Titani K (1983): Homology of amino acid sequences of rat liver cathepsins B and $\mathrm{H}$ with that of papain. Proc Natl Acad Sci U S A $\underline{80}$, 3666-3670

Talanian RV, Yang X, Turbov J, Seth P, Ghayur T, Casiano CA, Orth K und Froelich CJ (1997): Granule-mediated killing: pathways for granzyme B-initiated apoptosis. J Exp Med 186, $1323-1331$

Tenniswood MP, Guenette RS, Lakins J, Mooibroek M, Wong P und Welsh JE (1992): Active cell death in hormone-dependent tissues. Cancer Metastasis Rev 11, 197-220

Terabe M, Matsui S, Noben-Trauth N, Chen H, Watson C, Donaldson DD, Carbone DP, Paul WE und Berzofsky JA (2000): NKT cell-mediated repression of tumor immunosurveillance by IL-13 and the IL-4R-STAT6 pathway. Nat Immunol $\underline{1}$, 515-520

Thiel C, Osborn M und Gerke V (1992): The tight association of the tyrosine kinase substrate annexin II with the submembranous cytoskeleton depends on intact p11- and $\mathrm{Ca}(2+)$-binding sites. J Cell Sci 103 ( Pt 3), 733-742

Thiery J, Keefe D, Boulant S, Boucrot E, Walch M, Martinvalet D, Goping IS, Bleackley RC, Kirchhausen T und Lieberman J (2011): Perforin pores in the endosomal membrane trigger the release of endocytosed granzyme B into the cytosol of target cells. Nat Immunol $\underline{12}, 770-$ 777

Thomas DA, Du C, Xu M, Wang X und Ley TJ (2000): DFF45/ICAD can be directly processed by granzyme B during the induction of apoptosis. Immunity $\underline{12}, 621-632$

Towbin H, Staehelin T und Gordon J (1979): Electrophoretic transfer of proteins from polyacrylamide gels to nitrocellulose sheets: procedure and some applications. Proc Natl Acad Sci U S A $\underline{76}$, 4350-4354

Trapani JA und Smyth MJ (2002): Functional significance of the perforin/granzyme cell death pathway. Nat Rev Immunol 2, 735-747

Trapani JA, Browne KA, Smyth MJ und Jans DA (1996): Localization of granzyme B in the nucleus. A putative role in the mechanism of cytotoxic lymphocyte-mediated apoptosis. J Biol Chem $\underline{271}, 4127-4133$

Trapani JA, Jans P, Smyth MJ, Froelich CJ, Williams EA, Sutton VR und Jans DA (1998 a): Perforin-dependent nuclear entry of granzyme B precedes apoptosis, and is not a consequence of nuclear membrane dysfunction. Cell Death Differ $\underline{5}, 488-496$

Trapani JA, Jans DA, Jans PJ, Smyth MJ, Browne KA und Sutton VR (1998 b): Efficient nuclear targeting of granzyme B and the nuclear consequences of apoptosis induced by granzyme B and perforin are caspase-dependent, but cell death is caspase-independent. J Biol Chem $\underline{273}$, 27934-27938

Trinchieri G, London L, Kobayashi M und Perussia B (1987): Regulation of activation and proliferation of human natural killer cells. Adv Exp Med Biol 213, 285-298

Tschopp J, Schafer S, Masson D, Peitsch MC und Heusser C (1989): Phosphorylcholine acts as a $\mathrm{Ca} 2+-$ dependent receptor molecule for lymphocyte perforin. Nature 337, 272-274

Turk B, Dolenc I, Zerovnik E, Turk D, Gubensek F und Turk V (1994): Human cathepsin B is a metastable enzyme stabilized by specific ionic interactions associated with the active site. Biochemistry $\underline{33}, 14800-14806$

Turk V, Turk B und Turk D (2001): Lysosomal cysteine proteases: facts and opportunities. EMBO J $\underline{20}, 4629-4633$ 
Uellner R, Zvelebil MJ, Hopkins J, Jones J, MacDougall LK, Morgan BP, Podack E, Waterfield MD und Griffiths GM (1997): Perforin is activated by a proteolytic cleavage during biosynthesis which reveals a phospholipid-binding C2 domain. EMBO J 16, 7287-7296

Uyttenhove C, Pilotte L, Theate I, Stroobant V, Colau D, Parmentier N, Boon T und Van den Eynde BJ (2003): Evidence for a tumoral immune resistance mechanism based on tryptophan degradation by indoleamine 2,3-dioxygenase. Nat Med $\underline{9}, 1269-1274$

van den Broek ME, Kagi D, Ossendorp F, Toes R, Vamvakas S, Lutz WK, Melief CJ, Zinkernagel RM und Hengartner H (1996): Decreased tumor surveillance in perforin-deficient mice. J Exp Med 184, 1781-1790

van den Eynde B, Peeters O, De Backer O, Gaugler B, Lucas S und Boon T (1995): A new family of genes coding for an antigen recognized by autologous cytolytic $\mathrm{T}$ lymphocytes on a human melanoma. J Exp Med 182, 689-698

van der Bruggen P, Traversari C, Chomez P, Lurquin C, De Plaen E, Van den Eynde B, Knuth A und Boon T (1991): A gene encoding an antigen recognized by cytolytic T lymphocytes on a human melanoma. Science 254, 1643-1647

van Elsas A, Nijman HW, Van der Minne CE, Mourer JS, Kast WM, Melief CJ und Schrier PI (1995): Induction and characterization of cytotoxic T-lymphocytes recognizing a mutated p21ras peptide presented by HLA-A*0201. Int J Cancer 61, 389-396

Verret CR, Firmenich AA, Kranz DM und Eisen HN (1987): Resistance of cytotoxic T lymphocytes to the lytic effects of their toxic granules. J Exp Med 166, 1536-1547

Vetter CS, Groh V, thor Straten P, Spies T, Brocker EB und Becker JC (2002): Expression of stressinduced MHC class I related chain molecules on human melanoma. J Invest Dermatol $\underline{118}$, 600-605

Visscher DW, Sloane BF, Sameni M, Babiarz JW, Jacobson J und Crissman JD (1994): Clinicopathologic significance of cathepsin B immunostaining in transitional neoplasia. Mod Pathol 7, 76-81

Waisman DM (1995): Annexin II tetramer: structure and function. Mol Cell Biochem 149-150, 301 322

Walden PR und Eisen HN (1990): Cognate peptides induce self-destruction of CD8+ cytolytic T lymphocytes. Proc Natl Acad Sci U S A $\underline{87}, 9015-9019$

Walker PR, Saas P und Dietrich PY (1998): Tumor expression of Fas ligand (CD95L) and the consequences. Curr Opin Immunol 10, 564-572

Walsh CM, Matloubian M, Liu CC, Ueda R, Kurahara CG, Christensen JL, Huang MT, Young JD, Ahmed R und Clark WR (1994): Immune function in mice lacking the perforin gene. Proc Natl Acad Sci U S A 1ㅜ, 10854-10858

Wang T, Niu G, Kortylewski M, Burdelya L, Shain K, Zhang S, Bhattacharya R, Gabrilovich D, Heller R, Coppola D, et al. (2004): Regulation of the innate and adaptive immune responses by Stat-3 signaling in tumor cells. Nat Med $\underline{10}, 48-54$

Warwas M, Haczynska H, Gerber J und Nowak M (1997): Cathepsin B-like activity as a serum tumour marker in ovarian carcinoma. Eur J Clin Chem Clin Biochem 35, 301-304

Whiteside TL und Herberman RB (1995): The role of natural killer cells in immune surveillance of cancer. Curr Opin Immunol $\underline{7}, 704-710$

Widlak P (2000): The DFF40/CAD endonuclease and its role in apoptosis. Acta Biochim Pol 47, $1037-1044$

Willstätter R und Bamann E (1929): Über die Proteasen der Magenschleimhaut. Hoppe-Seyler's Z Physiol Chem $\underline{180}, 127-134$ 
Wirl G und Schwartz-Albiez R (1990): Collagen-binding proteins of mammary epithelial cells are related to $\mathrm{Ca} 2(+)-$ and phospholipid-binding annexins. J Cell Physiol 144, 511-522

Wolfel T, Hauer M, Schneider J, Serrano M, Wolfel C, Klehmann-Hieb E, De Plaen E, Hankeln T, Meyer zum Buschenfelde KH und Beach D (1995): A p16INK4a-insensitive CDK4 mutant targeted by cytolytic T lymphocytes in a human melanoma. Science $\underline{269}, 1281-1284$

Wong LH, Krauer KG, Hatzinisiriou I, Estcourt MJ, Hersey P, Tam ND, Edmondson S, Devenish RJ und Ralph SJ (1997): Interferon-resistant human melanoma cells are deficient in ISGF3 components, STAT1, STAT2, and p48-ISGF3gamma. J Biol Chem 272, 28779-28785

Woo EY, Chu CS, Goletz TJ, Schlienger K, Yeh H, Coukos G, Rubin SC, Kaiser LR und June CH (2001): Regulatory CD4(+)CD25(+) T cells in tumors from patients with early-stage nonsmall cell lung cancer and late-stage ovarian cancer. Cancer Res $\underline{61}$, 4766-4772

Wortzel RD, Philipps C und Schreiber H (1983): Multiple tumour-specific antigens expressed on a single tumour cell. Nature $\underline{304}, 165-167$

Xu ZL, Mizuguchi H, Ishii-Watabe A, Uchida E, Mayumi T und Hayakawa T (2001): Optimization of transcriptional regulatory elements for constructing plasmid vectors. Gene 272, 149-156

Yan S und Sloane BF (2003): Molecular regulation of human cathepsin B: implication in pathologies. Biol Chem $\underline{384}$, 845-854

Yan S, Berquin IM, Troen BR und Sloane BF (2000): Transcription of human cathepsin B is mediated by Sp1 and Ets family factors in glioma. DNA Cell Biol 19, 79-91

Yan Z, Deng X, Chen M, Xu Y, Ahram M, Sloane BF und Friedman E (1997): Oncogenic c-Ki-ras but not oncogenic c-Ha-ras up-regulates CEA expression and disrupts basolateral polarity in colon epithelial cells. J Biol Chem 272, 27902-27907

Yang X, Stennicke HR, Wang B, Green DR, Janicke RU, Srinivasan A, Seth P, Salvesen GS und Froelich CJ (1998): Granzyme B mimics apical caspases. Description of a unified pathway for trans-activation of executioner caspase-3 and -7. J Biol Chem $\underline{273}$, 34278-34283

Yannelli JR, Sullivan JA, Mandell GL und Engelhard VH (1986): Reorientation and fusion of cytotoxic $\mathrm{T}$ lymphocyte granules after interaction with target cells as determined by high resolution cinemicrography. J Immunol 136, 377-382

Yoshino I, Peoples GE, Goedegebuure PS, Maziarz R und Eberlein TJ (1994): Association of HER2/neu expression with sensitivity to tumor-specific CTL in human ovarian cancer. $\mathbf{J}$ Immunol 152, 2393-2400

Young JD, Hengartner H, Podack ER und Cohn ZA (1986): Purification and characterization of a cytolytic pore-forming protein from granules of cloned lymphocytes with natural killer activity. Cell $\underline{44}, 849-859$

Young JD, Damiano A, DiNome MA, Leong LG und Cohn ZA (1987): Dissociation of membrane binding and lytic activities of the lymphocyte pore-forming protein (perforin). J Exp Med $\underline{165}, 1371-1382$

Zinkernagel RM und Doherty PC (1974): Restriction of in vitro T cell-mediated cytotoxicity in lymphocytic choriomeningitis within a syngeneic or semiallogeneic system. Nature $\underline{248}$, 701-702 


\section{Danksagung}

Mein Dank gilt zunächst dem Direktor der Abteilung Zelluläre und Molekulare Immunologie der Medizinischen Fakultät der Georg-August-Universität Göttingen, Herrn Prof. Dr. Jürgen Wienands, für die Möglichkeit, die vorliegende Dissertation in seiner Abteilung durchzuführen.

Ebenso danke ich Herrn Prof. Dr. Ralf Dressel für die Überlassung des interessanten Themas, die gute Betreuung und für die vielen wertvollen Anregungen und Diskussionen.

Herrn Dipl.-Biol. Sebastian Monecke danke ich für die unermüdliche Unterstützung und Beratung bei der Planung und Durchführung der Experimente.

Darüber hinaus danke ich Frau Leslie Elsner, die mir mit ihrer langjährigen Erfahrung bei allen Problemen der täglichen Laborarbeit stets weiterhelfen konnte.

Auch bedanken möchte ich mich bei Herrn Nico Westphal vom Deutschen Primatenzentrum Göttingen für die Unterstützung bei der DNA-Sequenzierung und bei Frau Sandra Becker der zentralen Serviceeinheit Cell-Sorting der Universitätsmedizin Göttingen für die Sortierung der Zellen. 